MALAYSIAN TERTIARY STUDENTS' PERCEPTIONS OF CONSTRUCTIVE ALIGNMENT IN LEARNING IN EAP CLASSROOMS:

\title{
A QUALITATIVE STUDY
}

\author{
BY \\ BHARATHI NAIDU VIJAYAN
}

\begin{abstract}
A thesis
submitted to Victoria University of Wellington in fulfilment of the requirements for the degree of Doctor of Philosophy
\end{abstract}

VICTORIA UNIVERSITY OF WELLINGTON 



\section{Dedication}

This thesis is dedicated to my parents: Vijayan Raman and Patmavathy Govindarajoo and

my brother, Dinesh Vijayan. You have always inspired me with words of encouragement that have always increased my motivation.

My utmost thanks to you for believing in me and for giving me the opportunity to spread my wings to venture out of Malaysia when everyone else was against the very idea.

Thanks for lending me your shoulders when I needed them to lean on. You have taught me to believe in the saying never say die before you try. 


\begin{abstract}
English for Academic Purposes (EAP) is offered as a course in many Malaysian institutions of higher learning. In contrast with English taught at secondary schools, at the tertiary level EAP courses primarily cater to learners' language needs that arise from learning in a range of disciplines, in the workplace, and eventually in the wider society.

This study explores 12 Malaysian tertiary students' perceptions of how learning takes place in EAP classrooms during reading activities. Biggs' Constructive Alignment framework and the 3P model (Presage, Process and Product) provide a theoretical framework. The research investigates how students' factors in learning and the tasks given in the classrooms align with the students' views of outcomes in learning and by considering the constructive alignment of the student factors, the task and the outcomes (the presage, process and product stages), it is possible to see the potential for deep approaches to learning and to consider whether that potential is realised in particular tasks.
\end{abstract}

This study uses a single embedded explanatory case, consisting of 12 Malaysian tertiary students from three EAP classrooms in a public university in Malaysia. The data collection methods used for this study were semi-structured interviews, stimulated recall interviews and students' written samples of EAP tasks undertaken in the three classrooms. The tasks were adapted from an EAP workbook used at the university.

The data were analysed using Braun and Clarke's thematic analysis. An analytic tool was created using Biggs' and Collis' SOLO Taxonomy to ascertain the potential of the tasks to allow a deep approach to learning. The findings of this study showed the complexity of the learning process among these learners in the academic English classroom.

The findings showed that the learners did not see the alignment between the presage, process and product stages. In the presage and process stages, the findings showed that there were multiple factors such as background, motives for learning, anxiety in learning, topic and content interests, and prior knowledge that influenced the learners' engagement with the tasks. Motives for learning were particularly important since the other factors either influenced or were influenced by them. Further, these factors also influenced students' perceived outcomes of learning in the EAP classroom.

In the process and product stages, the students reported that they found the content taught in class did not align with their motives for learning. They also said that they had difficulties seeing the transfer of learning from the content taught in the EAP classroom to their other subjects at the university. Although the students showed some interest and engagement with the reading 
tasks in the classroom, the lack of alignment could contribute to a surface motive for learning in the EAP classroom.

This study also found that a process of internal compromise took place within the learners to adapt themselves to the learning situations in the EAP classroom which was clearly evident in their responses to the reading tasks in the classroom as well as in their opinions about learning in academic English as a whole. Biggs' concept that learning takes place within a system is particularly important in EAP courses where the learning should be designed to transfer to students' achievements in other subjects, in the workplace and beyond.

An understanding of constructive alignment in EAP courses will enable EAP course designers, material writers and EAP instructors to use this powerful tool to support the achievement of the aims of EAP courses. It also has implications for EAP educators when they consider the design of tasks in their courses and the issues that affect the potential for deep or surface approaches to learning. 


\section{Acknowledgements}

I would like to thank the Almighty for giving me the strength to complete this thesis. This journey was been difficult for me from the start to the finish. I faced many challenges during this time. I had multiple health complications during the last quarter of my $\mathrm{PhD}$ journey and had to be on bed rest a few times. During this difficult period, the only thing that gave me a glimmer of hope was my prayers and perseverance to go further with the writing of it.

I am greatly indebted to both my supervisors - Dr Carolyn Tait and Dr Gillian Hubbard - who took me under their wing. You have been extremely helpful and sensitive to my needs as an international student. Thanks for all the encouragement and words of wisdom when I doubted myself. Through your guidance and supervisory skills, I managed to shape my thesis to what it is now. Thanks for providing constructive criticism to improve my writing and for constantly reminding me not to be cryptic. Thanks also for always asking the 'why' question. That question helped me immensely in writing this thesis. The years we spent working on it taught me a valuable lesson, to not be cryptic and not to accept any information at face level.

My sincere thanks to my flatmates - Jill Fernandez, Amilie Bentley and Sandra Cortés-Acosta - for your patience in listening to me constantly talk about my thesis. I would also like to thank Sukuna Vijayadevar for her help and guidance many times when I most needed them. Thanks to Shih Min Loo, Anna Hoang and Phuong Anh Do (Fank) for the great times during my study here in New Zealand. Also, thanks for making me aware that I was not the only struggling $\mathrm{PhD}$ student on the planet and for helping me when I faced health issues. I spent a lot of time venting my frustrations, alongside laughter and special moments with you guys and I will keep the fond memories close to my heart. A special thanks to Susan Kaiser for taking the time to proofread my writing.

My gratitude goes to the Administration staff at the Faculty of Education, VUW, especially Stella Watta for rendering your professional and moral support during my studies. I have bugged you many times regarding the protocols, but you have always been there making my life easier. I still remember the time when I was new in New Zealand and you walked with me to the Countdown supermarket! I am also grateful to the Faculty of Graduate Research in awarding the submission scholarship. It helped me immensely towards the end of my study when my finances were low.

Finally, my deepest appreciation to my participants who volunteered to be part of this research project. I know you were busy but still made time for me to conduct my research. Thanks for working around your busy schedule and for replying to my text messages. 


\section{Table of Contents}

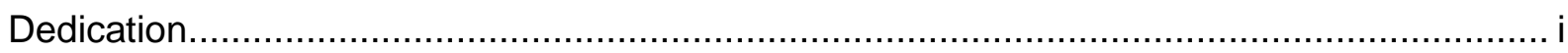

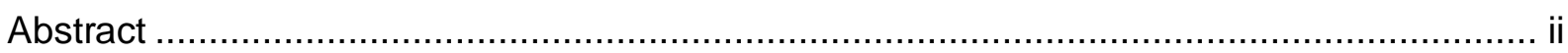

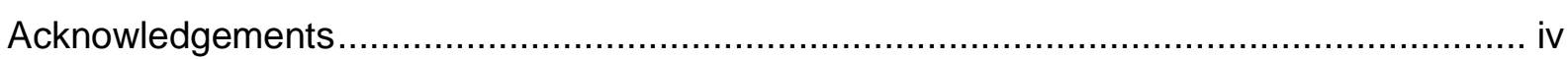

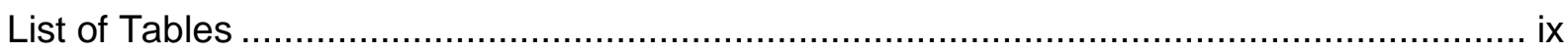

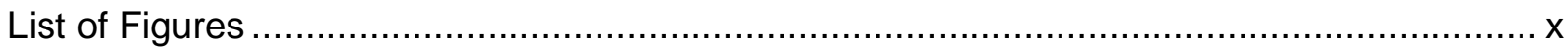

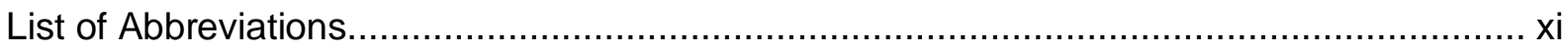

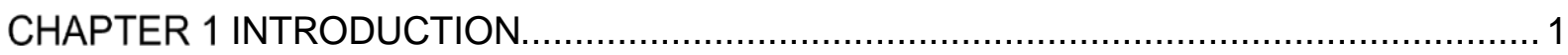

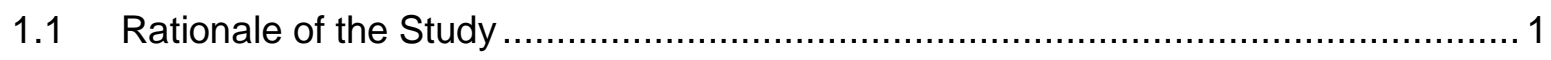

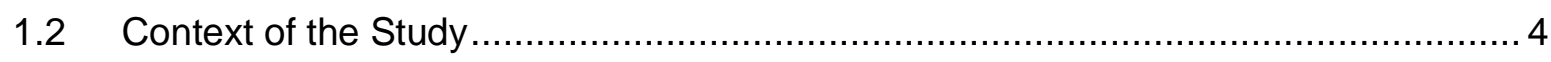

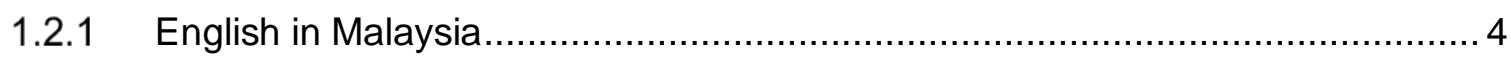

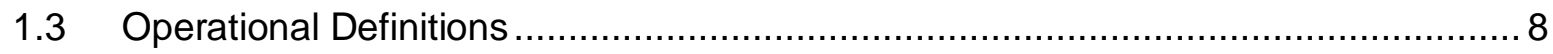

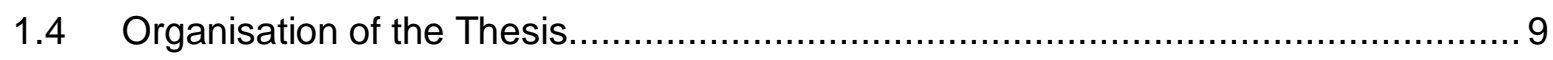

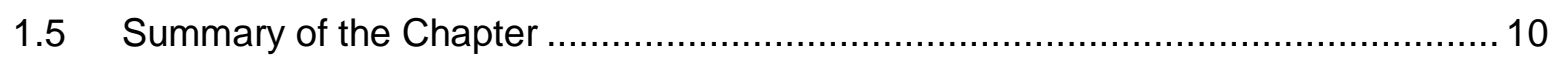

CHAPTER 2 THEORETICAL FRAMEWORK OF THE STUDY ...................................... 13

2.1 Constructive Alignment (CA) Framework .................................................. 14

2.1.1 Formation of Constructive Alignment....................................................... 14

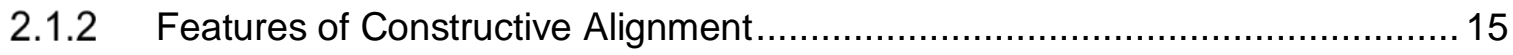

2.1.3 Studies using Constructive Alignment ...................................................... 16

2.1.4 Criticisms of Constructive Alignment ...................................................... 19

2.1.5 Using Constructive Alignment in a Qualitative Approach ................................ 20

2.2 Biggs' 3P Model of Teaching and Learning ................................................. 21

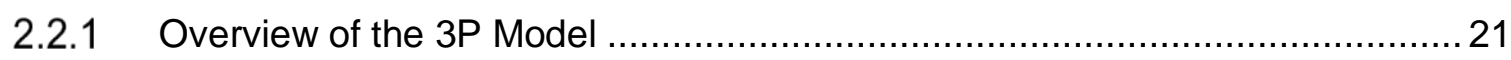

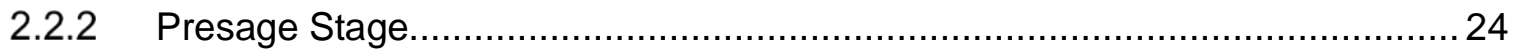

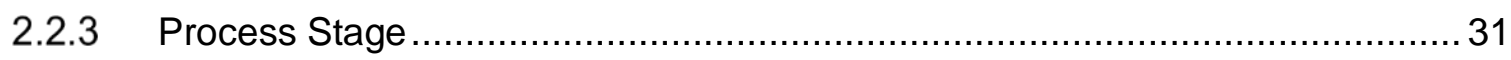

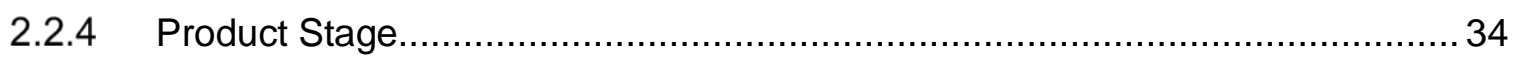

2.2.5 Past Studies on the Presage, Process and Product Stages........................... 38

2.3 Using the 3P Model and Constructive Alignment in Learning ............................... 39

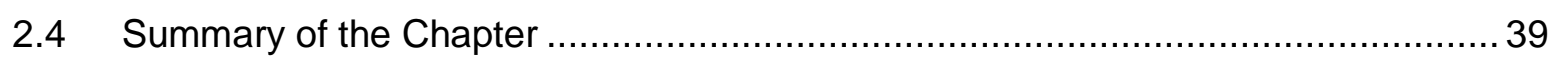

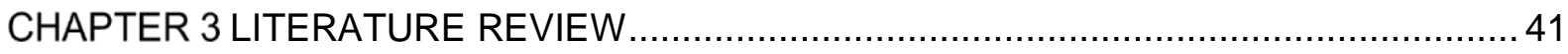

3.1 Incorporating the Literature into the Framework of this Study ............................. 41

3.2 Academic English in Tertiary Education .................................................... 43

3.2.1 The Nature of English for Academic Purposes ........................................... 43

3.3 Factors that Influence Learning in the EAP Classrooms .................................... 48

3.3.1 Interest and prior knowledge of topics ................................................. 48

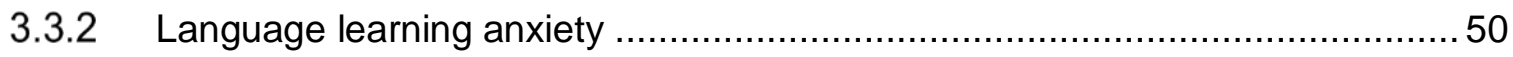

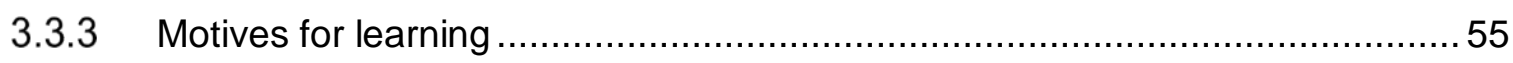

3.3.4 Learners' background as a contextual factor ......................................... 57 
3.4 Reading Skills, Reading Tasks and Requirements in EAP Classrooms .59

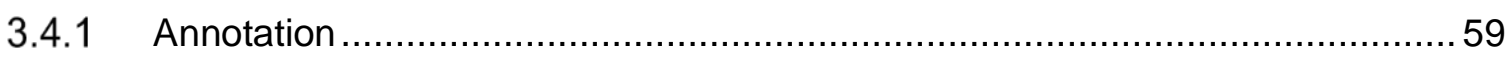

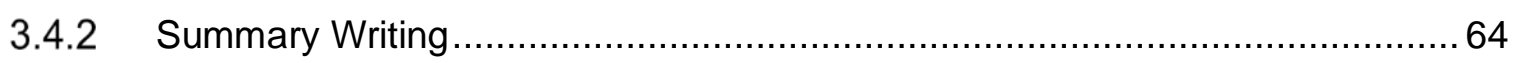

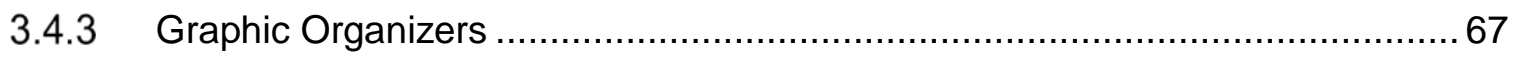

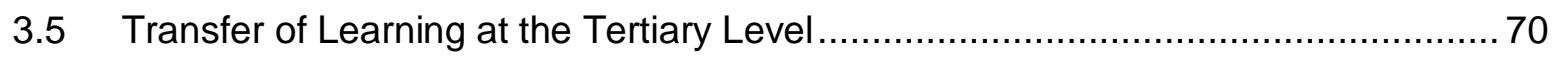

3.5.1 Students' Perceptions of Transfer of Learning in Tertiary Level Education ...... 70

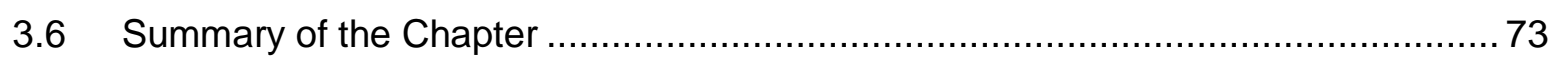

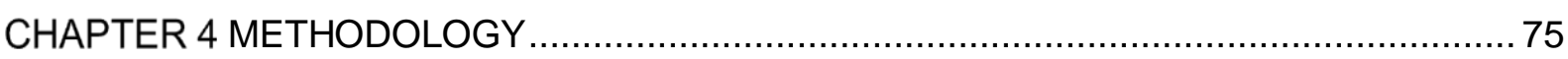

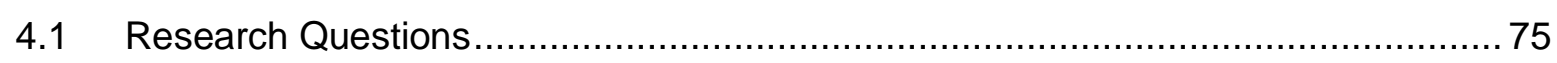

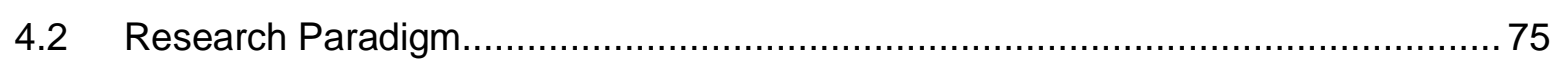

4.3 The Research Design Used for this Study .................................................... 76

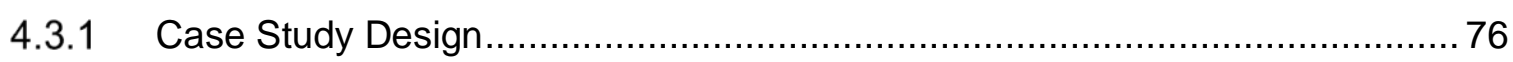

4.4 Data Collection and Data Analysis Phases................................................... 78

4.4.1 Summary of Data Collection Procedure ..................................................... 79

4.5 The Selection of the Tertiary Institution and Sampling Methods ........................... 80

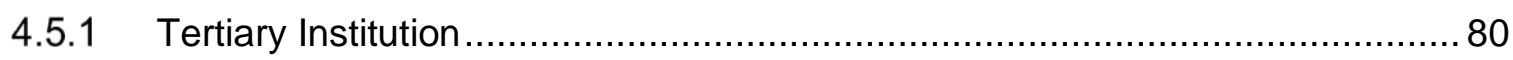

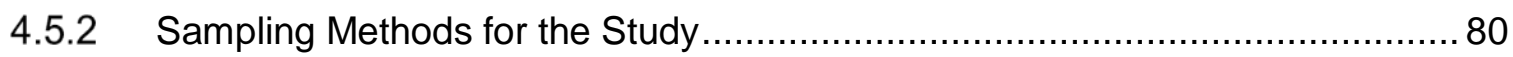

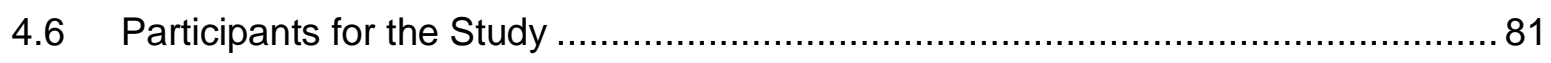

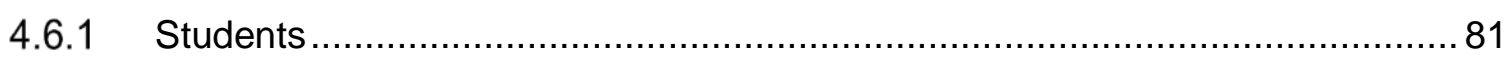

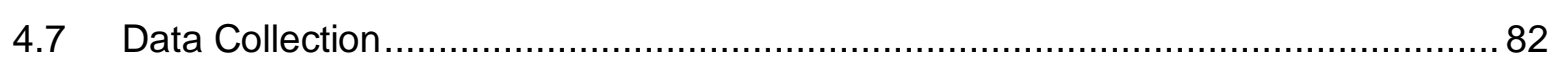

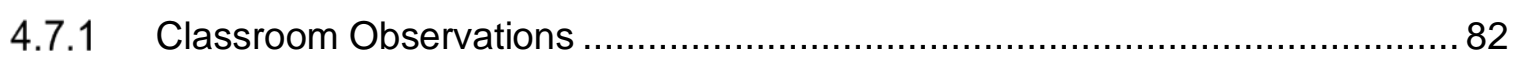

4.7.2 Selection of Reading Tasks for the Interview ............................................ 83

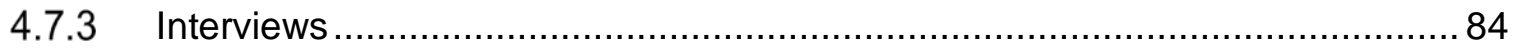

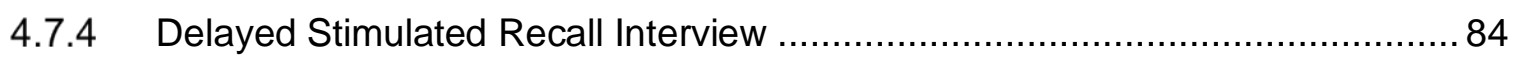

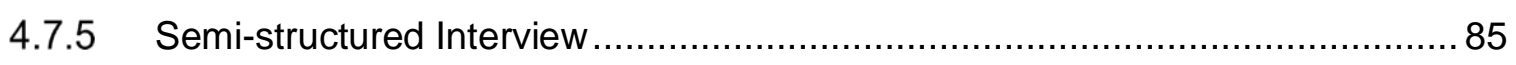

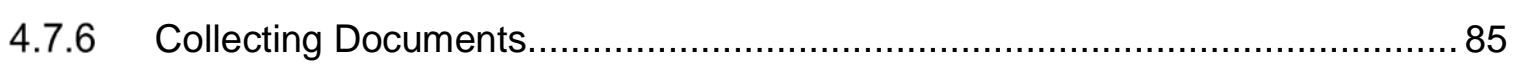

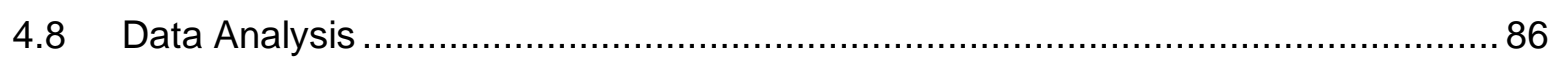

4.8.1 Pre-analysis Work: Transcribing, Translating and Verifying Interview

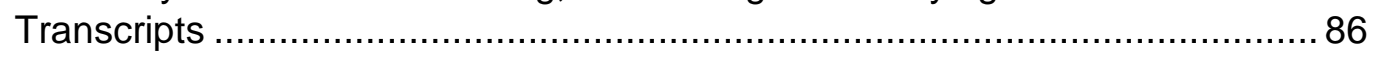

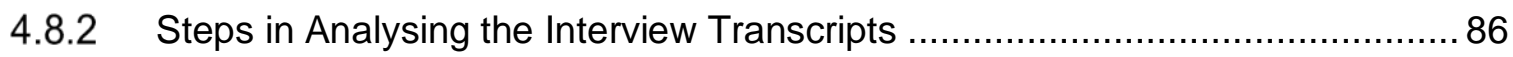

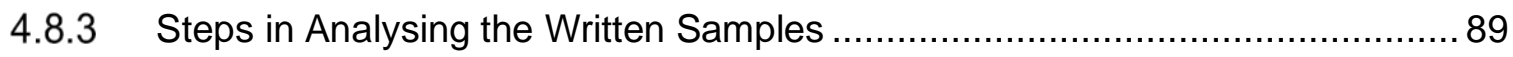

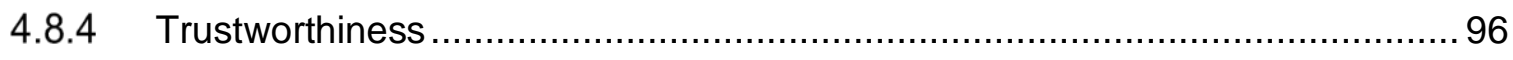

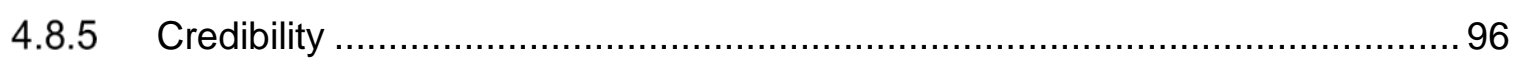

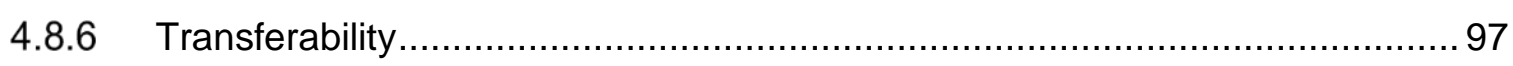

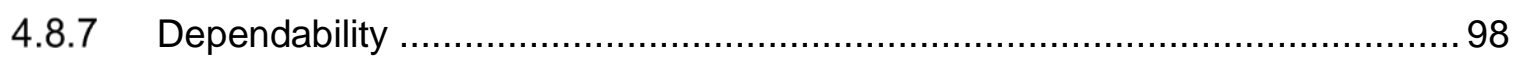

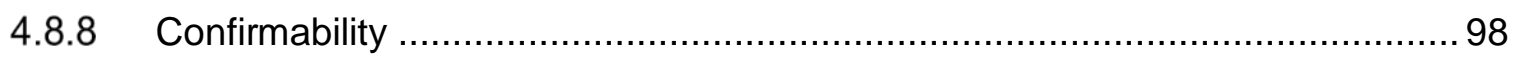

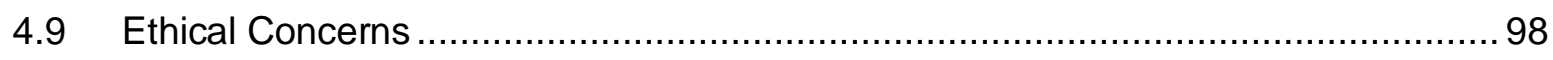

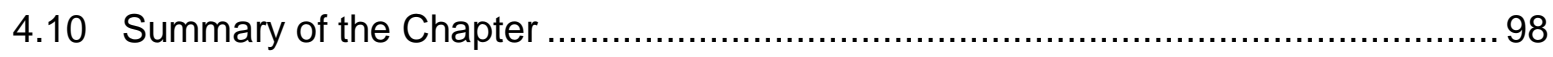

CHAPTER 5 FINDINGS OF THREE UNITS OF ANALYSIS .................................... 101 
$5.1 \quad$ Unit 1 .

5.1.1 Responses to Learning in the EAP Classroom .......................................... 101

5.1.2 Responses to Specific Task .............................................................. 110

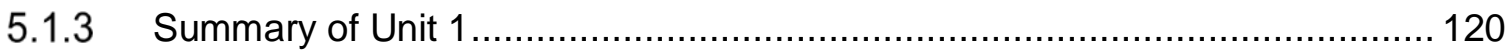

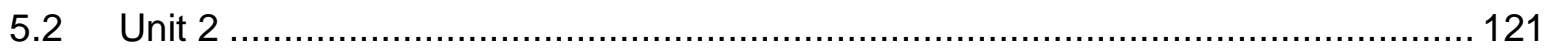

5.2.1 Responses to Learning in the EAP Classroom ......................................... 121

5.2.2 Responses to a Specific Task ............................................................ 134

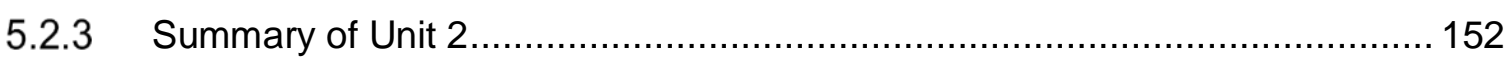

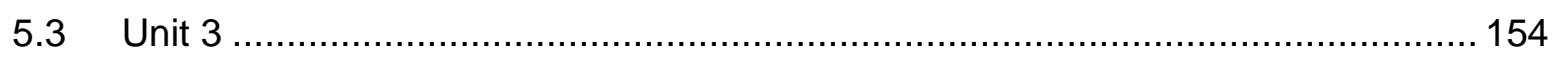

5.3.1 Responses for Learning in the EAP Classroom ...................................... 154

5.3.2 Responses to a Specific Task ............................................................... 167

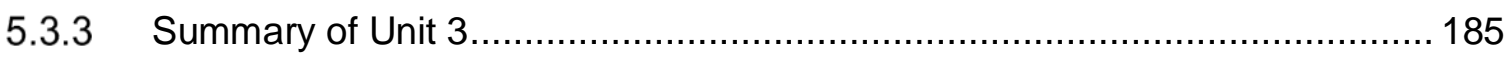

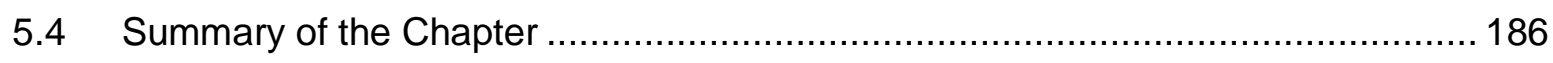

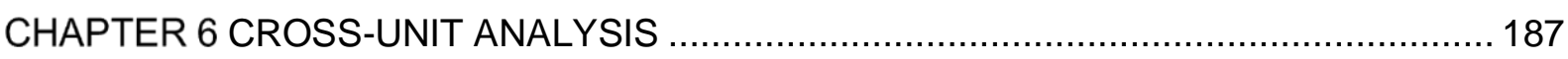

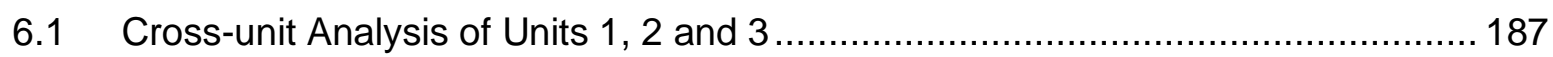

6.1.1 Cross-unit Analysis of Responses to Learning in the EAP Classroom ........... 187

6.1.2 Cross-unit Analysis of Specific Tasks in the EAP Classroom......................... 193

6.2 Revisiting the Research Questions in Relation to the Cross-unit Analysis ............ 197

6.2.1 What Factors Influence Students' Learning in the EAP Classroom? .............. 198

6.2.2 How do Students Respond to Specific Tasks in the EAP Classroom? ........... 198

6.2.3 How do Students Perceive the Outcomes of Learning in the EAP

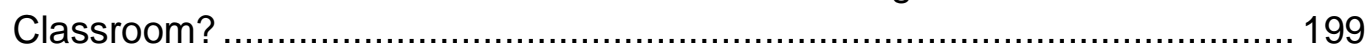

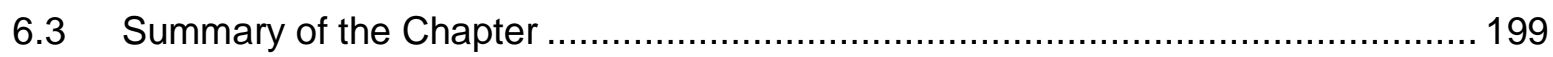

CHAPTER 7 3P MODEL AND THE MISMATCH OF ALIGNMENT IN THE EAP

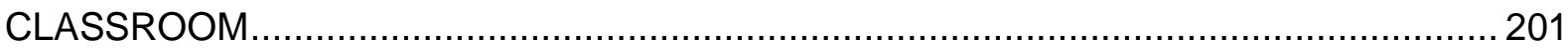

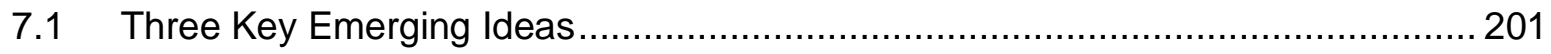

7.2 The Use of Constructive Alignment and the 3P Model......................................203

7.2.1 Part 1: Constructive Alignment and Specific Tasks: Learning Factors and the Learning Process involved in Responding to the Specific Tasks..............204

7.2.2 Part 2: Constructive Alignment and Learning of Academic English in the EAP Classrooms: Learning Factors and Perceived Learning Outcomes........ 214

7.3 Mismatch of Alignment Leads to an Internal Process of Compromise: Students'

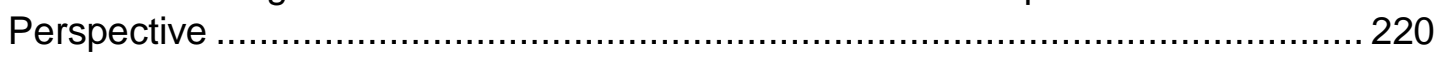

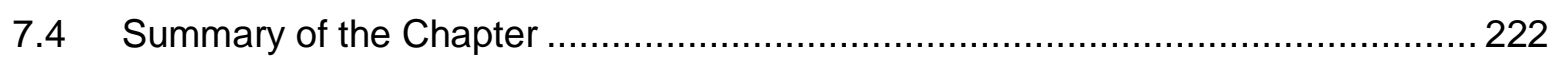

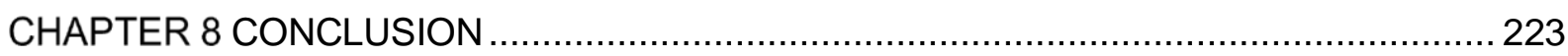

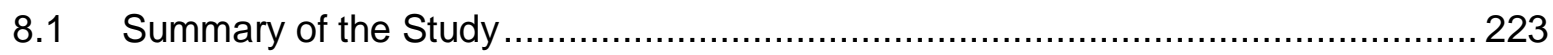

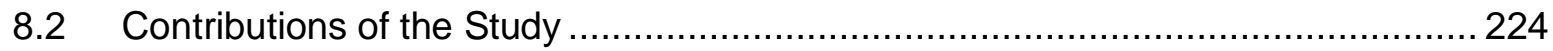

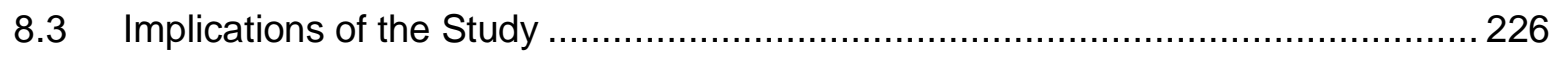

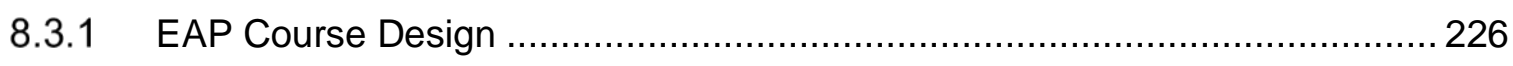

8.3.2 EAP Practitioners and Learners ...................................................... 227 


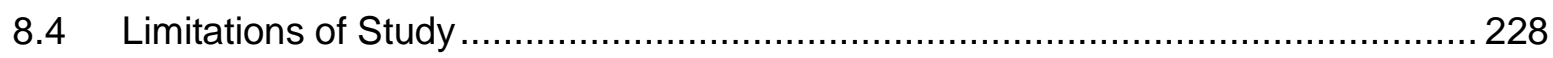

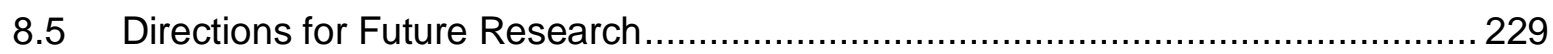

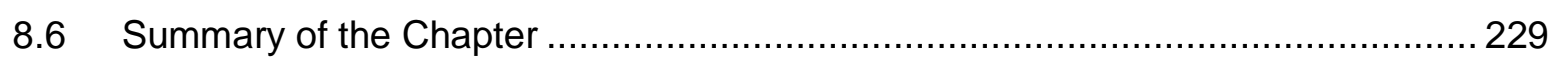

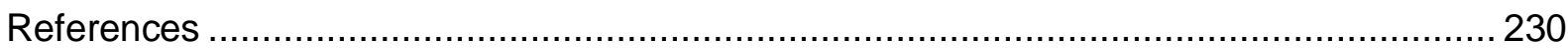

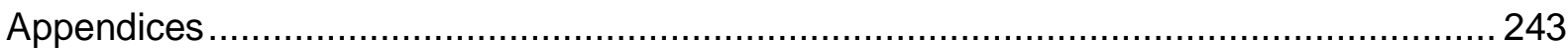

Appendix A: Ethics Approval from the VUW Ethics Education Committee ..................... 244

Appendix B: Approval to Conduct Research in Malaysia from the Prime Minister's

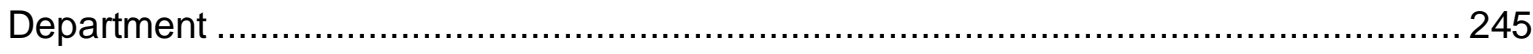

Appendix C: Approval from Cambridge University Press ..........................................246

Appendix D: Information Sheet for the Management of the University ......................... 247

Appendix E: Consent for the Management of the University ..................................... 250

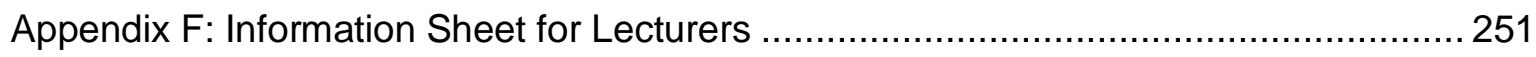

Appendix G: Consent for the Lecturers.................................................................. 253

Appendix H: Information Sheet for Survey Participation ......................................... 254

Appendix I: Information Sheet for Principal Participants ......................................... 256

Appendix J: Consent Form for Principal Participants .............................................. 258

Appendix K: Information Sheet for Observation Participants..................................... 259

Appendix L: Consent Form for Students (Observation Participation) ............................. 261

Appendix M: Interview Guide for Research Participants ........................................... 262

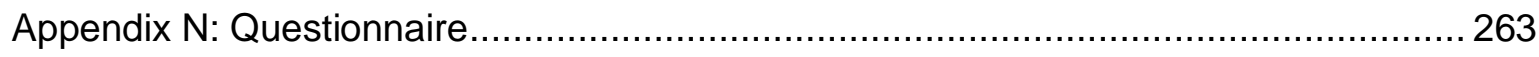

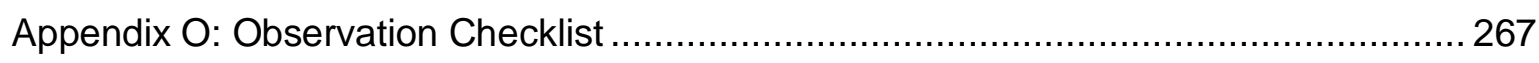

Appendix P: Sample of the Process of Combining Codes to Categories ....................... 268

Appendix Q: The Print Revolution Passage.......................................................... 269

Appendix R: Cyberculture: the artificial world of the internet Passage .........................270

Appendix S: Sample of Participants' Written Work for Unit 1, Unit 2 and Unit 3 ............. 271 


\section{List of Tables}

Table 1. Key definitions in this study 8

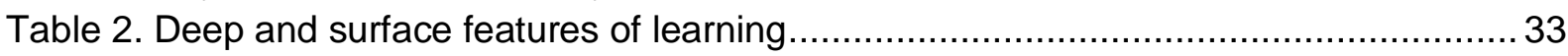

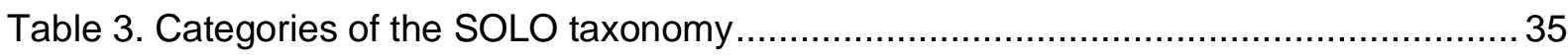

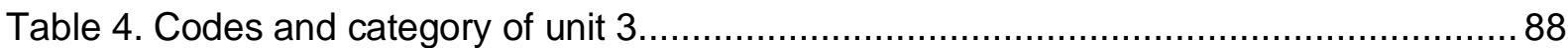

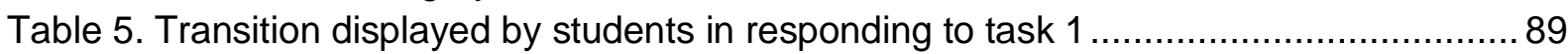

Table 6. Criteria for compare and contrast task......................................................... 90

Table 7. Transition displayed by students in responding to the task ................................... 91

Table 8. Verbs used for intended learning outcomes from the SOLO taxonomy ..................92

Table 9. Rubrics for content and organisation in summary writing .....................................94

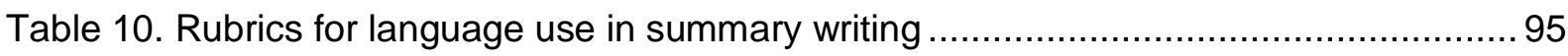

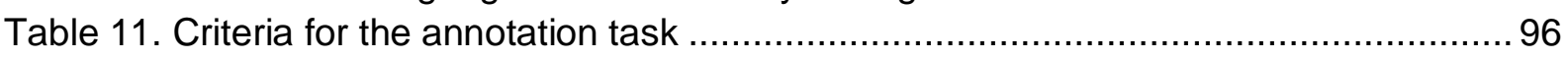

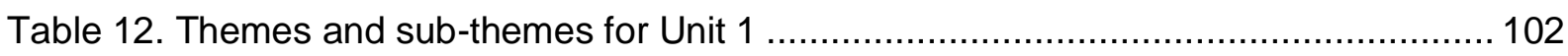

Table 13. Comments on Affiq's and Halim's mind map .................................................. 111

Table 14. Comments on Immanuel's mind map ............................................................. 113

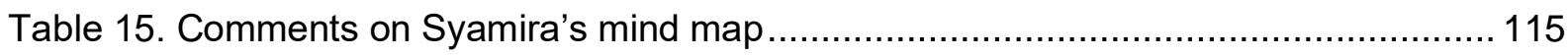

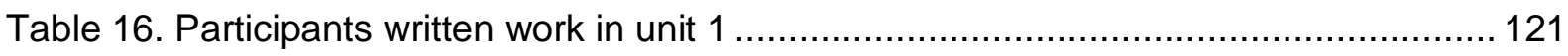

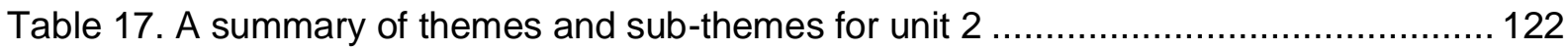

Table 18. Comments on Azraq's and Samad's summary writing ...................................... 139

Table 19. Comments on Hussein's summary writing ..................................................... 143

Table 20. Comments on Nazira's summary writing .................................................. 147

Table 21. Summary of the participants' responses to the written work in Unit $2 \ldots \ldots \ldots \ldots \ldots . . . .153$

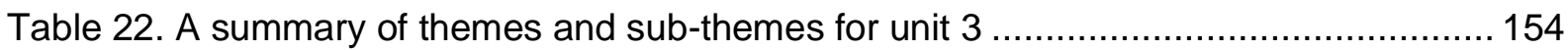

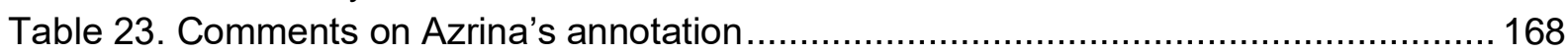

Table 24. Comments on Ezadura's annotation................................................................. 170

Table 25. Comments on Najla's annotation............................................................. 175

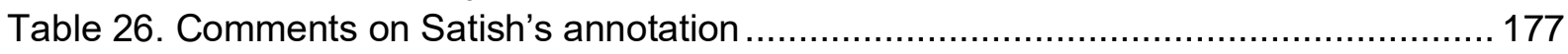

Table 27. Summary of the participants' responses to the written work in unit $3 \ldots \ldots \ldots \ldots \ldots \ldots . . . .185$

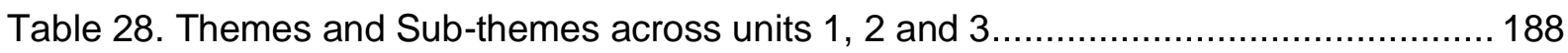

Table 29. Participants' response to the specific reading tasks in the EAP classrooms ....... 194

Table 30. The requirements for the reading tasks and the learners' level of

achievement according to the SOLO taxonomy 208 


\section{List of Figures}

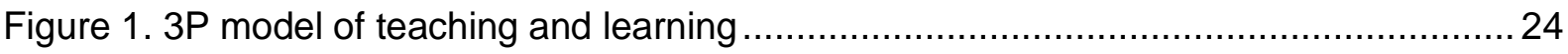

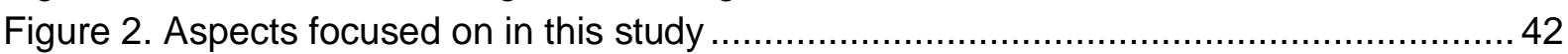

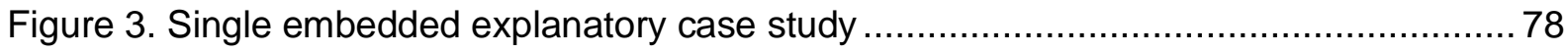

Figure 4. Summary of the data collection procedure ......................................................... 79

Figure 5. Affiq's and Halim's mind map on the similarity of effects .................................. 111

Figure 6. Immanuel's mind map on the similarity of effects ........................................... 113

Figure 7. Syamira's mind map on the similarity of effects ............................................... 115

Figure 8. Mind map of print revolution - Azraq's and Samad's work ............................... 134

Figure 9. Mind map of cyberculture - Azraq's and Samad's work ................................... 135

Figure 10. Compare and contrast table of the effects of print revolution and

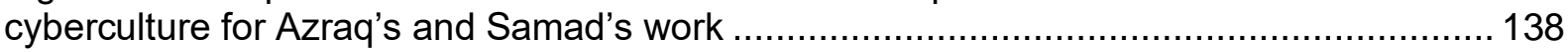

Figure 11. Compare and contrast table of the effects of print revolution and

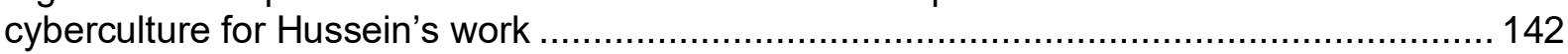

Figure 12. Mind maps on 'print revolution' and 'cyberculture' for Nazira's work .................. 145

Figure 13. Compare and contrast table of the effects of print revolution and

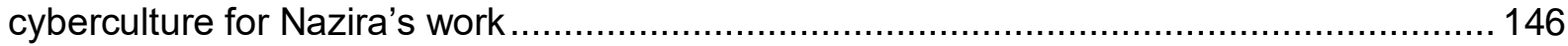

Figure 14. Azrina's annotation of 'Intelligence: heredity versus environment' .................... 167

Figure 15. Ezadura's annotation of 'Intelligence: heredity versus environment' .................. 171

Figure 16. Ezadura's annotation of 'Intelligence: heredity versus environment' ................. 172

Figure 17. Ezadura's annotation of 'Intelligence: heredity versus environment' ..................173

Figure 18. Najla's annotation of 'Intelligence: heredity versus environment' ...................... 174

Figure 19. Satish's annotation of 'Intelligence: heredity versus environment' ................... 177

Figure 20. The relationship between students' learning factors, learning process and perceived outcomes of learning in the EAP classroom in this study .................................202

Figure 21. Organization of this discussion................................................................ 204

Figure 22. The relationship between students' learning factors and learning process in

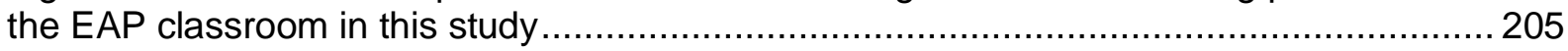

Figure 23. The relationship between learning process and perceived outcomes of learning in the EAP classroom in this study ....

Figure 24. The relationship between learning factors and perceived outcomes of learning in the EAP classroom in this study 


\section{List of Abbreviations}

CA Constructive Alignment

EAP English for Academic Purposes

ESL English as a Second Language

SOLO Structure of Observed Learning Outcomes 
This page is intentionally left blank 


\section{CHAPTER 1 \\ INTRODUCTION}

This study explores Malaysian undergraduate students' perceptions of learning in English for Academic Purposes (EAP) classrooms with a particular focus on reading tasks. It also considers learners' wider perceptions about learning academic English at university in Malaysia. This study examines the relationship between learning within the academic English classroom and the students' perceptions of the wider purposes for using academic English. The research uses Biggs' (1996) Constructive Alignment Framework (hereafter, referred to as CA) and his (2003) 3P Model using a social constructive perspective. It considers the learners' perceptions of learning in relation to all of the presage (personal factors and contextual factors), process (learners' responses to specific reading tasks) and product (level of achievement with the tasks measured by the SOLO taxonomy (Biggs \& Collis, 1982) and the potential transfer of knowledge) stages. The existence of alignment or lack of alignment within Biggs' system provides insights into the tensions within the learning process for a particular group of EAP learners in Malaysia. Given the importance of academic reading at the tertiary level and for learners' future careers, it is useful to have a close focus on the process of learning and the learners' perceptions of its usefulness. Biggs' (1996) CA has not been widely used within the EAP context of research learning. Using this model allows consideration not only of the responses to specific classroom tasks but also of the wider potential transfer of learning to the academic context.

This introductory chapter starts with the rationale of the study. It is followed by the context of the study, the organisation of the thesis, and situating the researcher. Finally, the definitions of key terms are included.

\subsection{Rationale of the Study}

This research explores learners' perceptions of the alignment in learning in terms of the learning factors, specific reading tasks, and learners' perceived outcomes in their learning of academic reading skills in EAP classrooms. This section outlines the rationale for conducting this research study by describing the struggles and challenges that learners face in learning academic English and the multiple issues that contribute to these struggles. This section also explains the rationale for focusing on reading within the EAP course and the adoption of the CA framework.

Most institutes of higher learning in Malaysia offer EAP courses to their students to assist them in developing the language skills needed for academic studies. Studies show that, for multiple reasons, students come to tertiary education without the necessary academic or language 
skills. As a result, Malaysian undergraduates find it difficult to adapt to the literacy expectations set by institutions of higher learning (Musa, Koo, \& Azman, 2012; Nambiar, 2007; Noor, 2010). This occurs because teaching in Malaysian secondary schools is often highly teacher centred and examination based which does not encourage students to offer their views and develop the ability to be critical thinkers (Musa et al., 2012; Thang, 2005). The issue identified through empirical research has also been recognised more officially in Malaysia by the Ministry of Education. In order to curb the problem of an examination-focused curriculum and to provide more opportunities for learners to be creative and innovative, in 2011 the Ministry of Education began implementing in phases a new policy of School Based Assessment in public schools in Malaysia (Hashim, Ariffin, \& Hashim, 2013). However, this new curriculum has been criticised for various reasons, from the instructors' point of view, such as an increase in workload, time constraints, a lack of training and facilities, and focusing too much on implementing the curriculum rather than teaching (Hashim, Ariffin, \& Hashim, 2013; Rashid, Rahman, \& Yunus, 2017). This assessment change is fairly recent, and it may take time to reveal the long-term effectiveness of it for students.

Another strand of research indicates that Malaysian undergraduates struggle to use English effectively, partly because of the lack of sufficient vocabulary and lack of the ability to make sense of complex sentences at the tertiary level (Musa et al., 2012). This leads to the inability of students to perform well in their mainstream programmes, some of which may be taught in English (Musa et al., 2012). Empirical research in the Malaysian context identifies that there is a particular gap in preparation for the academic vocabulary of university subjects. Secondary schools focus more on teaching vocabulary associated with English for General Purposes, rather than academic English (Manan, Ali, \& Shamsudin, 2013). These authors contend that, since vocabulary is an important aspect of academic subjects and is used in reading, writing, listening and speaking, learners who pursue their studies to the tertiary level are not sufficiently prepared for the vocabulary load in undergraduate courses and they find themselves struggling to cope with the lessons. Manan et al. (2013) noted that the aim for teaching English, as stated in the national English language syllabus for secondary schools for Form Five (2003), is to teach learners, among other things, to acquire knowledge that could be associated with pursuing their studies at post-secondary level. However, the word list taught to the students from Form One to Form Five consists of words that are mostly for general use (Manan et al., 2013). A further area of empirical research has identified that some tertiary learners lack generic study skills such as being able to take down notes during lectures (Musa et al., 2012; Mustaffa, 2006). This further adds to the problem of learners finding themselves struggling to cope with the academic language used at the tertiary level. A body of relatively recent research in Malaysia as well as official concern has, in other words, established a sense of some urgency in the need to address Malaysian students' academic English language skills. 
As an EAP instructor, I became interested in students' learning process, particularly in the area of reading. It may be relatively easy to understand the process students go through with academic writing, but it is harder to gain a glimpse inside the way students process information in academic reading. I wondered whether my students were approaching the reading tasks for the sake of completing the tasks without much engagement with the content. I have noticed a general pattern in which most students struggle to make meaning, identify the writer's purpose, and offer their personal reflection on the text they read. In addition, many students are mostly passive learners and do not participate actively in class, preferring to wait for answers to be provided for them. I have also often wondered whether students enjoy the reading material and tasks done in class, although they seemed happy at times. My curiosity about how students perceive reading in the EAP classrooms and whether their perceptions align with their future plans led to the undertaking of this research study. I believe that students at the tertiary level should acquire the capability to be analytical in their reading. All these concerns have stirred my interest to conduct this research study.

Reading is an important academic skill as most of the information is imparted through reading in the academic context at the tertiary level (Grabe \& Stoller, 2018). To process the information in reading, students need reading skills such as paraphrasing and summarising, strategies which can allow deep and surface learning to take place. Reading at the tertiary level is more demanding than reading done in schools. Tertiary learners are expected to employ deep approaches to learning which foster connections beyond the text itself and which involve critical reflection on texts (Nambiar, 2007). This contrasts with approaches used for reading in schools which stress reading for understanding and emphasise the importance of examinations. Hence, students must be prepared to face the demanding environment of higher order thinking in tertiary education. Reading at the tertiary level requires learners to be evaluative and analytical (Zin, Wong, \& Rafik-Galea, 2014). Most learners at the tertiary level however, struggle to employ deep approaches to learning in reading due to the lack of higher order thinking taught at the school level (Noor, 2006, 2010). The reading skills taught in the EAP classroom assist learners to develop their academic reading skills and promote higher order thinking. However, the problem is that learners in the EAP classroom may not recognise the importance of these skills for their academic progress and as a result may fail to see the need to develop the skills for academic thinking. Learning in the EAP classroom can then become lacking in relevance and thus impersonal and mechanical.

In order to understand what happens with reading in the Malaysian EAP classroom it seems helpful to understand learners' perceptions of the process and outcomes of the learning. With the purpose of investigating this issue, I chose to consider learners' perceptions in relation to all the parts of the learning process. To understand the nature of the learning process, I considered Biggs' CA and 3P model as the framework for this study. The CA framework was 
adopted for this study because it helps instructors to align the teaching and learning activities in the EAP classroom with the intended outcomes of learning and the transfer of these outcomes to the academic context (Tweedie \& Kim, 2015). The endpoint of teaching at the tertiary level is to encourage deep learning among the students (Biggs \& Tang, 2011). This framework emphasises creating an appropriate teaching and learning environment to promote deep learning among students. This tool for teaching and learning provided a useful framework for this research. The 3P model (Biggs, 2003), consisting of the presage, process and product stages, was used to investigate how learning in the EAP classroom in a Malaysian context took place by examining student interview responses and a small sample of student work in relation to different parts of the model. Having an overview of these three stages and their interaction helped me to understand some of the complexity of the student perceptions, not only of how learning takes place but also what influences learning and how these influences lead to the achievement, or lack of achievement, of the outcomes of learning.

Biggs' system represents what happens within the classroom as well as the influence of the out-of-classroom factors and of the wider social context (Biggs, 1993a). Biggs' approach to learning allowed me to drill down into the combination of factors that might influence the learning of EAP reading skills. Learning languages is influenced by learners' background, culture, and their beliefs as well as the way learning takes place within the classroom.

The next section explores the background of the study, including the use of English and the teaching of English in Malaysia.

\subsection{Context of the Study}

\subsubsection{English in Malaysia}

In order to describe the context of this study, this section provides a brief introduction to the history of English in the Malaysian education system, the people, and the use of English among Malaysians.

\section{English in the Malaysian education system}

The teaching of English at all levels has a complex history. This is partly because English in Malaysia is associated with the history of colonialism, and Bahasa Malaysia is associated with nationalism and national unity. This history may influence learners' attitudes towards the learning of English in the Malaysian context. In this section, the inclusion of English in the Malaysian education system and major reforms in the curriculum in the teaching of English are briefly discussed. These historical changes included the change from an English medium curriculum in schools to Bahasa Malaysia to unite multicultural Malaysia, to a movement to and then away from teaching mathematics and science in English to raise Malaysian students' English proficiency in a globalised world. 
Currently in Malaysia, English is taught in schools as a compulsory subject to students from primary Year One (7-year-olds) to secondary Form Five (17/18-year-olds). Students are enrolled in primary schools from Year One (7 years old) to Year Six (12 years old) and then proceed to secondary schools from Form One (13/14-year olds) to Form Five (17/18-yearolds) (Ministry of Education; MoE, Malaysia, n.d.). Students then opt to further their studies at the pre-university level or, at times, they enrol directly at the tertiary level. English language is a compulsory part of the curriculum to ensure that Malaysian students are able to communicate and to be competitive at the global level (MoE, 2013). The Education Act (1996) and the Private Higher Educational Institutions Act (1996) recommended the use of English as the medium of instruction in post-secondary education in Malaysia (Grapragasem, Krishnan, \& Mansor, 2014). To understand the inclusion of English in the Malaysian education system, it is necessary to consider its role in the system in recent history.

The role of English in the Malaysian education system has undergone many changes since Malaysia gained its independence. Malaysia, at that time known as the Federation of Malaya, received its independence from the British in 1957. After Malaysia was granted its independence, Bahasa Malaysia (also known as the Malay language) was declared to be the national language while English was still widely used in the civil service (Foo \& Richards, 2004). "Bahasa Malaysia is the standardized form of the Malay language" (Rashid, et al., 2017, p.102). After independence, English was used as the medium of instruction in the national schools until the introduction of a new educational policy in 1970 when Bahasa Malaysia was implemented as the medium of instruction (Foo \& Richards, 2004). Prior to 1970, the newly formed government of Malaysia aimed to unite the major ethnic groups, namely the Malays, Chinese and Indians, under one national language and aimed to make English a second language (Foo \& Richards, 2004; Selvaraj, 2010). After 1970, Bahasa Malaysia became the medium of instruction in the national schools and the formal language in the civil service (Selvaraj, 2010). One of the reasons for the changes in the medium of instruction was due to the nationalists striving to "defend the supremacy of the Malay language" as they believed "English language equals to British imperialism and they refused to be slaves to the policies and language of the colonial master" (Selvaraj, 2010, p. 51).

The government of Malaysia has always realised the importance of English in globalisation and as a language of technology and trade. One of the improvements in English language teaching in the Malaysian education system is the inclusion of the English 1119 syllabus in the national examination (the Malaysian Certificate of Education (SPM)), in 1995 (Selvaraj, 2010). This syllabus is determined by the United Kingdom-based Cambridge Examination. The Malaysian Ministry of Education also introduced English Literature as part of the English syllabus in 2001 (Selvaraj, 2010). English Literature was included in the national examination as part of the English examination. 
Another major reform took place when the Ministry of Education introduced the teaching of Science and Mathematics in English in 2003 (Foo \& Richards, 2004; Rashid, et al., 2017). This policy was introduced in phases and was fully carried out by the year 2008 (Rashid, et al., 2017). However, the policy was faced with much criticism such as the lack of English language proficiency, causing learners to perform poorly in these subjects and to have teachers who are not trained to teach these subjects in English (Rashid, et al., 2017; Selvaraj, 2010). In 2012, this policy was retracted with the re-introduction of teaching Science and Mathematics in Bahasa Malaysia (Rashid, et al., 2017; Selvaraj, 2010). In 2012, a new policy was introduced to replace the teaching of Science and Mathematics in English. The policy was termed Memartabatkan Bahasa Malaysia Memperkukuh Bahasa Inggeris (MBMMBI) (To uphold Bahasa Malaysia, to strengthen the English language). Under this policy, Bahasa Malaysia was established as the medium of instruction in schools and as the national language of Malaysia (Ministry of Education, 2014) while learners were able to explore the different types of knowledge and were able to compete internationally by strengthening their command of English (Ministry of Education, 2014). Further, in 2016, English was made a compulsory pass subject at the national examination in order to obtain the SPM (Rashid, et al., 2017).

At the pre-university level, the Ministry of Education had introduced the Malaysian University English Test (MUET) for the students. MUET was introduced in 1998 and has been tested nationwide since then (Selvaraj, 2010). This test covers the four skills of reading, writing, listening, and speaking and is designed for students who plan to continue their studies at the tertiary level. The learners at the pre-university level are trained in these skills prior to taking the test. The aim of MUET is to prepare learners for the demands of the tertiary level by developing their English language skills (Selvaraj, 2010).

Despite the introduction of these language policies by the Ministry of Education, learners still struggle to use English effectively after 11 years of learning the language in both primary and secondary schools (Musa et al., 2012; Yamat, Fisher, \& Rich, 2014). This is evident at the tertiary level where learners struggle to understand the teaching of other subjects in English. Although Bahasa Malaysia is used as the medium of instruction in national schools and public institutions of higher learning (Grapragasem et al., 2014), English is used interchangeably at times. The teaching and learning is sometimes conducted in English because learners from various parts of the world enrol in Malaysian tertiary institutions. Private institutions of higher learning use English as a medium of instruction which is in line with the government's aim to make Malaysia an education centre and encourage foreign investors (Grapragasem et al., 2014).

The implementation of the English language in the education system has often been politicised in Malaysia. There has always been a fear of English becoming dominant which may 
undermine the role of Bahasa Malaysia as the national language. The nationalist groups have always endeavoured to uphold the importance of the national language compared to other languages in Malaysia (Hashim, 2014). The implications of implementing Bahasa Malaysia as the medium of instruction have affected the level of English proficiency in Malaysia (Hashim, 2014; Rashid et al., 2017). However, the advocates of the English language argued that it is important for graduates to be able to communicate and use the language effectively to be able to attain jobs in international companies where English is used widely (Hashim, 2014).

This tension in the national discourse between the value of Bahasa Malaysia as a language of national unity and English as the global language of the international marketplace inevitably affects students' perceptions of the value of learning in the EAP classroom.

In the next section, I will discuss multicultural Malaysia along with the use of English among Malaysians.

\section{The use of English among multicultural Malaysians}

This section describes the outlook of multicultural Malaysians on the English language. Malaysians are considered bilingual/multilingual as most are able to speak their native language, Bahasa Malaysia (the national language), and English. Malaysians comprise three major ethnic groups - Malays, Chinese and Indians - and other minority ethnic groups. The estimated population in Malaysia was 32 million in 2018 based on the 2017-2018 projection by the Department of Statistics. The total estimated population in 2018 was divided into Malays (69.1\%), Chinese (23\%), Indians (6.9\%) and others (1.0\%) (Department of Statistics, 2018). On the whole, the Malay ethnic group speaks Bahasa Malaysia and other local dialects, whereas the Chinese ethnic group speaks Mandarin and other Chinese language varieties. Similarly, the Indian ethnic group speaks predominantly Tamil, and some are able to speak other Indian language varieties. Although Malaysians are multicultural as they are from different ethnic groups practising various religions and cultures, they are all united in their ability to communicate in Bahasa Malaysia, the national language.

The multicultural Malaysian groups have their own unique identity, for example as Malay Malaysians, Chinese Malaysians and Indian Malaysians with their own cultural beliefs and diverse linguistic origins as mentioned earlier. The proponents of native languages are very concerned about maintaining their own identity. For example, the vernacular schools, namely the Chinese and Tamil schools, were against the implementation of the teaching of Science and Mathematics in English policy (Rashid et al., 2017). They wanted to maintain Mandarin and Tamil as the medium of instruction in teaching Science and Mathematics at the vernacular schools to safeguard their cultural identity as Chinese Malaysians and Indian Malaysians. The 
multiple identities of Malaysians will be further explained in the literature review chapter of this thesis.

However, with globalisation and internationalisation taking place, English has gained popularity in Malaysia in recent years. According to Hashim (2014), the use of English goes beyond education such as in trades and mass communication in Malaysia. She stated that English has become a mode of communication in the multilingual environment among Malaysians. English is used more often in the urban and suburban areas as compared to the rural areas in Malaysia. The use of English as a home language is significantly increasing in Malaysia (Hashim, 2014) but this takes place most often among people from the middle and uppermiddle class (Rashid et al., 2017). English is still not widely spoken in the rural areas and among people from the low socioeconomic strata. Darmi and Albion (2013) pointed out that language learners from the rural areas, for example, prefer to speak in their native language as they do not see a reason to use English. Despite this, there has been a shift in the mindset of Malaysians, particularly those living in the urban and suburban areas, in terms of accepting English as a Lingua Franca. In Malaysia, English has become a language that shows social background and depicts educational credentials as well as the ethnicity of a person (Hashim, 2014; Rajadurai, 2010). However, Hashim also highlighted that it is important for language policy makers to take into consideration the current situation in the use of English in Malaysia and to design policies that will fit the situation.

Although the government of Malaysia and Malaysians in general do understand that English is used internationally, there has always been a debate about the extent to which English is used and learnt in Malaysia. It is important to note that the data collection phase was carried out before the change of administration of the Malaysian government that took place in the 2018 general election, the first since its independence. The National Front Party (Barisan Nasional) had ruled for sixty-one years until recently when the Alliance of Hope (Pakatan Harapan), a coalition party, won the $14^{\text {th }}$ General Election in Malaysia (Muhamad, 2018). With the change of administration in the government, new changes are being slowly introduced to various policies and at the administration level.

\subsection{Operational Definitions}

The key terms used in this thesis are listed in Table 1, along with the chapters where they will be explained further.

Table 1. Key definitions in this study 


\begin{tabular}{|c|c|}
\hline Surface approach to learning & $\begin{array}{l}\text { A surface approach to learning focuses on "reliance on rote- } \\
\text { learning and memorization in isolation to other ideas" (Duff, Boyle, } \\
\text { Dunleavy, \& Ferguson, 2004, p. 1908). The definition will be } \\
\text { further elaborated in Chapter 2: Theoretical Framework. }\end{array}$ \\
\hline Deep approach to learning & $\begin{array}{l}\text { According to Duff et al. (2004), a student who practises a deep } \\
\text { approach to learning focuses on the "meaning in the matter being } \\
\text { studied and relates those ideas to other experiences and ideas } \\
\text { with a critical approach" (p. 1908). The definition will be further } \\
\text { elaborated in Chapter 2: Theoretical Framework. }\end{array}$ \\
\hline $\begin{array}{l}\text { Structure of Observed Learning } \\
\text { Outcomes (SOLO) Taxonomy }\end{array}$ & $\begin{array}{l}\text { Biggs and Collis (1982) explained that the SOLO taxonomy can } \\
\text { be used as an "instructional as well as an evaluative tool" ( } p \text {.xi) } \\
\text { because it assesses the quality of responses. The definition will } \\
\text { be further elaborated in Chapter } 2 \text { : Theoretical Framework. }\end{array}$ \\
\hline 3P Model & $\begin{array}{l}\text { According to Biggs (2001), teaching and learning is a system and } \\
\text { the } 3 P \text { model reflects this system. He further stated that the } 3 P \\
\text { model is an interactive model consisting of three stages: the } \\
\text { presage stage (before teaching and learning happens), process } \\
\text { stage (when teaching and learning happens) and the product } \\
\text { stage (after teaching and learning happens). The definition will be } \\
\text { further elaborated in Chapter 2: Theoretical Framework. }\end{array}$ \\
\hline Motives for Learning & $\begin{array}{l}\text { Motives for learning reflect the intention in learning or responding } \\
\text { to specific activities (Biggs, 1987). Learners' motives are often } \\
\text { associated with intrinsic motivation and extrinsic goals in learning. } \\
\text { The definition will be further elaborated in Chapter 2: Theoretical } \\
\text { Framework. }\end{array}$ \\
\hline Constructive Alignment (CA) & $\begin{array}{l}\text { CA is a teaching design which aligns teaching and assessment } \\
\text { with the intended learning outcome (Biggs, 2014). The definition } \\
\text { will be further elaborated in Chapter 2: Theoretical Framework. }\end{array}$ \\
\hline $\begin{array}{l}\text { English for Academic Purposes } \\
\text { (EAP) }\end{array}$ & $\begin{array}{l}\text { EAP refers to language research and instruction which focuses } \\
\text { on the specific communicative needs and practices of particular } \\
\text { groups in academic contexts (Hyland \& Hamp-Lyons, 2002, p. 1,). } \\
\text { The definition will be further elaborated in Chapter 3: Literature } \\
\text { Review. }\end{array}$ \\
\hline
\end{tabular}

\subsection{Organisation of the Thesis}

This thesis is divided into eight chapters and is organised as follows.

Chapter Two: In this chapter, I discuss the social constructivism paradigm in education. Relevant literature pertaining to the theoretical framework used in this study is reviewed. This chapter consists of three parts: Biggs' CA framework, the 3P model in learning at the tertiary level, and SOLO taxonomy as an evaluation tool which was used in the study.

Chapter Three: In this chapter I present the literature related to EAP in tertiary education. I include the ongoing debate that revolves around EAP and the different stances of the EAP practitioners in the teaching of EAP. I also explore the factors that influence the teaching and learning of EAP at the tertiary level and the reading skills of, and tasks given in the EAP classrooms. This chapter also includes literature on the transfer of knowledge from the EAP classroom to mainstream academic programmes. It concludes with the contribution of the current study to the EAP literature. 
Chapter Four: The methodology used in this study is described and justified. This chapter explores the qualitative methods used to collect the data. I discuss the use of a single embedded explanatory case study in this research. This chapter also discusses the data collection procedure and the data analysis. I conclude this chapter by including the strategies used to ensure trustworthiness and by describing how the research ethics were upheld in this study.

Chapter Five: This chapter explores the findings of this study. The findings are organised according to three units that reflect the three EAP classrooms at a public university. This chapter is organised into two parts. The first part describes the participants' perceptions of learning in the EAP classroom. The second part includes the participants' responses to the written work given in the classroom. The findings of this study revealed that there are various learning factors that influence the participants' learning in the English academic classroom and that influence how they approach their learning as well as their perceptions of the outcomes of learning.

Chapter Six: This chapter is organised into two parts. The first part presents the cross-unit analysis between the three units. The cross-unit analysis explores the patterns that emerged from the findings. There were some differences and similarities found across the three units of analysis. The second part of the chapter focuses on the research questions. This part explores the answers to the research questions.

Chapter Seven: Chapter Seven presents the discussion of the findings based on the CA framework and the 3P model. The chapter uses the 3P model to show the relationship between the presage, process and product stages that take place in the academic English classroom. This chapter is divided into two parts. The first part explains the existence of alignment and learners' responses to specific tasks. The second part discusses the existence of alignment and learning in the academic English classroom as a whole. Finally, the learners' process of learning as an internal process of compromise is explained.

Chapter Eight: Lastly, this chapter concludes the research study by providing a summary of the research. The contributions are described in terms of the theory, the methodology and the EAP practice. The implications of this study include the ways the findings could assist in the construction of the EAP course design, and could also assist the EAP practitioners as well as the learners themselves. The limitations of this study and suggestions for future research are also included.

\subsection{Summary of the Chapter}

This chapter described the context of study, how learning English is viewed in Malaysia. It is evident that English plays an important role in Malaysia despite being a second language. 
English is viewed as a language that is used in the private sector, and is spoken in everyday situations but is also a threat to the national language. Regardless of these perspectives, Malaysians are not proficient in English, especially tertiary students.

This study was designed to delve further into Malaysian tertiary students' perspectives of learning in the EAP classroom. I situated myself as the researcher of this study to make sense of my observations as an instructor while teaching at the tertiary level. A summary of the key terms used in this thesis as well as a summary of each chapter of the thesis was also included in this chapter. 
This page is intentionally left blank 


\section{CHAPTER 2 \\ THEORETICAL FRAMEWORK OF THE STUDY}

In this chapter, I will discuss the framework used for this study. This chapter explores the use of the CA framework (Biggs, 1996) and the 3P model (Biggs, 2003) of teaching and learning. It also discusses how both the CA framework and the $3 \mathrm{P}$ model fit within the social constructivism paradigm.

This study adopts a social constructivism paradigm. Social constructivism emphasises "the importance of social interaction in acquisition of skills and knowledge" (Schunk, 2012, p.230). Taking into account the influence of social interaction is unavoidable in language learning because languages are used for interaction purposes (Vygotsky, 1962). The interaction that takes place between a speaker and the context promotes cognitive development (Schunk, 2012). In other words, the interaction between the learners and their socio-cultural context influences their thoughts.

Further, social constructivism is a branch of constructivism. Similarly, to constructivists, social constructivists believe that learners come into a setting with existing knowledge. Learners' existing knowledge can be in the form of experience which could be gained from their background, their social interaction, and their culture (Schunk, 2012). Hence, social constructivism emphasises that learning is contextual and prioritises the interaction that takes place between a person and the environment. A person's personal experience and perceptions of learning influence how he or she interacts in an academic context.

Biggs' CA framework provides the theoretical framework for this research. The 3P model is used to support the use of CA in this thesis. Biggs' CA framework and the 3P model are derived from the constructivism paradigm. Biggs stated that learners are not empty vessels but have existing knowledge. Constructivism states that learners create their own knowledge from their prior knowledge with support provided by their instructors (Biggs \& Tang, 2011). I have drawn on the broader affordances of Biggs' work on the CA framework and the 3P model by using a social constructivism lens. My study explores students' perceptions of learning academic English at a tertiary institution within a L2 environment. Learning English involves not only learning within the classroom context but also the environment out of the classroom. Learners' background and the influence of society's perceptions of learning English in a multilingual context play a role in learning English.

The use of the CA framework in tertiary education and the 3P model will be explained in the following sections in this chapter. 


\subsection{Constructive Alignment (CA) Framework}

The purpose of this section is to discuss the suitability of using the CA framework as a theoretical framework to guide the research study. In this section, I will discuss the formation and the definition of $\mathrm{CA}$, the features of this framework, past studies that have employed this framework, and the critiques of this framework.

\subsubsection{Formation of Constructive Alignment}

CA was formed as a result of a trial portfolio assessment by Biggs in a Bachelor of Education Course (Biggs, 1996; Biggs \& Tang, 2011). Biggs had taught an educational psychology course to in-service teachers at the University of Hong Kong. He realised that the assessment methods that were designed for the course were mostly about declaring the knowledge that the students had learnt (Biggs, 1996, Biggs \& Tang, 2011). Biggs' aim was "not to teach students about psychology, but to get them to think about teaching and learning, and to enact classroom decision-making, in a way enriched by psychological knowledge" (Biggs, 1996, p. 352). Biggs recognised that in order to achieve this aim, he would have to design assessments which indicated the students' various levels of understanding such as being able to comprehend what they learnt, employ it in their teaching, and lastly to reflect on their teaching (Biggs, 1996). He wanted the students to be able to understand what they learnt at a personal and a professional level (Biggs, 1996).

Inspired by the portfolio assessment designed in an elementary school in Canada, he decided to use a similar assessment method to achieve his aim (Biggs, 1996; Biggs \& Tang, 2011). Biggs (1996) compared assessments such as short answer questions, multiple choice questions and essay questions that required students to regurgitate facts that they had learnt without having any actual understanding, with portfolio assessment which allowed students to demonstrate how they act on their understanding.

Biggs had created four intended learning outcomes for the course that he taught (Biggs \& Tang, 2011). He had included a reflective diary and small group discussions as part of the learning activities and had urged the students to critically reflect on their experience of teaching (Biggs \& Tang, 2011). He had asked them to have a portfolio that included four tasks that the learners felt resonated with most of the intended outcomes of learning, a reflective journal on the learners' own teaching practice for each session, and justification for choosing the four tasks for the portfolio (Biggs \& Tang, 2011). Seeing the successful result of the portfolio experiment, Biggs broadened his teaching method into a model of instruction that he termed Constructive Alignment (Biggs \& Tang, 2011). The term 'constructive' is derived from the constructivist theory of learning that depicts learners as constructing their own knowledge with the help of their existing prior knowledge (Biggs, 1996; Biggs \& Tang, 2011). The term 'alignment' comes from the curriculum theory which argues that suitable instructional designs 
such as assessment methods should be aligned with the intended outcomes stipulated in the curriculum (Biggs, 1996; Biggs \& Tang, 2011). According to Biggs (1996), CA is a "marriage" between constructivist theory and appropriate instructional design (p. 347).

\subsubsection{Features of Constructive Alignment}

Before the nineties, teaching and learning in tertiary education could be considered decentralised in that the instructors chose what and how they preferred to teach (Biggs, 2014). According to Biggs, this decentralisation affected the quality of teaching and learning at the tertiary level (Biggs, 2014). This decentralised system slowly changed to consider what the students should be learning and ways to help students learn (Biggs \& Tang, 2011). Biggs (1996) stated that in order for this to take place, the teachers should have a clear understanding of what they wanted their students to learn.

Biggs and Tang (2011) argued that tertiary education at times tends to focus on teaching declarative knowledge to their students. Declarative knowledge is an understanding of content based on what is in books or transmitted by instructors (Biggs, 2003). Biggs and Tang (2011) stated that providing declarative knowledge to the students is appropriate because it is crucial to have an understanding of a particular concept or theory. However, it is equally important to be able to move beyond declarative knowledge to functioning knowledge where students employ the knowledge that they have learnt (Biggs \& Tang, 2011). Some of the examples of functioning knowledge are "solving problems, designing buildings, planning teaching or performing surgery" (Biggs \& Tang, 2011, p. 82). Biggs (2003) mentioned that to demonstrate functioning knowledge, students needed to have declarative knowledge, procedural knowledge (the skills needed) and conditional knowledge (being aware of when to use the knowledge). Promoting a high level of cognitive thinking for students is important. This is because it provides them not only with conceptual knowledge but also the ability to act on the knowledge that they have acquired. CA reveals how this transformation of understanding takes place within the curriculum (Walsh, 2007). The transformation of understanding could be executed by instructors by setting appropriate intended learning outcomes that relay the functioning knowledge. This is followed by designing the teaching and learning activities and finally the assessments to evaluate the students' understanding. Further, Biggs (2003) stated that students should be educated to execute their learning in their future professional career rather than declaring what they have learnt. CA then assists students in preparing them to face the challenges in their career upon completing their studies (Walsh, 2007).

Biggs and Tang (2011) explained that CA provides a systematic design that helps instructors to discover how their teaching results in changes in their students. Biggs (2014) stated that CA is an approach used to provide the intended learning outcome prior to the commencement of the teaching and learning in the classroom. In other words, the teaching methods and the 
assessments are designed to meet the intended learning outcomes that students should learn. These assessments and teaching methods should be created and delivered in an engaging way to assist learners to meet the intended learning outcomes (Biggs, 2014). In addition to being systematic, CA is also consistent (Biggs \& Tang, 2011). The application of the verbs from the intended learning outcomes to the teaching and learning activities to the assessment tasks indicates that the goal of learning is present throughout the teaching and learning process (Biggs \& Tang, 2011). This consistency that takes place in CA helps the students as well as the instructors to keep monitoring what should be achieved as a result of the learning.

Biggs used the earlier devised $3 \mathrm{P}$ model consisting of presage, process and product to represent the existence of alignment in the parts of the curriculum (Walsh, 2007). The 3P model explains the alignment between the intended outcomes of learning, the teaching and learning activities designed to encourage engagement among students, and the display of output of learning by using appropriate assessments. The use of the 3P model will be further elaborated in the next section of this chapter.

Although the CA framework undoubtedly assists instructors in preparing an aligned system of teaching, its focus is very much on the students and their learning. Biggs observed the importance of Shuell's (1986) claim that students' role is more important in the learning process compared to the teachers' role of imparting knowledge (Biggs \& Tang, 2011). Biggs and Tang stated CA's agenda is "how" and "what" the students have actually learned (p. 97). In other words, the output of learning is based on the "activities and experience" that the students have accomplished or acquired (Walsh, 2007, p. 80). Hence, the students' opinion about how well learning was accomplished is more important than how well the instructors designed their teaching. This is because ultimately the students' performance of understanding is the focal point of CA. This principle is particularly applicable because it points to the importance of considering the students' perceptions of their learning.

\subsubsection{Studies using Constructive Alignment}

Biggs viewed education at the tertiary level as a system in which each of the stakeholders is considered as a sub-system (Biggs, 1993a). These sub-systems are the "student system, the classroom system, the institutional system and the community system" (Biggs, 1993a, p. 77). He claimed that to have quality teaching and learning, it is important for these sub-systems to work within, as well as across the system in order to reach a balance (Biggs, 1993a). This balance promotes quality education at the tertiary level (Biggs, 1993a). In other words, an alignment between the sub-systems is crucial for achieving quality teaching and learning.

CA has been employed in many areas of education by stakeholders (Biggs, 2014). A number of relatively recent studies have been conducted using this framework in various subject areas 
such as social sciences: learning academic English (Mavor \& Trayner, 2001; Tweedie \& Kim, 2015) and social work (Moulding, 2010); sciences: biochemistry (Hartfield, 2010) and health science (Raeburn, Muldoon, \& Bookallil, 2009); and commerce (Kuhn \& Rundle-Thiele, 2009). These studies show that the instructors had integrated CA as a framework to reflect on how teaching is delivered within the classrooms. Moving away from the teaching context, studies on CA in education were also conducted at the institutional level. The framework is used to evaluate course programmes at this level too. Studies conducted by McMahon and Thakore (2006), Wang, Su, Cheung, Wong, and Kwong (2013) and Salleh, Lit, and Lias (2013) indicate that $\mathrm{CA}$ is also used to evaluate the courses offered at both the faculty and institutional levels. For example, Salleh et al. observed the use of the CA framework in an electronic engineering programme in a public university in Malaysia. The researchers considered how CA was used to align the programme outcomes with the course outcomes as well as the teaching and learning activities and the assessment methods. Each course outcome was matched with the appropriate programme outcome in the course. Then the course outcomes were further broken down to the topics covered in the course, the teaching and learning activities used, and how the topics were assessed. This breakdown demonstrated the alignment between the learning activities, the assessments and the course outcomes as well as the programme outcomes as a whole. In other words, CA could be used to align students' learning with the intended outcomes of learning of a course within the classrooms as well as in relation to a broader aspect such as programmes in a faculty.

Larkin and Richardson (2013) stated that limited studies have been conducted on integrating and evaluating CA in the classroom from students' perspectives. Students are considered important stakeholders in education. Hence, being aware of how they perceive learning should be considered an equally important key factor in facilitating their achievement of quality learning. Moreover, in a large classroom, at times, using assessment as an indicator to determine whether the learning outcomes have been met can be quite challenging (Davis, 2007; Kuhn \& Rundle-Thiele, 2009). Inquiring into students' views on how they perceive the teaching and learning in the classroom could prove beneficial as it offers better insights into students' progress and achievement of the intended learning goals (Harvey \& Baumann, 2012; Kuhn \& Rundle-Thiele, 2009).

Harvey and Baumann (2012) conducted research with 102 participants in two cohorts of undergraduate students studying Management at a university in Australia and a university in Denmark. The researchers aimed to find whether the curriculum for the course and the learners' reflections about learning in the Brand Management subject aligned with using word clouds. The data were collected using students' reflections on learning, the researchers' reflections, and the course outline which contains the intended learning outcomes. The researchers asked the participants to document their own reflections on learning as part of a 
group assignment. The findings showed that students' reflections on learning and the intended outcomes of learning for the course were aligned. The findings were divided into three categories: reflection on Marketing and Branding, reflection on research experience, and reflection on teamwork in the group assignment. The reflection indicated that the participants were able to relate this course to a wider context of the use of brand marketing, they were able to relay their understanding of the theories and models taught in the course, they had a positive experience in conducting the research project, and they were able to work effectively as a team by negotiating. The value of this study is that it shows the potential to consider the effectiveness of alignment in a course from students' perspectives.

In a longitudinal study carried out in a tertiary institution in Malaysia, Abdullah (2013) explored the students' perceptions of learning, their preferred approaches to learning and whether the assessments enabled them to develop higher order thinking skills in business subjects. The overall findings showed that the learners' perceptions of learning, the approaches used and their opinion about the assessments had influenced students' development of higher order thinking skills to a certain level. However, it was also mentioned that the students preferred a surface approach to learning which could be related to their lack of language proficiency in English as English is a second language for them. This provides evidence that the students were willing to learn, although they faced challenges. Hence, exploring students' views has the potential to contribute to producing a better alignment between the teaching mode, the assessments, and the outcome that is supposed to be achieved in a classroom.

There has been very little empirical research conducted on students' experience of learning in the EAP classroom explicitly using Biggs' framework of CA. Some studies such as those by James (2010) and Green (2015) (these research studies will be discussed in detail in the transfer of learning section in the literature review chapter), although not explicitly using CA, examined the students' perceptions of the content of learning in the classroom and the transfer of learning that takes place out of the EAP context (Tweedie \& Kim, 2015). They were indirectly referring to a potential alignment between the content learnt and the transfer of this content to other subjects and they found that a possible transfer is likely to occur if learners' needs in other subjects are carefully considered while designing and teaching EAP courses. The EAP course was designed to enable learners to use the language skills in the academic context that made the alignment between the content taught and the transfer of this content to the mainstream academic context important.

In their study, Tweedie and Kim (2015) conducted research among international students at a university in Canada. The researchers aimed to explore post-EAP students' perceptions of the alignment between the EAP content and the mainstream courses taught at the university. The findings revealed that students found some content taught in the EAP course aligned and some 
did not align with the mainstream courses. The participants claimed that they found the skills taught on the EAP course, the teaching method such as group discussions and practising speaking were aligned with the objectives of the course as they were able to make use of the skills in the mainstream courses. They also found the assessment methods, vocabulary and the length of reading passages were not aligned with the objective of the course. This research study focused on the existence of alignment in terms of transferring the knowledge learnt in the EAP course to mainstream programmes. This research study is different to the studies conducted in the area of commerce by Harvey and Baumann (2012) and Abdullah (2013) (discussed above) who investigated the existence of alignment within particular subjects. The research studies conducted by James (2010), Green (2015) and Tweedie and Kim (2015) suggest that students find it hard to transfer some of the elements in the content such as the skills and the mechanics of using the English language taught in the EAP classroom to other subject areas. Some of the reasons from the student data were the lack of opportunity to apply the skills and the irrelevance of the EAP skills to the other subjects. This limited but still informative empirical research suggests that more work needs to be done to align the content taught in the EAP classroom with the mainstream academic context.

The CA framework could be used in many ways to align students' learning with the intended outcomes of learning. This framework can be used within a course or within a faculty programme as well as within classroom teaching and learning contexts.

\subsubsection{Criticisms of Constructive Alignment}

CA has received some notable criticism of its suitability as a teaching design. One line of criticism focusses on the nature of setting learning outcomes which establish the purpose of the teaching and learning and to which everything else must align. Hill (2012) claimed that setting the outcomes could be regarded as a "rigidification of pedagogy" that makes instructors feel stifled and the teaching inflexible (p. 114). Hill further stated:

the feeling that flexibility, creativity and imagination had been stifled by bureaucratic rigidification means that some academics have adopted what they consider to be subversive practices including 'weaning' or 'resocialising' students away from the constraints of narrowly conceived education. (p. 118)

Biggs (2014), however, replied that the instructors are given the freedom to choose the outcomes which are usually constructed by themselves or with a committee. Hence, they should be able to determine the suitability of the outcomes as well as the levels of these outcomes. Another criticism from Jervis and Jervis (2005) is that predetermined learning outcomes in CA may curtail students' capability. They mentioned that there are also incidents where the instructors failed to identify learning outcomes that the students produce. This leads to a mismatch between the outcomes expected and those that were demonstrated. Biggs 
(2014) responded that instructors are free to use "open ended verbs such as "design, create, hypothesis, reflect" as well as "open ended" assessments (p. 12). He added that these types of assessments provide wider opportunities for students to demonstrate their learning.

Biggs' notion of CA is student centred because knowledge is not directly transferred from instructors to students, but the model allows students the opportunity to create their own knowledge through the information that they have, along with appropriate learning activities (Biggs, 2003). However, the degree to which the learning is student centred has been contested. Biggs claimed that suitable teaching and learning materials should be selected by the instructors for the students. Jervis and Jervis (2005) claimed that in CA students are "trapped into activities but free to construct the knowledge they may or may not acquire in the process, in their own way" (p. 8). Hence, CA does not fully conform to the principles of a student-centred approach as it takes away students' autonomy to choose what they would like to learn. Jervis and Jervis also claim that CA has a stimulus-response association which means it is actually behaviourism. They claimed that providing stimulus in the form of verbs as intended outcomes conforms to a behaviourist pedagogy. On the contrary, according to Biggs, having these verbs as intended outcomes aims to merely set up an environment to encourage students to engage and perform at a higher-level (Biggs \& Tang, 2011) as well as not to stray from the aim of what is to be taught to the students. Having said that, Biggs and Tang also clarified that CA provides space for unintended outcomes of learning to emerge. As mentioned earlier, using "open-ended" tasks such as portfolios and reflective diaries allows the occurrence of unintended learning outcomes as these types of assessments probe students' experience and do not have a fixed right answer (Biggs \& Tang, 2011, p. 216).

The heart of these critiques of CA is the notion of being teacher centred as the instructor determines what needs to be learned. Biggs' defence of CA is that it is indeed a studentcentred approach which minimises the involvement of teachers in the learning process. CA does not spoon-feed information to the students; instead, it allows the instructors to become facilitators. CA promotes autonomy by permitting students to act on what they learn. Instructors, on the other hand, provide an appropriate environment for the students and thus become a bridge that assists them to create their own meaning (Biggs \& Tang, 2011). Autonomy could be promoted by designing assessments or learning activities that stimulate learners' thinking in ways that will provide an opportunity to construct their own meaning.

\subsubsection{Using Constructive Alignment in a Qualitative Approach}

Past studies on evaluating the alignment of teaching and learning have been predominantly quantitative (Kuhn \& Rundle-Thiele, 2009; Larkin \& Richardson, 2013). When seeking students' opinions of their experience of learning in general, questionnaires, which are a common quantitative research tool, have been used extensively (Griffin, Coates, McInnis, \& 
James, 2003; Kember, Leaung, \& Kwan, 2002; Larkin \& Richardson, 2013). Larkin and Richardson stated that these types of questionnaires provide information that the instructors can reflect on in their teaching. However, using such quantitative approaches causes individual perspectives to get lost as these approaches tend to provide quite broad summations of students' perceptions. Using a qualitative research method in research studies provides a detailed picture of the learning experiences that may be missing if a quantitative approach is used on its own (Jones \& Asensio, 2001). As mentioned earlier in this section, "what" and "how" students learn is a crucial part of CA. Hence, further exploring students' perceptions and experiences of learning has the potential to reveal a deep understanding of the existence of alignment.

To summarise, there are not many studies conducted in EAP classrooms using Biggs' (1996) CA framework. The current study explores how tertiary students perceive learning in the EAP context. The CA framework is used to understand the existence of alignment or the lack of it in an EAP classroom from the students' point of view.

\subsection{Biggs' 3P Model of Teaching and Learning}

\subsubsection{Overview of the 3P Model}

Biggs (2003) asserted that "education is about conceptual change, not just the acquisition of information" (p. 13). Just having the information and not being able to use it will not provide any benefit to the learner. Biggs believes that in order for conceptual change to take place, two elements - the individual and the context - should interact with each other (Biggs, 1978, 2003). Students should realise what they really want to learn, why they want to learn it, and how they are going to achieve it. The instructors should be able to provide the students with the appropriate environment to support the students' objectives (Biggs, 2003). These objectives, along with the teaching methods and learning process, form the 3P model. The 3P model explores what happens prior to learning, during learning, and what happens after learning takes place (Biggs, 2003).

Biggs' 3P model was originally adapted from Dunkin and Biddle (1974) (Biggs, 2003). Biggs first published the 3P model in 1978 and was refined multiple times until 1999. In 1978, Biggs had proposed a general model of the study process that depicts how personal and institutional factors create "values and attitudes which in turn determine the processing of academic information" (Biggs, 1978, p. 267). This cause and effect model showed a linear pattern which started from the presage stage, then moved to the process stage, and finally into the product stage. Although Biggs had not explored the impact of presage and product in the 1978 version, he had suggested that there is a direct effect from the presage to the product stage. The presage stage of the 1978 model comprised personal and institutional factors. The personal factors included cognitive styles, personality, IQ and home background. The situational factors 
were subject area, teaching method, evaluation modes and procedures, and course structures. The values, motives and strategies cover the process stage and the academic performance maps the product stage. The personal and institutional factors at the presage stage construct the values that influence the motives for learning. These motives then influence the strategies that the students opt to employ in their learning. This then leads to the academic performance of the students. The elements within the model have been refined over the years but the three stages - pre-learning, during learning and post-learning - remain unchanged.

The multiple changes to the 3P model made from 1978 to 1999 (refer to Figure 1) show that Biggs had realised that the influence of the presage-process-product stages is not linear but is interactive. As he mentions numerous times, Biggs considers learning to be systemic (Biggs, 1993a, b). Hence, all the components of the latest version of the 3P model interact with each other to form part of the system. The presage stage and the process stage interplay as the factors involved in learning interact with the learning activities. The product stage is influenced by both the presage and process stages, but it influences the presage and process stages where the feedback provided through the examination of the product affects learners' future learning as well as the instructor's approach to teaching (Biggs, 1993a). Therefore, changes to one aspect of the model will influence the other two aspects. For example, having relevant prior knowledge will influence the students so they are more engaged in the learning activities than, for example, students who have less relevant knowledge (Biggs, 2003). Hence, for appropriate learning to take place, there should be an alignment between the components of the three aspects of presage, process and product in the 3P model.

Although this study employs the latest version of the 3P model (Biggs, 1999, 2003), one of the factors from previous iterations of the model - language competence - is more closely related to the purpose of learning in my study. Language competence (Biggs, 1990) existed in the earlier version of the 3P model as a factor in its own right. I have made it an addition to the otherwise 1999 version of the 3P model for the purposes of this study. My study examines L2 students learning EAP in language classrooms. Language competence is one of the factors that influences language learning of L2 learners (Grabe \& Stoller, 2011).

Language competence was included in the 1990 version of the 3P model because Biggs realised that language proficiency is a crucial factor for Asian learners who are learning the content in L2. The inclusion of language competence in the model derived from Biggs' observation while teaching in Hong Kong. Biggs' notion of language competence is related to learners' choices of an approach to learning. In producing this revised model, Biggs (1990) asserted that being competent in the language in which the teaching and learning are conducted influences the learning performance. However, at the same time, he stated that Asian learners tend to create their own strategies to accommodate the learning that happens 
in L2. Biggs affirmed that these students tend to focus on what they intend to learn and try to understand the content in L1 before translating it to L2 (Biggs, 1990). This makes understanding the content easier for the learners. Biggs further stated that this strategy could be considered deep learning, but it may not be effective in a language classroom. This is because semantics are fundamental in responding to reading or writing tasks and any attempt from the students to understand a theme or a main idea without having an understanding of the semantics leads to incoherent arguments (Biggs, 1990).

After the 1990 model, language competence was not included in later versions of the 3P model. For the purposes of this study, however, I consider the inclusion of language competence as one of the student factors in the 3P model to be crucial for studies conducted in an English as a second language context. This is because students from the ESL context do at times face problems with language proficiency and this is likely to influence their performance, especially when the content taught is in learners' L2. Learners' low level of language proficiency is one of the causes of anxiety in learning among non-native speakers of English (Horwitz, Horwitz, \& Cope, 1986). In the EAP classroom, students are both learning language in L2 but also the kinds of academic reading and writing strategies required of learners in L1 contexts. The effects of language competence on learning among L2 students will be further discussed in the literature review chapter.

Learners' background is also seen as a presage factor in the 3P model that influences how learners approach learning. In 1972, Biggs viewed home background as one of learners' personal factors that influences learning among students. Biggs' study was conducted among students from two high schools in Melbourne, Australia. The study was conducted to determine whether high school students' study behaviour was influenced by context, namely the teaching-learning environment and home background. Within the home background factor, Biggs had included aspects such as religion and father's qualifications. In terms of home background, he did not find enough evidence to claim that students' religion played a role in their study behaviour at both the high schools as there were a number of students with immigrant parents. Having immigrant parents could have influenced learners' study behaviour (Biggs, 1972). Another aspect that Biggs took into consideration was the father's qualifications. Biggs again reported conflicting findings; students who were highly motivated in tasks given at school had poorly educated fathers in school A but the opposite applied for school B. However, father's education was positively associated with examination techniques; students with educated fathers seemed to be more inclined to use examination techniques. Biggs concluded that the home background factor was one of the aspects that influenced study behaviour among these high school students. In the 1972 study, Biggs had narrowed the home background factor to the existing situation within the home environment. 
Biggs had maintained the home background factor in the 1978 and the 1985 versions of the 3P model, stating that this factor was part of learners' experience that contributes to how they approach learning. However, Biggs had mentioned that more detailed work needed to be carried out in terms of the home background factor as its relationship to learning was not clear (Biggs, 1978). From Biggs' explanation, it could be said that he viewed home background as the immediate condition of the home environment and not the influence of the wider society which could influence the practices at home. This wider influence, however, could potentially be seen especially in second language learning where the influence of a community plays a part in how learners view learning a language. In other words, beliefs about language learning in a community could be an important background factor that influences learning and is a reason why I consider this factor to be a student factor in the presage stage. This was important to consider since my study took place in multilingual Malaysia.

Figure 1. 3P model of teaching and learning

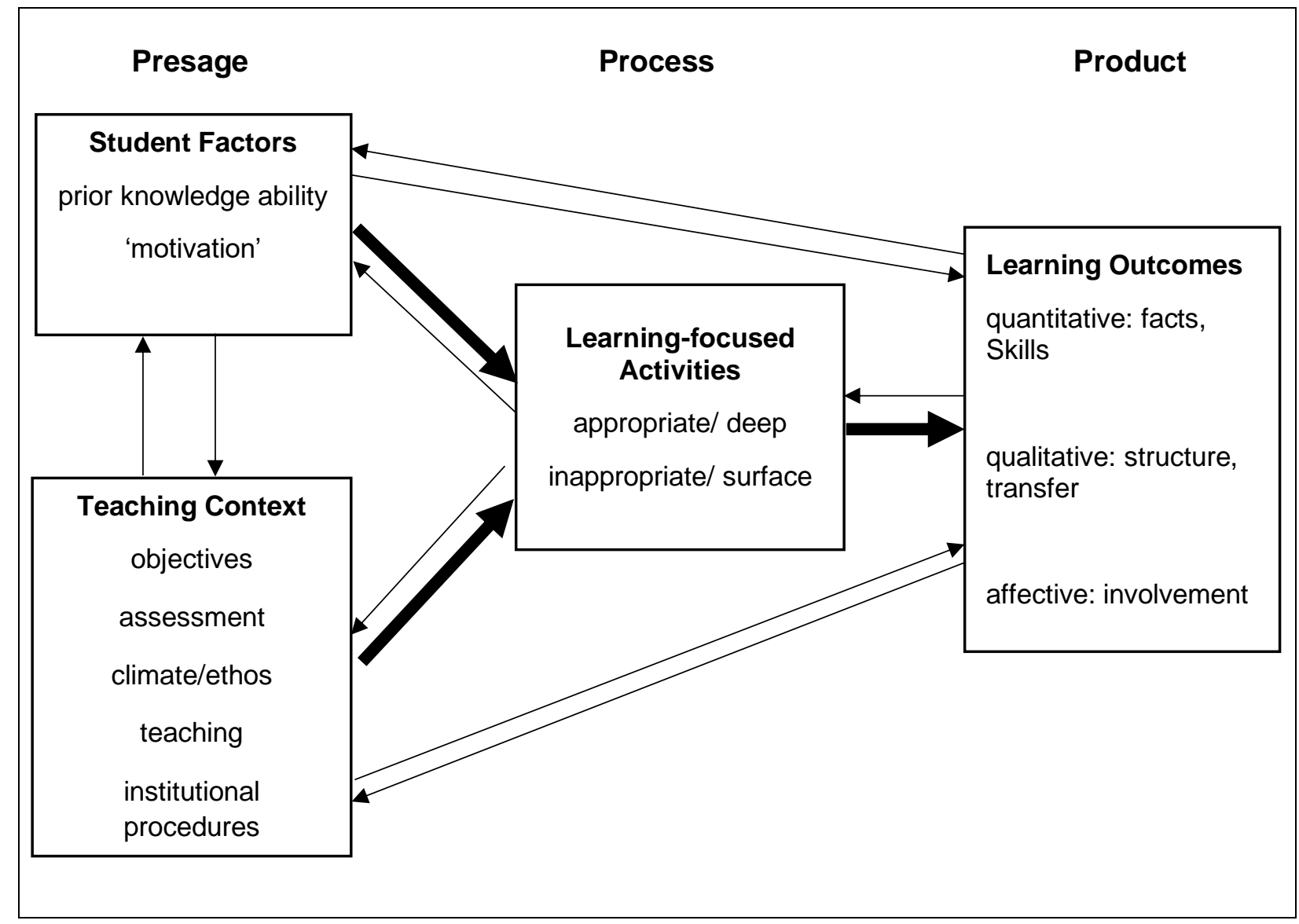

Adapted from Biggs, 2003, p. 19

\subsubsection{Presage Stage}

The presage stage indicates the elements that exist or should be taken into consideration before teaching and learning takes place. The reason these factors are considered prior to learning is because they influence how learning is achieved (Biggs, 2003). The presage factors are divided into personal factors and the teaching context. The personal factors in the presage 
stage focus on the characteristics that students possess. These personal factors are important as these elements influence the learning process that learners are involved in. Biggs (2001) stated that there are two types of factors in learning that students have: "hard" and "soft" (p. 87). According to Biggs (2001), the hard factors such as cognitive styles and ways of learning are difficult to change whereas the soft factors such as approaches to learning and motivation are those that could be influenced through teaching. Biggs (2001) stated that "the hard presage factors influence the soft, and the soft and the teaching context mutually interact at the process level to determine the students' immediate learning-related activities, that is, their approaches to learning" (p. 87).

The factors in the teaching context are the selection of the content, how the content is taught, and how it is assessed as well as the environment where the teaching takes place (Biggs, 2003). The step of selecting the content for learning comprises objectives, teaching methods, and expertise and assessments whereas the environment comprises the climate of the classroom and institutional procedures (Biggs, 2003). Selecting appropriate content is important because the content should reflect the intended outcomes of learning. As mentioned earlier in this chapter, the CA framework was formed to ensure that the intended learning outcomes are reflected in the teaching and learning activities and the tasks. The instructors should then select teaching and learning activities that will assist the achievement of the objectives that they think are suitable for the learners. This is then followed by creating assessments that will determine how well the students have learnt the content. In terms of the environment where the teaching takes place, the instructor will have to adapt to the rules of the institution but may have the autonomy to structure the learning environment in the classroom (Biggs, 2003).

\section{Student factors and teaching context}

The 3P model has been used across the globe in both western and eastern contexts and has undergone numerous revisions to suit the contexts where it is used. Various factors in the presage stage influence teaching and learning in the classroom. In my study selected elements emerged from the analysis of the findings and so became the focus of investigation in the study and these will be discussed in more detail below. They are prior knowledge, anxiety in learning, interest in learning, and motives for learning.

\section{Studies on presage and process stages}

The 3P model is an interactive model; therefore, the presage, process and product stages influence each other. In this section, studies on the presage stage and its relationship with the process stage, particularly approaches to learning, will be discussed. 
Prior knowledge: This concept connects with a key principle of constructivist theory, that learners make meaning from existing knowledge. Constructivist theory advocates that learners are not empty vessels but come with basic knowledge acquired from many forms of experience. Thus, within the scope of constructivist theory, possessing relevant prior knowledge is an important factor that assists learners in engaging with the learning activities that take place in the classroom (Biggs, 2003). Prior knowledge could be seen in terms of background knowledge of content or prior learning experience as a whole. Prior learning experience is different to prior content knowledge. Prior learning experience refers to a wider concept of students' learning experience such as their academic achievement, motivation, gender, and perceptions of learning that the students bring into an educational environment (Ashwin \& Trigwell, 2012). This differs from prior content knowledge which focuses on the learners' background knowledge of the information in a particular context (Hedgcock \& Ferris, 2009). For example, within the area of reading, prior content knowledge refers to learners' background knowledge of the information presented in a reading text (Hedgcock \& Ferris, 2009).

Students equipped with sufficient content knowledge and intrinsic interest in the activity will be able to understand the whole picture of what is being taught to them (Biggs \& Tang, 2011). Having this understanding would help learners to choose the type of approaches to employ in the learning activities given to them (Biggs, 2003; Biggs \& Tang, 2011). Prior content knowledge is combined with interest in learning which would then lead to how meaningful the learning would be. There seems to be a scarcity of empirical research using the 3P model that has investigated the influence of prior content knowledge at the tertiary level. In a second language context, having sufficient prior knowledge of the content of what is to be learned is important because learners are learning through their second or additional language.

Although studies in terms of prior content knowledge with relation to the 3P model are scarce, there have been studies exploring prior learning experience among tertiary students. These studies are not directly related to the 3P model, but they are linked to approaches to learning, which is an aspect of the $3 \mathrm{P}$ model. The quantitative studies show that prior learning experience does influence students' learning (Ashwin \& Trigwell, 2012; Trigwell, Ashwin, \& Milan, 2013). Ashwin and Trigwell (2012) aimed to find the relationship between undergraduates' evoked prior experiences investigated through three aspects: "evoked conceptions of learning, evoked motivation, and their evoked self-efficacy, and their perceptions of the learning environment" (p. 452). The researchers posted questionnaires to a total of 831 first year undergraduates from the various faculties at the University of Oxford. This questionnaire was piloted by Trigwell and Ashwin (2006) and included constructs on learners' evoked prior experiences, approaches to learning and perceptions of the context of learning. The findings showed that the three aspects of evoked prior learning experience - 
evoked conceptions of learning, evoked motivation, and evoked self-efficacy - influenced learners' approaches to learning and their perceptions of the learning context. The researchers stated that students who are interested in acquiring new knowledge are more motivated and believe that they are able to succeed in that learning environment. This enables them to choose a deeper approach to learning.

In a study with senior level undergraduate students from various disciplines at the same university, Trigwell, Ashwin, and Milan (2013) found that prior experience, perceptions of the context of learning and approaches to learning influence students' academic achievement. The researchers noted that the students' academic achievement at the University of Oxford is only assessed at the end of their degree course. Hence, their evoked prior learning experience needed to be seen as experience during their study years. The researchers found that students' evoked prior learning experience in terms of self-efficacy, motivation (students' perceptions of task value and stimulation to learn) and conceptions of learning influence their academic achievement which is the learning outcome. The findings showed that students who are more confident in their learning perceive a greater value of the workload and find the teaching quality leads to a better learning outcome. Both these studies show that students' prior learning experience is one of the factors that affects students' approaches to learning as well as the final product of learning. Prior learning experience, which is an aspect of prior knowledge, plays a role in learners' motivation to learn as well as contributing to their achievement.

The sub-connections with motivation and approaches to learning, which is a part of the $3 \mathrm{P}$ model, have been made in various studies (Balasooriya, Hughes, \& Toohey, 2009; Dull, Schleifer, \& McMillan, 2015; Holmes, 2018; Papinczak, 2009; Tiwari, et al., 2006). Motivation theory is not the focus of this study, but it must be considered in the body of the study to the extent that motivation is seen as part of learning and therefore is a factor at the presage stage.

Anxiety in learning: Anxiety in learning is considered to be a student factor of the presage stage of the 3P model (Matters, 2009). Anxiety in learning has been associated with surface approaches to learning in various studies which have been selected here because they draw on approaches to learning and other factors that are associated with the $3 \mathrm{P}$ model (Balasooriya, et al., 2009; Papinczak, 2009). A study conducted by Balasooriya et al. (2009) with medical students showed that the majority of students opted for a surface approach to learning when introduced to a problem-based learning approach. The researchers interviewed 18 out of 44 participants who volunteered in a pilot programme. The findings showed that only five participants out of a total of 18 adopted a deeper approach to learning. The problem-based learning approach aimed to develop a deeper approach to learning. The majority of the students reported that they felt uncertain about the teaching approach and thus anxious about 
it. The findings showed that students' frustration was caused by multiple factors such as uncertainty about the learning outcome that should be achieved, a mismatch of learning style with the teaching method, their desire to have more guidance instead of being autonomous, and the pressure of workload and time management. These factors had stimulated them to adopt a surface approach. The students reported that they felt the traditional teaching method was more systematic and had clearer learning objectives compared to the problem-based learning approach. The students reported that the unclear learning goals had prompted them to be focused on accomplishing the tasks, rather than deep learning for its own sake.

Papinczak (2009) also carried out a study with medical students. Although she did not use the 3P model directly, she had found similar findings to the study of Balasooriya et al. (2009). In her study, Papinczak aimed to identify medical students' perceptions of the problem-based learning approach in the course. The research conducted by Papinczak showed that the participants who adopted a surface approach to learning had reported being stressed by the mismatch between their preference for learning and the teaching method. The students who adopted a deep approach to learning, however, had also felt frustrated by the PBL approach. These students reported that they had personally welcomed the problem-based learning approach but because some of their peers were not interested in it this affected their group discussions. In this case, the anxiety of some affected the process of all.

Anxiety in learning can also be caused by lack of language proficiency (Horwitz et al., 1986). Anxiety in learning caused by lack of language proficiency is an important factor, especially for students from a second language context. Students who learn in the L2 environment at times find themselves unable to engage in the learning process due to their lack of proficiency in the language. Although Biggs' latest version of the 3P model did not include language competence as a factor, it is still more generally considered an important factor for learners in the ESL context. This is because anxiety in learning can also be caused by lack of proficiency in the language used for teaching and learning as learners are self-conscious and have a fear of being judged by others (Horwitz et al., 1986). Lack of proficiency will be further discussed in the literature review chapter of this thesis.

Interest in learning: Interest is associated with deep approaches to learning as learners find a pleasure in learning that causes them to want to know more about the knowledge that they are learning (Biggs \& Tang, 2011). Students' interest and desire to learn are influenced by both personal factors (Kember, 2016; Kember, Hong, \& Ho, 2008) as well as the learning context (Holmes, 2018; Kember, 2016; Kember, Ho, \& Hong, 2010 Wigfield \& Cambria, 2010). Wigfield and Cambria have stated that interest in learning can be influenced by both students' personal interest and the situational interest. Personal interest can be defined as learners' interaction and involvement with particular activities, for example, learners' continuous liking 
of a subject or task that causes an intrinsic interest (Hidi, 2000; Renninger, 2000), whereas situational interest is aroused by the environment and this interest may or may not be consistent (Hidi, 2000; Renninger, 2000).

Situational interest could be influenced by two aspects: firstly, learners' initial reaction to learning something that is interesting or creates curiosity; and secondly, how learners' interest is maintained and further explored in the situation (Hidi, 2000; Wigfield \& Cambria, 2010). Situational interest in other words can be associated with the teaching context where the assessments, teaching and learning activities inclusive of tasks and workload, the teaching methods, and the learning institution influence learners' interest in learning. Hence, students' interest in learning could vary depending on the type of learning activities given or other factors that exist within the teaching context as well as their own personal assessment of learning (Wigfield \& Cambria, 2010).

Kember et al. (2010) found that there are various factors that influence interest in learning. Their qualitative study of three Hong Kong universities showed interest in learning could be divided into interest in the type of course, the teaching and learning context, and the relevance of the content taught to the students. The findings showed that students' own preference for the choice of programme they enrol in, for the teaching methods and the principle of teaching, for the learning activities and assessments, the students' perception of the relevance of the content taught to them and their relationships with the instructors and their peers are the factors that affect learners' interest in learning. In another qualitative study, Holmes (2018) aimed to investigate the effect of interest in the topics on students' approaches to learning at two universities in northern England. The findings showed that students tend to adopt a deeper approach when they are interested in the topics. The findings from the studies conducted by Holmes (2018) and Kember et al. (2010) were similar in the sense that if learners have invested interest in the content, they tend to have deeper and more meaningful learning.

In another study, Kyndt, Berghmans, Dochy, and Bulckens (2014) found interest was closely linked to students' perceptions of workload. The researchers found that although time was an essential part of workload, students' interest was also a determining factor in learning. The findings showed that when the learners like the teaching method and the curriculum design, they perceive a low workload. The students claimed that they are eager to participate when they are interested in the subjects and when they are given group work and project-based tasks.

Learners' interest in learning is influenced by learners' personal factors which are influenced by their perceptions of the teaching context. When learners are interested, they tend to be more engaged and participate in learning. 
Motives for learning: According to Biggs and Tang (2011), learners prefer their learning to be significant. They engage in learning when they can see the "value" in what they are doing and they believe that they will be able to attain "success" (Biggs \& Tang, 2011, p. 35). Hence, learners have motives for learning. Learners' motives for learning could be linked to intrinsic and extrinsic motivation in learning (Biggs \& Tang, 2011). One way to view extrinsic motivation is when students learn to attain material recognition such as receiving some credit for being able to complete an activity or to avoid being punished (Biggs, 2003; Biggs \& Tang, 2011). In contrast, intrinsic motivation occurs when learners have a personal interest in what they learn (Biggs \& Tang, 2011). Learners' extrinsic and intrinsic reasons for learning are related to their adoption of the type of approach to learning. The relation between learners' reasons for learning and the approaches to learning at the tertiary level could be seen in two ways: learners' reasons for learning in the course as a whole (Kember et al., 2008) and learners' reasons for engaging with particular tasks given in the class (Biggs \& Tang, 2011). It is not surprising that there are instances where learners may not be engaged in all the tasks given in the classroom.

Learners' interest in learning and their reasons for learning in a course complement each other (Biggs \& Tang, 2011; Kember et al., 2008). Learners' reasons for learning in a course or a programme at the tertiary level are because of their desire to know more, the influence of their past experience and their beliefs about the requirements for skills and knowledge in future professions (Biggs \& Tang, 2011). A study conducted by Kember et al. (2008) among Hong Kong undergraduates showed that one of the factors influencing the desire to enrol in undergraduate programmes is the undergraduate's future career plans. These students reported that the reason they enrolled in the course is because they were interested in it and they plan to get a job where they can employ what they have learnt. These learners reported having a reason for learning which was investing in their career. Learners' reasons for learning could also involve academic achievement. Asian learners in particular are more focused on their grades and scores (as their assessments are usually determined by examinations) and the expectations of their parents (Kember, 2016).

In terms of learners' interest in tasks, Biggs (2003) and Biggs and Tang (2011) suggested that learners tend to employ deep approaches to learning for a task when they are intrinsically interested in it. This approach leads to the attempt to perform well and produce a better outcome. This shows that the learners' reason to engage in the task is caused by their own interest in knowing more or because they simply like the task given to them. On the other hand, learners whose intention is focused on completing the task tend to employ a surface approach to learning (Biggs \& Tang, 2011). The focus for these learners is more on the outcome of the task than the process. 
Motives for learning influence to what extent learners engage in their learning; they depend on their own goals for learning and are influenced by students' perceptions of the tasks.

\section{Conclusion for the presage stage of the model}

Learners come to class with their personal factors such as prior knowledge, interest in learning and reasons for learning. Their personal factors are influenced by the factors that exist in the teaching context such as assessments and teaching methods which determine how the learners approach their learning. In other words, both the student factors and teaching context interact with each other at the process level (Biggs, 2001). This interaction leads to students choosing the approaches to learning according to the learning activities given to them. For example, students become anxious when their expectations for learning are unmet (Papinczak, 2009), leading to a lower level of interest in learning (Kember, 2010), which eventually influences their responses to the teaching and learning related activities. This shows that one or more student factors could interact with the teaching context which will then influence their adoption of the type of approaches they employ in learning. Students' approaches to learning will be further explained in the process stage.

\subsubsection{Process Stage}

The process stage involves the interaction that takes place between the student and the learning related activities. The elements that exist in the presage stage influence the interaction of these learning activities. Biggs explained that at this stage, a student is inspired by his or her reasons to learn (motives) and the strategies used that suit the reasons for engaging with the activities (Biggs, 1987, 2001, 2003, 2001). Biggs had proposed deep, surface and achieving approaches to learning in the process stage of the earlier version of the 3P model. Based on a later study, Biggs, Kember and Leung (2001) reconceptualised the learning approaches into just deep and surface. Biggs decided that achieving approaches to learning could be absorbed into the surface and deep approaches. The deep and surface approaches to learning will be further explored in the next section of this chapter.

\section{Approaches to learning in the process stage}

McCune and Entwistle (2000) stated that learners' approaches to learning depend on their behaviour and the context for learning. Biggs mentioned that there are two ways to view approaches to learning: firstly, "learners' ongoing approach" (Biggs et al., 2001, p. 137) to tasks or their immediate approach to tasks; and secondly, learners' "preferred approaches" (Biggs et al., 2001, p. 137) or "predispositions to use a particular approach" (Biggs, 2001, p. 85). In other words, learners could use the approaches to learning to interact with immediate learning activities or the approaches to learning could also be used as preferences during the learning process. Further, the approaches to learning that the learners employ depend on the learner's 
characteristics, context, and learning activities (Biggs, 2001; Biggs et al., 2001). This is because the type of approach to learning depends on what suits the learning activities, the learner's preference for a particular approach as well as the teaching environment (Biggs, 2001; Biggs et al., 2001). This study adopts both the definitions stipulated by Biggs. Approaches to learning are a part of the 3P model which form the system that has been mentioned numerous times in this chapter.

\section{Deep and surface approaches to learning: Motives and strategies}

The studies conducted by Marton and Saljo (1976a, b) are considered seminal studies as this research was the foundation for more research developments in the area of students' approaches to learning. They are particularly interesting for my study because their focus is on reading. These researchers had aimed to find the relationship between students' approaches to learning and the way they responded to reading texts. The researchers found that the participants' reason for reading the article determined how they go about reading it. The findings in this study showed that learners who wanted to have a deeper understanding of the text, for example, they wanted to know what the author had intended to say in the article, had opted for a deeper approach, for example, of considering what the reason was for writing the text. In contrast, the participants who wanted to remember as many facts as possible from the text had decided to memorise the information. The researchers categorised the students' approaches to learning as deep-level processing and surface-level processing.

Applying particular learning approaches depends on a cluster of influences which are derived from students' personal factors and the teaching context (Biggs et al., 2001). These factors influence learners' motives and the strategies that they use in their learning (Biggs et al., 2001). Biggs referred to the motives as deep motives and surface motives in learning accompanied by deep strategies and surface strategies. Biggs termed the combinations of motives and strategies as approaches to learning. Deep motives refer to an intrinsic liking of what is learnt (Biggs, 1987; Biggs et al., 2001). Learners' personal engagement in learning causes them to find strategies to help them to have a better understanding of what they learn (Biggs et al., 2001, Entwistle, McCune, \& Walker, 2001). These strategies are known as deep strategies. Learners who apply deep strategies tend to focus on the "underlying meaning, main ideas, themes, principles" (Biggs, 2007, p. 24). Hence, deep approaches to learning refer to a deep understanding of the content that the students learn (Biggs, 2003; Biggs \& Tang, 2011; Entwistle \& McCune, 2004) and also their desire to be engaged in learning which requires high cognitive thinking (Biggs, 2003). Surface motives refer to an intention to meet the necessary requirements set (Biggs, 1987). Learners with surface motives have less connection with learning which is derived from their purpose to find an easier way to get their learning done. Surface strategies cover, for example, "rote learning selected content instead of understanding it, padding an essay, listing points instead of addressing an argument, quoting secondary 
references as if they were primary ones" (Biggs, 2007, p. 22). The surface approaches to learning then focus on students' extrinsic need which requires a rather low cognitive level of thinking (Biggs, 2003) and is most often used to meet the minimum requisite set (Biggs, 2003; Biggs \& Tang, 2011).

Entwistle et al. (2001) argued that although the motives for deep and surface approaches are defined in a broad sense for all areas in education, the strategies used to accomplish these motives have to be designed according to specific areas. This is because the strategies used for learning are closely related to learners' "conceptual understanding" of the specific educational field (p. 108). For example, in the EAP course, students' strategies for learning are not related to and thus are not helped by producing information by memorisation. Learners who adopt a surface approach to learning produce the information in terms of copying the original source. Entwistle et al. (2001) provided a list of the strategies used in the social science discipline for reading and writing. These strategies differed from the list of strategies drawn up by Biggs et al. (2001) which is much broader. Table 2 shows the features of deep and surface approaches to learning (excluding the strategic approach) listed by Entwistle et al. (2001).

Table 2. Deep and surface features of learning

Deep approach Seeking meaning

Intention: to understand ideas for yourself

- Relating ideas to previous knowledge and experience

- Looking for patterns and underlying principles

- Checking evidence and relating it to conclusions

- Examining logic and argument cautiously and critically

- Being aware of understanding developing while learning

- Becoming actively interested in the course content

Surface approach Reproducing

Intention: to cope with course requirements

- Treating the course as unrelated bits of knowledge

- Memorising facts and carrying out procedures routinely

- Finding difficulty in making sense of new ideas presented

- Seeing little value or meaning in either courses or tasks set

- Studying without reflecting on either purpose or strategy

- Feeling undue pressure and worry about work

Source: Adapted from Entwistle et al. (2001, p. 109). The strategic approach is excluded from this table

\section{Past studies on the process of learning}

Teaching at the tertiary education level generally aims to promote the use of deep approaches to learning (Biggs \& Tang, 2011). Having said that, there are many factors that influence learners' orientation to learning as mentioned earlier in the presage stage of the 3P model. Hence, although the aim in teaching is to encourage deep approaches to learning, the 
influence of student learning factors may play an equally important role in how and why learners choose certain approaches to learning. Empirical studies on the influence of the presage stage and process stage have already been discussed in the previous section (refer to section 2.2.2, presage stage).

\subsubsection{Product Stage}

The third stage in the 3P model is the product stage. This stage is affected by the previous two stages of presage and process. Student factors as well as learners' ongoing approaches to the learning in the learning activities are the two elements apart from context factors that influence the product stage. For example, students' pre-existing knowledge, their motives for learning, and their interest in the topic affect their approach to learning which then influences the outcome (Biggs, 2003).

In the product stage, the learning outcomes of learners are influenced quantitatively and focus on how much learners have learned, how well they have learned emphasising the qualitative aspect, and also in affective ways that involve students' engagement (Biggs, 2003, 1993b). The quantitative outcome refers to being able to relay declarative or procedural knowledge independently without combining the knowledge acquired in any way (Biggs, 1995, 2003). In other words, learners are only able to state the facts or skills that they have learnt. In contrast, the qualitative outcome refers to functioning knowledge (Biggs, 2003). Functioning knowledge refers to having appropriate knowledge that can be transferred in different situations.

Multiple choice questions or essay questions that require learners to list information or facts lead to a quantitative outcome (Biggs, 1995). This type of assessment encourages surface learning where learners often memorise the facts. Assessments that include problem solving require learners to use the deeper approach which shows conditional knowledge (a combination of procedural and declarative knowledge) that then leads to functioning knowledge (Biggs, 2003). These types of assessments lead to a qualitative outcome. In other words, learners who know what to do, how to do it, and why they have to do it respond in a certain way to achieve a qualitative outcome. One way outcomes of learning can be measured is by using the SOLO taxonomy devised by Biggs to determine the level of understanding of learners (Biggs, 2003) and thus, in this sense, are associated with his system.

The next section of this chapter will describe the construction of the SOLO taxonomy. It will also explore how the SOLO taxonomy is used by educators as an evaluation tool to assess learners' quality of learning. 


\section{The Structure of Observed Learning Outcomes (SOLO) taxonomy}

As mentioned previously, the third stage of the 3P model considers the learning outcomes. The SOLO taxonomy was introduced by Biggs and Collis in 1982 to "evaluate learning quality" in schools and tertiary education (p. xi). The construction of the SOLO taxonomy was a result of Biggs' and Collis' observation of the learning outcomes in various subject areas. They stated that learners' understanding of the learning materials and content taught gradually increases to display a structural complexity. This situation is similar to the tasks done in various subject areas (Biggs \& Collis, 1982). The increase in learners' understanding could be seen through quantitative and qualitative aspects: “...quantitative, as the amount of detail in the student's response increases, and qualitative, as that detail becomes integrated into structural pattern" (Biggs \& Tang, 2011, p. 87). In other words, the quantitative aspect of understanding occurs before the qualitative aspect (Biggs \& Tang, 2011).

According to Biggs and Collis (1982), learning is generally made up of learners first comprehending the content, for example, "facts, skills, concepts or problem-solving strategies," and then the learner employing the knowledge by "explaining what he has learned, solving a problem, carrying out a task or making a judgement" (p. 3). Then the instructors evaluate the responses of the students according to the degree of understanding that they had displayed in the tasks (Biggs \& Collis, 1982). The SOLO taxonomy then becomes an essential tool that assesses how well the students understand or process the information taught to them (Hattie \& Purdie, 1998).

The SOLO taxonomy consists of five categories which were designed to methodically evaluate the quality of students' responses (Biggs \& Collis, 1982). These five structures are prestructural, unistructural, multistructural, relational, and extended abstract. The structures are categorised from the lowest level, which is prestructural, to extended abstract, which is the highest level in the taxonomy. Table 3 provides a description of the categories in the SOLO taxonomy. The prestructural level shows that the learner did not understand the question and thus has not answered the question (Biggs \& Tang, 2011). Responses at the unistructural level indicate that the learner has responded to one feature in the task (Hattie \& Purdie, 1998). The multistructural level indicates that two or more features in a task are tackled but the responses are not linked (Hattie \& Purdie, 1998). In other words, the responses are not brought together to show the connections. The relational level shows that most of the features in a task have been integrated to show the connections. Lastly, the extended abstract indicates that the learner is able to go beyond the given task to generalise it (Hattie \& Purdie, 1998). Biggs and Tang (2011) stated that responses at the extended abstract level provide arguments that will make the reader reflect on their thoughts and perceptions about the question asked.

Table 3. Categories of the SOLO taxonomy 


\begin{tabular}{l|l}
\hline Levels & \multicolumn{2}{|c}{ Descriptions } \\
\hline Prestructural & $\begin{array}{l}\text { The task is not attacked appropriately; the student has not } \\
\text { understood the point }\end{array}$ \\
Unistructural & $\begin{array}{l}\text { One or few aspects of the task are picked up and used } \\
\text { (understanding as nominal) }\end{array}$ \\
Multistructural & $\begin{array}{l}\text { Several aspects of the task are learned but are treated separately } \\
\text { (understanding as knowing about) }\end{array}$ \\
Relational & $\begin{array}{l}\text { The components are integrated into a coherent whole, with each } \\
\text { part contributing to the overall meaning (understanding as } \\
\text { appreciating relationships) }\end{array}$ \\
Extended abstract & $\begin{array}{l}\text { The integrated whole at the relational level is reconceptualised at a } \\
\text { higher level of abstraction, which enables generalisation to a new } \\
\text { topic or area, or is turned reflexively on oneself (understanding as } \\
\text { far as transfer, and as involving metacognition) }\end{array}$ \\
\hline
\end{tabular}

Adapted from Biggs, 1996, pp. 351-352.

One of the criticisms that the SOLO taxonomy faced is that categorising responses can be inconsistent (Chan, Tsui, Chan, \& Hong, 2002). Chan et al. (2002) explained that problems might still arise when the response is mistakenly placed in the wrong category or where a good response (extended abstract) is categorised as a poor or undeveloped response (unistructural). This issue could be avoided if the instructor has a clear understanding of the SOLO taxonomy and does not mistake the facility that SOLO offers. Further, Biggs and Collis (1982) have stated that transitional categories can assist educators to place responses that fall in between two categories. The transitional categories devised by Biggs and Collis are $1 \mathrm{~A}$ (from prestructural to unistructural), 2A (from unistructural to multistructural), 3A (from multistructural to relational) and $4 \mathrm{~A}$ (from relational to extended abstract).

According to Hattie and Purdie (1998), the SOLO taxonomy can be used to determine the type of approach to learning that learners use to respond to tasks. Hattie and Purdie explained that learners employed surface approaches to learning to meet the requirements of the tasks without investing much effort or time in doing the tasks. Surface approaches include listing ideas and memorising, and regurgitating pieces of information that have been learnt without making any arguments (Biggs, 2003; Hattie \& Purdie, 1998). The unistructural and multistructural levels of the SOLO taxonomy describe the surface levels of learning where the learners merely put together the information that they had learnt (Hattie \& Purdie, 1998). In contrast, the deep approaches to learning comprise learners' intrinsic interest in acquiring knowledge and being engaged in the tasks (Biggs, 2003; Hattie \& Purdie, 1998). Learners who employ a deep approach to a task attempt to make sense of the meaning, find the main ideas, and find ways to put the concept that they had learnt together (Biggs, 2003; Hattie \& Purdie, 1998). The relational and extended abstract levels of the SOLO taxonomy describe the deep levels of learning where learners are able to work at a complex conceptual level by employing higher order thinking skills (Hattie \& Purdie, 1998). 
Apart from using the SOLO taxonomy as an instructional tool (Biggs \& Collis, 1982), this taxonomy can also be used to outline the aims of a programme or the curriculum (Biggs, 2003) and to evaluate responses to categorise teachers' behaviour in classrooms (Hattie \& Purdie, 1998). Past studies using SOLO as an assessment tool have been conducted in various subjects such as accounting (Lucas \& Mladenovic, 2009; Ramburuth \& Mladenovic, 2004), biology (Lake, 1999), and mathematics (Chick, 1998; Groth \& Bergner, 2006), but not many have been conducted in evaluating learners' responses in the English subject, especially in the reading component.

Whalley, et al. (2006) conducted a study on reading and comprehension skills to determine a group of novice programming students' performance. The researchers used both the SOLO taxonomy and Bloom's taxonomy to analyse the data. Although the researchers intended to determine the students' comprehension skills, the study was mainly focused on computer programme writing and reading programming code. In another study, Campbell, Smith, and Brooker (1998) aimed to investigate how 46 undergraduate students enrolled in the Bachelor of Education at a university in Australia responded to a writing task. The participants were asked to write a 1500-word literature review on developmental or psychology topics and were interviewed on their understanding of the assessment criteria and the process of accomplishing the task. The researchers analysed the students' essays using the SOLO taxonomy. The findings indicated that most students were categorised in the unistructural, multistructural and relational categories. From the interviews the researchers concluded that there was a major contrast in the stages of writing the essay between students writing unistructural and relational essays. Students at the unistructural stage were listing ideas while those at the relational stage were reconstructing ideas and arguments. In another example, Wong (2007) carried out a study in an English department at a university in Hong Kong which investigated the use of the SOLO taxonomy among academics. The researcher aimed to identify the lecturers' opinions on the use of the modified SOLO taxonomy and ways to improve it. The researcher found that the majority of the lecturers were comfortable using the SOLO taxonomy for assessment criteria, although a few claimed it was difficult to follow. Some of the lecturers claimed that the taxonomy allowed them to differentiate between levels and was useful in designing tasks for students.

The SOLO taxonomy can be used in many ways in various subjects, disciplines, levels, and situations. Further, using the SOLO taxonomy in assessing the extent of learners' understanding provides a picture of how much learners actually comprehend. In this section, I have made a case for the use of the SOLO taxonomy as a way of understanding the demands of a task and to evaluate responses. My research study uses the SOLO taxonomy as an evaluation tool to assess the EAP learners' responses to the reading tasks. 


\subsubsection{Past Studies on the Presage, Process and Product Stages}

Biggs (2003) mentioned that learners' approaches to learning are influenced by multiple elements from both the presage stage and the product stage. The influence of these factors on learners' approaches to learning could be seen in studies such as those by Clinton (2014) and Chan (2014).

Clinton (2014) wanted to find out what occurs during the process stage of the 3P model and what influenced the process of learning. In order to find this out, she narrowed the focus of the study to explore whether the undergraduate students' preferred approaches to learning influenced their ongoing approaches to learning which then affected their performance. This study was conducted among multiracial students from one of the universities in the USA. The researcher used the R-SPQ-2F questionnaire and think aloud protocol with participants' reading expository texts to find the relationship between students' preferred approaches and their ongoing approaches. The researcher gave two assessment tasks to identify students' approaches to learning: recall and open-ended comprehension tasks. The recall task, which required the participants to recall information after reading the texts, was designed to identify their surface approach. The open-ended comprehension questions, which required participants to use higher order thinking skills, were designed to identify their deep approach. The researcher hypothesised that there would be a positive relationship between deep approaches to learning and accurate answers in the open-ended comprehension task and a positive relationship between the surface approaches and the number of ideas recalled in the recall task. The findings showed that there was a positive relationship between the students' preferred deep approach and their ongoing deep approach to learning. Further, the findings also showed that the participants' preferred deep approach and the accurate responses to the open-ended comprehension questions were based on two strategies: making connections, and examining the logic of information. In terms of the surface approach, the findings did not support the hypothesis that the surface approach would have a positive relationship with recalling the number of ideas. The researcher claimed that the recall task could have been turned into a deep approach task by the participants. Hence, the study shows that students' preferred approaches and their ongoing approaches do influence their performance. Further, this study also shows that the design of the tasks does play a vital role in students' adopting particular ongoing approaches to learning (Biggs \& Tang, 2011).

Another study by Chan (2014) on students' learning approaches and their academic achievement among full-time and part-time Hong Kong Chinese students showed that high achievers were students who employed a deep approach and how they performed academically can be predicted by their learning approaches. The researcher used the R-SPQ2F questionnaire and Grade Point Average (GPA) to determine the relationship between approaches to learning and academic achievement. The researcher hypothesised that there 
would be a positive association between deep approaches to learning and the learners' academic performance. The researcher also hypothesised that mature (part-time) students would practise deeper approaches than the younger (full-time) students in the business programme. The findings showed a modest relationship between deep approaches to learning and students' academic performance, confirming the hypothesis that there was a positive relationship between approaches to learning and academic achievement. In terms of age, the hypothesis was not supported as there was no significant difference found between age and approach to learning. This study shows that age is not a factor that influences the type of approach used to learn. There are various factors that come into play when using approaches to learning such as appropriate understanding of study skills, motive in learning, and context of learning.

\subsection{Using the 3P Model and Constructive Alignment in Learning}

As mentioned earlier in this chapter, the CA framework ensures that the intended learning outcome is relayed in the teaching and learning activities as well as the assessments given to students. In order to form a balanced system, all the components must be aligned (Biggs, 2003). The 3P model could be used to picture how the alignment takes place in learning. The presage stage in the $3 \mathrm{P}$ model focuses on learners' personal learning factors and contextual factors that cover the content, what learners should learn and how they will be assessed, while the process stage focuses on how learners approach the learning activities given to them, and lastly the product stage looks at the outcomes of learning which are based on the teaching and learning activities (Walsh, 2007). The existence of alignment of the three stages - presage, process and product - within the 3P model would indicate an alignment between the assessment, teaching and learning activities and the intended learning outcome (Walsh, 2007).

The existence of non-alignment could be seen when there was a disparity between what was expected and what was achieved (Biggs, 2003). In other words, the existence of non-alignment provides a stimulus for instructors and the students to reflect on how teaching and learning should be done or could be improved.

The 3P model helps in visualising how constructively aligned teaching and learning takes place in a classroom. Aligned learning would prepare tertiary learners to internalise what they learn and to use the knowledge appropriately as they are aware of how to use it.

\subsection{Summary of the Chapter}

The 3P model and the framework of CA in learning are used as the guide for this study. When all three stages in the 3P model are aligned, learners will be able to achieve the intended outcomes of learning. How learning happens could be seen through the interaction that takes 
place between the learning factors (presage), the responses to the learning activities (process) and the outcomes of learning achieved (product). Further, the approaches to learning are embedded in the 3P model to show how each stage - the presage, process and product form an integrated system.

This study is designed to address the scarcity of empirical studies in terms of learners' perspectives on learning, the influence of learning factors, learners' responses to specific learning activities, and their perceived outcomes of learning in the EAP classroom. As mentioned earlier, there is still much to be done in the area of academic English on how students perceive the alignment in learning (if there is any) in these classrooms. 


\section{CHAPTER 3}

\section{LITERATURE REVIEW}

This literature review chapter will consider empirical research that illuminates the context of the research study and will discuss literature related to the learning of academic English in tertiary education. There are three parts to this chapter: learning academic English in tertiary education, reading tasks, and the transfer of learning.

\subsection{Incorporating the Literature into the Framework of this Study}

This section provides a brief explanation of the integration of the related literature with the framework of the study. The research was conducted among the multicultural Malaysian tertiary students at a public university in Malaysia. This chapter explores literature related to the teaching and learning of EAP. Using CA as the framework of the study with the help of the 3P model, this study focuses on the three aspects - factors in learning, reading tasks, and transfer of knowledge - that influence learning among the EAP learners.

The CA framework focuses on the alignment between the teaching and learning activities, assessments, and the intended learning outcomes. The 3P model looks at the presage stage, the process stage, and the product stage of learning. The related literature in this chapter is drawn from the framework of the study, namely the factors related to learning, the reading tasks, and the transfer of knowledge. The literature includes studies from learning academic English and in some cases a wider scope of learning English. The integration of the literature with the framework of this study is explained in Figure 2. 
Figure 2. Aspects focused on in this study

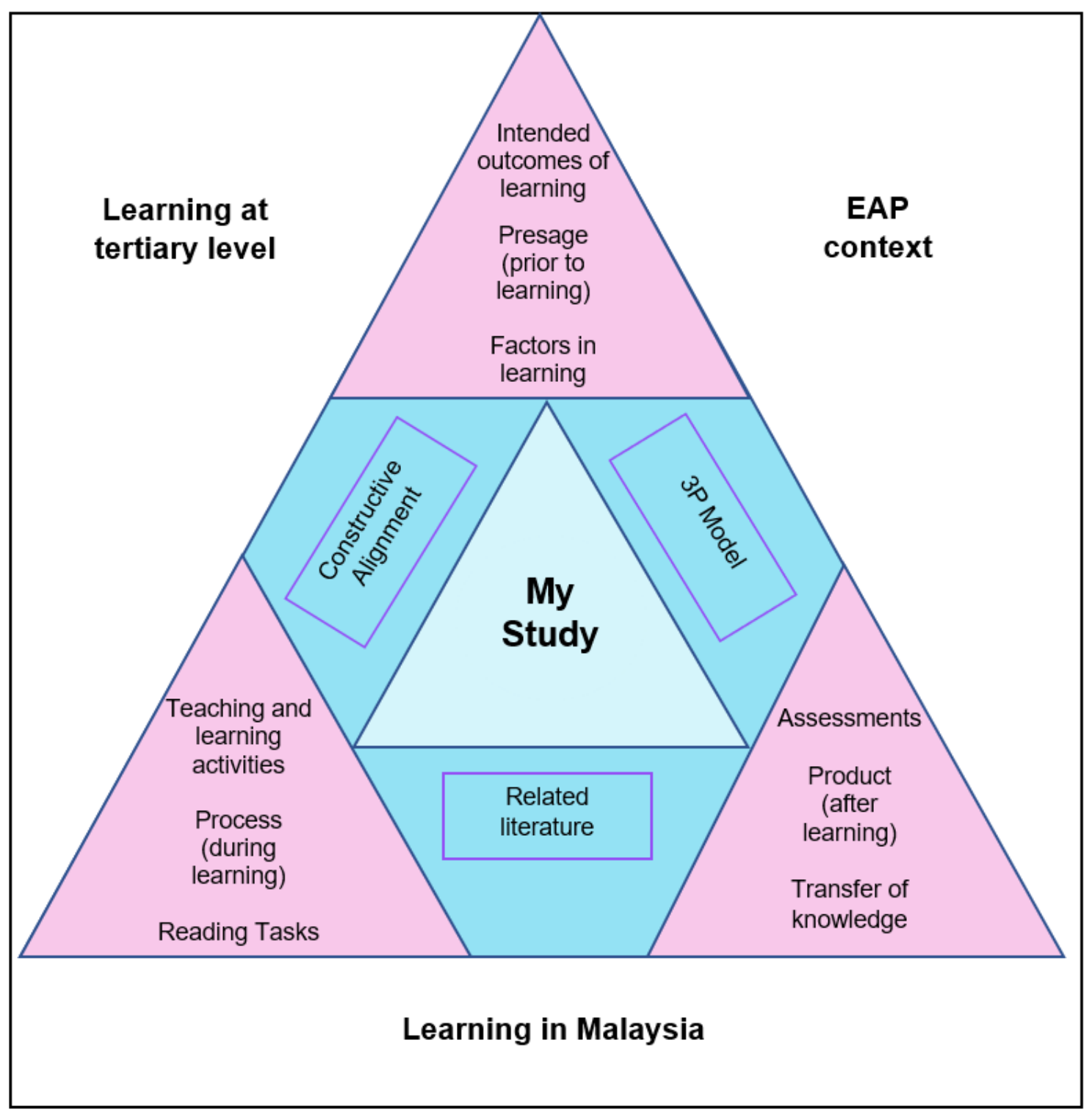

The intended outcomes of learning in the CA framework as well as the presage stage in the 3P model are seen as the content taught in the EAP classroom in this study (refer to the pink triangle on the top part of Figure 2). The content taught in the EAP classroom is included in the factors in learning that are explored in the literature review section. As Biggs often stated, factors in learning are viewed as student factors and contextual factors (Biggs, 2003). Hence, related factors are also explored in this study. Further, the teaching and learning activities in the CA framework and the process stage are explored as reading tasks in this chapter (refer to the pink triangle on the bottom left of Figure 2). Lastly, the assessments in the CA framework and the product stage in the 3P model are seen as involvement in learning and the transfer of knowledge in the literature review chapter (refer to the pink triangle on the bottom right of Figure 2). 
Thus, this study is governed by the CA framework and the $3 \mathrm{P}$ model to show how learning is accomplished in the EAP classrooms in Malaysia from the learners' perspectives. The next section of this chapter will explore the nature of academic English and the different views regarding these definitions.

\subsection{Academic English in Tertiary Education}

This section presents research on the teaching and learning of academic English in institutions of higher learning. The on-going debates on the definition of EAP and the practice of EAP in Malaysian tertiary education are explored.

\subsubsection{The Nature of English for Academic Purposes}

The definition of academic English, which is more commonly known as English for Academic Purposes (EAP), is unclear (Campion, 2016; Charles \& Pecorari, 2016; Hyland \& Hamp-Lyons, 2002). There are a number of terms used in this field: ESP, EGP, and ESAP. At times, EAP is confused with English for Specific Purposes or even English for General Purposes (Campion, 2016; Hyland \& Hamp-Lyons, 2002). Generally, EAP is the "teaching of English with the specific aim of helping learners to study, conduct research or teach in that language" (Flowerdew \& Peacock, 2001, p. 8). Hyland (2002) added that EAP emphasises the particular needs of learners in an academic context. EAP is a branch of a bigger field called English for Specific Purposes (ESP) (Charles \& Pecorari, 2016; Hyland \& Hamp-Lyons, 2002). ESP is an umbrella term that is defined as teaching English for "specialized purposes," and the academic context is considered to be a specific domain that constitutes the reason for categorising EAP as a branch of ESP (Charles \& Pecorari, 2016, p. 8). English for general purposes (EGP), on the other hand, focuses on "conversational and social genres of the language" (Hamp-Lyons, 2001, p. 127). In other words, EGP focuses on a broader teaching of English based on communicative skills used for everyday purposes.

In the field of EAP, there has been an on-going debate about defining what encompasses EAP and how it caters to the learners' needs (Flowerdew, 2013). Hyland, for example, stated that the teaching of EAP should focus on "specificity" of language use within the academic context (Hyland, 2016). Hyland argued that the teaching of EAP should be specific to the academic disciplines (Hyland, 2016; Hyland \& Hamp-Lyons, 2002). Hyland used a term, English for specific academic purposes (ESAP), which is a branch of EAP (Hyland, 2016). He stated that ESAP focuses on teaching specific features in the various disciplines in the academic context (Hyland, 2016). Hyland rationalised that "each discipline draws on different lexical, grammatical, and rhetorical resources to create specialized knowledge" (Hyland, 2016, p. 21). Charles and Pecorari (2016), in their textbook for EAP, had a similar view that the teaching of EAP covers the four basic skills - listening, speaking, reading, and writing - which are best taught in a subject-specific academic environment such as engineering. Hyland (2016) 
provided an example of how disciplinary specific teaching works; for example, natural science students may require different lexical features, such as needing to classify and explain experiments and technical terms, compared to social science students who focus on explaining abstract concepts.

There is some concern that if EAP is not grounded in disciplines it will not help students with the language of those disciplines. Baik and Greig (2009) reflected on an EAP course that taught generic skills to the international students at the University of Melbourne. Baik and Greig stated that there was no evidence that EAP students learning generic skills were either able or unable to improve their language and academic skills and transfer learning into disciplinespecific programmes. The researchers noted that students in that cohort had performed well in the EAP course but poorly in the discipline-specific subjects. Baik and Greig (2009) stated that this was one of the reasons that the university had decided to remove the generic EAP course and adapt a content-based ESL subject. In this way they supported Hyland who argued that while generic skills such as skimming and scanning for information and taking lecture notes was helpful for students in general, these features were not applicable for all disciplines (Hyland, 2016). He added that teaching these generic skills to students without taking the discipline into account would be detrimental to learners' motivation for learning. When students are not able to transfer these skills into their own disciplines they have less motivation to learn in the EAP classroom (Hyland, 2016). Charles and Pecorari (2016), on the other hand, question the applicability of ESAP in the academic contexts. They stated that teaching EAP in a broader context may be more cost effective than teaching ESAP to learners from specific disciplines. This issue was observed by Hyland (2016) who noted that in most cases ESAP is not taught because of the cost of hiring experienced practitioners but is still considered that it is important to take into consideration the effectiveness of teaching focusing on disciplines.

Charles and Pecorari (2016) stated that the reason EAP is considered to be a subdivision of ESP is because listening, speaking, reading and writing skills are part of a subject-specific academic environment, such as engineering. The teaching of EAP is done in collaboration with experts from a specific discipline. EAP differs from ESP in terms of its pedagogic approach as EAP is designed to meet the students' needs by satisfying the requirements of an academic context. In many countries, including EAP courses as a component of tertiary institutions has been increasing due to the necessity to produce students who are able to use English successfully within the academic context as well as in work-related contexts (Hyland \& HampLyons, 2002).

Hyland and Hamp-Lyons (2002) stated that the teaching of EAP includes the "understanding of the cognitive, social and linguistic demands of specific academic disciplines" (p. 2). Charles and Pecorari (2016) stated that learning at the tertiary level requires a high level of thinking 
because students need to be able to understand and process the different concepts taught. Ideally, an EAP course should assist students in generating higher order thinking skills. In this way the EAP course should go beyond the teaching of language proficiency (Liyanage \& Walker, 2014) by assisting students to use English appropriately to cater to the different purposes within the academic context (Gao \& Bartlett, 2014) and the socio-cultural context (Hyland \& Hamp-Lyons, 2002).

One of the ways to equip students with the knowledge of using English purposively is by teaching the four skills - reading, writing, listening, and speaking - which are deemed important at the tertiary level. It could be more challenging for non-native speakers of English than native speakers to use these skills in an academic context. Students who are non-native speakers of English face more challenges compared to native speakers because they will have to deal with the complex level of learning at the tertiary level as well as with learning in an English medium (Charles \& Pecorari, 2016). Evans and Green (2007) indicated that ESL students often find that they do not have the appropriate academic skills and this makes it hard for them to articulate their thoughts. This often leads to instructors focusing on the academic skills and how to survive in the academic context. Similarly, Ananyeva (2014) added that EAP courses should be designed to support the learners' needs. She further argued that although general academic skills are taught, caution should be practised when the EAP curriculum is designed. This is because learners from different fields have different language needs. For example, engineering students' needs in an EAP course may differ from those of social science students (Ananyeva, 2014).

Often EAP becomes the subject of criticism because it neglects the culture and the background of the students (Hamp-Lyons, 2015; Hyland \& Hamp-Lyons, 2002). Hamp-Lyons (2015) stressed that both socio-cultural and socio-political contexts are a part of a community and thus affect the teaching of EAP. Even more strongly, Canagarajah (2014) asserted that it is impossible for the teaching and learning of EAP to ignore the socio-cultural context as EAP content and purpose are strongly influenced by the situations that occur out of the EAP classroom. Exposing students to critical genres and teaching them ways to understand and critique these types of texts enable students to conceptualise how the community works (Hyland \& Hamp-Lyons, 2002). However, Hamp-Lyons (2015) claimed that integrating the socio-political context with EAP is still under researched and more work needs to be done in this area.

In attempting to replicate the cultural context in the classroom, the learning materials used to achieve the aim of EAP are important. (Hyland \& Hamp-Lyons, 2002). With the development of technology, it is important for educators to choose learning materials such as web-based materials as well as appropriate text books (Siew, et al., 2012) to allow the replication of the 
cultural context of the classroom (Hyland \& Hamp-Lyons, 2002). Siew et al. (2012) conducted research on EAP students' perceptions of using online material and textbooks as part of their course materials at a public university in Malaysia. The researchers employed a blended learning approach which was part of the redesigned course material for the EAP course. The researchers found that in general the participants were positive towards the teaching method used in the course. However, there were mixed views about the course material, particularly the textbook used in the course. Students with low English language proficiency found the tasks in the textbook helpful and the language not too difficult, whereas the highly proficient students found the tasks too easy.

\section{EAP in Malaysia}

This section discusses the teaching and learning in the EAP courses taught in Malaysian tertiary institutions. As mentioned in the introduction chapter, English language learners in Malaysia lack competency in English (Musa et al., 2012). Taking this into consideration, tertiary institutions in Malaysia offer English courses. English is taught either for academic purposes or for specific purposes or as a general proficiency course at the institutions of higher learning (Too, 2017).

Learners at the tertiary level in Malaysia are not well equipped with the necessary academic skills that they need in order to perform well (Musa et al., 2012). The English language educators at the tertiary level in Malaysia are concerned with the learners' lack of English competency. Their concern could be seen through the frequent revamping of the structure of the courses, course materials and teaching methods to provide suitable course content for their learners (Othman \& Rashid, 2011; Siew, et al., 2012; Storey, 2013; Too, 2017). EAP courses taught at the tertiary level largely favour the four skills - reading, writing, listening, and speaking - with the inclusion of soft skills such as critical thinking and teamwork. The inclusion of soft skills in English courses at the tertiary level is in line with the Ministry of Education's policy to develop soft skills among learners at the tertiary level (Too, 2017). The policy was introduced in 2006 and called Development of Soft Skills for Institutions for Higher Learning.

At the National University of Malaysia (UKM), a public university in Malaysia, Othman and Rashid (2011) found that the university had initially offered three courses - English for General Purposes, EAP, and English for Specific Purposes - depending on the results from the Malaysian University English Test (MUET). The team of ELT educators at the university found that there were still gaps that had not been filled by the current programme. The researchers stated that the programme had not included learners' ability to use English effectively in the workplace and the course offered did not fit into the existing academic context as most of the textbooks in the other subjects were in Bahasa Malaysia. Hence, a proposal to revamp the structure of the programme was suggested by introducing "English for Academic 
Communication" and "English for Workplace Communication" courses (p. 10). As in the previous practice, these courses were offered to students according to their MUET results. They covered reading skills that could be used with texts from various disciplines including the use of English in the workplace.

In terms of teaching methods, empirical studies have been conducted on the various modes of teaching used in the EAP classroom (Maulan \& Ibrahim, 2012; Siew, et al., 2012; Too, 2017). Both Maulan and Ibrahim (2012) and Siew et al. (2012) investigated learners' perceptions of the blended learning method used in the academic English classroom, while Too (2017) examined the teaching approaches used by EAP practitioners. The study conducted by Siew et al. (2012) was discussed in the above section. Studies conducted by Maulan and Ibrahim (2012) and Siew et al. (2012) indicated that the EAP learners' perceptions of a blended learning approach were positive. They were interested in having both the traditional and the online methods of delivery. The findings from both the studies showed that the learners faced issues with internet connections that affected their participation in the online activities, but the learners stated that they found the content beneficial and that it aided their learning. Too (2017) conducted a study at three universities - a public university, a private university, and an international university campus - in Malaysia to investigate the type of teaching approaches used by the English language practitioners. The researcher distributed 98 questionnaires and received 46 completed questionnaires in return and then interviewed three instructors, one from each university. The researcher mentioned that the language teaching in these universities was rather diverse with the inclusion of EAP, ESP and language proficiency courses. The overall findings showed that the teacher participants used communicative language teaching, task-based language teaching, and various other approaches that seemed appropriate. The researcher mentioned that communicative language teaching and task-based language teaching were influenced by the development of the soft-skill policy that the Ministry of Education had introduced. The findings also showed that the instructors faced challenges in teaching the language. The learners' low motivation for learning and low proficiency were of concern to the instructors in the three universities. The instructors' concerns were that the knowledge taught in the mainstream programmes took precedence among the learners compared to the English courses taught at the universities as well as the expectations of management that the instructors produce learners who improved dramatically.

The EAP courses offered at the institutions of higher learning in Malaysia are designed to enable learners to use English effectively within the academic context. However, there are no specific guidelines on the design of EAP courses, which leads to various perspectives on how EAP could be taught to the learners. Further, empirical studies conducted on EAP in Malaysia are still scarce and not much information could be gathered in terms of how EAP is taught in the various institutions. 
The next section will discuss the various factors that influence learning in the EAP classroom.

\subsection{Factors that Influence Learning in the EAP Classrooms}

Numerous studies have been conducted in terms of the influence of various factors that affect the learning of academic English in the EAP classroom internationally (such as Ercetin, 2010; Liu, Chang, Yang, \& Sun, 2011; Ohata \& Fukao, 2014). Often these multiple factors are interrelated and rarely appear in isolation in the learning of academic English. Students' perceptions of the influence of these factors in learning are as important as the instructors' and other stakeholders' opinions. This is because how students perceive learning in the EAP classroom contributes to how and whether the transfer of knowledge takes place within the academic context. This section will discuss the factors that influence learning in the EAP classroom with regard to Biggs' (2003) 3P model. Factors such as interest and prior knowledge of topics, language learning anxiety, motives for learning, and background are discussed.

\subsubsection{Interest and prior knowledge of topics}

Interest and prior knowledge are important factors that influence learning. Although it is generally known that students who have an interest in the topic or content taught to them will be able to engage more deeply than those who are not interested (Biggs, 2003), past studies show conflicting results. For example, Ercetin (2010) found learners with high topic interest perform better at learning activities. However, Eidswick (2010) and Martinez (2013) found that prior knowledge, rather than interest, has a significant effect on learners' responses to all the tasks given in the classroom. However, there are some contrasting views from studies about how prior knowledge and interest are related.

Ercetin (2010) investigated topic interest and prior knowledge among 54 EAP Turkish undergraduates enrolled in an English language teaching programme. The researcher aimed to find the effects of topic interest and prior knowledge on text recall and annotation on L2 learners engaged in reading a hypermedia text and used various instruments to collect the data: an electronic text, a tracking tool that saved the participants' interaction with the texts, recall protocols where the participants wrote down everything that they remembered immediately after reading the text, a test with five open-ended prior knowledge questions administered two days before the hypermedia text was read, a topic interest questionnaire adapted from Schiefele and Krapp (1996) and semi-structured interviews. The researcher found that there was a weak correlation between participants' prior knowledge and topic interest. Ercetin (2010) found that participants with high topic interest, regardless of their level of prior knowledge, were able to recall more text propositions than participants with high prior knowledge and low topic interest. The researcher found that high topic interest facilitates annotation and text recall as compared to high prior knowledge. Participants with high interest were able to recall a higher number of text propositions than those with low interest. The 
findings also showed that participants with high topic interest had closely followed all the links and annotations in the hypermedia text compared to those who had less interest. Hence, topic interest supported engagement with the text.

On the other hand, Eidswick's (2010) study with 23 second year private college students enrolled in an intermediate level English course in Japan found that prior knowledge had a more significant influence on reading comprehension compared to topic interest. Eidswick aimed to find the influence that topic interest and prior knowledge have on reading comprehension among the students in an English class. This English course is a required course to meet the English standards set by the university. The researcher used 11 nonacademic topics to identify the relationship between topic interest and prior knowledge. The researcher sourced these topics from Wikipedia and had attempted to find topics that were least likely to be taught in schools. The topics that were selected by the researcher were Akashiya Sanma (a popular Japanese comedian), candle making, chocolate, concrete, eco cities, ghosts, Japanese cuisine, Michael Jackson, perfume, Takafumi Horie (founder of a website who was arrested for fraud), and viruses. The participants were asked to read 11 summaries of articles and rate their interest and their prior knowledge using a 6-point Likert scale. Based on the descriptive analysis, topics that were rated as being of the highest interest and prior knowledge $(\mathrm{HH})$, the lowest interest and prior knowledge (LL), and the highest interest and lowest prior knowledge $(\mathrm{HL})$ were selected for the next part of the study. Topics rated $\mathrm{HL}$ and the lowest interest and the highest prior knowledge $\mathrm{LH}$ were selected using the criteria so that the mean score for interest and prior knowledge should have a greater difference compared to the other topics. Since none of the LH pairs met the criteria, this category was not selected for the study. Topics that were selected for the next stage were Michael Jackson $(\mathrm{HH})$, Ghosts $(\mathrm{HL})$ and Concrete $(\mathrm{LL})$. In the next step in the study the researcher modified the text taken from Wikipedia by shortening the length and then running a Flesch-Kincaid readability scale test to measure the readability of the articles. He then created 10 multiple choice questions for these articles. The comprehension test results and the three categories of interest and prior knowledge were analysed using a one-way repeatedmeasures Analysis of Variance (ANOVA). In terms of topic interest and prior knowledge of the 11 articles, the findings showed a high correlation on three out of the total 11 topics (Takafumi Horie: .64, Akashiya Sanma: .46 and Michael Jackson: .45). In terms of the comprehension test, the descriptive statistics showed that the highest mean in the comprehension test was for the article on Michael Jackson. The findings also showed that there was a significant difference when $\mathrm{HH}$ was compared with $\mathrm{HL}$ and LL. However, when $\mathrm{HL}$ and LL were compared, there was no significant difference. The author deduced that there were two possibilities to explain these results. One possibility was that prior knowledge has a positive influence on reading comprehension compared to topic interest, and the second was the possibility that both topic interest and prior knowledge influence reading comprehension in different ways. 
Martinez (2013) also had similar findings to Eidswick (2010). She found that prior knowledge has a more significant effect on all the reading-related tasks compared to topic interest. Martinez (2013) conducted a study with 129 participants enrolled in an intermediate English course at a university in Spain. She used various assessment methods: a written recall task where the participants had to write the passage that they had read without looking back at the text, an open-ended question task where the participants had to fill in sentences based on the content of the task, and ten multiple choice questions. The reading passage was taken from the University of Cambridge ESOL examinations. Martinez (2013) found that there is a significant difference between prior knowledge and learners' performance on all three tasks. However, perceived interest has a significant effect on reading comprehension when writtenrecall and multiple-choice questions are used but no significance was found when open-ended questions are used. The researcher considered the lack of correlation between learners' interest and their performance on the open-ended question was probably because the task allows restricted reconstruction of the text and does not allow learners to be free with their responses compared to the written-recall task that allows a free construction of text. Further, the researcher mentioned that the information provided for this task was not enough for learners to give accurate responses. Hence, there is a possibility that the interest was related to the task, rather than the topic of the text itself.

The studies on topic interest and prior knowledge show mixed findings on the influence that both these factors have on reading comprehension and suggest a complexity related to the task as well as to interest and prior knowledge.

\subsubsection{Language learning anxiety}

Language learning anxiety is another factor that influences students' learning in the academic English classroom. Learners who are non-native speakers of English are prone to face language related issues while pursuing their tertiary studies (Evans \& Green, 2007; Evans \& Morrison, 2010, 2011). These language related issues lead to language learning anxiety which affects their engagement in learning activities. Language learning anxiety can be viewed from two aspects: the role of personal factors that cause language learning anxiety, and the effect of the environment on language learning anxiety.

\section{i) Language learning anxiety and personal factors}

In the area of academic English, studies show that learners' lack of sufficient linguistic resources have a negative effect on their engagement with teaching and learning activities (Cao, 2011). Lack of proficiency (Cao, 2011; Delaney, 2008; Liao \& Wang, 2015) and lack of experiences needed to respond to the activities (Campbell, 1990) are some of the reasons that lead to insufficient linguistic resources among non-native speakers of English. Learners' feelings of self-consciousness due to their lack of proficiency further affect their reluctance to 
engage in the academic English classroom (Cao, 2011). Horwitz et al. (1986) found that language learning anxiety is based on performance evaluation that takes place within the classroom and out of the classroom and is closely related to "communication apprehension, test anxiety and negative evaluation" (p. 127). The researchers constructed a 33-item questionnaire to identify the type of anxiety foreign language learners face while practising the language. This questionnaire has also been adapted by researchers of second languages (Chin, Ting, \& Yeo, 2016; Darmi \& Albion, 2014; Hiew, 2012; Zulkifli, 2007). Horwitz et al. (1986) stated that communication apprehension is caused by fear of communicating in the presence of others. Learners often feel anxious when they become the object of focus, for example, speaking in a group (Horwitz et al. 1986). Test anxiety is faced by many learners who fear failing the assessments in the classroom (Horwitz et al., 1986). According to Horwitz et al., negative evaluation refers to learners' fear of being negatively judged by others. The researchers stated that negative evaluation goes beyond test anxiety as this aspect covers a broader social context such as "interviewing for a job or speaking in [a] foreign language class" (p. 128). When learners perceive that they have a lack of proficiency, it may create language learning anxiety in a range of situations where they are required to use English.

However, a moderate level of the anxiety that non-native speakers face in language learning can promote learning (Philips, 1992; Spielmann \& Radnofsky, 2001). According to Spielmann and Radnofsky, the anxiety in language learning faced by non-native speakers is positively influenced by their expectations of, and beliefs about language learning. Spielmann and Radnofsky stated that learners' expectations of becoming proficient speakers in the target language create tension which is accepted by the learners. Tension, according to Spielmann and Radnofsky, can be helpful or unhelpful in learning a language; for example, learners feeling frustrated with the excessive amount of homework in a language classroom or enjoying doing a difficult task that requires reflection and creativity. Having moderate anxiety is beneficial because learners realise that in order to achieve their aim of being proficient language learners, they have to reinvent and "reinternalize" themselves to work to achieve their goals (Spielmann \& Radnofsky, 2001, p. 269). Hence, having a moderate level of anxiety in learning the target language can be beneficial but having excessive anxiety, which is often caused by learners' fear, can be detrimental to them as this will hinder instead of promote language learning.

One of the reasons that causes anxiety or discomfort in language learners, as mentioned in the previous paragraph, is learners' low level of proficiency in English. Learners' low level of proficiency restricts their engagement with class activities (Delaney, 2008; Liao \& Wang, 2015). For example, the writing produced by non-native speakers of English is at times viewed as non-academic (Campbell, 1990). This is because non-native speakers' lack of English proficiency causes them to opt for much simpler language and they also tend to use an 
inconsistent "style and tone" while writing (Campbell, 1990, p. 224). A qualitative study of international EAP students' willingness to communicate in the classroom in a university in New Zealand (Cao, 2011) found that three dimensions - environmental, individual, and linguistic are interrelated in learners' willingness to communicate. These dimensions influence learners' participation in the EAP classroom. The data were collected using classroom observation, stimulated-recall interviews, and journals. The classroom teaching and learning included teacher-directed activities, group work and pair work. Cao (2011) found that the majority of participants reported that the immediate classroom environment, learners' individual emotions and perceptions as well as their ability to communicate their thoughts hindered their participation in the classroom. When they face difficulties in communicating their thoughts, they lose interest in an activity which leads to boredom (Cao, 2011). The findings also showed that the participants tend to use their L1 when they face difficulties in participating in the classroom.

Language learning anxiety, related to lack of English proficiency, can have an impact on engagement and, in some circumstances, anxiety can enhance performance.

\section{ii) Language learning anxiety and environmental factors}

Environmental factors such as the classroom climate and the teaching approaches contribute to language learning anxiety. Liao and Wang (2015) carried out a study among Taiwanese students enrolled in a compulsory general English course in their freshman year. The researchers conducted an experimental study to test whether a different teaching approach could reduce the anxiety of the language learners. The researchers carried out this study with participants from an experimental and a control group of students using the post-structural feminist pedagogical learning (PFPL) method to promote interaction and participation in the class. Three hypotheses were generated by the researchers: hypothesis 1) Students in the PFPL group would report lower English classroom anxiety, hypothesis 2) Students in the PFPL group would score higher (become more proficient) in English, and hypothesis 3) Students in the PFPL group would report greater satisfaction with the course. The researchers employed the post-structural feminist pedagogical learning method on the experimental group to reduce the authoritative nature of teaching conducted by instructors while the lecturers of the control group employed the conventional instructor lecture format. The data were collected using the English Classroom Anxiety Scale (ECAS) questionnaire adapted from the Foreign Language Classroom Anxiety Scale (FLCAS) constructed by Horwitz et al. (1986), the English proficiency test taken from the Longman English Interactive question bank, the Student Satisfaction Questionnaire (SSQ) constructed by Wang, Chao, and Liao (2011) and student interviews. Both groups used the same workbook called Top Notch 2. The ECAS questionnaire was administered prior to the intervention. The results showed that both the experimental group $(M=116.03)$ and the control group $(M=117.55)$ of students had similar anxiety levels about the English class. A pre-test on student proficiency was also carried out prior to the intervention. 
The results of the pre-test showed that students from the experimental group $(M=61.41)$ and the control group $(M=59.78)$ had a similar level of proficiency. The intervention was carried out for twelve weeks. At the end of the intervention, the ECAS questionnaire, a post-test language proficiency assessment, and the SSQ questionnaire were conducted. After the twelve-week intervention, the ECAS score showed a significant decrease in anxiety among the experimental group compared to the control group. An increase in English language proficiency was apparent in the post-test among the experimental group which also reported a higher level of satisfaction in learning. The qualitative interview results also supported the quantitative findings in this study. Liao and Wang (2015) found that the PFPL method allowed learners to feel free to communicate their thoughts without having their language corrected by the instructor. The participants in the experimental group reported that they felt secure discussing their thoughts with their peers and that they experienced a sense of kinship with them.

The findings from Liao and Wang's (2015) study are different to the findings from Cao's (2011) study. The findings in Cao's study showed that learners' lack of proficiency among other factors such as the classroom environment and learners' individual perceptions and emotions, affected their participation in class activities. The findings in Liao and Wang's study showed that participants had improved their language proficiency and were satisfied with the learning in the classroom. It could be inferred that although the teaching approach looked similar between the two studies, it is possible that the instructor in Cao's study did not emphasise student-led discussions which were the main focus of the study carried out by Liao and Wang. Another possible reason for the contradictory findings could be the homogenous group of Chinese speaking students in Liao and Wang's study as compared to the multicultural participants in Cao's study. The multicultural participants could have faced difficulties communicating their thoughts compared to the homogenous participants in Liao and Wang's study. Teaching approaches can affect language learning environments and language learning anxiety.

Another issue that causes lack of engagement in the classroom is the fear of losing face. Horwitz (2000) argued that how non-native speakers viewed themselves and how they assumed others viewed them cause language learning anxiety. These learners are conscious of being presented negatively to others. For example, being corrected by instructors in front of their peers (Lio \& Wang, 2015; Zulkifli, 2007) may make them look less intelligent in the eyes of others (Horwitz, 2000). Although the fear of being embarrassed can happen with any foreign/second language learners regardless of background, studies conducted in Asian countries on language learning anxiety show that one of the reasons that cause anxiety in learning is the fear of losing face (Chin et al., 2016; Liao \& Wang, 2015; Zulkifli, 2007). Hwang and Han (2012) stated that the fear of losing face is more common among those who are brought up in an Asian context than among Westerners as Asians are predominantly 
influenced by a collectivist culture. Hwang and Han (2012) stated that "the richness of organizational behaviour in Asia is better predicted by an individual's external attributes such as face than by internal attributes such as desires, emotions, and cognition," hence, attempting to maintain a good image in the eyes of others is important for most Asians

Studies in Malaysia show contradictory findings about undergraduate Malaysian students in relation to their fear of being judged by others in the English classrooms (Chin et al., 2016; Hashim \& Mohd Isa, 2012; Rafek, Ramli, \& Hasni, 2015). The studies conducted by Hashim and Mohd Isa (2012) and Rafek, Ramli, and Hasni (2015) indicated that ESL learners in Malaysian tertiary education faced fear of negative evaluation which is commonly derived from their fear of feeling embarrassed in front of their peers due to their lack of competence in the language. Hashim and Mohd Isa (2012) conducted a study with 40 diploma students from the Department of Tourism and Hospitality enrolled in a communicative English course at a polytechnic in Malaysia. The researchers found that the students rated fear of negative evaluation as the highest among the four constructs of the FLCAS questionnaire. The students rated communicative English classroom anxiety as the lowest. These findings are different to the findings from a study by Chin et al. (2016). Chin et al. (2016) conducted a study using the original FLCAS questionnaire to explore the level of anxiety experienced by university students. The study was conducted with 149 first year Malaysian Diploma students from the Faculty of Engineering, Public Administration and Business Management at a public university. The findings showed that the participants experienced a moderate level of anxiety as English language learners at the university. Of the four constructs, anxiety in the English class was the highest factor perceived by the students as compared to fear of tests, communication speech apprehension and fear of negative evaluation. The majority of the students seem to be unmotivated to attend the English lessons at the university. Fear of negative evaluation was the least impactful factor. The reason for the contradictory findings from the two studies is possibly that the study conducted by Hashim and Mohd Isa (2012) was focused on a specific course which was Communicative English where they have to speak or present their ideas in front of their peers. The study conducted by Chin et al. (2016) was a more general study on university students' perceptions as ESL learners.

Anxiety in language learning among non-native speakers of English could play a major role in their learning, and I have presented some evidence that this may be particularly the case in the Malaysian context. This has an impact on learners' engagement in the learning activities in the language classroom. 


\subsubsection{Motives for learning}

In this section, I will discuss L2 learners' motives for learning English. This section will comprise the reasons that motivate learners in the EAP classrooms and ESL learners, to learn academic English.

Tertiary students have purposes for learning, and they tailor their learning to meet these reasons (Biggs \& Tang, 2011). Similarly, past studies show that EAP learners have purposes for learning academic English (Ananyeva, 2014; Evans \& Morrison, 2011; Liu et al., 2011; Ohata \& Fukao, 2014). These motives for learning are often shaped by their goals for learning (Ananyeva, 2014; Evans \& Morrison, 2011; Liu et al., 2011). EAP learners' goals for learning can be categorised as short-term and long-term goals (Evans \& Morrison, 2011; Liu et al., 2011).

Liu et al. (2011) compared Taiwanese university students' motives for learning academic/ specific English (EAP/ESP) and English for general purposes (EGP). The researchers aimed to find the EAP/ESP and EGP students' reasons for enrolling in the English courses and their needs for learning. Students' needs for learning were divided into three sub-categories: students' needs-necessities, wants, and lacks. The 972 participants were recruited from either EAP/ESP or EGP courses from six universities in Taiwan. A 95-item needs analysis questionnaire was developed to identify the learners' needs and reasons for enrolling in the EGP and EAP courses. The questionnaire was piloted using 20 undergraduates before the final version was produced. The questionnaire was divided into four language skills: listening, speaking, reading, and writing. The needs section of the questionnaire explored various tasks that reflect the four language skills while the reason for enrolment section explored the purpose in terms of distal and proximal goals in learning. The results from the questionnaire showed that the reasons for students to be enrolled in both EGP and ESP were influenced by their proximal and distal goals. These proximal and distal goals included learning for a future career, learning for academic purposes, and learning to pass the examinations. The findings also showed that the EAP and EGP learners did not see the four skills as equally important. Their needs for these four skills were complex as there may not be any relationship between the needs for learning (such as "necessities", "wants" and "lacks"). For example, it was revealed that learners' lack of proficiency in a particular skill does not mean they desire to learn that skill or they feel that it is a necessary skill to learn. The overall data showed that both the EAP and EGP students claimed that they were not proficient in writing, but the EGP students preferred to develop their speaking skills whereas the EAP students preferred to develop their reading skills. The EGP students' necessities, wants and lacks were different to those of the EAP students. For example, the EAP students' responses to the "necessities", "wants" and "lacks" of speaking skills included 'answer questions in conference'. The EGP students' main necessity for speaking skills was to be able to introduce themselves in English, their main want 
was to converse with others in English and their main lack was the ability to speak English with foreigners socially. The researchers suggested that the reason for this discrepancy was because the EAP students had a clearer understanding of the objectives of the course compared to the students in the EGP course.

Learners' motives for learning English could then be seen as related to investment. L2 learners find that they can benefit from learning English as it is a lingua franca. Norton (2010) stated that second language learners invest in learning with a purpose of getting a return. This leads to situations in classrooms where students tend to be more focused and engaged in tasks which they assume will assist them in attaining these returns (Pittaway, 2004). Returns could be in the form of imagined identities of whom or what language learners want to be in the future (Darvin \& Norton, 2015; Norton, 2010). This could be narrowed to what Norton termed as symbolic and material resources that contribute to language learners' cultural capital (Darvin \& Norton, 2015; Norton, 2010; Norton Peirce, 1995). Norton (2010) stated that when cultural capital increases, "learners' sense of themselves, their identities, and their opportunities for the future are reevaluated" (p. 3). Liu et al. (2011) found that the participants' proximal and distal goals could be seen as an investment in learning. The participants' motives for learning English were for future use, as well as to achieve academically which could be described as a return. Although generally the term investment in learning a language is related to the idea of reward, investment requires a longer process of learning as it is continuously constructed and reconstructed across time and space (Norton, 1995, 2013).

Another important aspect that influences motives for learning is learners' perceptions of the EAP course. In Ohata and Fukao's (2014) study, the researchers found that learners' conceptions of learning in the EAP classroom influence their goals in learning. In this study, the EAP learners' motives for learning in the EAP course changed when their conceptions of learning changed. Ohata and Fukao carried out their study in an EAP course at a university in Japan. The EAP course focused on the critical reading of academic texts. The researchers aimed to find the learners' conceptions of their learning in the EAP course. The in-depth interview sessions with the ten participants showed that enrolling in the EAP course had made them realise that academic reading is purposeful and requires higher order thinking as compared to their experience of learning English at the high school level. This realisation about the EAP course changed how the participants read academic texts. The researchers quoted one participant who mentioned that her goal in reading texts changed from aiming to score good grades, to appreciating the content of the texts and her ability to relate this content to her own life. Ohata and Fukao's study showed similar findings to those of Liu et al. (2011) where the EAP learners' understanding of the nature of the EAP course is an important aspect that influences learners' motives for learning. 
EAP learners at the tertiary level are mature learners who have various motives for learning. Having these motives assists learners to achieve their individual goals of learning in the EAP classroom.

\subsubsection{Learners' background as a contextual factor}

In this section, I will discuss the influence of L2 learners' cultural background on the learning of academic English. I will draw on literature from studies on L2 learners and the influence of cultural background in the academic English classroom. These studies show how various background factors influence how L2 learners approach learning English and their attitude and beliefs towards learning English as a whole.

Learners' backgrounds such as their home experience (Gardner, Masgoret, \& Tremblay, 1999; Hartas, 2011), their socio-economic status (Hartas, 2011) and the community that they live in (Gardner et al., 1999) influence their attitude towards learning a language. Situations at home such as parents' encouragement or lack of encouragement to learn a second language could influence learners' attitude to learning (Gardner et al., 1999). Gardner et al. claimed that there can be contradictory influences on language learning from learners' home experience. When parents encourage the learning of a second language, the children are motivated to learn. However, there are also situations where parents can sound encouraging of learning a second language, but at the same time can have negative feelings towards the language. Another aspect that influences language learning is the community that a learner lives in. Gardner et al. found that the amount of contact that a learner has with the target language community could influence the learning of a second language although this is debatable as L2 learning can be done in a monolingual context such as a classroom. These factors usually influence learners at the early stage of learning (Gardner et al., 1999; Hartas, 2011). Gardner et al., however, researched a group of 109 psychology undergraduates at the University of Western Ontario. The participants who had learned French at high school claimed that their early experience in learning the second language influenced their current attitude to learning the language. The participants had responded to a questionnaire that explored their reaction to learning French at high school as well as their present-day opinion of learning French. The questionnaire covered the participants' motivation for learning French, anxiety in learning and using French, their view of French Canadians, the course evaluation at high school, parents' involvement, participants' attitudes and desires for learning French, their view of foreign languages, bilingualism, and their language proficiency in speaking, reading and writing skills. The findings show that that the variables - namely motivation, anxiety in learning, parents' involvement, and the French community - are correlated with attitudes and beliefs. In other words, the learners' early experience affects their attitudes and beliefs about learning and using French in the present day. Hence, learners' attitudes and beliefs about learning a 
language may be, at least in part, influenced by the contextual factors such as their backgrounds.

The influence of context could also be linked to L2 learners' identity which affects learners' beliefs about, and attitudes to learning a language. For example, English language learners in countries such as Malaysia have multiple identities due to the multicultural context that they live in (Lee, 2003; Musa et al., 2012). The community that the language learners live in influences their use of English. The complex social structure that exists in Malaysia causes people from different ethnicities to react differently to the use of English. Rajadurai (2010), in her study on 12 Malay undergraduates enrolled in Teaching English as a second language (TESL) at a public university in Malaysia, found that the participants had to continually negotiate their identities to suit their home community. These participants claimed that they are snubbed and given the cold shoulder when they converse in English. Often these participants were reluctant to practise English because they felt that they would be judged by others as showing off within the Malay community or would be seen as less religious. This shows that the community's mind-set affects their identity as Malays who are proud of their origin. The participants also claimed that the non-Malays view them as being incapable of speaking English simply because they are not Malays. Hence, a general mind-set that is held by the community influences language learners as they themselves are part of this community. A similar finding was reported by Lee (2003) among 14 postgraduates enrolled in the Master of Arts (English language) at a public university in Malaysia. The researcher aimed to find how the English language affects the construction of identities among Malaysian English language learners. The participants claimed to have to continually negotiate their identities as English language speakers to fit into the different contexts they are in.

According to Lee (2003), the context that the learners are in influences the type of identity they put forward. For example, they have to switch identity to fit into a group that is hostile towards conversing in English (Lee, 2003). This shows that the community's perceptions have an impact on English language learners in Malaysia. A notable point about these two research studies is that the participants were considered proficient language learners and were able to converse in English. As such, their perceptions of conversing in English were different to those of the general community who viewed English as a threat. As mentioned earlier, since language learners themselves are part of this community, they tend to have an aversion to learning the language that is brought to the language classroom.

Often L2 learners bring their beliefs and attitudes to the English classroom. Learners' beliefs and attitudes towards language learning are formed by their ideology and identity which are shaped over time and depend on the contextual factors. These contextual factors in turn influence the language learners' attitudes towards learning. 
All in all, the four factors - interest and prior knowledge of topics, language learning anxiety, motives for learning, and learners' background as a contextual factor - affect how language learners approach learning. As discussed in the above sections, these factors have complex positive and negative impacts on learning academic English in the classroom.

\subsection{Reading Skills, Reading Tasks and Requirements in EAP Classrooms}

The distinction between skills and strategies is still unclear in reading (Grabe \& Stoller, 2011). According to Grabe and Stoller (2011), the term 'skills' refers to "linguistic processing abilities" such as "word recognition" that take place automatically (p. 8). However, Schunk (2008) states that skills lead to the learning outcomes of specific tasks. Hence, skills can be learned over time and become automated. Due to the lack of clarity between the definition of skills and strategies, Grabe and Stoller (2011) argue that skills can become strategies when readers consciously use them for a purpose. Likewise, strategies can become skills when learners automatically process what they read, like for example "skipping an unknown word while reading" (p. 9). In this thesis, I will employ Schunk's (2000) definition of skills. I will use the term reading skills because three of the skills - annotating information, summary writing, and concept mapping - are skills that learners acquire over time while learning in the EAP classroom.

EAP courses should enable learners to understand and engage in the academic context in the other subjects they are studying. EAP courses at the tertiary level offer reading, writing, speaking and listening to learners separately or combined within one course. Often the EAP course provides generic skills in order to prepare learners to perform effectively in the academic context. This section draws attention to some of the generic skills and tasks that are taught in the EAP course such as annotation, concept maps and summary writing, and students' responses to the reading tasks.

\subsubsection{Annotation}

In this section, I draw on literature from studies in EAP classrooms where students are second language learners and classrooms where students are being prepared for the language demands of tertiary study. These studies show the effectiveness of annotation for different purposes.

The annotation skill is considered a read-to-write skill that includes both reading and writing activities (Hedgcock \& Ferris, 2009; Porter-O’Donnell, 2004). According to Feito and Donahue (2008), annotation is one way that enables learners to get closer to a text (Feito \& Donahue, 2008; Spack, 1993). Spack stated that readers have various ways of annotating the information that they read. According to Spack (1993), annotation can be done for each paragraph or can be done in bigger blocks of information, it can be in the form of phrases or a full sentence, also 
signs such as circles or underlining can be made on the information, and lastly annotation can be a summary of the information that the readers read or it can be the reflection of the readers upon reading the information. Hence, using annotation encourages learners to have an active engagement with the texts that they are reading (Feito \& Donahue, 2008; Porter-O'Donnell, 2004). Hedgcock and Ferris (2009), however, warned that annotating alone may not be beneficial as learners have to keep in mind that annotation is purposeful and should differ according to the different reasons for reading a text and the type of genre that they are reading.

Annotation, like reading skills in general, can be divided into cognition and metacognition. The cognitive level focuses on constructing meaning in a text (Devine, 1993). The metacognitive level focuses on the effectiveness of employing the action at the cognitive level (Devine, 1993). Similarly, annotation can be used at the cognitive level or at the metacognitive level. For example, learners identifying pertinent information in a text such as "main ideas (argument or claim), supporting ideas (evidence), key content vocabulary words, definitions, and transitions within the text" (Zywica \& Gomez, 2008, p. 156) are actions used at the cognitive level. In contrast, learners using textual annotation to claim "ownership over someone else's language, translating it into their own voice, rendering it accessible for future reference and reflection" (Feito \& Donahue, 2008, p. 296) are actions used at a metacognitive level which is a higher level than the cognitive level. Hence, annotation can be used at a surface level such as understanding the gist of the text or on a deep level where learners question the information in the text or provide critical opinions on what they read.

One of the factors that influences students to select the type of annotation depends on the requirements of the task at hand. If the task requires a surface strategy of annotation such as identifying the main idea in each paragraph of a text, the students will then select the pertinent information to meet the requirement. If the task requires a student to comment on the argument in a text or reflect on the argument, the students will then employ the deep strategy. Further, while annotating is considered a helpful skill in reading, there has always been a question as to why learners annotate certain information in a text (Feito \& Donahue, 2008) when responding to annotating tasks.

Annotation in the EAP classroom appears to be an area where there has been a dearth of research. However, annotation has been studied in English classrooms. Past studies show that annotation skill has been used as part of reading by instructors to enable learners to have a structured approach to reading tasks for understanding (Feito \& Donahue, 2008; Liu, 2006; Mohd Nor, Azman, \& Hamat, 2013; Wolfe, 2002). Feito and Donahue conducted a study to find the types of annotation ESL learners use to understand Shakespeare's play, King Lear. The researchers aimed initially to find the process of annotating the play as part of a bigger research project in an on-going study. They collected textual annotations from 32 first year and 
second year undergraduates enrolled in a general education course at a college in California. The researchers constructed a taxonomy using Iser's 'reader response theory' to categorise the participants' annotations. In the initial findings, the researchers found that the participants annotated using four types of textual annotations - trackings, identification of gaps, individual repertoire, and literary repertoire - in reading and understanding the play. The findings showed that learners use 'trackings' to annotate. Trackings, as a term, cover underlining, highlighting, questioning, paraphrasing, and finding sources from outside. The second category is 'identification of gaps'. This refers to the participants' understanding that they must make meaning on their own because the text does not offer all the information. The researchers also found that upon realising the gap, the participants attempted to fill it by interpreting the information that they read. The third category is 'individual repertoire' which refers to the participants relating the information that they read to their own life. They are able to compare the issue that they read about with personal experience or knowledge, for example 'moral debates' (p. 303). The last category is literary repertoire where the participants employ their understanding of literary terms. Students were able to use a range of annotations to understand text. This study is specific to a particular literary context, but it is useful in showing the range of possibilities for annotation and a taxonomy of increasingly complex conceptual understanding emerging from different types of annotation.

In another study on using annotation in a read-to-write assignment, Liu (2006) aimed to explore participants' learning strategies and their ability to write critical and analytical essays. The researcher used deep and surface approaches which she categorised as poor annotation styles and skilful annotation styles. She then compared these categories with the participants' final examination essay results. Liu conducted this study with 40 undergraduates enrolled in a freshman composition course at a university in New York. This was a compulsory course for which she prepared the students for the University's proficiency examination. Liu used annotation notes and an open-ended questionnaire to investigate participants' metacognition during the use of annotation skills. The questionnaire was distributed after the participants had completed their read-to-write tasks and their final exam essays. The essays were marked by two examiners using a blind grading system. As a preliminary exercise, the researcher selected reading materials with three themes, namely gender and identity, race-ethnicity and identity, and language and mass media. Each theme had four to five articles. Liu collected the annotations and essays about these practices. The participants were provided with the definition of annotation and were taught step-by-step to annotate the articles given in the class as practice. Step one was 'skim and scan' where the participants were instructed to use a green marker to indicate unfamiliar words and yellow for pertinent information found in the articles. The second step was 'annotation'; the participants were required to reread the article while stopping to check the highlighted words and providing comments and critiques on the margin of the articles. The third step was a 'reading log' where the participants had a double 
entry reading log. The participants were asked to use this log if there was not sufficient space at the margin. The researcher added that having this log further strengthened the practice of the annotation. The fourth step was 'group discussion' where the participants discussed their own thoughts and critiques as well as their peers' thoughts based on the annotation notes that they wrote. The last step was 'tweaking and shaping ideas': the participants were required to choose one of the two questions given in the handout and write a response to the question. The essay activity required students to summarise the articles from the same theme, identify the relationships between the author's ideas, and include their own experience to provide a detailed explanation of their writing. Keeping these steps in mind, the researcher asked the participants to complete the final examination essay. The essays were coded into two categories: deep or skilful approach and surface or poor approach. The deep or skilful approach referred to "meaningful highlighted passages, marginal responses to and questions of such highlighted parts, circles that emphasize key ideas, and arrows that join or point to related ideas and/or arguments". In contrast, the surface or poor approach referred to "minimal marginal responses or questions with either no highlighted parts or long, indiscriminate highlighted passages (Liu, 2006, p. 203). The findings showed that of the 40 participants, 27 passed the final exam, seven failed, three withdrew and three were absent. The researcher stated that most of the participants who had passed had employed a skilful approach. They had consistently used the annotation skills in their practice as well as in their final exam essay. Meanwhile, out of the seven who failed, five had used a poor approach. Those who had understood the skilful approach made progress and received a pass from the two final examination markers. However, those who lacked the skilful approach had produced weak essays where they had not had extracted information from reading materials without critiquing or analysing them.

The task requirements for Liu's (2006) study comprised a deep approach to annotation skills. Having repeatedly practised the annotation skills had enabled the majority of the students to use the skills even in their final examination, although there were some who were unable to do so. It could be deduced that annotation skills could be used at a deep or metacognitive level or at a surface level depending on the students' understanding and the requirements of the tasks.

With the advancement of technology, the annotation skill has been further extended from print material to reading online. Mohd Nor et al. (2013) carried out a study of 81 undergraduates enrolled in a compulsory English Language Studies course at a public university in Malaysia. These students were from various programmes such as English Language Studies, Teaching English as a Second Language as well as Literature. The researchers used an online reading system to investigate the use of the annotation tool to understand online reading texts. They collected the data using questionnaires to explore the participants' perceptions of the online 
reading system. The questionnaire that was distributed at the end of the semester explored the general use of the computer, the amount of time the system was used, the tools that exist in the system and the usefulness of these tools in assisting the participants to understand the text. A total of 53 questionnaires were returned to the researchers. Focus group interview sessions consisting of 14 participants were conducted to acquire more information on the participants' perceptions of the system. The online system consisted of a two-paragraph text on "language acquisition." To facilitate the annotation activity, questions were provided above the text, a forum was set up to further help the participants to discuss the text with their peers, and the instructors provided feedback on the annotation done by the participants. The participants were given three more texts during the semester to continue the annotating activity. The findings showed that the participants claimed that the annotation tool helped them to comprehend the texts that they read online and that a majority of the students agreed that highlighting information helped them understand the texts better. Highlighting being a useful skill was followed by making notes on the texts and using the annotation tool to share their understanding with their peers. The analysis of the types of annotation made on reading the texts showed that the participants had used various processes such as questioning, using synonyms, defining terms, summarising information, giving their opinion, reflecting and thinking about their stand on the issues and making inferences. The researchers found that the annotation tool had assisted the learners on a personal level of learning as well as on a collaborative level of learning with their peers. The participants claimed that at a personal level, the annotation tool enabled them to organise their thoughts and gave them access to refer to their own notes. They further claimed that they were actively involved in their own understanding of the texts that they read. On a collaborative level, the participants stated that they were able to get different types of ideas and compare them with their own as well as reflect on their ideas. The findings from this study then showed a different result to Spack's (1993) claim that annotating is an individual activity. Spack makes this claim because each reader has a different way of reacting to the information that they read which leads to different types of annotation skills used in reading. However, the findings from Mohd Nor et al. (2013) showed that using annotation can be beneficial at an individual level as well as in a collaborative mode where learners compare, reflect, and decide on their thoughts and understanding.

The purpose of annotating texts is to assist learners in comprehending what they read. There are various ways to annotate depending on the learners' purpose for annotating the texts. This activity can influence learners in either having a surface understanding of the gist of what is being said in the text or it can provide an in-depth understanding by making readers reflect deeply on what the author is saying in the text. 


\subsubsection{Summary Writing}

In this section, I will discuss the literature related to writing summaries of academic texts by second and foreign language learners of English. The empirical studies that will be discussed in this section show that this form of summary writing is an important skill that enables learners to review what they have read and make sense of it (Delaney, 2008; Hirvela \& Du, 2013). First, I will draw on the definitions and purposes of summary writing that are used in the literature.

Reading-to-write is integral for learners to achieve academically at the tertiary level as the skills of both reading and writing are used across most disciplines in the academic context (Grabe \& Zhang, 2013). This is one reason summary writing is taught in the EAP classroom. There are several tasks that can be categorised as reading-to write, namely "summarizing, synthesizing information, critically responding to text input, or writing a research paper" (Grabe \& Zhang, 2013, p.10). Summarising information assists readers in their understanding of the text (Spack, 1993). It is a metacognitive level reading skill (Allen, 2003). This is because summarising information requires readers to monitor their understanding of what they have read (Allen, 2003; Spack. 1993). When learners monitor their understanding, they are then employing metacognition strategies. When summary writing activity requires metacognitive processing, it makes summary writing a higher-level task.

Hedgcock and Ferris (2009) agree that summarising is a read-to-write skill. They stated that in summarising information in a reading text, learners must be able to determine the important ideas in the text that will be included in the summary and the less important ideas that will not be included in a summary. In writing a summary, Hedgcock and Ferris (2009) argue that the writer must be able to paraphrase the important ideas using his or her own words. Thus, distinguishing important points from supporting points and paraphrasing the points become essential in summary writing. However, summarising is not as easy as it seems. It is "a complex skill to master" and learners need to be trained repeatedly to practise this skill (Hedgcock \& Ferris, 2009, p. 185). Nonetheless, summarising is considered an important way to check readers' understanding of the text (Hedgcock \& Ferris, 2009). Hedgcock and Ferris point out that by summarising, readers will be able to get the gist of the text which is essential before proceeding to more cognitively demanding activities such as analysing or providing critical responses to the text.

In the EAP classroom, the read-to-write tasks usually consist of selecting and summarising information from different sources before writing an essay. The learners are taught to write a summary from sources to familiarise them with the demands of reading and writing in other subjects in the mainstream academic context (Grabe \& Zhang, 2013). However, being able to carry out these activities can be demanding for $L 2$ learners. This is because $L 2$ students often do not possess a strong command of vocabulary which helps in paraphrasing (Grabe \& Zhang, 
2013). Further, L2 learners face difficulties in writing summaries as they have limited knowledge of composing a summary (Grabe \& Zhang, 2013).

Several studies have been conducted on summarising tasks as part of read-to-write tasks among L2 learners and the challenges that they face in meeting the task requirements (Delaney, 2008; Hirvela \& Du, 2013; Keck, 2006). Although possessing the read-to-write skills is crucial in the academic context, it is rather complex to master them (Delaney, 2008). This is because the read-to-write tasks involve different skills which are in turn influenced by educational background and language proficiency (Delaney, 2008).

Delaney (2008) carried out a study with 139 graduate and undergraduate participants including 50 native speakers and $89 \mathrm{ESL}$ and EFL students who responded to two read-to-write tasks: a summary and a response essay using the same textual resource. The researcher aimed to find out whether both reading abilities and writing abilities influence the reading-to-write task or it is an independent construct. In the reading task, the participants were asked to read and to summarise the main ideas in the textual source and in the writing task the participants were asked to write an essay responding to a question pertaining to the main idea in the source. To determine the participants' reading level, they were given a 'Nelson-Denny Reading Test' which consisted of two sections: vocabulary with 80 multiple choice questions and comprehension with 38 multiple choice questions. The participants' writing ability was assessed using a task adapted from Khaldieh's (2000) study. The participants' responses to this task were assessed using an analytical rubric adapted from Jacobs, Zinkgraf, Wormuth, Hartfiel, and Hughey (1981). Firstly, the findings from the read-to-write tasks show that the reading-to-write tasks are an independent construct. In other words, the performance of the participants on the read-to-write tasks is influenced by individual factors such as proficiency level and educational level which influence the tasks differently. Secondly, the findings showed that the native speakers performed better than the non-native speakers in the overall tasks. Moreover, the graduates outperformed the undergraduates in the response essay but the score was not significantly different for the summary writing. The researcher explained that both the reading and writing tasks were from different dimensions because the response essay required more analytical thinking than the summary writing. The summary writing was considered less challenging as the requirement was to produce a compressed version of the authors' ideas. Further, the findings also indicated that lack of language proficiency and the academic experience with these tasks hindered the participants from expressing their thoughts and thus the content that meets the tasks' criteria. Hence, lack of proficiency and lack of familiarity with tasks are some of the challenges that influence learners' performance in doing the read-to-write tasks. 
Hedgcock and Ferris (2009) expressed a similar view to that of Delaney (2008). They too saw both summary writing and response tasks as involving different dimensions. The findings from Delaney indicate that the response essay is a more complex task than the summary writing due to its requirement of critical thinking. This is because summary writing focuses on the author's ideas while the response essay focuses on the reader's own reaction to the information read in the text (Hedgcock \& Ferris, 2009). However, both these tasks require learners to be able to relay their opinions clearly with sufficient information. This could be achieved by having appropriate training to respond to the tasks (Hedgcock \& Ferris, 2009) at an adequate proficiency level.

Similarly, another challenge that hinders learners from meeting mastering the summary writing task is the inability to paraphrase (Hirvela \& Du, 2013; Keck, 2006). Keck explored L1 and L2 students' attempts to paraphrase. A total of 165 participants included 79 native speakers of English, 12 bilingual and 74 non-native speakers of English enrolled in an intensive English programme at a university in the United States. The participants were asked to write a one paragraph summary after reading a text which was written in a Microsoft Word document. The researcher traced the original text and the paraphrasing attempts to see whether the original text was used in the summary. Then the researcher coded the paraphrase using linguistic characteristics such as length, reporting phrase, unique links, and general links. A reporting phrase involves citing the authors in the summary. Unique links are a word or words that exist in a specific place in the original text that were used in the summary. General links are a word or words that occur but not only in a specific place of the original text. A Taxonomy of Paraphrase Types was designed to evaluate the participants' paraphrasing attempts. The taxonomy was divided into "near copy, minimal revision, moderate revision and substantial revision" (p. 268). The findings showed that in terms of attempted paraphrases, native speakers and non-native speakers did not differ significantly. Both these groups used an average of five attempted paraphrases in a summary. The findings also showed that the highest near-copy instances were written by the non-native speakers while the highest with substantial reference instances were written by native speakers. The researcher stated that one of the reasons for a high rate of non-native speakers writing near-copy incidents in the study is probably because they were not aware that it is considered plagiarism in the universities in the United States. Moreover, the researcher added that another reason that causes a high rate of near copy among the non-native speakers is probably their lack of proficiency in English. Paraphrasing in summary writing could be a difficult skill to master for non-native speakers.

In another study on using paraphrasing in summary writing, Hirvela and Du (2013) looked at how ESL learners' understanding of paraphrasing influences the act of paraphrasing in the classroom. The researchers conducted the study with two ESL undergraduates from China 
enrolled in an academic writing course at a university in the United States. The data were collected using think-aloud protocols in which the participants discussed the process of paraphrasing such as making decisions while paraphrasing. The second data collection tool were text-based interviews where the researchers had collected the drafts of the paraphrasing activities. In the drafts, the participants were asked to make notes of what and what not to paraphrase, when and when not to paraphrase and why and why not paraphrase. Both the think-aloud protocols and text-based interviews were transcribed and coded. Triangulation was also conducted to compare both these data collection methods. The findings indicated that although the participants were comfortable in using paraphrasing, they were unable to see the transfer of this to their research paper. The researchers stated that the participants were able to paraphrase for "decontextualized knowledge telling purposes" (p. 96) but were unable to transfer this skill to more demanding tasks. This shows that the participants were unclear about the purpose of paraphrasing and how it could be integrated in the learning tasks. These findings have particular relevance to the EAP classroom because the tasks in the EAP may be decontextualised from the mainstream academic requirements and students may struggle to see the purposes of paraphrasing.

Summary writing is important as it provides a platform for the reader to understand a text before moving to tasks that are more demanding. In summary writing, students need to be able to identify and paraphrase the ideas of the author concisely and clearly. This process may be impeded by lack of English language proficiency or composing skills and the education experience. Writing a summary is complex, but with appropriate teaching, students may develop these skills.

\subsubsection{Graphic Organizers}

In this section, I will draw on the literature on the use of graphic organizers among tertiary students. I will first discuss the benefits of graphic organizers before discussing studies that have used graphic organizers as tasks and learners' responses to using graphic organizers.

One of the types of tasks conducted in EAP classrooms is creating graphic organizers. Graphic organizers such as mind maps, concept maps, fishbone, chain, compare and contrast, and so on are some of the commonly used maps in the teaching of reading. Graphic organizers are used at all levels of education (Hedgcock \& Ferris, 2009). There are many ways that graphic organizers assist readers: they help readers in understanding the organisation of the text (Grabe \& Stoller, 2011; Hedgcock \& Ferris, 2009), enable readers to draw pertinent ideas from a text (Hedgcock \& Ferris, 2009), provide a visual representation of how ideas are connected in reading comprehension (Grabe \& Stoller, 2011; Hedgcock \& Ferris, 2009), enable readers to connect new knowledge with existing knowledge, focus on the signal words present in the text and assist in read-to-write activities (Grabe \& Stoller, 2011). Further, as there are many 
types of graphic organizers, it is important to note that different genres of text require different graphic organizers (Hedgcock \& Ferris, 2009). For example, when readers are able to identify the organisation of the text, for example if the text is a compare and contrast text or cause and effect, they will then be able to determine the appropriate graphic organizer. The graphic organizer will then become a tool to assist the readers to further see the relationships that exist in the text and that also help in identifying key ideas.

Graphic organizers can promote deep learning (Davies, 2011). Davies described the way that graphic organizers can be used as mapping tools using software packages as part of teaching and learning. Davies stated that deep learning could be achieved when learners comprehend complex relationships, portray these relationships in a visual form, and are able to analyse this information. However, he cautioned that not all graphic organizers promote deep learning as there are different types of organizers such as mind mapping, concept mapping and argument mapping. Davies stated that mind mapping is used to show simple relationships while concept mapping is more structured and shows the relationships and inter-relationships between concepts and argument mapping which are used to show the "inferential structure of argument" (p. 286).

Several studies on graphic organizers show that positive changes in learners' understanding occur upon using graphic organizers (Hay, 2007; Hay, Wells, \& Kinchin, 2008; Setiasih, 2015). In a study conducted by Hay et al. (2008), the researchers aimed to find out how the use of concept mapping changed learners' understanding in a mental health course at a college in London. A total of 18 participants took part in this study. The course was called Dual Diagnosis and the participants learned about "mental illness and substance abuse" (p. 223). The participants were introduced to concept mapping in the first session of the course. Prior to starting the teaching and learning, the participants were then asked to complete a map on their understanding of dual diagnosis. The maps were then collected by the instructor. Then the participants were given short answer questions as a pre-test of their prior knowledge of the content of the course. The concept map and the post-test short answer questions were repeated at the end of the course. The findings could be seen from a quantitative perspective (pre-test, post-test and essay grade) and qualitative perspective (quality of learning). The pretest and post-test scores were then analysed. The concept maps were analysed in two ways: using Kinchin's (2000) approach to learners' structural understanding and analysing the quality of learning derived from Hay's (2007) work. The conceptual map criteria were divided into spoke, chain, and network based on Kinchin's approach. The quality of learning derived from a combination of sources was summarised into non-learning, rote learning consisting of surface learning, and meaningful learning consisting of deep learning. The findings were divided into three parts: the use of concept maps encourages understanding among learners, learners' understanding can be compared over time, and the changes to learners' quality of 
learning can be measured. The overall findings in terms of pre-test and post-test scores show that most of the participants had scored higher in the post-test, but the average scores show that the participants did not move more than one place in the ranking. In terms of structural changes, the findings showed that only two participants had constructed concept maps that were different in pre-test and post-test. One of the participants had constructed a chain in pretest and a network in post-test. The other participant had constructed a chain in pre-test and an unclassified map in post-test due to a lack of connections in the concept map. In terms of quality of learning, only two participants (Amy and Tammy) managed to attain meaningful learning which reflected deep learning. Tammy's knowledge change revealed that she had a mix of surface and deep learning. The researchers added that she had learnt some of the content deeply and had used prior knowledge and the new knowledge learnt together but there were some ideas in the map that showed surface understanding where there was no link to other ideas. Amy's map on the other hand showed more meaningful learning taking place. She had elaborated her ideas as compared to the pre-test map. This showed that she had acquired new understanding of the content and was able to link these ideas with other ideas. However, not all learners were able to achieve meaningful learning, Harry, for example, had almost replicated his pre-test map in his post-test map. The structure of the map did not change but he had added some new ideas, although his ideas were not linked to the main concept in the map. He showed a mix of non-learning and rote learning in relation to the criteria. Another participant, Bella, had no cross-link with other ideas in the pre-test and had only four crosslinks in the post-test. The connections made with other ideas were not significant to the larger concept map. Bella had done poorly in the pre-test and post-test as well as the essay. She had failed the course. A case similar to that of Bella was Rose, who, although having a complex concept map as compared to her pre-test map, revealed a poor understanding of content. Rose's map showed she had misunderstood some of the concepts. She scored moderately in her pre-test and post-test but failed in her assignment. Overall, she failed the course. The researchers added using concept maps allows learners to have a visual understanding of what is being learnt as well as integrating new knowledge in their own understanding.

In a study of using graphic organizers in reading as one of the teaching methods, Setiasih (2015) aimed to find the effectiveness of using chunking, mapping, elaborating and summarising in reading among EAP learners at a university in Indonesia. The researcher employed an experimental study consisting of pre-test and post-test in experiment and control groups. The experiment group received treatment while the control group did not. The treatment group received training on activating their prior knowledge; next the chunking strategy was introduced in which students were taught to chunk what they read as phrases to make meaning; thirdly, they were taught to elaborate, which consisted of activating their existing knowledge of the world and further strengthening their critical thinking skills; and lastly they were asked to create a chart of the ideas in the text and summarise them using their own 
words. The effectiveness of this treatment was measured with a pre-test and post-test using multiple choice questions and subjective answer questions. The findings from the post-test showed that the treatment group had received significantly higher scores than the control group. The scores of the pre-test and the post-test showed that both groups had started with somewhat similar scores in the pre-test, but the treatment group had achieved higher scores in the post-test. Although participants' scores in the control group for the post-test did increase, the scores were not as high as those of the treatment group. The researcher stated that the four strategies that were introduced to the EAP learners had helped in understanding the text. Although mapping was the main focus of this study, it did not contribute to the participants' achievement in understanding and making sense of the text that they read.

Graphic organizers can be used with different types of texts regardless of the complexity level of the texts. This is because graphic organizers enable learners to visualise their understanding of the content and assist in linking the ideas. Further, using graphic organizers allows learners to deepen their thinking as they are able to make connections between the concepts and employing their own knowledge.

There is evidence that different types of reading skills taught in the EAP classroom assist learners in making sense of what they read.

The next section of this chapter will explore how the content taught in the EAP classroom is transferred to the mainstream academic context.

\subsection{Transfer of Learning at the Tertiary Level}

\subsubsection{Students' Perceptions of Transfer of Learning in Tertiary Level Education}

Transfer of learning in a general sense could be defined as learners employing the knowledge learnt from one situation to another situation (Larsen-Freeman, 2013). In the area of EAP, the objective of an EAP course is to ensure students are able to transfer the knowledge that they learn in the classroom to outside of the EAP classroom. However, whether this objective is being achieved is still unclear (Green, 2015). Further, studies on the transfer of knowledge between EAP courses and mainstream courses showed mixed findings (Green, 2015; James, 2010, 2012).

\section{Studies conducted in EAP in relation to transfer of learning and mainstream academic context}

A research study conducted by Green (2015) indicates that the students who took the EAP programme were able to transfer the knowledge that they had learnt to other courses within the university. Green conducted a quantitative study of 39 participants at an international college in Thailand. The participants were enrolled in an English communication course, the final level of the EAP programme in the college. A set of online questionnaires was used to 
collect the data. The questionnaire was divided into sections: demographic details, students' perceptions of transfer of learning; and students' perceptions of instructors' teaching methods. The researcher used the terms "low-road" and "high-road" from Perkins and Solomon (1988) to describe the instruction methods used by the instructors. The term "low-road" showed a rather implicit teaching method where modelling or simulations were given by the instructor. "High-road," on the other hand, refers to when the instructor actively asks learners to use metacognition strategies where learners monitor their learning and reflect on what they are learning. The findings showed that a majority of participants claimed that they were able to transfer knowledge learnt in the EAP course on reading, research and writing to other courses. However, the participants claimed that transfer of knowledge took place specifically in social science courses where the theoretical content was most similar to the content taught in the EAP courses. The researcher stated that the reason for transfer to occur with social science courses is probably because of the nature of assignments which require writing skills. Hence, participants tend to use strategies such as selecting sources or using referencing in their assignments. The findings also showed that there was positive significant difference between the low-road and high-road methods as a whole and participants' perceptions of transfer of writing knowledge. Green (2015) also noted that the instruction methods were mostly related to low-road strategies as compared to high-road strategies.

In a qualitative study, James (2010) aimed to explore 52 ESL students' perceptions of transfer climate and the challenges faced by EAP students in mainstream courses. These students were from various countries around the globe enrolled in an EAP course specifically for ESL students at an urban university in the USA. James used the term transfer climate to refer to support for transfer of learning in a target context. The researcher had conducted semistructured interview sessions with the students. The semi-structured questions revolved around the support offered by instructors for transfer to take place, classmates' support for transfer to take place, and the impact of transfer on grades as predicted by the participants. The findings show that a transfer climate was likely to occur but it differed from individual to individual and there were different aspects to the transfer climate. The analysis of the findings also suggested that there was not much support from peers and instructors from the mainstream courses to facilitate this transfer. Most of the participants could not see support for transfer of learning in the mainstream academic context. Participants mostly faced challenges in terms of academic writing, language use, lack of connection between the language use and grades they receive, a lack of relationship in activities between EAP and mainstream academic activities and the generally unrelated nature of the EAP course and mainstream course. The findings also suggest that the transfer of learning from the EAP course is only applicable to some disciplines. This shows that the transfer of learning from the EAP course could be discipline specific. Green's (2015) study corroborates James' (2010) finding 
that transfer of learning varies according to the mainstream disciplines in which the EAP learners are enrolled.

In a different study, James (2012) investigated EAP learners' motivation in relation to the transfer of learning. A total of 42 participants from the EAP writing course had volunteered to participate in this study. He collected the data in 2007 at a university in the United States. The participants in this study were of different nationalities such as Saudi Arabian and South Korean and were enrolled in various programmes at the university. The researcher focused on three aspects - desire, favourable attitude, and effort - in relation to motivation and transfer of learning. The findings from the semi-structured interviews revealed that the majority of participants were not motivated to transfer learning to the mainstream programmes. The findings showed that there were many factors that influenced learners' motivation to transfer in this study. These factors were categorised into two types: context and learners. The context factors were resource availability, opportunity for transfer, requirements for transfer, expected impact of transfer, attitudes toward learning outcomes, attitudes toward learning, and transfer context/tasks. Learner factors were personal beliefs about transfer and competence. The findings showed that participants mostly had the desire to transfer and had a favourable attitude towards transfer but there was less effort made in the transfer. The lack of effort was mainly because of the participants' perceptions of opportunity provided by the mainstream courses for transfer to take place and participants' personal beliefs. The participants either felt transfer was not important or they thought transfer should be automatic rather than being done consciously.

The three studies discussed in this section show that transfer of learning from the EAP context to the mainstream context depends on how learners perceive its relevance. Learners may be more inclined to transfer if they are provided with the relevant opportunities to employ the knowledge they learn in the EAP course. From the studies above, it could be seen that these opportunities could derive from the type of task given as well as the type of programme. The findings from the studies conducted by Green (2015) and James (2010) highlighted this by stating that learners are likely to make the transfer if they find similarities in the content taught in the mainstream programme and in the EAP course.

Another aspect that James (2010) emphasised was that EAP course instructors needed to explain to their students how the transfer could occur in various academic settings so that effective transfer of learning took place within the academic setting. This is in tandem with Charles and Pecarori's (2016) view that in order for transfer of learning to take place, EAP learners must be able to see the value of learning the content. This could be achieved by taking into consideration what the mainstream programmes required from students in terms of language skills. 
It should not be taken for granted that transfer of learning takes place automatically from the EAP to mainstream programmes. However, the literature above suggests that with careful planning and interaction with the learners as well as with course designers from the mainstream programme, transfer of learning is possible.

\subsection{Summary of the Chapter}

This chapter has been organised to fit Biggs' (2003) 3P model and to show the related issues that take place in learning of EAP at the tertiary level at each stage, namely the presage (before learning - factors of learning), the process (during learning - responses to tasks) and the

product (after learning - transfer of learning). The variety of definitions for EAP make understanding what should be taught to learners complicated. Further, EAP learners have their own perceptions and expectations of learning in the EAP course which may go undetected during the course of learning.

The learning of EAP is complex as there are many factors that influence learning and all these factors are interrelated. This study is designed to explore the complexity of this learning through the perceptions of Malaysian learners. 
This page is intentionally left blank 


\section{CHAPTER 4 \\ METHODOLOGY}

This chapter discusses the methodology used in the study of Malaysian tertiary students' perceptions of learning academic English. I will first discuss the research design used in this study followed by the data collection techniques and the data analysis procedure. Finally, I conclude by discussing the ethical requirements.

\subsection{Research Questions}

This study is designed to address the following research questions:

Main question:

How do 12 Malaysian tertiary students' perceptions of factors in learning in the EAP classroom align with their responses to tasks and their perceived outcomes of learning in the EAP classroom?

Specific questions:

1. What factors influence students' learning in the EAP classroom?

2. How do students respond to specific tasks in the EAP classroom?

3. How do students perceive the outcomes of learning in the EAP classroom?

\subsection{Research Paradigm}

In choosing appropriate research designs, researchers should first consider whether the intended design fits the study. Creswell (2009) stated that selection of research designs should be based on "the nature of the research problem or issue being addressed, the researchers' personal experience, and the audience for the study" (p. 3). In other words, researchers have to be aware of their philosophical assumptions in choosing the best approach for their study (Creswell, 2007). Taking these elements into consideration, I employed a qualitative design to address the research questions in the current study. Further, I chose a qualitative research design because of my worldview. I believe that there is not one reality, but multiple realities and each individual's opinion and experience may not be the same.

Social constructivists believe that language learning is produced through interaction which is closely influenced by the socio-cultural context. Hence, social constructivism is associated with qualitative research (Merriam \& Tisdell, 2016). According to Merriam and Tisdell, social constructivism is often used instead of interpretivism. Meaning can be interpreted in various ways and is subjective (Merriam \& Tisdell, 2016). A social constructivist researcher then aims 
to focus on the participants' views to understand what is happening in the context (Creswell, 2007). Further, social constructivists analyse the findings with an open mind and do not confine themselves to a particular theory (Creswell, 2007). This helps them to explore what the participants think and experience. According to Creswell, social constructivists interpret how the participants construct meaning by using their own experience. In other words, the researchers interpret the findings by placing "themselves" in the research to "acknowledge how their interpretation flows from their own personal, cultural, and historical experiences" (Creswell, 2007, p. 21).

\subsection{The Research Design Used for this Study}

\subsubsection{Case Study Design}

A case study "explores in depth a program, event, activity, process or one or more individuals" (Creswell, 2009, p.13). Stake (2006) stated that qualitative case studies are designed to observe a real-life situation in a specific setting. Although case study researchers are said to have little control of events that take place as the study proceeds, the method has the ability to "deal with a full variety of evidence" (Yin, 2014, p. 12). Hence, the various types of evidence such as "documents, interviews, artefacts and observations" (Yin, 2014, p.12) collected by the researcher produce abundant and rich information that will be beneficial for the study. Having said that, a case study is governed by time and the researcher collects thorough information from the various types of evidence within a specific period of time (Creswell, 2009). Mackay and Gass (2016) point out that case studies have been widely used in second language learning as the approach allows the researcher to describe classroom scenarios or give details about the students in academic settings.

Yin (2014) categorised three types of case study: exploratory, descriptive, and explanatory. Yin explained exploratory questions such as "what" aim to develop a hypothesis or propose further inquiry in a study. Descriptive cases on the other hand aim to describe a phenomenon in a study. Lastly, research questions asking "how" and "why" are explanatory as they aim to explain why and how a particular condition or situation occurs (Yin, 2014). I decided to use the explanatory case study model because the research question for this study requires me to explain how undergraduate students' perceptions of learning factors align with their responses to the tasks and their perceived outcomes in learning. I aimed to find out how the undergraduates' perceptions influence their learning in the EAP classroom.

According to Yin (2014), a single case study with embedded units of analysis provides an indepth analysis of the case. This study adopts the single embedded explanatory case design. The single embedded explanatory case design is situated in one context with one case or multiple embedded units of analysis within one case. This design is suitable because it allowed me to explore how different units of analysis within a case react to learning. In this study (refer 
to Figure 3), the public tertiary institution is the context, the EAP course is the case, the EAP classrooms are the units, and the participants are the units of analysis. Yin cautioned that in using an embedded case study, researchers often tend to focus too much on the units of analysis and do not return to the case which is the area of analysis. Taking this into consideration as part of the analysis of the data, I performed a cross-unit analysis to make sense of what I found and to connect to the original case which is learning academic English in the EAP course in the public institution of higher learning.

Merriam (2009) stated that one important feature of case studies that needs to be taken into consideration is the focus of the study. Similarly, Baxter and Jack (2008) stated that it is important for researchers to bind their case to avoid generalising the scope of study. Stake (2006) stated that a case has two sides: what happens within a case and what goes on outside a case. Setting the boundaries of the case will assist in differentiating what the researchers are studying and what they are not studying (Merriam, 2009; Stake, 2006; Yin, 2014) which will help in the data collection phase (Yin, 2014). The boundaries of my study are three EAP courses conducted in year 2016 in a Malaysian university. The phenomenon is on how learning takes place within the EAP course in relation to three particular reading tasks.

This study incorporated the single embedded case study as the research design. The next section will explore the data collection phase of this study. 
Figure 3. Single embedded explanatory case study

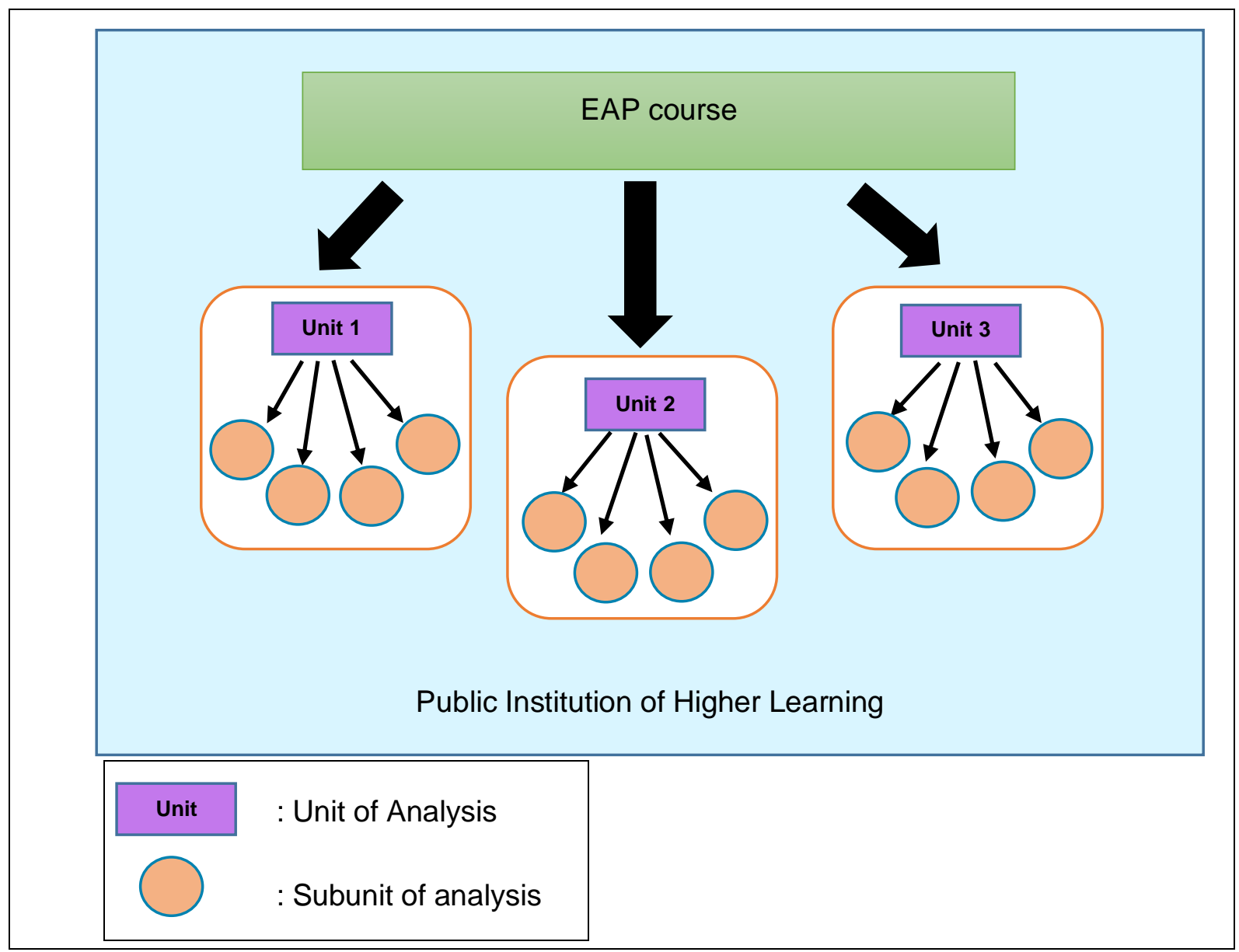

\subsection{Data Collection and Data Analysis Phases}

The figure below shows a summary of the data collection and data analysis procedures for this study. Although I collected the data from both public and private institutions, I only used the data from the public university for this study. I will further explain the reasons for this decision in the next section (4.5). 
Figure 4. Summary of the data collection procedure

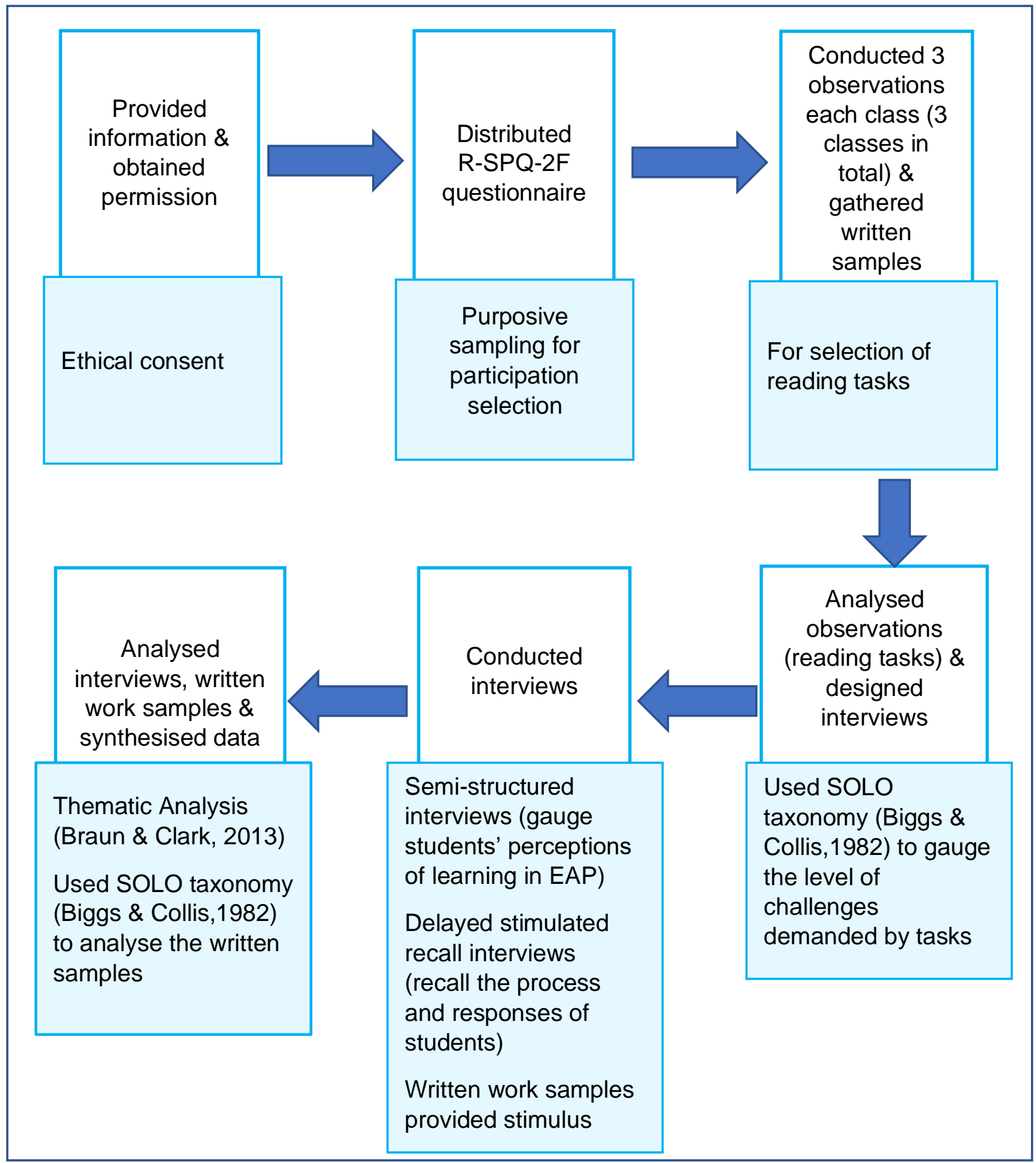

\subsubsection{Summary of Data Collection Procedure}

I first contacted the Economic Planning Unit at The Prime Minister's Department of Malaysia to obtain approval to conduct my research in Malaysia (further explained in the ethical requirements section).

Following that, I approached the Dean of the Language Academy at the public university to explain my research study and seek consent to conduct my research. Then, I proceeded to 
meet the lecturers teaching the EAP course. This is because I recruited the student participants from these lecturers' classes and the reading tasks used in the classrooms were collected for analysis. Some of the lecturers agreed to participate, and some were reluctant. I distributed the consent forms and information sheets to the lecturers who agreed to participate.

I approached the students of the lecturers who agreed to participate and recruit my participants. I provided a brief outline of my research study at the end of a lesson to these students. During this session, I distributed the consent forms and information sheets to the students to invite them to participate in the study. Once I had obtained the student participants' consent to be part of this research, I proceeded to collect the data. Only the students who gave their consent to participate in the study were considered for the research.

\subsection{The Selection of the Tertiary Institution and Sampling Methods}

\subsubsection{Tertiary Institution}

I collected the data from two institutions: one public and one private institution. I only used the data from the public institution for this study because the quantum of data collected was unmanageable for one study. In addition, the participants from the public university were from different backgrounds. The variety of backgrounds had the potential to enable a greater range of data than from the private institution. The data from the private institution will be used for further journal article publications later.

The public institution of higher learning that I selected for my study is situated in Johor, one of the states in Malaysia. The state of Johor was chosen for its strategic geographic position which is on the tip of South East Asia. The Iskandar project (implemented by the Malaysian government to bolster the economy) established a number of international tertiary institutions to upgrade the education sector in Malaysia. The state of Johor was chosen as a prospective research site as it is my home town and thus minimised the costs of the research.

\subsubsection{Sampling Methods for the Study}

I employed two levels of sampling in this study. Merriam (2009) stated that qualitative case studies often have two levels of sampling. For the first level, the researcher selects the case that he or she intends to study and for the second level, the researcher selects the units of analysis within the case. At the first level, I used convenience sampling to approach the lecturers to discuss my research study and to select the classrooms (units) that I would be studying. Convenience sampling was used to recruit participants who were willing to participate in a research study (Johnson \& Christensen, 2014). Johnson and Christensen stated that although the convenience sampling method is not an ideal way to collect data as the sample may not represent the population, at times researchers face challenges in recruiting the participants and have to adapt to the situation. I used this method because not all the lecturers 
were interested in participating in the study. I only approached the students of the lecturers who agreed to allow me access to their classes. I also needed to collect written samples of students' work and I had to obtain the lecturer's permission. Two lecturers agreed to allow me access to their students.

At the second level of sampling, I used the purposive sampling method to recruit the student participants. Purposive sampling enables researchers to specify criteria that are needed in a research study and recruit participants according to these criteria (Johnson \& Christensen, 2012). I did this because I wanted to include students who practised both deep and surface approaches to learning. As mentioned in the Theoretical Framework Chapter (page 31), deep approaches and surface approaches to learning are a continuum where learners may move to either end of the spectrum based on their preferred approaches to learning or to fulfil the demands of a task. I used the revised study process questionnaire (R-SPQ-2F) by Biggs et al. (2001) (Appendix N) to recruit and select the participants who had a range of combinations of preferred deep and surface approaches. This enabled findings from a range of participants with different combinations of approaches. I did not classify data gathered from these participants in analysing the qualitative data as the focus of this research was the wider context of learners' EAP learning.

\subsection{Participants for the Study}

\subsubsection{Students}

Students doing their Bachelor's degree in a public institution were invited to participate in the study. These students are young adults majoring in engineering and were enrolled in an EAP course for a semester. The students were of various ethnicities (Malay, Chinese and Indian), genders and religions. Students from three EAP classrooms comprising 89 students in total were invited to participate in the study. I distributed the questionnaires to these students.

I then analysed the questionnaires and selected four students who displayed a variety of approaches to learning from each classroom. Some of the students who I approached informed me that they were not interested. I then approached one of the participants who had agreed to participate and asked him to introduce any of his peers who would like to volunteer to participate in the study. I ensured the selection included a variety of approaches to learning. Finally, I had four participants for the qualitive study. No participants who wished to be in the study were rejected. 


\subsection{Data Collection}

I conducted observations of each EAP class at the research site. These observations aided my understanding of the academic setting in the public institution and helped me select the reading tasks for the interview sessions. Each reading lesson was generally held for about three hours a week. I provided an audio recorder for the participants while they were doing the reading tasks. This audio recorder was placed next to the participants while they carried out the tasks to capture discussion. The audio recordings were later transcribed and used during the stimulated recall. I also collected samples of students' written work from them. The selection of these is described in the section below. I then conducted interviews with the students to get a better understanding of how they perceived learning in the EAP classrooms. These interviews were held after I had finished transcribing the audio recordings. During the interview sessions, I used the written work samples and the audio recording transcripts as stimuli to assist the participants to recall the process that they went through while responding to the tasks. The data from the samples of written tasks were analysed using the SOLO taxonomy. The data derived from the interviews were coded and general themes were gathered. I analysed the first half of the data by following an iterative procedure. This procedure enabled me to shift back and forth from collecting and analysing data. In this way I was able to organise the data from the audio recording of the participants and the written tasks while conducting the interview phase.

\subsubsection{Classroom Observations}

Classroom observations enable researchers to "observe people's behaviour directly rather than relying on instruments like questionnaires to elicit such information" (Bryman, 2008, p. 256). Similarly, my aims, as I mentioned earlier, were to select reading tasks for the interview sessions and to get a sense of how EAP lessons are taught at the public institution. I used this data collection method as a secondary method for these purposes. I wanted to select the reading tasks that were challenging for the students. One way for me to find these tasks was by observing what took place during typical activities in class.

It is possible that at times during observations participants could claim they behave in a certain manner when they do not do so in reality (Bryman, 2008; Johnson \& Christensen, 2014). Hence, to curb this issue of students behaving differently and to make them feel more comfortable with my visits, I decided to visit the EAP classrooms once prior to the observation visits. I was a non-participant observer where I observed the lessons without taking part in the discussions in the classroom. Mulhall (2003) stated that at times researchers fail to inform participants of the true nature of the observation. I took careful measures to minimise this threat by clarifying my intentions and informing the participants of the purpose of the classroom observations during the briefing I had with them. I then mentioned it again before I started 
observing the lessons. This gave them some information on my study and my presence during their reading lessons.

I observed each class three times at the lecturers' invitation. During each observation, I audio recorded the lecturers' teaching and the discussions that took place in the classroom. A checklist that had been modified from Biggs and Collis (1982) and Biggs (2003) was used to assist the observations (Appendix O). The observation checklist was trialled with a group of students pursuing the Foundation Programme at Victoria University of Wellington to ensure its effectiveness. The checklist was based on the SOLO taxonomy and had five categories varying from "unistructural" to "extended abstract". I also took field notes during the observations. Based on the information that I gathered in the checklist and the field notes, I then selected the reading tasks.

\subsubsection{Selection of Reading Tasks for the Interview}

The reading lessons were conducted using Oxford EAP: Upper-Intermediate textbook. The reading tasks for this study were taken from this book. I wrote to the Oxford University Press to gain their approval to use the material in the textbook (Appendix $\mathrm{C}$ ).

I chose the tasks based on two criteria: the level of difficulty of the task and the amount of individual work done. I determined the level of difficulty based on my observations and field notes taken during the lessons. I used the SOLO taxonomy to determine the level of difficulty of the tasks. I noticed that some tasks were less challenging than others, for example, creating a mind map based on information from one text compared to forming a mind map from information selected from two texts. I decided to choose the more challenging tasks because I wanted to delve deeper into the students' struggle to complete the tasks given by the lecturer.

I also decided to pay attention to the amount of individual work done in class by the participants. This was because the focus of my study is on participants' perceptions of learning in the EAP classroom and their responses to the tasks given in the classrooms. I also wanted to capture how the students proceeded when doing the reading tasks and what transpired while doing the tasks. I selected one reading task (classroom activity) from each classroom as the subject of the interviews.

I used the reading tasks in class as part of the data collection rather than design my own reading tasks. This is because I wanted to get as close as I could to the context and the situations that transpired in the class. I did not want to interrupt the flow of teaching and learning in the classrooms by asking the participants to do any individual tasks for the sole purpose of getting the outcome that I needed. 


\subsubsection{Interviews}

Johnson and Christensen (2014) define the interview as a data collection method for which the interviewer asks questions to the interviewee to gain information. This enables researchers to get glimpses of what, why and how things happen in participants' lives (Rubin \& Rubin, 2005). Interviews allow researchers to acquire information, such as participants' views, when they are unable to conduct observations (Creswell, 2014). Furthermore, interviewers can probe the interviewees to gain more information on questions asked (Johnson \& Christensen, 2012). A qualitative interview is also very flexible because interviewers are allowed to deviate from the guide prepared for the interview to suit the situation (Bryman, 2008; Johnson \& Christensen, 2014).

Conducting interviews, however, can influence the participants' responses because of the researcher's presence during the sessions (Creswell, 2014). In addition, the responses collected by researchers can be indirectly based on the interviewees' opinions (Creswell, 2014). To minimise these issues, different data collection methods were used to triangulate the findings. The written samples were used to counter-check the responses to ensure the meaning of information provided by participants during the interviews. This study employed a stimulated recall post-observation interview and a semi-structured interview method to collect the data. Taking the above arguments into consideration, I was careful not to pressure the participants into tailoring their responses by leading them.

\subsubsection{Delayed Stimulated Recall Interview}

Lyle (2003) stated that stimulated recall is used widely in the area of teaching. Participants' behaviours are recorded and replayed to recall their thinking and actions at the time of recording. Gass and Mackey (2000) stated that stimulated recall stimulates learners' thoughts during a task or after the task has been done. In this study I used an audiotape recorder as compared to the usual video recorder because this enables the participants to feel more comfortable during the data collection procedure. This data collection technique was used to recall the participants' actions and interactions in class during the reading activities. I asked the participants to audio record their discussions of reading tasks in the class. The most suitable task was selected, and parts of the audio recording were then transcribed. The transcripts from the recording were later given to the participants to read. These audio recordings were recorded simultaneously with the classroom observation while I was observing the activities. A set of questions (Appendix M) was used to prompt the participants into recalling their thinking during the reading activities.

I faced some challenges in conducting the stimulated recall interview as I had to compromise with the time for the interviews, working around the availability of the participants, yet getting the interviews done while the participants' recollections were still reasonably fresh. Moreover, 
I had taken approximately two days to listen to the audio recording of each participant (each recording was three hours long) and to type the transcripts to be given to the participants.

\subsubsection{Semi-structured Interview}

According to Merriam (2009), the semi-structured interview is categorised between formal and informal interview techniques. The interviewer usually constructs a list of questions prior to the interview but these questions are prepared in a less structured manner (Merriam, 2009). Johnson and Christensen (2014) termed the semi-structured interview as an interview guide approach. They stated that the interviewer does not need to follow the order the questions were designed in or to exactly follow the topics that they had prepared. Johnson and Christensen stated that the interviewer has the flexibility to reword the questions asked during the interview session.

In most cases, the researcher prepares some specific questions or issues that he or she intends to explore through the interview, but these questions are used as cues to get more information from the interviewees (Johnson \& Christensen, 2014; Merriam, 2009). I prepared a set of questions (Appendix $M$ ) to gauge the participants' perceptions of learning in the EAP classrooms. The interview was conducted bilingually, in Malay and English. Both the participants and I code switched during the interview session to make it easier to communicate.

In conducting interviews, Mackay and Gass (2016) caution that the "halo effect" may come into play during the interview sessions (p. 226). Mackay and Gass (2016) stated that the halo effect occurs when the interviewee attempts to please the interviewer by providing responses that he or she thinks are what the interviewer expects. Taking this into consideration, I avoided leading questions during the interview (Johnson \& Christensen, 2014) and constructed some open-ended questions (Mackay \& Gass, 2016) such as "how did you approach the reading text?" I also probed with 'why' and 'how' questions when the interviewees' responses were not clear.

\subsubsection{Collecting Documents}

One of the advantages of using documents as a data collection method is that they are convenient as researchers can take their time to analyse them (Creswell, 2014). Corbetta (2003) stated that one of the limitations of using documents is that researchers cannot clarify the information received relating to the interview method, where the information can be clarified with the interviewees. Bryman (2008) added that access to documents needs to be restricted to researchers as at times people are wary of allowing others to see their documents. In the current study, I approached the participants to seek their consent for collecting their written samples. These written samples were the reading tasks done in the EAP classrooms. I collected three samples of reading tasks from each participant. As mentioned in section 4.7.2 
(selection of reading tasks), I selected one reading task for each EAP classroom to be analysed and then discussed at interviews. These written samples were triangulated with data collected from interviews and the stimulated recall sessions.

\subsection{Data Analysis}

\subsubsection{Pre-analysis Work: Transcribing, Translating and Verifying Interview Transcripts}

Prior to analysing the data, I conducted some pre-analysis work. I first transcribed the interview transcripts and then translated them before verifying the transcripts (Hennink, Hutter, \& Bailey, 2011). My first step of pre-analysis work was transcribing the semi-structured interviews and stimulated recall interviews.

I firstly transcribed the interviews verbatim before translating them (Hennink et al., 2011). The semi-structured interviews and stimulated recall interviews were transcribed word-for-word including the fillers and pauses. Then I checked the audio recording of the interviews against the transcripts to ensure I had not left out any information.

Next, the transcripts were translated from Malay to English. I translated the transcripts to make it easier for me to discuss them with my supervisors and also to assist my discussion on coding with my supervisors. While translating, I was careful to maintain the style of the colloquial language used by the participants. I was aware that translating required care because what the participants said represented the local culture and quite often meaning gets lost in translation (Hennink et al., 2011).

I then removed any information that could reveal the participants' identity from the transcripts (Hennink et al., 2011). The information that contained personal details was removed and a general term was replaced in brackets. This was done to prevent participants' identities from being revealed in my study.

Finally, I checked the translated transcripts against the original document to ensure I had not misunderstood any information. Then, I contacted a fellow PhD student who was a native speaker of Bahasa Malaysia to read through sections of the interview transcripts, which I emailed her. She then read through the transcripts and provided feedback. Upon reading the feedback, I met her and discussed with her the suggestions she recommended.

\subsubsection{Steps in Analysing the Interview Transcripts}

I used thematic analysis to analyse the data. The first step in thematic analysis was coding the transcripts. I then categorised the codes before combining them into themes. 


\section{Thematic analysis}

Thematic analysis is a qualitative analysis method designed to analyse almost any kind of qualitative data collection technique (Braun \& Clarke, 2013). Thematic analysis allows themes to emerge from either a 'bottom-up' approach where the researcher does not rely on any theories to identify information from the data (Braun \& Clarke, 2013). I used thematic analysis to build the themes for my study. I used thematic analysis separately for both the semistructured and stimulated recall interviews. This is because the semi-structured interviews focused on students' perceptions of learning in the EAP classroom while the stimulated recall focused on the tasks done in the classrooms. Firstly, I coded the data, then I categorised them and finally I combined them into themes.

\section{The process involved in coding the data}

Saldana (2013) states that coding is the process where researchers move from data collection to analysing what has been collected. Creswell (2014) views coding as a process where chunks of "text data or pictures" are placed in "categories and labelling those categories with a term" (p. 198). Miles, Huberman, and Saldana (2014) stipulate that coding goes beyond the technical mechanics of preparing data to include "deep reflection about, and thus, deep analysis and interpretation of the data meanings" (p. 73). Hence, as a researcher I realised coding is an important stage in analysing the qualitative data.

This research had twelve participants in total. Hence, I started to code one participant's semistructured interview transcript before continuing to the next participant's interview transcript. Saldana (2013) states that this technique influences the recoding phase of the earlier participant's data as well as the next data. Hence, I kept a codebook of the labels that I created across all three units (EAP classrooms). The labels that I created in the previous transcripts influenced, to a certain extent, my coding of the following transcripts.

A code is "a word or short phrase that symbolically assigns a summative, salient, essencecapturing, and/or evocative attribute for a portion of language-based or visual data" (Saldana, 2013, p. 3). In a similar vein, Miles et al. (2014) classified codes as "labels that assign symbolic meaning to the descriptive or inferential information compiled during a study" (p. 71). The data transcripts in this research were coded using several stages. I started with pre-coding the data transcripts. I highlighted some of the interview excerpts that I found interesting and made short notes on the transcripts. I then reread the transcripts and started labelling them. Words, phrases and sentences (Johnson \& Christensen, 2014; Saldana, 2013) in the interview transcripts were coded interchangeably based on the intensity of the information provided in the data. 
I determined a coding scheme for coding the interview transcripts. Two cycles of coding were used in this study. I used initial coding and process coding to code the data. Focused coding was used in the second cycle. Initial coding is used to see data as it is without any preconceived ideas from researchers (Charmaz, 2014). Similarly, I used initial coding to code segments of the data. I read through the transcripts, line-by-line, with an open mind while coding them. I also used process coding concurrently with initial coding. Process coding using gerunds was employed in this study to indicate actions taking place (Saldana, 2013). In my study, the participants were responding to tasks given in the EAP classrooms as well as thinking about their learning of academic English. Both of these instances show actions being done. A second cycle of coding was used as there were many codes. I employed focused coding to determine the categories. Below is a sample of how the codes were combined into categories. NVivo version 11, a Computer Assisted Qualitative Data Analysis software, was used to organise and store the codes.

\section{Category: Responding to reading tasks in the EAP classroom}

Upon coding the codes in NVivo 11, I read through the excerpts under individual codes. I decided to do this because I wanted to ensure the participants were speaking about the reading tasks such as the reading process they employed, how they worked on accomplishing it, and their thoughts while they responded to the tasks. Once I had worked out the codes that went together, I created sub-categories. I created a mind map in order to have a visual representation of the codes that were placed under the category (Appendix $\mathrm{P}$ ). I discussed the rationale for placing the codes into the said category with my supervisors. The table below shows an example of the codes and the category of unit 3.

Table 4. Codes and category of unit 3

\begin{tabular}{|c|c|}
\hline Codes & Category \\
\hline $\begin{array}{l}\text { 1. Attempting to employ knowledge learnt } \\
\text { 2. Learning from mistakes } \\
\text { 3. Overcoming learning problems } \\
\text { 4. Participating in class } \\
\text { 5. Willing to practise language }\end{array}$ & Making efforts to learn \\
\hline
\end{tabular}

\section{Finding patterns to form themes}

Themes are broader than the codes. Themes capture a broader issue that answers the research questions (Braun \& Clarke, 2013). Braun and Clarke stated that a theme "has a central organizing concept, which tells us something about the content of the data that's meaningful, something about how, and in what way that concept appears in the data" (p. 224). Different people may derive different themes from the same set of data (Braun \& Clarke, 2013). 
Hence, in coming up with the themes, it is helpful to find issues which a few codes are related to (Braun \& Clarke, 2013), where a pattern can be seen. Similarly, I looked for patterns in the categories. I then presented the themes to my supervisors who were my sounding boards. We discussed whether the themes could be further refined or should be kept.

\subsubsection{Steps in Analysing the Written Samples}

\section{a) The construction of an analytic tool for task 1}

\section{i) Describing and placing task 1 in the SOLO taxonomy}

Students were asked to read two passages; "Print Revolution" and "Cyberculture". They were then asked to find similarity in the texts. They were instructed to produce the findings in the form of a graphic organizer. The passages were introduced in a previous session where they had to annotate each paragraph and discuss the main idea of the passages with the lecturer.

The SOLO taxonomy was used in this study to determine the difficulty level of the task. This is because this taxonomy identifies the intended learning outcome of a course as well as "where students should be operating and for evaluating learning outcomes so that we can know at what level individual students actually are operating" (Biggs \& Tang, 2007, p .76). The different levels described in the SOLO taxonomy are used to categorise the reading task.

This task was placed at the relational level of the SOLO taxonomy. The task was designed to be completed in stages. This assists students to get a better understanding of how to respond to the task. A transition from the unistructural to relational level of the SOLO taxonomy can be seen through this reading task. The task required students to first read the two passages to refresh their memory of what the passages were about. They started skimming and scanning the passages. This is the unistructural level of the SOLO taxonomy. This constitutes a response to one aspect of the task where students only read the passages and form an idea of what the passages are about. Reading the articles first seemed to be a general strategy that all the participants employed. Next, the students were required to extract 'effects' presented in the passages. They were then asked to compare similar effects in both passages. This falls in the multistructural level where information is taken from two sources. Finally, the students were required to make the connection between the two sources. This is at the relational level. Table 6 indicates the stages that the participants went through to accomplish the task.

Table 5. Transition displayed by students in responding to task 1

\begin{tabular}{|l|ll|}
\hline Unistructural & - $\begin{array}{l}\text { The students started reading both the passages and form an } \\
\text { idea of what the passages are about }\end{array}$ \\
\hline Multistructural & $\bullet \quad$ They then extracted the information found in the texts \\
\hline
\end{tabular}




\begin{tabular}{|l|l|}
\hline & $\bullet \quad$ Students compared the two passages to find similar effects \\
\hline Relational & $\begin{array}{l}\text { Students brought together similar information from the two } \\
\text { passages }\end{array}$ \\
\hline
\end{tabular}

The lecturer instructed the students to produce their findings in the form of a graphic organizer. Below I describe the construction of the analytic tool.

\section{ii) Constructing the criteria for task 1}

The sources used to construct the rubrics for task 1 are from Hook and Mills (2012), McPhan (2008) and Biggs and Collis (1982). The analytic tool was divided into three categories of the SOLO taxonomy, namely unistructural, multistructural, and relational. Based on the participants' written work, there were no prestructural responses evident. Hence, the prestructural category was not included in the analytic tool. The extended abstract category was not included as well because the overall task was placed on the relational level. Hence, the responses from the participants were expected to reach the relational level of the SOLO taxonomy. Table 7 shows the criteria for task 1 .

Biggs and Collis (1982) stated that students at the unistructural level would be able to accomplish one aspect of the task. Using the descriptor from Biggs and Collis (1982) as the basis, the unistuctural level was designed. The response at this level shows that a theme is formed upon reading the articles.

Students at the multistructural level are able to do more than one aspect but are unable to connect these aspects (Biggs \& Collis, 1982). The criteria for this level show that ideas are expanded from the theme. These ideas are grouped together but there is no connection made between them.

At the relational level, Biggs and Collis (1982) stated that the students are able to bring the aspects identified together and discuss the connections between them. The rubrics for the relational level show that there is evidence of why and how the links are made between the two articles. The responses would show why there are links between the articles and how they are linked in terms of the similarity in effects of the two articles.

Table 6. Criteria for compare and contrast task

\begin{tabular}{|l|l|l|}
\hline Levels of SOLO & $\begin{array}{c}\text { Biggs and Collis (1982) description of } \\
\text { SOLO }\end{array}$ & \multicolumn{1}{c|}{ Description of criteria } \\
\hline Unistructural & $\begin{array}{l}\text { Can generalise only in terms of one } \\
\text { aspect }\end{array}$ & $\begin{array}{l}\text { The student identifies one } \\
\text { relevant similarity (Hook \& } \\
\text { Mills, 2012) }\end{array}$ \\
& $\begin{array}{l}\text { A number of independent } \\
\text { explanations are made from the } \\
\text { theme (McPhan, 2008) }\end{array}$ \\
\hline
\end{tabular}




\begin{tabular}{|c|c|c|}
\hline Multistructural & $\begin{array}{l}\text { Can generalise only in terms of a few } \\
\text { limited and independent aspects }\end{array}$ & $\begin{array}{l}\text { - The student identifies several } \\
\text { relevant similarities (Hook \& } \\
\text { Mills, 2012) } \\
\text { - These ideas are linked within } \\
\text { the branch (McPhan, 2008) }\end{array}$ \\
\hline Relational & $\begin{array}{l}\text { Can generalise within given or } \\
\text { experienced context using related } \\
\text { aspects }\end{array}$ & $\begin{array}{l}\text { - There are explanations of why } \\
\text { the ideas are relevant to the } \\
\text { whole (Hook \& Mills, 2012) } \\
\text { The outcome shows that the } \\
\text { student is able to see the } \\
\text { connection between both the } \\
\text { articles (McPhan, 2008) }\end{array}$ \\
\hline
\end{tabular}

\section{b) The construction of an analytic tool for task 2}

\section{i) Describing and placing task 2 on the SOLO taxonomy}

Task 2 required students to write a summary on the effects of "Print Revolution" and "Cyberculture". Students read both the articles and extracted information from the articles. Next, they compared the information presented in both the articles. Finally, they wrote a summary stating the similarities and the differences of effects in "Print Revolution" and "Cyberculture".

Students responded to tasks based on the requirements of a specific task. Hence, it is important to determine the outcome of the task and what is expected from the students at the end of the task. The requirement for task 2 was that students had to write a summary on the effects mentioned in the two articles. The descriptors in the SOLO taxonomy show "being able to summarize" falls under the relational category. The relational level indicates that the assessment requires students to be able to analyse the information as well as explain it. The task required students to bring information from two articles. The task also required them to organize the information and write a summary of the information collected.

Students started the task from a lower level before moving to a higher level of the SOLO taxonomy. They started from the unistructural level and moved to the relational level. Table 8 gives the summary of the transition made by students pertaining to the reading task that they did in the EAP class. Stimulated recall interviews were used to identify the process of each individual student in doing the reading task. This helped the researcher to identify students' approaches to learning as well as the transition from one level of the SOLO taxonomy to the other level.

Table 7. Transition displayed by students in responding to the task

\begin{tabular}{|l|l|}
\hline Unistructural & The students started reading to identify information in both texts. \\
\hline Multistructural & They were then listing and outlining information found in the texts. \\
\hline
\end{tabular}




\begin{tabular}{|l|l|}
\hline Relational & $\begin{array}{l}\text { Students had combined } 2 \text { articles to produce a compare- } \\
\text { contrast diagram on the effects of Print Revolution and } \\
\text { Cyberculture to help them write the summary. } \\
\text { This task needs close examination of } 2 \text { texts, to compare and } \\
\text { contrast and organise the information. }\end{array}$ \\
\hline Extended abstract $\left(^{*}\right)$ & Nil \\
\hline
\end{tabular}

\section{ii) Constructing criteria for Task 2}

The descriptors for the criteria for task 2 were obtained from Biggs and Collis (1982), Biggs and Tang (2011) and Walker (2012). Table 9 shows examples of verbs used by educators to create intended learning outcomes for courses, programmes and assessments (Biggs \& Tang, 2011). Prestructural is not included in the table as students are said to miss the points at this level of the taxonomy. The verbs from Table 9 were used to devise part of the rubrics for summary writing. Only three levels were used to evaluate the rubrics for the summary writing from the five levels of the SOLO taxonomy. This is because the summary writing task is placed on the relational level. The outcome of the task depends on the level at which the task is placed. Hence, the extended abstract level was not included in the rubrics.

Table 8. Verbs used for intended learning outcomes from the SOLO taxonomy

\begin{tabular}{|l|l|}
\hline Prestructural & Nil \\
\hline Unistructural & $\begin{array}{l}\text { Memorise, identify, recognise, count, define, draw, find, label, match, } \\
\text { name, quote, recall, recite, order, tell, write, imitate }\end{array}$ \\
\hline Multistructural & $\begin{array}{l}\text { Classify, describe, list, report, discuss, illustrate, select, narrate, } \\
\text { compute, sequence, outline, separate }\end{array}$ \\
\hline Relational & $\begin{array}{l}\text { Apply, integrate, analyse, explain, predict, conclude, summarise } \\
\text { (précis), review, argue, transfer, make a plan, characterise, compare, } \\
\text { contrast, differentiate, organise, debate, make a case, construct, } \\
\text { review and rewrite, examine, translate, paraphrase, solve a problem }\end{array}$ \\
\hline Extended Abstract & $\begin{array}{l}\text { Theorise, hypothesise, generalise, reflect, generate, create, compose, } \\
\text { invent, originate, prove from first principles, make an original case, } \\
\text { solve from first principles }\end{array}$ \\
\hline
\end{tabular}

Adapted from Biggs \& Tang (2007). Teaching for quality learning at university: what student does ( $3^{\text {rd }}$ ed., p. 80). New York: Open University Press.

The rubrics for summary writing are divided into two parts: content and organisation, and language use. This is because participants' responses do not fall neatly on a particular level and may differ across the levels. A participant's writing may have clear content but with many grammatical errors. This then makes placing the response on a similar level difficult. Furthermore, the participants are ESL so their proficiency in the language influences their ability to express themselves. ESL students face issues when they have an idea but find themselves unable to relay it due to their low level of proficiency in their additional language. 


\section{a) Content and organisation}

Three levels of the SOLO taxonomy were constructed based on the requirements of the task. According to Biggs and Collis (1982), students' responses to the task at the unistructural level are inconsistent. They continue indicating that students mostly give "the first relevant dimension that comes to mind, but at least it is relevant" (p. 28). Biggs and Collis (1982) state that students are able to provide one relevant part of the task that they are engaging in. Similarly, the rubrics for the summary writing were constructed based on the description provided by Biggs and Collis. The content for summary writing at the unistructural level indicates that the student is able to include some relevant information and some irrelevant information from the reading passages. The organisation for this level indicates that the student's written work has some organisation such as cohesion but there are some distorted parts evident in the writing.

Biggs and Collis (1982) stated that the Multistructural level response "faithfully marshals several of the relevant features but fails to link them together" (p. 27). Students at the multistructural level "see the trees but not the wood. Seeing trees is a necessary preliminary to adequate understanding, but it should not be interpreted as comprehending the wood" (Biggs \& Tang, 2011, p. 89). This then indicates that the response shows that the student is beginning to understand but it is still at a surface level and not much discussion and analysis are evident. Thus, the rubrics for the current study were built based on these descriptions. The content for this level indicates that most of the information from two articles was extracted and an attempt was made to elaborate the information. The organisation, on the other hand, shows that the summary is written with a clear organisation but with some minor errors. Compared to the previous level, in the multistructural level the summary is cohesively and coherently written but students make some errors. However, the ideas at this level are much clearer.

Responses at the relational level portray a much more thorough explanation of the concepts as well as integration between the concepts (Biggs \& Collis, 1982). However, the responses are limited to students' existing knowledge and no generalisation occurs at this level (Biggs \& Collis, 1982). Biggs and Tang (2011) explained that the responses at this level show:

the trees have become the wood, a qualitative change in learning and understanding, has occurred. It is no longer a matter of listing facts and details. This is the first level at which 'understanding' in an academically relevant sense may appropriately be used. (p. 89)

The content at the relational level indicates that all pertinent information from two articles is included in the writing of the summary. Students should be able to bring the information from the two articles together and discuss them. In terms of the organisation, the ideas are cohesively and coherently written without any mistakes. The readers will find the writing easy 
to follow and the writer's intention is clear. Table 10 indicates the rubrics for content and organisation for summary writing.

Table 9. Rubrics for content and organisation in summary writing

\begin{tabular}{|c|c|c|}
\hline \multirow{2}{*}{$\begin{array}{l}\text { Description of } \\
\text { SOLO by Biggs and } \\
\text { Collis (1982) }\end{array}$} & \multicolumn{2}{|c|}{ Description for Summary Writing } \\
\hline & Content & Organisation \\
\hline $\begin{array}{l}\text { Unistructural } \\
\text { Can generalise only } \\
\text { in terms of one } \\
\text { aspect }\end{array}$ & $\begin{array}{l}\text { - Student recognises the topic } \\
\text { but struggles to identify key } \\
\text { information from both texts } \\
\text { (Biggs \& Tang, 2007) } \\
\text { - Student lists some important } \\
\text { information in the text and } \\
\text { some irrelevant detail } \\
\text { (Walker, 2012) }\end{array}$ & $\begin{array}{l}\text { - The writing has some organisation } \\
\text { but becomes disorganised in parts } \\
\text { (Walker, 2012) }\end{array}$ \\
\hline $\begin{array}{l}\text { Multistructural } \\
\text { Can generalise only } \\
\text { in terms of a few } \\
\text { limited and } \\
\text { independent aspects }\end{array}$ & $\begin{array}{l}\text { - Student lists most of the } \\
\text { important information from } \\
\text { both the texts and manages } \\
\text { to somewhat elaborate it } \\
\text { (Walker, 2012) }\end{array}$ & $\begin{array}{l}\text { The main idea and supporting } \\
\text { ideas were discussed clearly } \\
\text { (Biggs \& Tang, 2007) }\end{array}$ \\
\hline $\begin{array}{l}\text { Relational } \\
\text { Induction. Can } \\
\text { generalise within } \\
\text { given or experienced } \\
\text { context using related } \\
\text { aspects }\end{array}$ & $\begin{array}{l}\text { - Student includes all the } \\
\text { important information in the } \\
\text { texts and elaborated it with } \\
\text { coherent textual information } \\
\text { (Walker, 2012) } \\
\text { - There is clear evidence of } \\
\text { analyses of two articles by } \\
\text { comparing and contrasting } \\
\text { information from both the } \\
\text { articles (Biggs \& Tang, 2007) }\end{array}$ & $\begin{array}{l}\text { The summary is extremely clear in } \\
\text { organisation, so the reader can } \\
\text { easily follow the line of thought } \\
\text { (Walker, 2012) } \\
\text { - The main idea and supporting } \\
\text { ideas were discussed clearly } \\
\text { (Biggs \& Tang, 2007) }\end{array}$ \\
\hline
\end{tabular}

b) Language features

Language features were separated from the main rubric because the participants are L2 learners enrolled in the EAP course. Being non-native speakers of English, a huge proportion of ESL learners in Malaysia tend to face difficulties in comprehending the language (Hiew, 2012; Maarof \& Munusamy, 2015). Students face difficulties in expressing themselves due to their limited vocabulary (Nambiar, 2007) which is transferred to their writing as well. Thus, language features are seen as a separate rubric because there are instances where the students are able to understand the information they read but are not able to relay it in their writing. This then produces grammatically incorrect sentences.

The unistructural level of the rubric shows the existence of some glaring grammatical errors and some fragments in the sentences. At the multistructural level, there are some minor grammar errors that exist in the writing. Lastly, at the relational level students have a clearer writing style as well as the ability to paraphrase the sentences. Placing 'paraphrase' on the multistructural or relational level depends on a student's ability to just replace a few words of the original source or think of changing the sentence while maintaining the meaning of the original source (Biggs \& Tang, 2007). Hence, paraphrase is placed on the relational level of 
the taxonomy because being able to paraphrase in a summary is equally important. Table 11 shows the rubrics for language use for summary writing.

Table 10. Rubrics for language use in summary writing

\begin{tabular}{|c|c|}
\hline \multirow{2}{*}{$\begin{array}{c}\text { Description of SOLO by Biggs and } \\
\text { Collis (1982) }\end{array}$} & Description for Summary Writing \\
\hline & Use clear language \\
\hline $\begin{array}{l}\text { Unistructural } \\
\text { Can generalise only in terms of one } \\
\text { aspect }\end{array}$ & $\begin{array}{l}\text { - The summary has some clear language and some } \\
\text { fragments (Walker, 2012) making it difficult to } \\
\text { understand }\end{array}$ \\
\hline $\begin{array}{l}\text { Multistructural } \\
\text { Can generalise only in terms of a few } \\
\text { limited and independent aspects }\end{array}$ & $\begin{array}{l}\text { - The summary has some clear language and some } \\
\text { appropriate language use (Walker, 2012) }\end{array}$ \\
\hline $\begin{array}{l}\text { Relational } \\
\text { Induction. Can generalise within } \\
\text { given or experienced context using } \\
\text { related aspects }\end{array}$ & $\begin{array}{l}\text { - The summary is clearly written without any grammar } \\
\text { issues (Walker, 2012) } \\
\text { - Being able to paraphrase when writing the summary } \\
\text { (Biggs \& Tang, 2007) (lecturer's requirement) }\end{array}$ \\
\hline
\end{tabular}

\section{c) The construction of an analytic tool for task 3}

\section{i) Describing and placing task 3 on the SOLO taxonomy}

The participants were instructed to read a passage titled 'Intelligence: heredity versus environment'. The students were then asked to annotate the passage. The lecturer instructed the students to annotate each paragraph in the passage.

The SOLO taxonomy is used in this study to assess the difficulty level of the task. This task could be placed on the multistructural level of the SOLO taxonomy. This is because the task requires students to read and annotate each paragraph by summarising it. How the students managed to summarise the paragraphs will be discussed later in the findings chapter.

\section{ii) Constructing criteria for task 3}

Similar to Task 1 and Task 2, criteria for Task 3 were created from various sources. Sources such as Biggs and Tang (2007), Porter-O'Donnell (2004), Feito and Donahue (2008) and Biggs and Collis (1982) were used to create the criteria for Task 3.

Verbs from the SOLO taxonomy were used to assist in building the criteria to evaluate the annotation task. Table 9 shows the verbs used for intended learning outcomes from the SOLO taxonomy. Moreover, the descriptions that explain the different levels of the SOLO taxonomy adapted from Biggs and Collis (1982) were also used. The explanation used by PorterO'Donnell (2004) and Feito and Donahue (2008) to teach annotation was also used to build the criteria.

The descriptions given by Biggs and Collis (1982) were used as the foundation to create the criteria to evaluate the annotation task. Table 12 shows the criteria for the annotation task. The 
unistructural level of the SOLO taxonomy indicates that the student is able to complete one aspect of a task. Using this description, I identified the descriptor used by Feito and Donahue (2008) in their study. This descriptor shows that the student is able to extract the information from the reading passage without summarising it.

The multistructural level shows that students can identify a few aspects of the task. The criteria to evaluate the annotation task were created using this description. The criteria at this level show that the student is not only able to extract pertinent information but also summarise the information to get the main idea.

Table 11. Criteria for the annotation task

\begin{tabular}{|l|l|}
\hline $\begin{array}{l}\text { Description of SOLO by Biggs and Collis } \\
\text { (1982) }\end{array}$ & \multicolumn{1}{c|}{ Description of criteria } \\
\hline $\begin{array}{l}\text { Unistructural } \\
\text { Can generalise only in terms of one aspect }\end{array}$ & $\begin{array}{l}\text { Readers identify what they read from the article (Feito } \\
\text { \& Donahue, 2008) }\end{array}$ \\
\hline $\begin{array}{l}\text { Multistructural } \\
\begin{array}{l}\text { Can generalise only in terms of a few limited } \\
\text { and independent aspects }\end{array}\end{array}$ & $\begin{array}{l}\text { Summarise the information (Porter-O'Donnell, 2004) } \\
\text { and get the main idea }\end{array}$ \\
\hline
\end{tabular}

I discussed with my supervisors the criteria that I constructed. I then proceeded to evaluate the participants' written samples from the three units. Comments were written on transcripts to assist the evaluation and to place the responses on the appropriate levels of the SOLO taxonomy based on the criteria constructed.

\subsubsection{Trustworthiness}

In doing a qualitative study, it is important to ensure there is trustworthiness in the findings and in the interpretation of what is found (Creswell, 2014). As a novice researcher as well as someone with teaching experience, I had to remind myself of the danger of being influenced by my experience. I implemented the features of trustworthiness specified by Lincoln and Guba (1985). Lincoln and Guba stipulated four features of trustworthiness - credibility, transferability, dependability, and confirmability - that qualitative researchers are recommended to establish. They stated that by ensuring the existence of trustworthiness, qualitative researchers are able to produce a study that is more reliable (Lincoln \& Guba, 1985). Further, Lincoln and Guba also stated that trustworthiness shifts from putting too much attention on the researcher to focusing on making the findings "confirmable" (Lincoln \& Guba, 1985, p. 300).

\subsubsection{Credibility}

Lincoln and Guba (1985) stated that methods such as triangulation and member checking assist in producing a more credible finding. Triangulation is a method that researchers often use to validate the information acquired from different people, different data sources or data 
collection techniques (Creswell, 2014). Triangulation is used to view the topic under investigation from at least two angles (Flick, 2007). In this study, I triangulated two data collection techniques: documents (participants' written samples) and interviews (stimulatedrecall interviews). The participants' written samples and the audio recording transcripts (recorded during the discussion of tasks) were triangulated with the stimulated recall interviews. First, I used the written samples and the participants' audio recording transcripts to understand the steps they took in responding to the reading tasks. Then, I used the participants' written samples and audio recording transcripts during stimulated recall interview sessions to inquire further into their responses to the reading tasks. The methodological triangulation was done according to each participant as a unit in this study. This gave me a better understanding of the interaction between the participants and their responses to the reading tasks.

Another important strategy that is used to ensure credibility is member checking (Lincoln \& Guba, 1985). Member checking is a good way to avoid misinterpretation because the participants get to clarify whether the researcher has misinterpreted what was said (Johnson \& Christensen, 2014). I emailed the interview transcripts to all twelve participants to get their feedback on the accuracy of the information. To ensure the participants' privacy, I created a password protected document which I emailed them and sent the password through the WhatsApp application. I allowed approximately three weeks for the participants to read and reply by email or the WhatsApp application with their opinion of the transcripts. In the email that I wrote, I stated that the participants were free to make any changes to the interview transcripts if they realised that I had misinterpreted their opinion. I received all twelve participants' responses via the WhatsApp application.

\subsubsection{Transferability}

Lincoln and Guba (1985) state that qualitative researchers, unlike quantitative researchers, cannot make definite and consistent claims that the findings can be generalised. One of the reasons for this is because of the different sampling methods used between quantitative and qualitative studies. One of the ways to increase the validity of qualitative studies is to produce a thick and rich description of the study. A thick and rich description in qualitative studies enables future researchers to relate the findings to the context of the study (Carlson, 2010; Creswell, 2009). I have provided a detailed description of the data collection and data analysis methods of this study. Further, I have also given substantial information in the findings chapter that will assist the readers to have a better understanding of how I derived the conclusions of my study. 


\subsubsection{Dependability}

One strategy used to show dependability is auditing (Lincoln \& Guba, 1985). I used auditors comprising two supervisors from my supervisory committee to assess the research project. I discussed my decision-making process with my supervisors. I usually discussed the rationale of my analysis with my supervisors and the steps I took to reach the rationale. I had discussions with my $\mathrm{PhD}$ colleagues to gain more feedback before refining my work again with my supervisors. These measures assisted me to refine the analysis of my data.

\subsubsection{Confirmability}

In qualitative research, practising reflexivity can minimise the predisposition to be influenced by prior experience and assumptions (Carlson, 2010; Lincoln \& Guba, 1985). Throughout my research study, I kept a reflexive journal where I recorded my decision-making process, how I derived the analysis of my data, what influenced my decision, and the challenges that I went through. As mentioned in the dependability section, I discussed the analysis process with my supervisors and colleagues. This strategy enabled me to understand and identify the influence of my background and beliefs on my interpretation of my data.

\subsection{Ethical Concerns}

Johnson and Christensen (2014) state that research ethics "are [a] guiding set of principles developed to assist researchers in conducting ethical studies" (p. 127). Hence, it is crucial to take into consideration ethical concerns while conducting research (Johnson \& Christensen, 2014). I applied for ethics approval from the human ethics committee at Victoria University of Wellington prior to collecting the data (Appendix A). I described the aim of my research, the data collection methods, and the analysis method of the findings as well as how the participants would be protected and not caused any harm.

I also applied for approval from the Economic Planning Unit at The Prime Minister's Department of Malaysia. I followed a similar process with the human ethics committee at Victoria University of Wellington. I was then required to visit the Economic Planning Unit to collect the approval letter (Appendix B) and the identity card which indicated that I was a researcher. I also used pseudonyms to protect the participants' identities in my study.

\subsection{Summary of the Chapter}

This chapter described the methodology used for this research study. Because I used a social constructivism paradigm, rich qualitative data from different sources were used. The phenomenon of the study looked at how learning takes place in the EAP course. The study is bounded within the three EAP classrooms. This then has enabled me to explore the participants' views and experiences of learning in the academic English lessons and their engagement with the tasks in the three EAP classrooms situated within the public institution. 
I also described the data collection procedure and the data analysis procedure. The different data collection techniques such as classroom observations, interviews and written works used in this study assisted in collecting in-depth information about the students' experiences and thoughts. Further, these data collection techniques provided credible research findings as the information collected was triangulated from different sources. The thematic analysis used for the interviews as well as the analytic tool used for the written work allowed high-level themes to emerge supported by detailed findings such as the nature of the understanding of each participant in doing the task.

Finally, I described the strategies used to achieve the trustworthiness of this study as well as how the research ethics were upheld. 
This page is intentionally left blank 


\section{CHAPTER 5 \\ FINDINGS OF THREE UNITS OF ANALYSIS}

This chapter presents the findings of three units from a public university in Malaysia. The findings show tertiary students' responses to learning English in the EAP classroom. Each unit consists of four tertiary students. These units are bounded and are unique as participants were exposed to different reading tasks and teaching instructions. The data showed that participants viewed learning English in the EAP classroom as a combination of reading skills and the learning of English in general. The findings are presented in three sections: Unit 1, Unit 2 and Unit 3.

\subsection{Unit 1}

Brief description on setting and demographic details of participants

Data for Unit 1 were collected from an EAP classroom in a public university. The class focused on reading skills in an academic context. The lessons were conducted twice a week. The participants were enrolled in an engineering programme, majoring in the Electrical division of the engineering degree. There were four participants in this unit: three Malay participants and one Indian participant. Three male students - Affiq, Halim, and Immanuel - and one female student - Syamira (all pseudonyms) volunteered to participate; they were all 19 or 20 years old.

This section of the chapter is divided into three parts: the responses to overall learning in the EAP classroom, findings from participants' responses to a specific reading task done in the EAP classroom, and the summary of Unit 1 .

\subsubsection{Responses to Learning in the EAP Classroom}

Five themes were generated based on the analysis: having multiple purposes for learning, engaging with the content, acknowledging the environment beyond the EAP classroom, feeling anxious about learning English, and making an effort to learn English. The themes as well as the sub-themes for Unit 1 will be discussed in detail. Table 13 lists the themes and sub-themes for Unit 1. 
Table 12. Themes and sub-themes for Unit 1

\begin{tabular}{|c|c|c|c|c|}
\hline \multicolumn{5}{|c|}{ Themes/ sub-themes } \\
\hline $\begin{array}{l}\text { Having multiple } \\
\text { purposes for } \\
\text { learning English }\end{array}$ & $\begin{array}{l}\text { Engaging with } \\
\text { the content }\end{array}$ & $\begin{array}{l}\text { Acknowledging } \\
\text { the environment } \\
\text { beyond the EAP } \\
\text { classroom }\end{array}$ & $\begin{array}{l}\text { Feeling anxious } \\
\text { about learning } \\
\text { English }\end{array}$ & $\begin{array}{l}\text { Making an effort } \\
\text { in learning } \\
\text { English }\end{array}$ \\
\hline $\begin{array}{l}\text { - Having a } \\
\text { personal liking } \\
\text { of English } \\
\text { - } \quad \text { Learning } \\
\text { through English } \\
\text { at the university } \\
\text { - Learning } \\
\text { English for } \\
\text { global } \\
\text { communication } \\
\text { - Learning for } \\
\text { future careers } \\
\text { - Having to do } \\
\text { EAP }\end{array}$ & & $\begin{array}{l}\text { Transferring } \\
\text { into other } \\
\text { subjects } \\
\text { - Having } \\
\text { perceptions } \\
\text { of the social } \\
\text { environment }\end{array}$ & $\begin{array}{l}\text { - Worrying } \\
\text { about the } \\
\text { level of } \\
\text { English } \\
\text { proficiency } \\
\text { - Feeling tired } \\
\text { during } \\
\text { lessons }\end{array}$ & 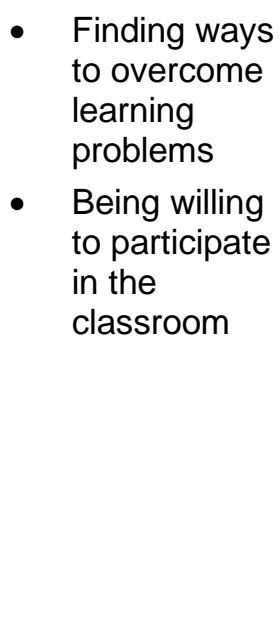 \\
\hline
\end{tabular}

a) Having multiple purposes for learning English

Participants claimed to have multiple purposes for learning English.

\section{i) Having a personal liking of English}

Immanuel mentioned that he has always liked to learn English. He claimed that he had been interacting in English since he was young:

Because English is the most, is the ... is the language that I speak the most, so when I go to the English class, I feel comfortable in reading in English.

[Semi-structured interview]

He further added:

Yes, I love to learn English.

[Stimulated recall interview]

Because the participant in the study found English was his strongest language, it seemed to be naturally reinforcing for him to have the opportunity to practise and develop his English in a more academic setting.

\section{ii) Learning through English at the university}

The participants shared the pragmatic realities of the English language as a medium for learning at the university. For Affiq, reading course textbooks was a necessity: 
I'm an engineering student. Most of the books are in English. So if we can't read English, we don't understand the books. ... So we need to try to understand the words.

[Semi-structured interview]

Immanuel concurred with this:

If you don't understand English, you won't understand the text. You won't understand the content.

[Semi-structured interview]

Syamira noted the significance of not learning in Bahasa Malaysia for Engineering:

Oh, my course needs English [refers to Engineering course]. Everything is English and not like in Bahasa Malaysia.

[Semi-structured interview]

The participants seemed to accept that if the course materials are mostly in English, they have to be able to understand the language in order to be able to make sense of the content.

\section{iii) Learning English for global communication}

A wider view that learning English could ultimately help the participants to communicate with people also emerged. Some of the participants viewed the English language as a tool for global communication. Syamira claimed:

If in the university, we mostly, like we have friends from overseas. So, we have to speak in English. We have to learn English.

[Semi-structured interview]

Affiq saw an additional purpose for communicating more widely in English as enabling him to share knowledge of Malaysia:

Communication, and maybe, to spread some information. Just like what happened in Malaysia. If, uh, history in Malaysia. We want to let everyone know about Malaysia. So we need to tell other people in English. We can explain to them in Malay (Bahasa Malaysia), but they doesn't [don't] understand. So, that way, English, is uh, important.

[Semi-structured interview]

Both Affiq and Syamira noted that they realised that being able to speak in English helps them to interact with foreigners.

Immanuel focused more on the potential for English to allow him to communicate with local people. He explained he uses English to communicate because of the existence of various races in Malaysia: 
English is a language that all of us know how speak. So even though we are from different race[s], the only language that we can work, eh, speak in English. So, in a positive way, English is very important to us.

[Semi-structured interview]

Syamira found that being able to communicate in English with foreigners boosted her confidence in using English:

When we are able to speak in English, the level of confidence is higher than normal.

[Semi-structured interview]

Participants also found that learning English is important because it helps them to interact through social media:

Even in ... Facebook, WhatsApp or what, it's all, texting, everything is in English.

[Semi-structured interview]

So, while the EAP course was seen as an obligation for the degree, these participants also had a positive feeling about some of the real-world purposes for learning English, that it was for communication either locally or with foreigners.

\section{iv) Learning for future careers}

The participants also conveyed a strong sense of the pragmatic need to learn English to get a job in the future. Affiq noted that he was aware that future employers expect graduates to be proficient in the English language:

The situation at present is, it is quite difficult for graduates to get jobs. One of the compulsory things [that employers look for] is if we can communicate really well in English and read well in English. Because it is one of the basic things that all graduates need, reading in English. So, it really helps us. So, like when we are in a job interview, we are usually asked to speak in English not Malay (Bahasa Malaysia). Normally.

[Semi-structured interview]

Immanuel agreed that he needs English in order to do work related projects:

I think for future career, we have to keep on doing more, will have more projects. And assignments. That time I will use these skills.

[Semi-structured interview]

More imminently, Syamira noted that she needs English to find out information about her future career:

If I want to know about my future career or any input, I have to read them in English.

[Semi-structured interview] 
So, what emerged was a clear feeling of the need to be able to use English effectively in the workplace. Because the participants recognised the expectations of future employers in terms of the English language, they conveyed an understanding of the importance of being proficient in the language.

\section{v) Having to do EAP}

For the participants, the EAP course was a compulsory subject that they had to take as part of their Bachelor degree programme. Affiq stated:

It is a syllabus for us to complete our degree. Compulsory subject.

[Semi-structured interview]

Immanuel claimed:

No. It's in the course spec. Compulsory.

[Semi-structured interview]

All the participants agreed that in order for them to graduate they had to have completed the EAP course. That the participants felt they did not have a choice whether to take the course came through quite strongly.

There were various reasons as to why the participants wanted to learn English. Their reasons did not match the reason for enrolling in the EAP course.

\section{b) Engaging with the content}

A strong feeling that the participants would prefer interesting and accessible content in the EAP classroom came through the data. The participants described the feeling that their interest in learning depended on the topics. Immanuel described the way a lack of understanding resulted in a lack of engagement:

Because the text. Because, it is something general you know. And then when we go sometimes, I don't understand. Then I keep on reading the same thing, I get bored.

[Semi-structured interview]

Affiq, on the other hand, had become interested in the content of one of the class reading tasks:

I love to read more about the capitalist people that uh, discriminated [against] other people so I find that even printing, the small things, small matter, they are trying to put printing into a business.

[Semi-structured interview] 
So, in different ways, both Immanuel and Affiq indicated that the topic of the reading materials was important to them and could motivate them or fail to motivate them to read.

Although Affiq had been interested in this topic, this was not always the case. As was the case for Immanuel, Affiq would lose interest when the content that was taught in the class did not meet his expectation and then he would find the learning boring:

Because, I, I don't have passion on [for] it.

[Semi-structured interview]

The result was much less effort made in the EAP classroom in comparison with other subjects. Affiq quantified this lack of effort in EAP:

In percent maybe 20. Compared to other subjects.

[Semi-structured interview] Halim too claimed that he made little effort in class. He also stated that he disliked reading in the EAP class and only reads because he is instructed to do so:

When the lecturer asks us to do things.

[Semi-structured interview]

Syamira too made little effort in the class because she found her timetable too hectic:

Honestly not much. Because of the time.

[Semi-structured interview]

There is a glimpse in these data of the possibility that some participants could be directly interested in the reading content of the EAP class. But it seems that this did not usually happen, and it resulted in low levels of engagement that some of these participants could directly compare with their level of engagement in other subjects.

\section{c) Acknowledging the environment beyond the EAP classroom}

Participants claimed that the educational environment and community play a vital role in learning and practising the language.

\section{i) Transferring into other subjects}

The participants described the difficulties of transferring the reading skills learnt in the EAP classroom to other subjects. Syamira said:

Not much reading in my other classes. More calculation. We don't really use it.

[Semi-structured interview] 
Affiq thought that the subjects that he took did not require reading skills:

No. Not really, because, like I said, I'm studying Electrical engineering, so my other subjects are mathematics, science, so it doesn't really help.

[Semi-structured interview]

Halim too found that the reading skills are not helpful:

Chemistry, it's memorizing. Memorize them exactly, it doesn't matter if you don't understand.

[Semi-structured interview]

Immanuel, on the other hand, found that he was able to use reading skills in one of the courses that he took that semester:

Let's say, in dynamics [course]. But Dynamics is in Malay (Bahasa Malaysia). ... Dynamics we have like history, on this year what happened so, [I] use the annotation [strategy], the timeline strategy I will use in dynamics ... So, I apply timeline in Dynamics.

[Semi-structured interview]

The engineering programme focused mostly on calculations which makes it hard for the participants to use the reading skills learnt in the EAP course.

\section{ii) Having perceptions of the social environment}

The perceptions of the community towards the practice of English emerged as a theme in the data. Affiq stated that one part of the community prefers to practise their native language:

Like Malays love to read Malay (Bahasa Malaysia) books, Chinese, read most of the Chinese books and same goes for Indians, they like to read Indian books.

[Semi-structured interview]

Syamira thought that being able to communicate in English:

Has level, status.

[Semi-structured interview]

Syamira seemed to believe that being able to communicate in English has a high status in the community.

Thus, a little of the tension between participants' own language background and English emerged through the data.

The participants in Unit 1 claimed that being out of the EAP environment influences their learning and practice of English. The participants did not find that the knowledge learnt in the 
EAP classroom was easily transferrable. Some were also conscious of the background tension; communities preferred to preserve their own native languages but at the same time the communities did realise the importance of English. This could make learning and practising English difficult in some situations when there was not much encouragement from the communities.

\section{d) Feeling anxious about learning English}

Participants also stated that they were anxious about practising the language.

\section{i) Worrying about the level of English proficiency}

Syamira shared that she felt comfortable speaking in Bahasa Malaysia, but she could feel inferior because of her inability to speak in English:

Because, most of my friends speak in English. So, when I'm unable to speak, I feel low, inferior.

[Semi-structured interview]

Halim more directly shared that he disliked English. This was most probably caused by his negative experience of learning English at school:

Just like ... because I'm weak in English since standard four. Very difficult to score. So, from English some words that are, I think ... certain thing is simple but for me it's difficult. So...

Halim added:

[Semi-structured interview]

I feel nothing. Because I don't like to speak in English .

[Semi-structured interview]

These negative feelings about lack of proficiency clearly continued to cause some participants feelings of discomfort when practising English in the EAP classroom.

\section{ii) Feeling tired during lessons}

Participants also mentioned that they felt tired during the lessons. Syamira stated:

The timetable is really packed on that day. We are like tired.

[Semi-structured interview]

Syamira claimed that she has classes continually without breaks. Based on my observation during the lessons, I noticed that the participants came late to the EAP class as they had another class prior to that.

Halim too added that he was: 
Sleepy. Because of the surroundings. It's cold, nice to sleep. Because on Tuesday, the 9-2... (Refers to his timetable: classes back to back).

[Semi-structured interview]

The packed schedule seems to contribute to a lack of focus in the class which in turn causes anxiety in learning.

So, there was an unfortunate compounding of anxiety in practising the language which was caused by a lack of proficiency in English and a busy schedule that affects concentration.

\section{e) Making an effort in learning English}

Despite some of the negative feelings generated by anxiety, tiredness and some possible lack of social support for learning English, participants still claimed to make an effort to learn it.

\section{i) Finding ways to overcome learning problems}

Some participants were able to describe ways they actively attempted to overcome some of the problems they had with learning. Affiq stated that he usually employs a trial and error method in learning:

I just do trial and error. But sometimes the word doesn't suit to describe. Doesn't solve the problem.

[Semi-structured interview]

Syamira described the perspective that learning English requires initiative:

Like do what the lecturer asks us to do. If we want to learn the language, we have to do what is necessary to improve our English language.

[Semi-structured interview]

Immanuel was able to describe the specific strategy that he uses to try to find the meaning of the words that he has difficulty understanding:

I search the net. I will start to write, I will take the simple one with the same meaning, but a simple word and write it down on the book.

[Semi-structured interview]

Syamira also seemed conscious that knowledge of vocabulary could be a barrier but was happy to take the less methodical approach of relying on her vocabulary knowledge from her wider reading:

If there are any difficult words I would roughly know the meaning, because I usually read at home and I'm too lazy to check in the dictionary.

[Semi-structured interview] 
The data give a little glimpse into the barriers that unknown vocabulary might present in text and the slightly haphazard, different approaches of two participants to this learning problem. It suggests participants try to resolve problems that arise in their own way.

\section{ii) Being willing to participate in the classroom}

Some participants shared that they try to participate in the class. Affiq stated:

I did contribute ideas from the annotation. I was giving the ideas.

[Semi-structured interview]

Halim mentioned he does:

Try ... when the lecturer asks what is it ... try to answer it.

[Semi-structured interview] Immanuel claimed that he participated by not only contributing ideas but also focusing in the lesson:

I do participate, but ... by discussing and concentrating in the lecture.

[Semi-structured interview]

I directly observed that the participants take the initiative to participate and engage in learning in the classroom.

The participants could be seen making an effort in various ways to learn English in the EAP classroom based on their discussion above.

\subsubsection{Responses to Specific Task}

\section{Analysis of a written task in the EAP classroom}

The four participants, Affiq, Halim, Immanuel and Syamira, participated in task 1. The class activities were usually done in pairs or in groups of three or four students. Task 1 was done in pairs. All four participants had read the passages before moving on to extract the information and finally construct the mind map. Affiq and Halim were in the same group and discussed the task together. I will first discuss Affiq's and Halim's responses to the task followed by Immanuel's and Syamira's. Stimulated recall interviews as well as audio recording during the discussions were used to acquire more details of how the participants accomplished the task.

\section{a) Affiq's and Halim's written work}

Both Affiq and Halim started the task by refreshing their memory of the passages. They read the passages again during the lesson to recollect what they knew about them. Figure 5 shows 
the mind map constructed by Affiq and Halim. Affiq and Halim listed the ideas for both 'Print Revolution' and 'Cyberculture' before selecting the ideas to form a mind map.

Figure 5. Affiq's and Halim's mind map on the similarity of effects

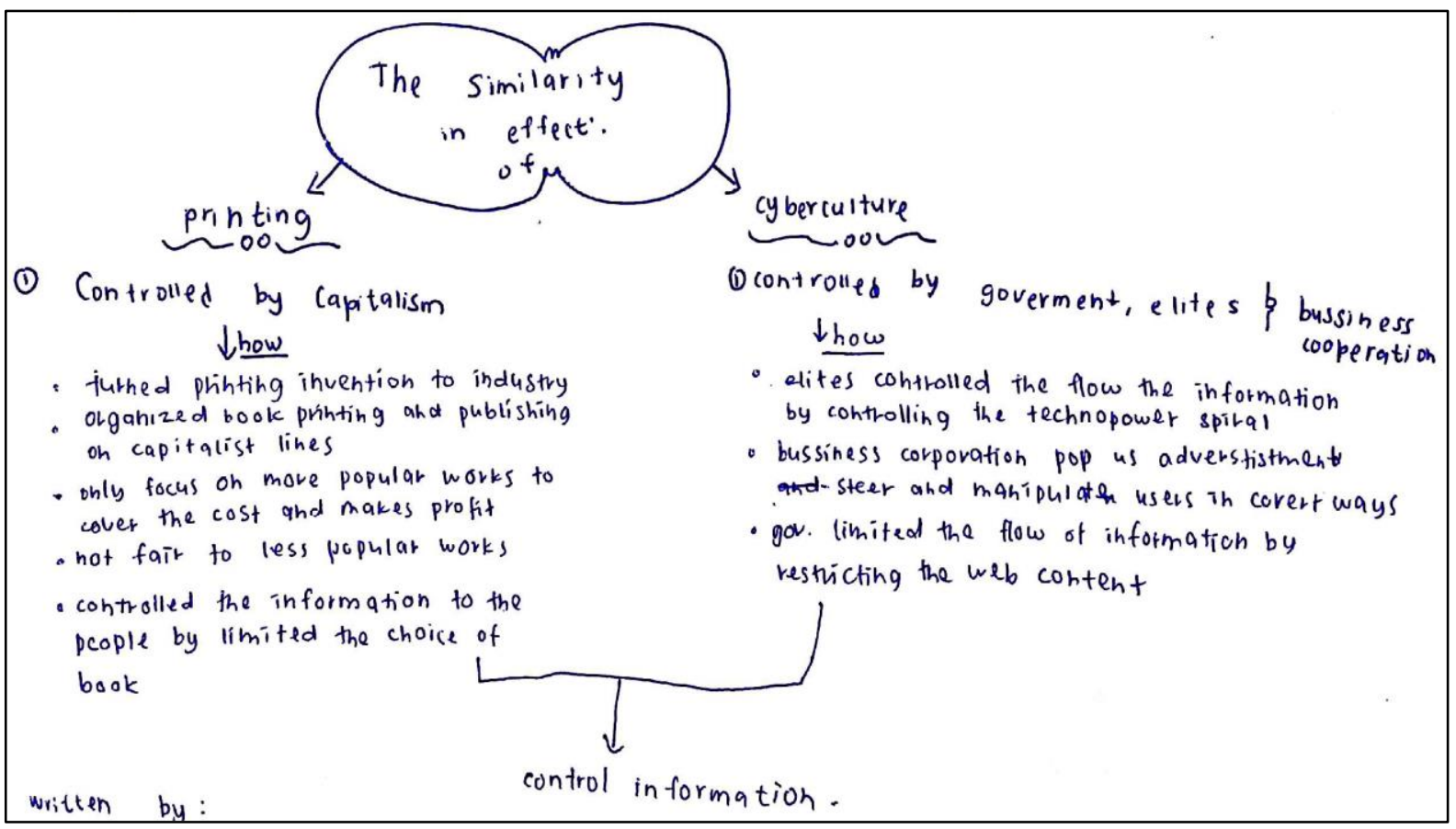

Table 14 provides the comments on Affiq's and Halim's mind map. These participants had managed to identify the theme and the sub-themes.

Table 13. Comments on Affiq's and Halim's mind map

- The theme as well as sub-themes were identified

- Explanations are given of how 'control' happens

- The similarities between these two passages are shown as well

- An attempt was made to show connections between the two passages.

The ideas were categorised into two main ideas, namely printing and cyberculture. The participants then created a sub-theme called controlled by capitalism and controlled by government, the elite and business corporations under the bigger ideas. They showed 'how' printing was controlled by capitalists. They used the same format for cyberculture. Affiq and Halim showed how cyberculture is controlled by government, elites and business corporations.

Affiq mentioned that he found doing the mind map difficult because of the need to shorten the information found in both the passages:

We need to short form the words. We need to find new words ... to replace the original words over here.

[Stimulated recall interview]

Affiq also mentioned that he found the task challenging: 
But to find the similarity, we need to read again. To look at the orientation. It was quite challenging. Quite challenging.

[Stimulated recall interview]

Both Halim and Affiq agreed that responding to the task was easier because of the annotation that they had done earlier for both the passages. Halim stated:

Easy if we have the annotation. If not, it will be bad.

[Stimulated recall interview]

The theme that the participants identified was 'control'. A repetition of the word 'control' could be seen on the mind map. For example, 'controlled by capitalism', 'controlled by government, elites and business corporation' and 'control information' could be seen on the mind map.

There were explanations about how printing is controlled by capitalists. For example:

Only focus on more popular works to cover the cost and makes profit.

[Mind Map Transcript]

This indicates that the participants were saying only books that are popular were being printed and other less popular books were not printed. This indicates printing was controlled by a capitalist ideology.

The participants had listed ideas on how cyberculture is controlled by the major stakeholders, namely government, elites and businesses. For example:

Business corporation ... steer and manipulate users in covert ways.

[Mind Map Transcript]

The similarity in effect of 'Print Revolution' and 'Cyberculture' (which is the question that was asked in the task) was provided as well. The participants identified 'control information' as the similarity in effect between the two sources.

It was apparent that the reading task was done with constant supervision from the lecturer. Halim stated:

At first we did a little then we asked the lecturer if it was correct. She said it was wrong. So [we] had to redo it.

[Stimulated recall interview]

The participants were constantly checking their progress and their understanding with the lecturer to ensure they were on the right path. 
Overall, the mind map could be placed on the relational level of the SOLO taxonomy. The participants were able to group the information separately into printing and cyberculture. Then they were able to bring the ideas together to show the connection between these sources.

\section{b) Immanuel's written work}

Like Affiq and Halim, Immanuel read the passages and annotated them. Figure 6 shows on Immanuel's mind map the similarity in effects of Print Revolution and Cyberculture. Immanuel divided the ideas into two: printing and cyberculture. In terms of printing, he stated business capitalist as the sub-theme. He then listed some ideas below business capitalist. For cyberculture, Immanuel identified three sub-themes: technical elite, commercial pressure, and political pressure. He further elaborated the ideas within these three sub-themes.

Figure 6. Immanuel's mind map of the similarity of effects

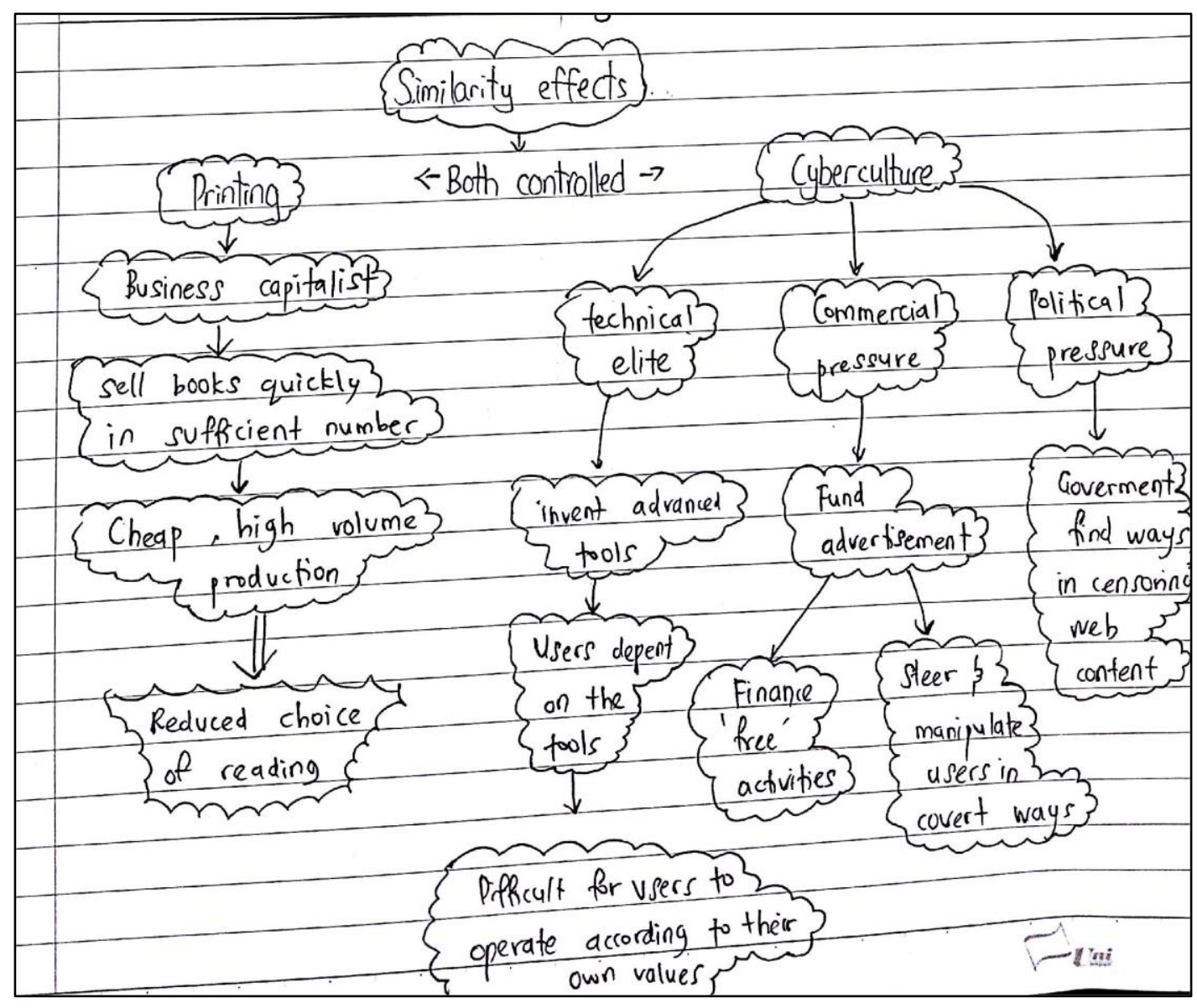

Table 14. Comments on Immanuel's mind map
- $\quad$ The theme was identified
- Sub-themes were identified
- Connections were made within branches

Table 15 shows the summary of evaluation of Immanuel's mind map. He identified 'both controlled' as the theme for the mind map. The sub-themes are clearly stated. This helps 
readers to understand that printing is controlled by 'business capitalist[s]', whereas cyberculture is controlled by 'technical elite', 'commercial pressure' and 'political pressure'.

Immanuel showed the link between each idea in a branch. For example, 'technical elite invent advanced tools' leads to 'users depend on the tools'. Finally, he showed the effect of technical elite is that it is 'difficult for users to operate according to their own values'.

Immanuel understood partially what both passages claimed. He tried to make the connection between the two passages. However, he understood the cyberculture passage wrongly as cyberculture is not controlled by business capitalists; the passage indicated that there was involvement of the government. Although in the mind map he stated clearly who controls the information in cyberculture, he had a different response during the stimulated recall interview. Immanuel stated:

What we study is actually, printing and cyberculture has one, same thing in common. Both are controlled by business capitalist[s].

[Stimulated recall interview]

He also mentioned that the task was challenging because he had to understand the passages first before extracting the information:

To understand and bring out the point form like this is quite challenging.

[Stimulated recall interview]

Based on the rubric created to evaluate the mind map, this work could be placed on the relational level of the SOLO taxonomy. Like Affiq and Halim, Immanuel was also able to identify who controlled the information and how the information was controlled from both the passages.

\section{c) Syamira's written work}

Syamira started the task by reading the passages, then annotating them before doing the mind map. Syamira divided the ideas into two groups, namely printing and cyberculture. She then listed 'control by capitalism' as the sub-theme under printing. Under cyberculture, she listed 'control by governments, elite and business' as the sub-theme. Below each sub-theme, she elaborated 'why' and 'how' control takes place. Figure 7 shows Syamira's mind map on the similarity of effects between the two passages. 
Figure 7. Syamira's mind map on the similarity of effects

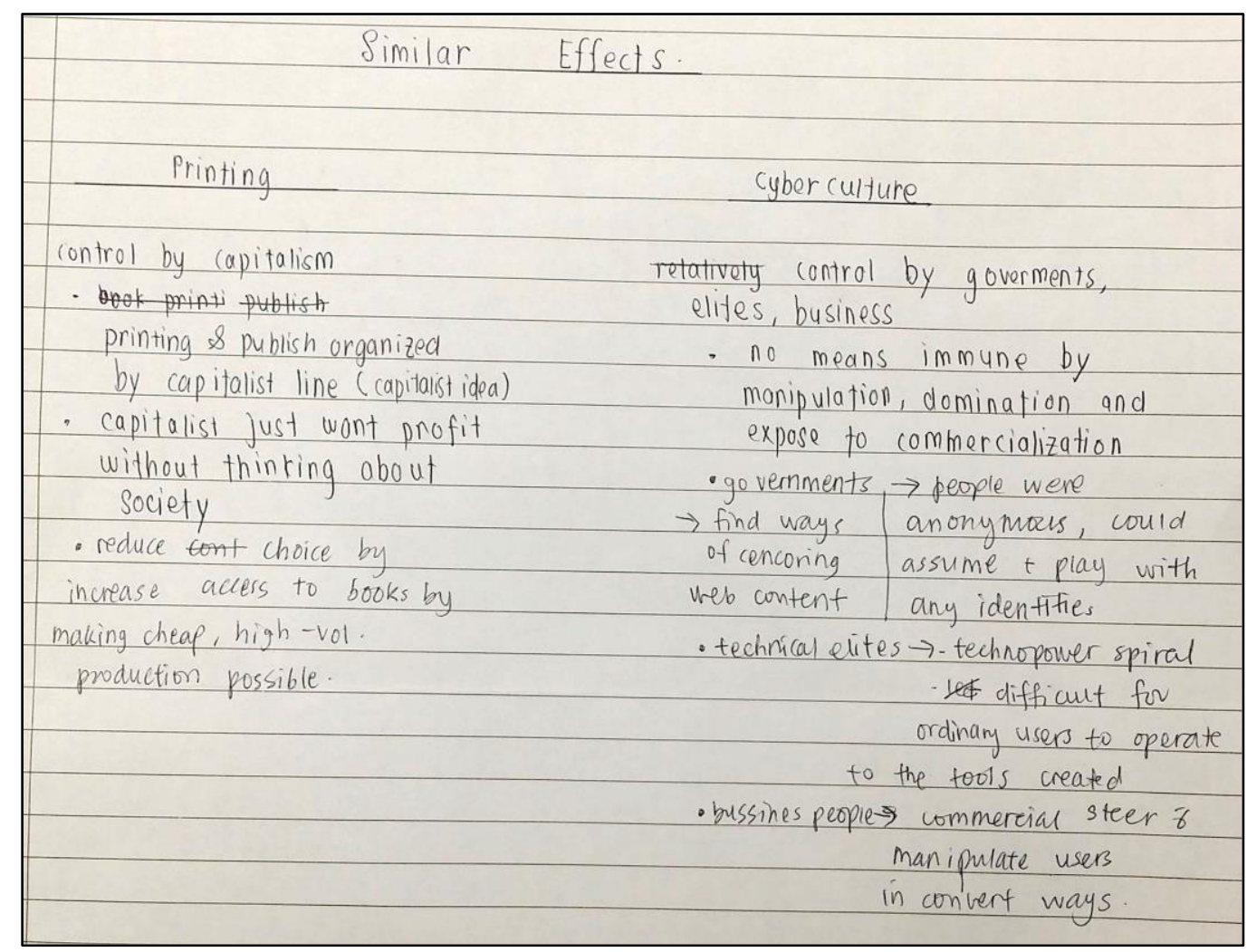

Syamira stated that there are many types of mind maps that exist and she had to determine the most suitable mind map for this task:

Mind maps have many structures. There are cause and effect, description and all that. So, this is more related to description because it informs us how.

[Stimulated recall interview]

This shows that she managed to grasp the preliminary requirement of the task which is to determine how to present the information.

Syamira stated that the reason she identified three groups that control cyberculture is because the main idea in the passage relayed that cyberculture was controlled:

The main point it was trying to relay is cyberculture is controlled by someone.

[Stimulated recall interview]

This shows that through the main idea she then managed to determine who controls cyberculture.

Table 15. Comments on Syamira's mind map

\footnotetext{
- Ideas are grouped together but not brought together

- Some ideas are misinterpreted

- Ideas are extracted from sources and placed without seeing how they are linked to the task

- No links made between both the main ideas
} 
Table 15 gives the summary of the evaluation of the mind map. Syamira grouped the ideas together in each section respectively. For example, under printing, she had identified why capitalists control printing:

Capitalist just want profit without thinking about society.

[Mind Map Transcript]

She had somehow misinterpreted the effect of printing:

Reduce choice by increase[d] access to books by making cheap, high-vol. production possible.

[Mind Map Transcript]

This idea is incorrect as the original text is:

While printing enormously increased access to books by making cheap, high-volume production possible, it also reduced choice.

[Mind Map Transcript]

It seems that this participant brought the last part of the sentence to the front. The idea that Syamira stated making books that are cheap and the high-volume production reduces choices. This is incorrect as the writers meant that although cheap and high volumes of books are produced, the choices are reduced because publishers only print popular books that make them a profit.

Under the cyberculture heading, the ideas are extracted from the passage and placed without much thought about the requirements of the task. For example:

No means immune by manipulation, domination and expose to commercialization.

[Mind Map Transcript]

This does not answer the question from the task which was to identify the similar effect between the two passages. However, with closer reading, it could be assumed that she meant cyberculture is dominated by and used for commercialisation.

On the other hand, Syamira was able to indicate how the different groups control cyberculture. For example, governments:

Find ways of censoring web content.

[Mind Map Transcript]

Although the ideas are listed, there is no evidence of how the ideas are brought together. This shows that only one part of the task, which is how the two aspects are controlled, is answered. The main question, which is what is being controlled, is not answered. Taking these features 
into consideration, it could be concluded that this mind map could be placed on the multistructural level of the SOLO taxonomy.

\section{Interaction with the task}

In this section, the participants discussed the process involved in doing the task, their interest in the task, the challenges, and the various approaches they used to overcome these challenges and how helpful the task was to them.

\section{a) Affiq's views on interacting with the task}

Affiq claimed to have a structured reading process while interacting with this task. He mentioned that he started by looking at the picture to get some ideas, followed by reading the passage once, before rereading it for a second time.

Affiq displayed the ability to see the connection between the two passages that he read. Reading about capitalism in the 'Print Revolution' helped him to see the connection with cyberculture:

Even cyberculture also is controlled by capitalists which is business corporates, government and elites.

[Stimulated recall interview]

In addition, he found the topic 'capitalism' interesting. The interest in the topic made him interact with the passage:

I love the things about politics. So, I love to read more about the capitalist people that uh, discriminate [against] other people...

[Stimulated recall interview]

This could also be seen when he tried explaining to his friend the nature of capitalism:

Capitalists are a group of people who own businesses, who control something, like for example printing. They monopolize something. This is what we call capitalism.

[Audio recording of group discussion/ dated: 27/10/16]

However, he faced some difficulties in understanding the 'Cyberculture' passage:

For the first article [refers to printing revolution], this is quite easy but the cyberculture article it is medium. Uh, maybe medium to hard.

[Stimulated recall interview]

This was because the words used in the cyberculture passage were difficult for him to understand: 
But this, there are few words like "converge" which we need to find meaning first to understand the words, er, the sentences.

[Stimulated recall interview]

He also stated that he finds that doing a mind map makes the content of the reading accessible:

Mind map is easy to determine. There are two different effects between two situations so it is easy for us to read it again. It is not complicated.

[Stimulated recall interview]

Affiq was able to relate the two passages that he read. At the initial stage he found it difficult to comprehend what he read but he was able to overcome the difficulties of understanding the passages. He also found the task helpful and he saw the usefulness of constructing mind maps in reading.

\section{b) Halim's views on interacting with the task}

Halim claimed that he found the 'Cyberculture' passage difficult to understand. He stated that he had difficulty in following the argument made in the passage:

The sentences were confusing. Confusing. First he said free, then not free. Then towards the end he said ... some were supporting the details. ... I didn't understand.

[Stimulated recall interview]

He too had a structured way of reading the passage:

First thing. I read the whole article. Then try to read ... slow-slow. From first paragraph, to ... another paragraph and next to the end. And take ... line some of the words that I don't understand.

[Stimulated recall interview]

Halim referred to the lecturer when he did not understand:

Ahh, just, ask the lecturer.

[Stimulated recall interview]

Halim's claims indicate that he attempted to interact with the task. However, he seemed to face some struggles in understanding the 'Cyberculture' passage which resulted in his having to ask his lecturer when he faced problems.

\section{c) Immanuel's views on interacting with the task}

Immanuel rated both the reading passages as medium in terms of the difficulty level in understanding them. However, he stated that he found the passage 'Cyberculture' to be harder than ‘Print Revolution': 
Here he supported cyberculture but then when the flow goes ... he is not supporting cyberculture.

[Stimulated recall interview]

He claimed that the argument made the passage difficult to understand compared to 'Print Revolution' where the intention of the writer was made clear in the first paragraph:

This one was very easy to understand, because from the starting the author told that it is controlled.

[Stimulated recall interview]

This shows that he was able to understand the text when it is straightforward. He struggled to understand the 'Cyberculture' passage because the author's stance was made clear only at the end of the text.

Immanuel was also able to determine the type of texts that he read and to choose the mind map based on the requirement of the task:

For description, you can just write, put a dash and keep on writing. If it's a cause and effect, you should use an arrow.

[Stimulated recall interview]

This shows his ability to think about how to answer the question in the task.

Immanuel mentioned that he had read the article repeatedly to understand:

Oh, many times, 5 or 6.

[Stimulated recall interview]

He also stated that he had approached the instructor when he did not understand the phrases in the passages. He further stated that although the task was challenging, he would be able to do similar activities of this nature in the future.

Immanuel did attempt to interact with the task. His interaction was focused on responding to the reading task given by the lecturer. He took the necessary measures to accomplish the task given to him.

\section{d) Syamira's views on interacting with the task}

Syamira claimed that she found both 'Print revolution' and 'Cyberculture' difficult to understand. She stated that compared to 'Print Revolution', 'Cyberculture' was harder to comprehend because of the length of the passage.

She also mentioned that she had difficulties with the passages because she is not good at identifying points from reading passages: 
Because I'm not good at extracting important information.

[Stimulated recall interview]

She also stated that doing annotations on the passages that she read helps her understanding:

Annotate means we extract, like if it's a line, we wouldn't be able to see the point clearly. So, if we annotate, we do it in point form, we will be able to see what the article is about.

[Stimulated recall interview]

Based on the responses given by Syamira, she also tried to interact with the task. She also seemed to be more interested in completing the task given to her.

The stimulated recall interviews showed that the participants had interacted with the task. Their interaction could be seen from the way they responded to the task. They responded by employing various reading processes and also by discussing the extent of their interest in the passage. Some of the participants claimed that they were goal oriented while doing the task, but it seems as though their goal was to accomplish the task as determined by the lecturer. This suggests that their interest in the task for its own sake was not their primary reason for doing it.

All four participants in Unit 1 had gone through similar stages in completing the task. They started by reading the passages, annotating them, and finally creating the mind map. The participants identified the two aspects that they later compared. The participants chose different ways to present the mind maps. Some used short phrases taken from the texts whereas some copied big chunks of information.

\subsubsection{Summary of Unit 1}

Participants in unit 1 described a range of reasons for learning English in the EAP classroom. They also claimed that the context they were in influences the learning of English. At the same time, they faced challenges in practising English.

A specific task in the EAP class was used to further explain how their expectations were met and also how they reacted to the teaching and learning done in the classroom. An individual analysis was conducted to explore the participants' responses to the reading task. Table 17 indicates a summary of the participants' written work in Unit 1 . The task was categorised at the relational level of the SOLO taxonomy. Most of the participants were able to achieve the relational level except for one participant who achieved the multistructural level. Three of the participants were able to connect the ideas from the two sources. This could not be seen in Syamira's work. 
The participants had faced some challenges in doing the tasks such as finding the passages difficult to understand. Despite the challenges they faced, they still made the effort to complete the task.

Table 16. Participants written work in unit 1

\begin{tabular}{|c|c|c|c|c|}
\hline Written work & Affiq & Halim & Immanuel & Syamira \\
\hline $\begin{array}{l}\text { Level of } \\
\text { SOLO } \\
\text { Taxonomy for } \\
\text { mind map task }\end{array}$ & - Relational & - Relational & - Relational & - Multistructural \\
\hline $\begin{array}{l}\text { Views on } \\
\text { interacting } \\
\text { with the task }\end{array}$ & $\begin{array}{l}\text { Used a } \\
\text { structured } \\
\text { reading } \\
\text { process to } \\
\text { read the } \\
\text { passages } \\
\text { - Struggled a } \\
\text { bit with the } \\
\text { task but had } \\
\text { managed to } \\
\text { overcome the } \\
\text { problems }\end{array}$ & $\begin{array}{l}\text { - Used a } \\
\text { structured } \\
\text { reading } \\
\text { process to } \\
\text { read the } \\
\text { passages } \\
\text { - The } \\
\text { "Cyberculture" } \\
\text { passage was } \\
\text { difficult to } \\
\text { understand but } \\
\text { he was able to } \\
\text { complete the } \\
\text { task }\end{array}$ & $\begin{array}{l}\text { - Used a } \\
\text { structured } \\
\text { reading } \\
\text { process to } \\
\text { read the } \\
\text { passages } \\
\text { - The writing } \\
\text { style made the } \\
\text { "Cyberculture" } \\
\text { passage } \\
\text { difficult to } \\
\text { understand but } \\
\text { he managed to } \\
\text { do the mind } \\
\text { map }\end{array}$ & $\begin{array}{l}\text { Used a } \\
\text { structured } \\
\text { reading } \\
\text { process to } \\
\text { read the } \\
\text { passages } \\
\text { Both the } \\
\text { passages } \\
\text { were difficult to } \\
\text { understand but } \\
\text { managed to } \\
\text { finish doing } \\
\text { the mind map }\end{array}$ \\
\hline
\end{tabular}

\subsection{Unit 2}

\section{Brief description of setting and demographic details of participants}

Data for Unit 2 were collected from an EAP classroom at a public university. The class focused on reading skills in an academic context. The lessons were conducted once a week. The participants were enrolled in an engineering programme, majoring in the electrical division. There were four Malay participants in this unit. Three male participants - Azraq, Samad, and Hussein - and one female participant - Nazira (all pseudonyms) volunteered to participate in Unit 2. The participants were 19 or 20 years old.

This section of the chapter is divided into responses to learning in the EAP classroom, responses to a specific class task, and the overall summary of Unit 2.

\subsubsection{Responses to Learning in the EAP Classroom}

This part discusses the themes generated from the analysis. There were five themes generated: having multiple purposes for learning, engaging with the content, acknowledging the environment beyond the EAP classroom, feeling anxious about learning English, and making an effort to learn English. Table 18 shows a summary of themes and sub-themes for Unit 2. 
Table 17. A summary of themes and sub-themes for unit 2

\begin{tabular}{|c|c|c|c|c|}
\hline \multicolumn{5}{|c|}{ Themes/ sub-themes } \\
\hline $\begin{array}{l}\text { Having multiple } \\
\text { purposes for } \\
\text { learning English }\end{array}$ & $\begin{array}{l}\text { Engaging with } \\
\text { the content }\end{array}$ & $\begin{array}{l}\text { Acknowledging } \\
\text { the environment } \\
\text { beyond the EAP } \\
\text { classroom }\end{array}$ & $\begin{array}{l}\text { Feeling anxious } \\
\text { about learning } \\
\text { English }\end{array}$ & $\begin{array}{l}\text { Making an } \\
\text { effort in } \\
\text { learning } \\
\text { English }\end{array}$ \\
\hline $\begin{array}{l}\text { - Learning } \\
\text { through English } \\
\text { at the university } \\
\text { - } \text { Learning } \\
\text { English for } \\
\text { global } \\
\text { communication } \\
\text { - Learning for } \\
\text { future careers } \\
\text { - Learning } \\
\text { English to } \\
\text { acquire } \\
\text { information } \\
\text { - Socialising } \\
\text { - Having to do } \\
\text { EAP }\end{array}$ & & $\begin{array}{l}\text { - Transferring } \\
\text { into other } \\
\text { subjects } \\
\text { Being } \\
\text { influenced by } \\
\text { the home } \\
\text { environment } \\
\text { - Having } \\
\text { perceptions of } \\
\text { the social } \\
\text { environment }\end{array}$ & $\begin{array}{l}\text { Worrying } \\
\text { about the level } \\
\text { of English } \\
\text { proficiency }\end{array}$ & $\begin{array}{l}\text { - Finding } \\
\text { ways to } \\
\text { overcome } \\
\text { learning } \\
\text { problems } \\
\text { - Being } \\
\text { willing to } \\
\text { participate } \\
\text { in the } \\
\text { classroom } \\
\text { Being } \\
\text { willing to } \\
\text { practise } \\
\text { language }\end{array}$ \\
\hline
\end{tabular}

\section{a) Having multiple purposes for learning English}

Multiple purposes for learning English were described by the participants. Some of the descriptions were: learning through English at the university, having to do EAP, learning English for global communication, for future careers, learning English to acquire information and for socialising.

\section{i) Learning through English at the university}

Some participants claimed that learning English is important as it is used as a medium for learning.

Hussein stated:

It helps. All the subjects are in English.

[Semi-structured interview]

Hussein explained that the courses are mostly in English. This made understanding English important to him.

Samad explained that at times he was taught by foreigners who were unable to communicate in Bahasa Malaysia. Hence it is vital for him to be able to understand English:

If it is a foreigner teaching us then it will be fully in English ... I understand what he/ she says. It would have been difficult if I couldn't understand what he/she said.

[Semi-structured interview] 
In other words, the participants conveyed the need to learn English because the subjects at the university are taught in English.

\section{ii) Learning English for global communication}

The participants stated that learning English helped them to communicate globally.

Hussein said he is able to interact with people when he is out of Malaysia:

So, like when we go to Singapore, it helps me when I communicate with Singaporeans.

[Semi-structured interview]

Nazira claimed that she finds learning English is important as it is a Lingua Franca:

Nowadays you know, English is like the world language. People understand English no matter where we go. So, it's very important for me to learn English.

[Semi-structured interview]

Samad too claimed that English helps him to communicate with foreigners:

I speak in English to foreigners because they can't understand anyway.

[Semi-structured interview]

So the participants conveyed a sense of being strongly motivated to learn English because they had found being able to understand English helps them to interact with people, especially with foreigners who do not understand Bahasa Malaysia. English becomes a means of communication as many people are able to understand the language.

\section{iii) Learning for future careers}

Some participants also claimed that learning English will help in their future careers.

Hussein remarked that English will assist him in completing his work-related projects:

It will help. Engineering is based on a lot of presentations. It's important. Communication is important. Communicate with customers, clients.

[Semi-structured interview]

Samad thought that communicating in English would help him to expand his business:

For example, if I plan to set up my own business, for the business to grow I have to meet higher officials.

[Semi-structured interview]

The participants thus felt that learning English would assist them to not only get a job but also to help them to excel further in whatever career path they choose. 


\section{iv) Learning English to acquire information}

Another reason that the participants felt learning English was important was to be able to get information. The participants said that they realised they needed English to get updates on what is happening around the globe as well as filtering the information that they get. A sense that this was not their preference and that they needed English to protect themselves came through as some of their reasons.

Azraq stated:

It is important because most of the things that we read are in English. Because there are not many people who translate from English to Malay (Bahasa Malaysia). So, whether we like it or not, we have to read in English.

[Semi-structured interview]

Samad remarked:

English is an international language. So it will be difficult if we can't understand it. For example, whatever happens out there, sometimes when we read we can't really understand it. Like countries that don't learn it, they won't be able to understand what's happening out there.

[Semi-structured interview]

Hussein also stated:

It helps us to avoid getting cheated ... Like, if you look at the surrounding, mostly things are in English. Sometimes people have to read in English. So, when someone who is fluent explains it to someone who is not, he or she could lie about the content of article. Probably the article says ' $A$ ' but the person lies that it means ' $B$.'

[Semi-structured interview]

In other words, the participants felt that they needed to be able to understand English in order to understand what they read and to determine whether the information from the wider global community is accurate.

\section{v) Socialising}

Lastly, one of the participants said that she learns English to be able to socialise.

Nazira stated:

Among friends and also in social media, I think I communicate more in English ... well it's not like I'm friends with white people but, people do speak in English in the social media, even Bahasa Malaysia speak in English so I could understand.

[Semi-structured interview]

Thus, she finds English useful for making friends and meeting people. 


\section{vi) Having to do EAP}

There did not seem to be a clear connection between the participants' understanding that English is useful for learning in subject courses and the EAP course. Some participants made it clear that the only reason for them to enrol in the EAP classroom was because it was compulsory to take the course. Nazira said that she was taking EAP:

"Because it is compulsory"

[Semi-structured interview]

Hussein claimed that he wanted to transfer the credit hours as he had taken the course at the Diploma level:

"Actually, we wanted to transfer it, but we couldn't do it.

[Semi-structured interview]

This indicates that he was not given a choice so he had to enrol in the course. All four participants in this group stated that they had to take the course.

It is clear from these varied reasons that the participants could see English assisted them in various scenarios but their feelings about learning English in the EAP classroom did not match that realisation.

\section{b) Engaging with the content}

The participants expressed a range of preferences for learning in the EAP classroom. They said they would prefer to be able to focus on the content taught in the classroom and that the reading activities in the class influenced their learning. The topic given in the classroom influenced the learning of some participants.

Hussein described the way even the title of the reading material in the class influenced his interest in learning:

Depends on the title .... When there is interest, then there is the urge to read.

[Semi-structured interview]

Nazira described her response when one of the topics taught in class was about sex education:

The recent one is about sex education. Sex education is quite interesting because we don't discuss that, you know. We are not really open minded. So, when (name of lecturer) discussed sex education, she was cool about it. So it was interesting"

[Semi-structured interview]

Interest in the topic had clearly led her to show more interest in learning in the classroom. 
As well as interest, the participants also described preferring to learn content that is useful to them. They would be more likely to overcome the obstacles to learning if they could see the usefulness of the content as Azraq claimed:

It's challenging but I can use it for my entire life. Because it is useful to me. If I were to read any articles, I would be able to extract points accurately.

[Semi-structured interview]

Samad also stated that he prefers to practise the content that he learnt in the EAP classroom when it seems relevant to his life:

It's not like it's not interesting but, like cyberculture (refers to a reading activity in class), we are able to relate to it. This has a little but not much (refers to a different activity). But this has more. Because it is related to our lives"

[Stimulated-recall interview]

On the other hand, the participants provided the insight that they feel forced when they do not have any interest in learning about the content. This then influences their effort in the classroom.

Hussein was able to quantify his level of interest. He stated that on a scale of one to ten, he would rate the effort he made to learn in the classroom as seven:

Because, seven is when the article is interesting, six is when it is interesting but difficult. Five is when I'm lazy.

[Semi-structured interview]

Nazira, on the other hand, rated her interest at five:

Because the article is not really interesting. So I don't really like it.

[Semi-structured interview]

Some of the participants stated that they preferred exciting topics as part of learning because this would stir their interest in learning in the EAP classroom. Some also stated that they preferred to learn content that can be used in their lives. Another way of stating these findings would be that they suggest the participants are often not engaged directly by the content within the EAP course.

\section{c) Acknowledging the environment beyond the EAP classroom}

The participants talked about the educational environment out of the EAP classroom and that being comfortable in socialising in Bahasa Malaysia played a role in learning and practising English. 


\section{i) Transferring into other subjects}

Mixed perspectives emerged among the participants about using the reading skills in other subjects at the university.

Azraq felt that he was unable to use the reading skills developed in the EAP classroom in other subjects. They were:

Not used always because it is less used in engineering subjects. It is more focussed on calculations so it's less used.

[Semi-structured interview]

Samad also found that he did not have the opportunity to use the reading skills. These subjects were:

More towards reading subjects and not calculations. This semester there are more of calculation subjects.

[Semi-structured interview]

Hussein, however, had a different opinion. He said that he found the reading skills could be used in other subjects:

Note making is quite interesting because it can be used for other subjects. For example, Signalling System (a subject) when I want to understand the process.

[Semi-structured interview]

Although Hussein introduced this opposing view about using the reading skills in other subjects, it seemed that the participants' feeling that there were not many opportunities to use the reading skills in other subjects predominated.

Some of the participants also predicted that the reading skills practised in the EAP classroom may be helpful in the future. Samad said that skills like making notes may help in extracting and transferring information in the future when he becomes an engineer:

For example, engineers, sometimes we start by straightaway creating and at other times we do something by looking at the basics first. So that's what we have to read and make notes then transfer the information. As I mentioned earlier it has to be correct [refers to the mind map], so that it will be easier for us to refer to. The mind map is easier to understand, not only for this passage.

[Semi-structured interview]

Nazira also predicted that the reading skills might be helpful. She saw the direct relevance to the use of reading skills in other subjects: 
If I need to study and read, I'll employ the same process. I will understand and extract the ideas.

[Semi-structured interview]

The participants in this group also noted that, in terms of practising English out of the EAP classroom, they were still studying in a Bahasa Malaysia speaking environment. Samad pointed out that lecturers often actually code-switch between Bahasa Malaysia and English while teaching in other engineering related subjects. In terms of using language there is:

A mix. If a Malay lecturer teaches us, then there is a mix of English and Malay (Bahasa Malaysia). If it is a foreigner teaching us then it will be fully in English.

[Semi-structured interview]

Nazira commented on the flexibility to move between the two languages in practice:

Presentation slides are in English but it's optional on how we explain to people. The lecturers give us leeway to speak in Malay.

[Semi-structured interview]

Nazira also noted that in practice she has to coordinate with the rest of the group members to determine the language that they would use to present their presentations:

But since I enrolled in the degree programme, we had to mix with other classes. So I'll have to agree with all the group members. This is because it won't look synchronized if we had some members speaking in English and some speaking in Malay (Bahasa Malaysia). So, if one of us decides to speak in Malay (Bahasa Malaysia), all of us will do the same.

[Semi-structured interview]

So, despite the subject being taught in English, the educational environment constrains some of the use of English in practice. This seemed to have affected Nazira's desire to practise the language as she felt thwarted when they have to unanimously agree to be systematic in the type of language they use.

Azraq also claimed that in practice the opportunities to practise in English are limited in the Bahasa Malaysia speaking environment:

Not much speaking is done because the environment influences. If I'm in the learning environment where people speak in English, I don't have a choice but to practise but since the majority speak in Malay. So it influences me.

[Semi-structured interview]

In this group a clear feeling emerged that the educational environment out of the EAP classroom influences their learning as well as the practice of English. 


\section{ii) Being influenced by the home environment}

Azraq stated that he has always spoken in Bahasa Malaysia at home and is very comfortable using it when he communicates:

As I mentioned I grew up in an environment that uses Bahasa Malaysia language. So it affects. Because it is less used. It's like driving a car, the more we drive, the better we become in driving. The concept is similar to that. If it is used often it will be different.

[Semi-structured interview]

So, because he was not as comfortable with English as Bahasa Malaysia he did not practise it as much as he practises Bahasa Malaysia.

\section{iii) Having perceptions of the social environment}

The participants stated that they felt comfortable communicating in Bahasa Malaysia rather than English in social situations.

Azraq mentioned that he communicates in Bahasa Malaysia with his friends:

Like I mentioned they are those who speak in Malay, Malay language (Bahasa Malaysia) users. So, the use of English is not a necessity because when they approach me, they use Malay (Bahasa Malaysia).

[Semi-structured interview]

Hussein stated:

If we speak to people who we don't know, usually we speak in English there [refers to Singapore] ... If it's a Malay whom I don't know, I speak in English. If I know them then I will speak in Malay (Bahasa Malaysia).

[Semi-structured interview]

Although the culture in Singapore does not differ much to that in Malaysia, there are some notable differences such as the normalcy of using English within the community. Hussein's remark that he communicates in English with people whom he does not know in Singapore, whereas he communicates in Bahasa Malaysia to people with whom he is familiar, indicates that he feels comfortable in interacting in Bahasa Malaysia but he does not mind using English when there is a necessity.

It seemed clear from the contributions made in the interviews with this group that the amount of English the participants do or do not speak out of the EAP classroom, both in other subjects and socially, is primarily influenced by their own background as well as the custom that is practised in a community rather than any of the reasons for learning English given above. 


\section{d) Feeling anxious about learning English}

Anxiety when using English also emerged as a factor in learning English in this group. The anxiety could be caused by the participants' feelings of lack of proficiency in English.

\section{i) Worrying about the level of English proficiency}

Participants claimed that they face issues with proficiency in English and as a result, they do not have much confidence in using English.

Samad replied to one line of questioning:

But if you are asking if I'm brave enough to speak in English to them, I don't think so.

[Semi-structured interview]

Nazira described feeling nervous about communicating with people whose proficiency is better than her own:

It's like to approach someone who is fluent in English is quite scary. I understand sometimes if I see someone who is fluent in English, I'm at times a bit afraid to approach them.

[Semi-structured interview]

Samad was able to describe an actual situation where anxiety interfered with his ability to communicate as well as he wanted to:

For example, I attended an interview once. I could speak but because I was nervous, I couldn't remember how to say "ilmu" in English. I remembered it was "knowledge" only after the interview ended. It's like I know but I'm just too nervous so I become panicky.

[Semi-structured interview]

Lack of proficiency also affects the understanding of reading material both in and out of the EAP class:

Samad described finding the words that he read in the news difficult to understand. They are:

Usually weird words in the news. Because they are slightly formal.

[Semi-structured interview]

Nazira described facing difficulties in the EAP class:

Just find it hard to be able to understand the sentences.

[Semi-structured interview]

On the other hand, some participants felt more confident speaking to people who they thought had a similar English proficiency level: 
For Nazira this is:

Because their English is not fluent too. Because people from that country are not fluent too. So it's okay.

[Semi-structured interview]

Samad expressed some delight when this was the case:

Hah, yeah. Moreover, his knowledge in English is not that good. That made me more confident.

[Semi-structured interview]

Samad also displayed admiration of people who speak English fluently:

Because they speak with confidence, and fast. The way they speak is great. Usually when I speak with my friends it is not much, normal. Nothing much.

[Semi-structured interview]

So, it seemed that lack of proficiency in English causes an uncomfortable feeling in not only learning but in practising the language too.

\section{e) Making an effort in learning English}

Various efforts to learn English had been made by the participants. They claimed that they had attempted to solve the challenges they faced while doing activities in the class.

\section{i) Finding ways to overcome learning problems}

Samad stated that he tried making notes to refer to later because otherwise he could lose the information that he has learnt:

I'm quite slow in comprehending. But I usually write the notes, when I want to recap I will look at the notes, that's how I understand.

[Semi-structured interview]

Part of this issue is about Samad needing more time to understand what he learns.

Azraq used electronic sources to support his learning:

If I don't understand I will do what I usually do, google it.

[Semi-structured interview]

Azraq also mentioned that he makes changes when realises his mistakes while doing some reading activities in the class: 
At times the most difficult is to find a suitable title. Sometimes the lecturer asks us to write a temporary one first. Then jot down. But half way through ... when we realize what the article is about, we change it.

[Semi-structured interview]

Azraq stated that he sees making changes as part of his learning process and he does not mind making the changes:

But I don't mind changing it. Because that shows our improvement. To me changing it is not a hassle. It is a form of improvement.

[Semi-structured interview]

Azraq had a further reason for this approach:

I don't think anyone will get it right the first time then we can improve from the existing version that we have.

[Semi-structured interview]

In other words, Azraq claimed that he did not mind making mistakes while doing learning activities in the class because to him learning is progressive.

Hussein's approach was different. It was to:

Translate, I tried to translate.

[Semi-structured interview]

So, his way to cope with English was an active move back to Bahasa Malaysia when he reads.

There is a sense from these comments of the participants that each had their own active way of trying to overcome their learning issues when they faced problems in learning English.

\section{ii) Being willing to participate in the classroom}

The participants talked directly about making an effort to participate in the EAP class.

For Azraq this was:

Usually like offering ideas ... at times I don't have to put up my hand. She asks the crowd, so students just give the answers, I join them too.

[Semi-structured interview]

Hussein had the same approach:

I don't have to put up my hand. I usually just say the answer.

[Semi-structured interview]

Samad also tried actively to: 
Offer my ideas, discussing, it makes it easier.

[Semi-structured interview]

Nazira also thought the way to contribute to the class was:

Maybe giving opinions. I speak to my friends instead of raising my hand to ask.

[Semi-structured interview]

For both Samad and Nazira it seemed important that they attempt to share their ideas while discussing lessons in class and all the participants seemed to feel the benefit of partaking directly in class by joining the classroom discussion as well as in group discussions.

\section{iii) Being willing to practise language}

In this group the participants also communicated their willingness to practise English. Nazira stated that she tries to speak although she is not good at it:

But at least I tried, and also I'm able to build up my confidence when I speak in English. [Semi-structured interview]

Hussein claimed that he also attempts to speak in English:

At home. Sometimes.

[Semi-structured interview]

Samad stated that he attempts to read in English:

I like to read the stories. The meaning I don't really look at it.

[Semi-structured interview]

So actively practising for this group was described as happening in both speaking and reading.

In short, participants in Unit 2 had multiple reasons for learning English in the EAP classroom. They mentioned the type of learning they preferred as well as how the environment out of the EAP classroom influences their learning and influences the transfer of learning. They had also faced challenges in terms of anxiety in learning the language. They had active ideas about how they made the effort to practise and learn English, solved difficulties in reading, practised English independently and how the reading skills used in the EAP classroom could be useful for them in the future. 


\subsubsection{Responses to a Specific Task}

\section{Analysis of a written task in the EAP classroom}

The class activities were usually done in groups and this task was done in groups of five or six. All four participants had created mind maps to help them in writing the summary. A descriptive mind map was used to describe the details found in the passages. A "compare and contrast" mind map was used to compare the information found in both the passages based on the instruction given by the lecturer. Both Azraq and Samad were in the same group and did the task together. I will first discuss Azraq's and Samad's written work before moving on to the rest of the participants.

\section{a) Azraq's and Samad's written work}

Both Azraq and Samad were in the same group and discussed the task together. Thus, the outcome of the written work was a joint effort between the group members. Azraq and Samad started the task by doing a mind map for each of the passages. They started with "Print Revolution" and proceeded to "Cyberculture".

\section{i) Mind map on print revolution}

Figure 8. Mind map of print revolution - Azraq's and Samad's work

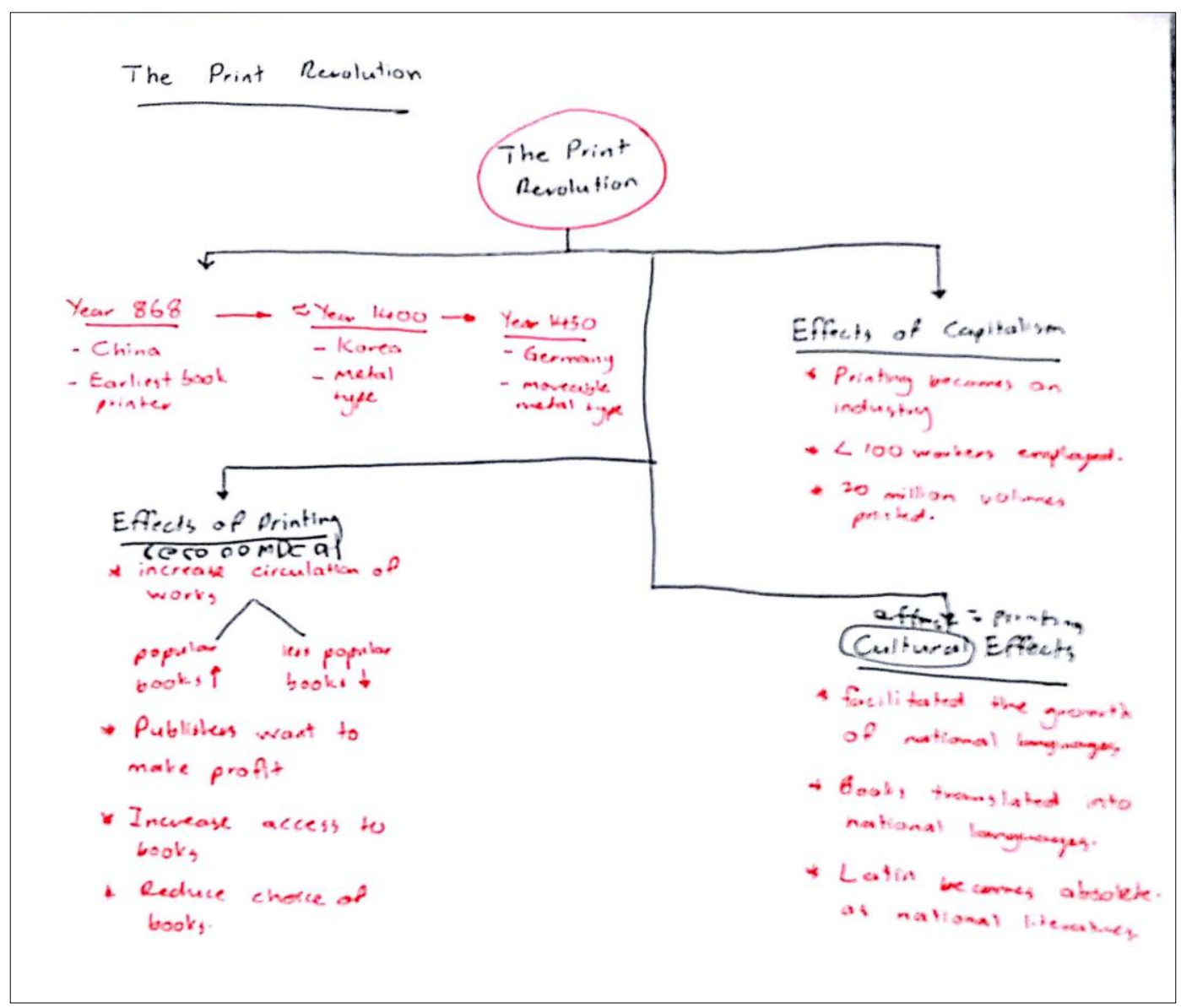

Note: Figure is unclear. 
Figure 8 shows Azraq's and Samad's mind map of "Print Revolution". Azraq and Samad with their peers divided the ideas into timeline, effects of capitalism, effects of printing in terms of economy, and effects of printing in terms of culture. They constructed a timeline depicting the evolution of printing through the years. They then discussed the effects of capitalism and effects of printing. However, they did not group the effects together as a whole but decided to separate them as individual ideas.

Considering that this is group work, a stimulated recall interview was used to acquire more nuanced details of both Azraq's and Samad's thoughts while responding to the reading task. Azraq stated:

As I mentioned earlier, I did a mind map for each paragraph [he meant annotate, he was getting a bit confused between the terms note making and mind map]. After that $I$ combined.

[Stimulated recall interview]

Azraq claimed that he annotated each paragraph of the passage "Print Revolution" before finally making a mind map of the information that he gathered. He also said that he designed the mind map which included a timeline based on the lecturer's suggestion:

Actually, this depends, not depends, uh, this is from the lecturer. She briefed us, ah, before we started to do it. She informed us, like if it's a timeline, draw a line, to show the time.

[Stimulated recall interview]

Samad, on the other hand, claimed that he tried to understand the type of passage that he read:

If you don't understand you can't do it. For example, we have to determine the type, if it is a timeline then we do it this way.

[Stimulated recall interview]

The mind map was then used to assist in the compare and contrast phase. The participants then moved to the "Cyberculture" passage where they created a descriptive mind map.

ii) Mind map on cyberculture

Figure 9. Mind map of cyberculture - Azraq's and Samad's work 


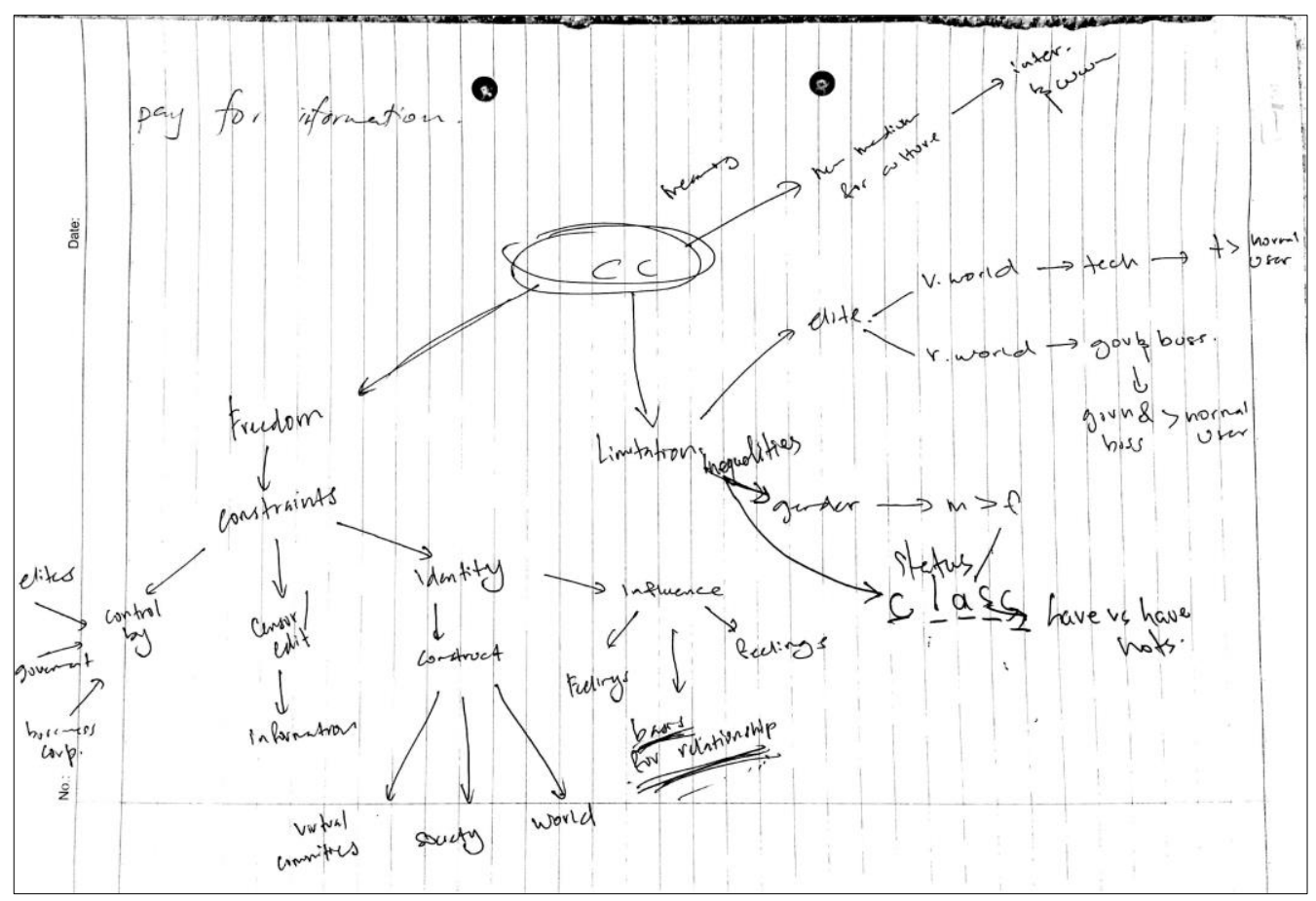

Figure 9 shows Azraq's and Samad's mind map of "Cyberculture". Azraq and his friends divided the information presented in the passage into three parts: meaning, limitations, and freedom. They summarised paragraph one as the meaning of cyberculture. Next, they discussed the limitations of cyberculture. They related inequalities, the elite, government, and business corporations (he used the term boss) to the limitations of using cyberculture. Next, they discussed freedom as part of cyberculture. They related freedom to constraints where they had sub-categories: controlled by, censor, and identity. They further described how control, censor, and identity are associated with constraints of cyberculture.

In the stimulated recall interview, Azraq mentioned that he had extracted only important information from the reading passage:

Find the important points like this is freedom, then this is the limitation. So, freedom is broken into more points. Like controlled by whom, then identity, who are ... the users. The users of cyberculture are anonymous.

[Stimulated recall interview]

Azraq, Samad and their friends divided the information into three categories. They took the ideas word for word without using their own words. Each of the categories was further divided into sub-categories and then broken down further. All these sub-categories as well as the subsub-categories were related to the main category. This showed that the students had the ability to choose the information and describe it.

Both the mind maps were used to compare and contrast the information found in the two passages. Azraq, Samad and their friends then moved to the next stage of comparing the information. 


\section{iii) Compare and contrast table}

The students compared and contrasted the information presented on both the mind maps. Figure 10 shows the compare and contrast table of the effects of "Print Revolution" and "Cyberculture". They determined the main ideas were economy and culture. They used both economy and culture to compare the effects of "Print Revolution" and "Cyberculture". However, they left the row of economy for cyberculture empty. 
Figure 10. Compare and contrast table of the effects of print revolution and cyberculture for Azraq's and Samad's work

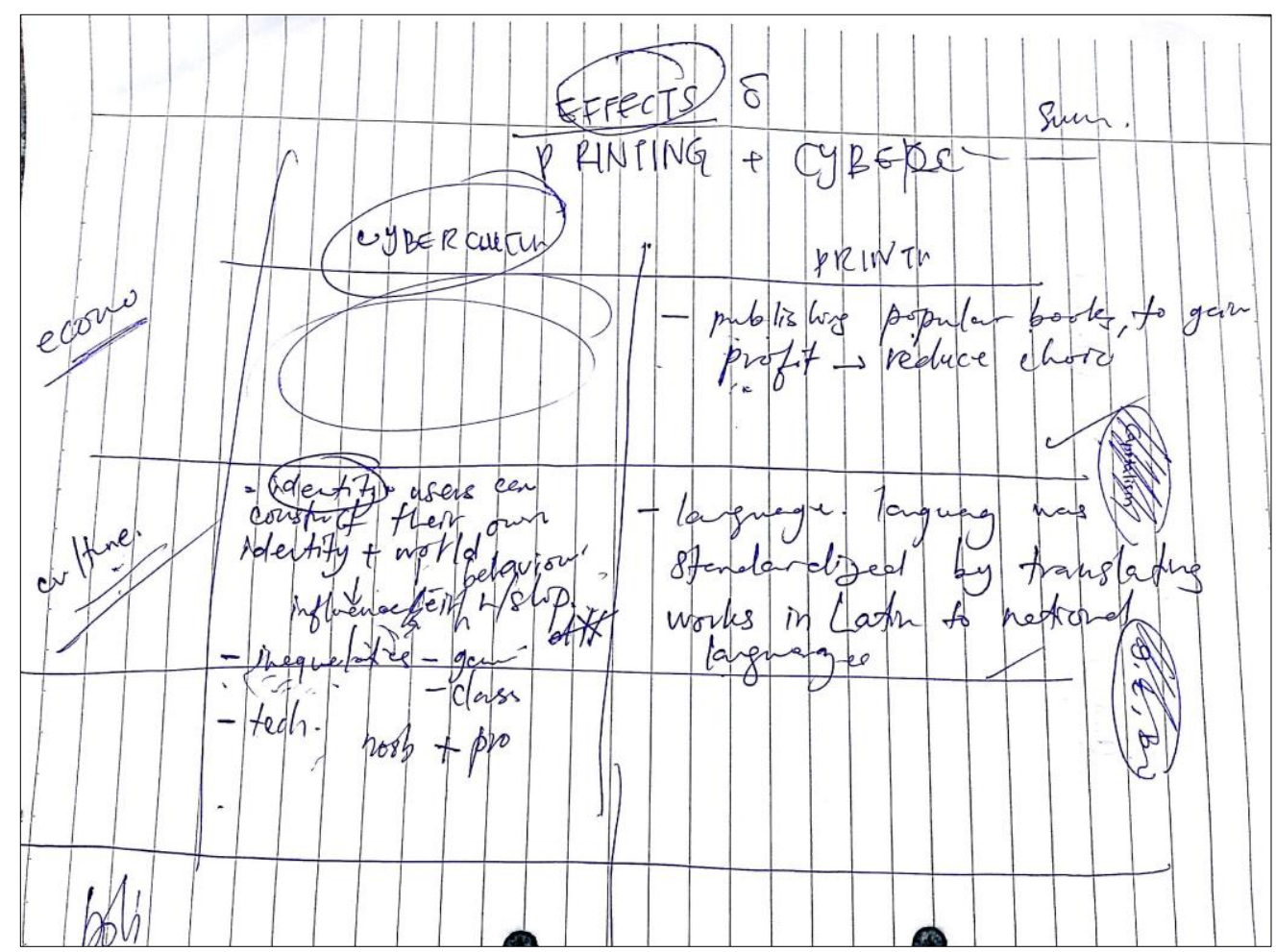

Azraq stated that constructing a compare and contrast table was a suggestion from the lecturer:

The lecturer taught us how to do it. She said it's best to do a table when we are comparing.

[Stimulated recall interview]

Samad also agreed that the lecturer had suggested that they do a table to compare and contrast both the passages:

I followed what the lecturer taught.

[Stimulated recall interview]

This shows that both Azraq and Samad followed their lecturer's suggestion to ensure that they were on the right path while responding to the reading task.

Samad stated that he extracted relevant points from both the passages:

Relevance between the two, what kind of connection, there is culture, connection with culture, there is also printing [the participant was reading from the mind map]:

[Stimulated recall interview] The information in the table shows that the participants have the ability to analyse and choose pertinent information that is required for the task. The compare and contrast table also shows 
that the participants are not only able to identify individual ideas (the "Print Revolution" mind map and the "Cyberculture" mind map) but also able to bring the information together.

Comparing and contrasting the information found in the mind maps shows that the participants are not only able to identify individual ideas but are also able to relate the information by comparing the information. Using the information found in the compare and contrast mind map, the participants then proceeded to write the summary.

\section{iv) Summary writing on the effects of print revolution and cyberculture}

This is the final product of the reading task. The students wrote a summary of the information that they accumulated in the compare and contrast table (Appendix S-2, page 273). They organised the ideas into similarities and differences. Table 19 shows the comments on the evaluation of the summary writing.

Table 18. Comments on Azraq's and Samad's summary writing

\begin{tabular}{|c|c|c|}
\hline Content & Organization & Language \\
\hline $\begin{array}{l}\text { - Ideas are accurately } \\
\text { extracted } \\
\text { - There are comparison of } \\
\text { effects } \\
\text { - Able to interpret } \\
\text { information presented in } \\
\text { text } \\
\text { - Most of the ideas are } \\
\text { elaborated but some are } \\
\text { unclear }\end{array}$ & $\begin{array}{l}\text { - } \quad \text { No introduction } \\
\text { - An attempt was made to } \\
\text { organise the writing in } \\
\text { some places } \\
\text { - Some problems with } \\
\text { organisation such as } \\
\text { similar ideas were } \\
\text { separated into two } \\
\text { paragraphs. } \\
\text { - Use of transition is seen to } \\
\text { contrast as well as add } \\
\text { further information. }\end{array}$ & $\begin{array}{l}\text { - Some minor grammatical } \\
\text { errors } \\
\text { - Some words were replaced } \\
\text { from the original sources. } \\
\text { So an attempt to } \\
\text { paraphrase could be seen. }\end{array}$ \\
\hline
\end{tabular}

In terms of content, the participants accurately extracted details from both the passages. They compared and contrasted the information which shows their ability to bring the ideas together:

In cyberculture, identity is the cultural effect. Users are allowed to create their own world and identity ... However, the cultural effect in printing is language, which was standardized by translating works from Latin to national languages.

[Summary Transcript]

They were also able to interpret the information presented in the passage:

Commercial pressures are blatantly present in the pop-up advertising which finances so much 'free' activity.

[Original passage: Cyberculture: the artificial world of the internet]

The economical effects in cyberculture is the growth of pop-up advertisements to make profit. 
However, some ideas are not elaborated well, making them unclear:

Other than that, the inequalities in gender and class where there are different genders and status of users.

[Summary Transcript]

In terms of organisation, the summary was relatively organised. However, there was no introduction given by the participants. The participants started the first sentence with an idea:

One of the effects of printing and cyberculture is cultural effects.

[Summary Transcript]

Furthermore, the participants separated the economic effect into two paragraphs rather than discussing the idea together. Nonetheless the participants attempted to use logical connectors to show contrasting ideas or to move to the next idea:

Besides that, the economic effect in cyberculture...

[Summary Transcript]

Azraq mentioned in the interview that the convention of writing a summary was taught by the lecturer. He then followed the instruction given by the lecturer:

The summary, the lecturer told us it will be good to reduce any repeating words. So just include crucial points. But don't be too direct. If it says "in addition", don't reuse it but change to "moreover".

[Stimulated recall interview]

His behaviour of following the lecturer's suggestions shows that he probably believes that the lecturer's suggestions could be the way to write a summary. However, he also mentioned that:

This is basic, from secondary school.

[Stimulated recall interview]

This indicated that he not only used his prior knowledge on writing a summary but also combined it with the knowledge that he acquired in the EAP class.

Samad, on the other hand, stated that writing a summary meant just taking important information:

Like this, we just take points that are above here, don't have to take all of it [indicating the cyberculture article].

[Stimulated recall interview]

He also gave a rather vague response in terms of his contribution to the reading task: 
The points that I gave? I can't remember the points but as I read along and they say "yeah this could be one" [meaning if the point seems relevant, I will accept his opinion]. Because at times the points are the same"

[Stimulated recall interview]

The use of language in the summary writing was quite good. There were some minor grammatical errors made;

Effect of printing is the increment of popular books...

[Summary Transcript]

Moreover, the participants paraphrased the details taken from the passages. They were able to paraphrase while keeping the meaning of the information. The response shows that participants are able to interpret the information as well:

... the economical effect in cyberculture is the growth of pop-up advertisements to make a profit.

[Summary Transcript]

Commercial pressures are blatantly present in the pop-up advertising which finances so much 'free' activity.

[Original passage: Cyberculture: the artificial world of the internet]

Overall, the participants managed to accomplish the reading task. However, in some parts of the writing the participants did not explain the idea and this meant the sentences were incomplete. The written work shows participants' ability to write a compare and contrast summary. The work also displays the ability to extract information from different sources. However, the participants were unable to bring some of the ideas together and discuss them clearly. The ideas seem to stand separately. Although the participants used key terms from the passage, they attempted to use their own words to write the summary. The content and organisation of the written work could be placed on the relational level of the SOLO taxonomy. The language use could be placed on the multistructural level because there were some grammatical errors.

All in all, based on the final product which is the summary writing, the written work could be placed on a relational level for content and multistructural level for language use. The earlier parts such as mind maps helped Azraq and Samad to produce the summary. Furthermore, this shows the process that the participants used to do the summary.

\section{b) Hussein's written work}

Hussein and his friends started the task by reading both the passages. Then they proceeded to compare and contrast the information. 


\section{i) Compare and contrast table}

Figure 11. Compare and contrast table of the effects of print revolution and cyberculture for Hussein's work

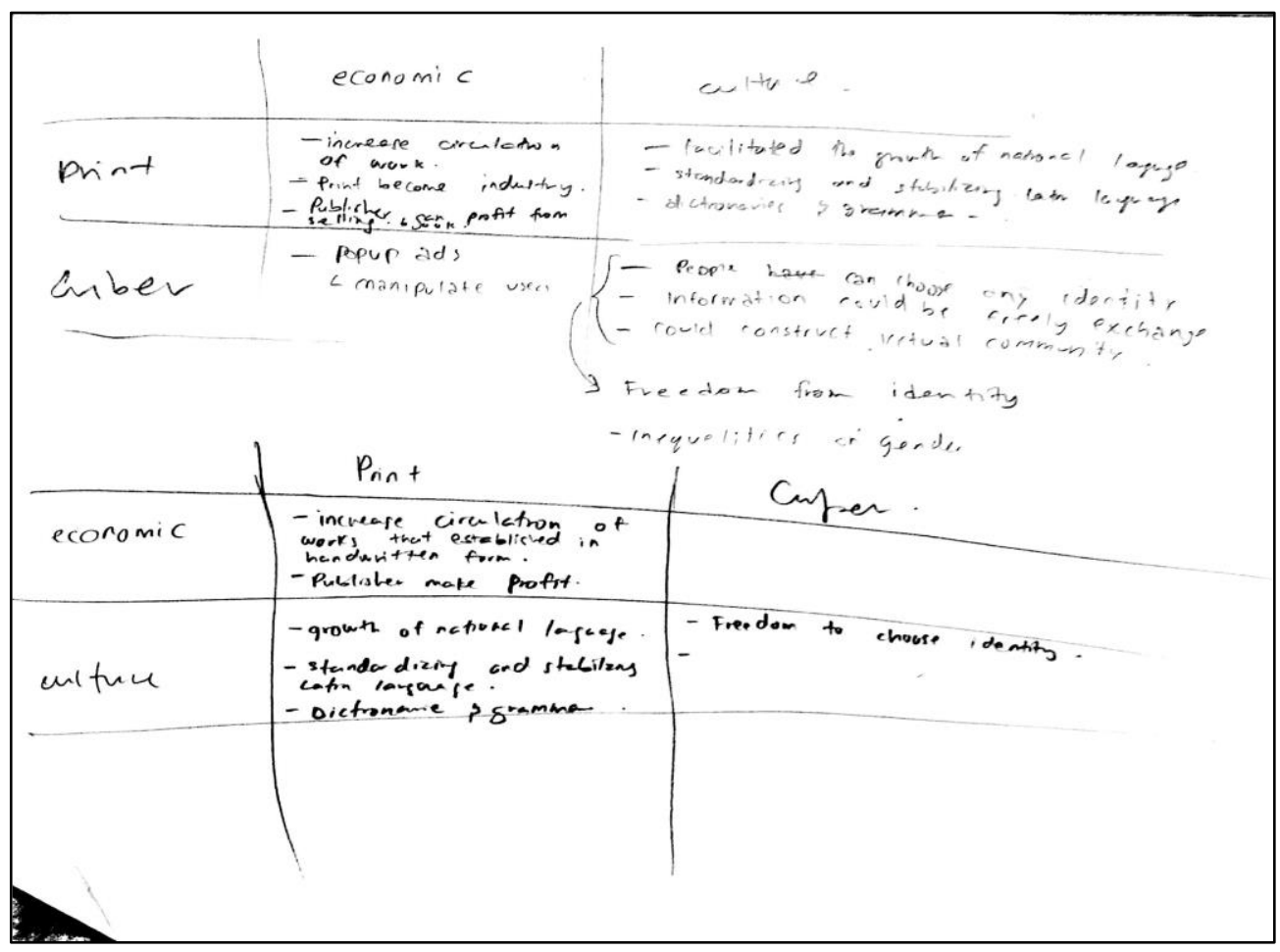

Note: Figure is unclear.

Figure 11 shows Hussein's compare and contrast table on the effects of Print Revolution and Cyberculture. Hussein and friends compared the "Print Revolution" and "Cyberculture" passages in terms of economy and culture. The comparison details were presented in a tabular form.

Hussein and his friends also mostly extracted the ideas word for word from the texts. Hussein stated that he and his friends read the passages to find similar ideas before putting them in the table:

We read first, when we find a point we grasp it like economy, effect, or social. Then when we find the points, we find points that can be related to the earlier point. Whether they relate to effect or economy.

[Stimulated recall interview]

He also stated that assembling the ideas into a table is much clearer compared to other types of graphic organizers:

A flow chart could be confusing. Like this is much straightforward.

[Stimulated recall interview] 
This suggests that he is unaware of the existence of the different types of graphic organizers and the purposes they serve.

ii) Summary writing on the effects of the print revolution and cyberculture The summary was written with the assistance of the compare and contrast table (Appendix S2 , page 274). Table 20 shows the evaluation of the summary writing.

Table 19. Comments on Hussein's summary writing

\begin{tabular}{|c|c|c|}
\hline Content & Organisation & Language \\
\hline $\begin{array}{l}\text { - Information was extracted } \\
\text { from different sources } \\
\text { - There was no comparison } \\
\text { made in the summary } \\
\text { - Inaccurate information } \\
\text { present in writing }\end{array}$ & $\begin{array}{ll}\text { - } & \text { No introduction } \\
\text { - } & \text { Ideas are distorted } \\
\text { - } & \text { Ideas are not cohesive }\end{array}$ & $\begin{array}{l}\text { - Sentence is fragmented } \\
\text { - } \quad \text { Glaring grammatical errors }\end{array}$ \\
\hline
\end{tabular}

In terms of the content of the summary, Hussein had extracted the information from 'Print Revolution' and 'Cyberculture' without combining the ideas. The ideas were merely stated without attempting to link the ideas.

The publisher makes profit by publishing books that would sell fast. Furthermore, printing revolution also gives a huge impact towards culture, such as growth of national languages from translation of Latin.

[Summary Transcript]

Hussein stated that the lecturer taught them not to elaborate in summary writing:

Based on what the lecturer taught us, we don't have to have elaboration in writing a summary"

[Stimulated recall interview]

This then could be the reason why the ideas are stated rather than compared. The ideas were separated into two parts; the first part talked about the printing revolution and the second part talked about cyberculture.

In terms of organisation, there was no introduction given in the summary. The writing started with an idea about the printing revolution. The ideas look distorted and lack cohesion. There was no flow between the sentences; moreover, there was inaccurate information in the summary as well:

... standardizing and stabilizing Latin language.

[Summary Transcript] 
The book trade soon produced translations into national languages emerging at this time. Printing indeed played a key role in standardizing and stabilizing these languages by fixing them in print.

[Original passage: Cyberculture: the artificial world of the internet]

"These languages" refers to the national languages but the students had misinterpreted it as Latin.

Fragments in sentences were present, making reading the summary difficult:

Because of the economic affected by printing revolution, the circulation of works that already popular is increasing.

[Summary Transcript]

The sentences had grammatical errors:

Cyberculture also effect, the inequality in gender that...

[Summary Transcript]

The content and organisation of the summary was placed on the unistructural level of the SOLO taxonomy. This is because although the students were able to identify information from two passages, they did not combine these ideas. The students seemed to choose a surface approach to writing the summary by stating the ideas from the two sources. The language use is placed on the multistructural level because of some glaring grammatical errors as well as fragments present in the writing.

\section{c) Nazira's written work}

Nazira and her group members started the task by doing mind maps for "Print Revolution" and "Cyberculture" passages.

\section{i) Mind maps for "print revolution" and "cyberculture" passages}

Nazira and her peers constructed the mind map for the "Print Revolution" passage by classifying them into economic effects and cultural effects. They used arrows to indicate the ideas. They had two main ideas that they concluded from reading the passages: economic effects and cultural effects. From these two main ideas they then elaborated the ideas further which led to economic and cultural effects.

Nazira stated in her stimulated interview that she and her peers decided to make the map readable by having a clear title and categories. She:

...also wanted to know the overall title and the specific title with smaller parts. So, when we did the mind maps with arrows, it is clearer.

[Stimulated recall interview] 
Nazira and her peers then created the mind map for "Cyberculture". They again used the arrows to distinguish the main categories and sub-categories. They divided the ideas into two political effects and social effects. Social effects were further expanded from categories to subcategories. Figure 12 shows Nazira and her peers' maps on "Print Revolution" and "Cyberculture".

Figure 12. Mind maps on 'print revolution' and 'cyberculture' for Nazira's work

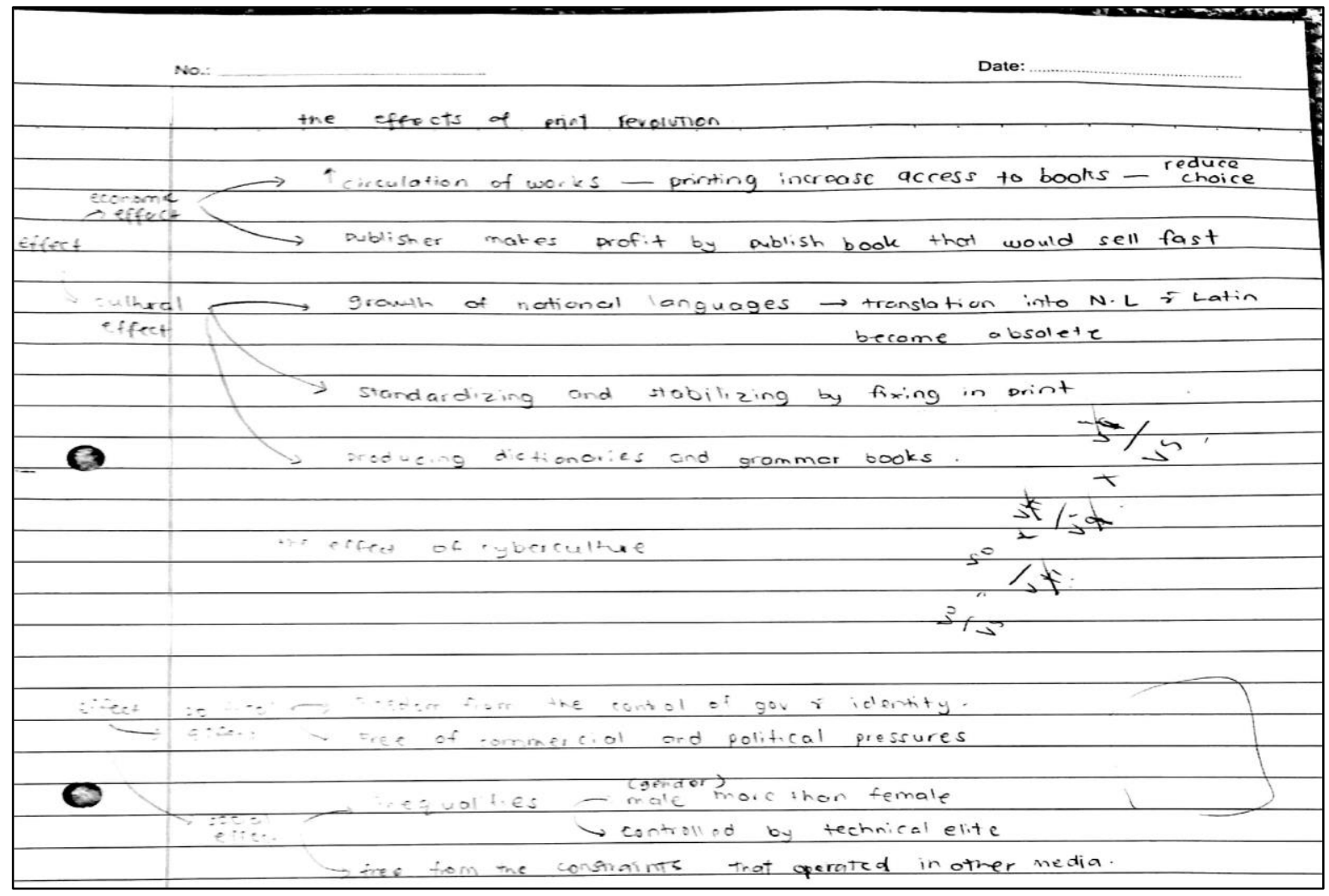

Note: Figure is unclear

From the mind maps for the two passages, they then proceeded to compare and contrast the details.

\section{ii) Compare and contrast table}

The students built a compare and contrast table to show the similarities and differences between their ideas. The students used the similarities and differences of details that they had identified earlier in the mind maps. Figure 13 shows Nazira and her peers' compare and contrast table of the effects of Print Revolution and Cyberculture. 
Figure 13. Compare and contrast table of the effects of print revolution and cyberculture for Nazira's work

\begin{tabular}{|c|c|c|c|}
\hline & eitect of printing & effect of iyberiuttural & \\
\hline ris 1 & -growth of rotional panguages $\rightarrow$ transletion & es $\rightarrow$ render-male more & \\
\hline $\begin{array}{l}\text { Bocial. } \\
\text { exect. }\end{array}$ & Irto N.L \& Lath beytre absolete & $\begin{aligned} & \text { Mon tenato } \\
& \text { sontroned by techinca }\end{aligned}$ & \\
\hline & - staindardizng of powovizing by fixing in & ente & \\
\hline & $\begin{array}{l}\text { print } \\
\text { - prosucting/dictionañes \$grammar books }\end{array}$ & - free from the constraints that & \\
\hline & & operated in olher media & \\
\hline$x-0$ - ettet & & $\begin{array}{l}\text { - freedom from the control of gor } \\
\text { s identity }\end{array}$ & \\
\hline & & $\begin{array}{l}\text { - free of tommercial s polition } \\
\text { piessites }\end{array}$ & \\
\hline serouc & A circustion of weys - pandang increase & & \\
\hline & 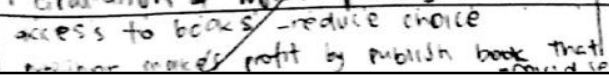 & fil fint & \\
\hline
\end{tabular}

Nazira stated that she and her friends decided to put the ideas in a table to show the differences and similarities:

Because we were comparing both printing and cyberculture. The similarities and the differences.

[Stimulated recall interview]

Initially they had four effects that they had identified in the mind maps: economic effects, cultural effects, political effects and social effects. The students then brought cultural and social effects together as one idea. The compare and contrast table shows the similarities which the students had categorised as cultural/social effects. They then identified political effects and economic effects as differences.

However, Nazira stated that she found it difficult doing the mind map:

It would have been hard if we did it without the lecturer's consultation. In the past we just read, just skim through although we didn't understand. But for this we have to really understand the articles. So, doing it without the lecturer's help would have been slightly difficult.

[Stimulated recall interview]

Nazira also admitted that some parts of the reading were difficult to understand. She discussed it with her peers to understand what was being said in the "Print Revolution" passage:

We were not sure if printing caused "standardizing and stabilizing language by fixing" so we were confused which was the cause and effect.

[Stimulated recall interview]

Nazira was confused about whether printing had caused standardising and stabilising the languages and so were her group members: 
Nazira: $\quad$ Printing caused standardize and stabilize these languages ... by fixing them in print, and producing dictionaries and grammar books.

Friend: $\quad$ No, it's one sentence ... this talks about print and produce book.

[Audio recording of group discussion/ dated: 18/10/16]

The students used the details from the compare and contrast table for writing the summary.

iii) Summary writing on the effects of print revolution and cyberculture

Nazira and her peers wrote the summary with the assistance of the compare and contrast table (Appendix S-2, page 275). Table 21 shows the comments on the evaluation of the summary writing.

Table 20. Comments on Nazira's summary writing

\begin{tabular}{|c|c|c|}
\hline Content & Organization & Language \\
\hline $\begin{array}{l}\text { - There is evidence of } \\
\text { compare and contrast } \\
\text { - There is some inaccurate } \\
\text { information presented in } \\
\text { the writing }\end{array}$ & $\begin{array}{l}\text { - The writing has a clear } \\
\text { introduction } \\
\text { - The ideas are not } \\
\text { developed in a cohesive } \\
\text { manner } \\
\text { - Ideas are distorted }\end{array}$ & $\begin{array}{l}\text { - Confusion of terms is } \\
\text { apparent in the writing. } \\
\text { This led to choosing wrong } \\
\text { vocabulary } \\
\text { - There were some glaring } \\
\text { grammatical errors }\end{array}$ \\
\hline
\end{tabular}

There was evidence of comparison and contrast in the written work:

....while for the cyberculture, there is inequalities....

[Summary Transcript]

There is some inaccurate information in the responses:

Cyberculture are free from the control of government and identity.

[Summary Transcript]

Governments can find ways of censoring Web content.

[Original passage: Cyberculture: the artificial world of the internet]

In terms of organisation, there was a clear introduction. The summary started with the thesis statement:

The effects of printing and cyberculture can be divided into three main categories which is social or culture effect, political effect, and economic effect.

[Summary Transcript]

However, the writing was not cohesive. The ideas are not well developed and seemed distorted:

There are also free of commercial and political pressure.

[Summary Transcript] 
The written response shows that students were confused between the terms which led to choosing inappropriate vocabulary:

The growth of national languages brings a social effect to the printing revolution.

[Summary Transcript]

The great cultural impact of printing was that it facilitated the growth of national languages.

[Original passage: Cyberculture: the artificial world of the internet]

There were some glaring grammatical errors in the writing:

... publisher also make profit...

[Summary Transcript]

The information was taken from the passage without any attempt to paraphrase. Nazira stated that she was not aware of the term paraphrase:

Does paraphrasing mean we copy and paste?

[Stimulated recall interview]

However, during the group discussion, the lecturer asked the participants to paraphrase the information taken from the passages:

I want to see your own words ... in this case it's called paraphrasing ... your structure is great ... the points you picked up are great but I want to see originality.

[Audio recording of group discussion/ dated: 18/10/16]

To conclude, the responses showed that participants were able to extract information from two passages. Although the writing shows there are comparisons between the two texts, the students did not elaborate the ideas clearly. Further, there was some inaccurate information in the writing. The content and organisation can be placed on the multistructural level of the SOLO taxonomy. The multistructural level dictates that the students were able to produce more than one aspect of the task. In this task, the writing shows that the students were able to compare and contrast the information although there were some inaccurate interpretations. The language use could also be placed on the multistructural level because there were some minor grammatical errors in the summary.

All four participants managed to complete the reading task. This task was done collaboratively with peers. Further explanation of the process of doing the task as well as their interaction with the task will be discussed in the next section of this chapter. 


\section{Interaction with the task}

This part discusses participants' interaction with the task that they did in the class. The participants discussed how they responded to the task, the challenges they faced, how they solved these challenges, and the usefulness of the task for their future learning. The participants also discussed their opinion of the usefulness of the task to their lives.

\section{a) Azraq's views on interacting with the task}

Azraq also showed his ability to make connections between the topics used in class and his existing knowledge on the topics. He displayed his ability to make connections while discussing the reading task that required comparison and contrast of the effects of "Print Revolution" and "Cyberculture". He mentioned that:

Well, another thing is in this article, in academic, they are not overly direct. They can be implicit. Meaning ... I got it from there [referring to the idea]. Meaning that, we have to understand the concept of implicit and explicit.

[Stimulated recall interview]

He realised an academic text could consist of both implicit information where he has to read and interpret and explicit information. Having that realisation made him cautious while reading and able to make connections with the information from the text.

Azraq was also able to relate his own experience to information in the passage:

Because it is related to us. For example, readers at times are able to make their own conclusion. Based on their experiences with people around them. Something like that.

At times, if we want to relate these things, we have to experience things that we observe. If not, we wouldn't be able to. Because I do face this problem [refers to popup ads]. That's why l'm able to relate to it.

[Stimulated recall interview]

Azraq mentioned another example of how his experience is transferred to the task:

At times the points are not true in the internet. So we have to manage.

[Stimulated recall interview]

He realised that the information that he reads may not be accurate and he needed to be able to determine whether to believe it by choosing appropriate information from his experience.

These examples indicate that Azraq has the ability to relate his observations of people's behaviour as well his own experiences to the reading. Thus, he displayed the skill of relating out-of-class experiences to the learning that is done in class. His ability to relate personal experience to the information read in the passage shows that he is able to draw implications 
from what he read. Because of this further step, his written work is placed on the relational level of the SOLO taxonomy, even though the summary writing task did not require him to use his ability to generalise his understanding.

\section{a) Samad's views on interacting with the task}

Samad seemed to have trouble relating the reading passages to his personal experiences. He admitted that he was disinterested in reading more about the topic:

Discussing with friends maybe yes... Only in class.

[Stimulated recall interview]

He also stated that he only googled to find meaning:

I google those that I don't understand.

[Stimulated recall interview]

This indicates that he was more interested in finding the meaning of terms or words that he had difficulty understanding, rather than getting to know more about the topic.

Samad had difficulties understanding both the passages, "Print Revolution" and "Cyberculture":

I wanted to try to understand. But it was difficult to understand when I read it once. It takes some time for me to understand.

[Stimulated recall interview]

He claimed that he liked "Cyberculture" but was unable to elaborate why he liked the passage:

I like to read articles like this. It gave me information that I didn't know. Like in cyberculture, like it changes all these, I got to know all that. So, for this article, if I get to learn something new is considered interesting, I like to read it, understand it.

[Stimulated recall interview]

He had a similar issue when he tried to explain what was interesting in the "Print Revolution" passage:

The points. We get to know new points.

[Stimulated recall interview]

Although he tried to explain his understanding of the passages, he may have been unable to express himself because he could not grasp the information in them. Further, the group work did not seem to help much with Samad's inability to understand. 


\section{b) Hussein's views on interacting with the task}

Hussein stated that he found the passages difficult to understand. He had read the passages seven to ten times to grasp the gist of them:

Firstly we had to go through. Then understand what it is about. Then the rest was more of trying to identify the information. Trying to find the connection, the effect and all that.

[Stimulated recall interview]

Although the reading was difficult to understand, he had a structured process of reading the passages:

Read it first. Since I did it in group so we read it individually first. After that we try to do it individually, then we compared and discussed.

[Stimulated recall interview]

Hussein also added that he was not interested in finding out more about the "Cyberculture" passage and "Print Revolution". He stated that the reading skills taught in class were helpful, but not the topics:

Note making is quite interesting because it can be used for other subjects. But if you ask about this article, it's less [refers to interest].

[Stimulated recall interview]

While Hussein found the reading task challenging, he also stated that both the topics taught in class were uninteresting. The skills taught in class seemed helpful to him and he claimed that he could use the skills in other subjects.

\section{c) Nazira's views on interacting with the task}

Nazira stated that she faced difficulties while reading the "Print Revolution" and "Cyberculture" texts. She found the "Cyberculture" passage slightly more difficult than "Print Revolution". She stated that she had to read the "Cyberculture" text a few times to understand it:

...quite a number of times for cyberculture. Because some of the paragraphs in cyberculture were easy to understand. But there are some difficult ones. So sometimes like .. for example, paragraph six took quite a long time.

[Stimulated recall interview]

She also stated that the lecturer guided them through the task:

It would have been hard if we did it without the lecturer's consultation.

[Stimulated recall interview]

That she required the lecturer's assistance to guide her through the task suggests the reading level was above an independent reading level for at least some of the group. 
In addition, she mentioned that she was not interested in non-fiction passages such as "Print Revolution" and "Cyberculture":

Probably because I was not interested in these types of articles. Like very serious, facts. This is more of an opinion. Not entertaining so it was a bit difficult.

[Stimulated recall interview]

It became clear that Nazira found the reading task quite challenging. She found the "Cyberculture" passage difficult to comprehend compared to "Print Revolution". She also struggled to make sense of paragraph six of the 'Cyberculture' passage.

The interview with Azraq showed a relatively high level of interaction with the reading task. $\mathrm{He}$ was able to use his own experience in the task. He took the initiative to identify examples to be included in the discussion. There was a gap between his written work and his explanation of his understanding of the task. His oral explanation showed that he was more engaged with the task but this was not evident in the written work. The rest of the participants claimed that they all had difficulties in doing this task. They faced some difficulties in understanding the passage due to their low level of proficiency of English as well as the complex way the information was presented in the passage. The participants also claimed that they were not interested in the reading topic.

All four participants had gone through similar phases of responding to the reading task. They had started reading the passages before constructing a graphic organizer that assisted them in writing the summary. Three of the participants - Azraq, Samad and Nazira - built mind maps for the 'Print Revolution' and 'Cyberculture' passages before putting the information into a compare and contrast table. Hussein, on the other hand, read and discussed the ideas with his peers and then proceeded to construct a compare and contrast table that aided his summary writing.

\subsubsection{Summary of Unit 2}

In short, Azraq, Samad, Hussein and Nazira claimed to have various purposes for learning English in the EAP classroom. These purposes are related to their more distant goals of being able to communicate with people, being able to obtain information as most things are written in English, and also to acquire jobs. The participants also said that they have specific expectations of learning English in the EAP classroom. The participants claimed that they would like to learn interesting topics and about knowledge that is useful to them.

The data from one specific task in the EAP class help to further support the participants' views on learning in the EAP classroom. Table 22 gives a summary of the participants' responses to the written work in Unit 2. 
Table 21. Summary of the participants' responses to the written work in Unit 2

\begin{tabular}{|c|c|c|c|c|}
\hline Written work & Azraq & Samad & Hussein & Nazira \\
\hline $\begin{array}{l}\text { Level of } \\
\text { SOLO } \\
\text { Taxonomy for } \\
\text { mind map } \\
\text { task }\end{array}$ & $\begin{array}{l}\text { - Content: } \\
\text { Relational } \\
\text { - Language: } \\
\text { Multistructural }\end{array}$ & $\begin{array}{ll}\text { - } & \text { Content: } \\
& \text { Relational } \\
\text { - } & \text { Language: } \\
& \text { Multistructural }\end{array}$ & $\begin{array}{l}\text { - Content: } \\
\text { Unistructural } \\
\text { - Language: } \\
\text { Multistructural }\end{array}$ & $\begin{array}{l}\text { - Content: } \\
\text { Multistructural } \\
\text { - Language: } \\
\text { Multistructural }\end{array}$ \\
\hline $\begin{array}{l}\text { Views on } \\
\text { interacting } \\
\text { with the task }\end{array}$ & $\begin{array}{l}\text { Challenging } \\
\text { task but used } \\
\text { various ways } \\
\text { to overcome } \\
\text { the difficulties } \\
\text { - Was engaged } \\
\text { in the task and } \\
\text { was able to } \\
\text { use personal } \\
\text { experience to } \\
\text { understand } \\
\text { the reading } \\
\text { passages }\end{array}$ & $\begin{array}{l}\text { Challenging } \\
\text { task. He had } \\
\text { difficulties } \\
\text { understanding } \\
\text { the passages } \\
\text { Disinterested } \\
\text { in the } \\
\text { passages }\end{array}$ & $\begin{array}{l}\text { Challenging } \\
\text { task. He read } \\
\text { it numerous } \\
\text { times to make } \\
\text { sense of the } \\
\text { passages. } \\
\text { Disinterested } \\
\text { in the } \\
\text { passages }\end{array}$ & $\begin{array}{l}\text { - Challenging } \\
\text { task. She faced } \\
\text { difficulties in } \\
\text { understanding } \\
\text { one of the } \\
\text { passages and } \\
\text { found the } \\
\text { information } \\
\text { confusing. } \\
\text { Disinterested in } \\
\text { the passages }\end{array}$ \\
\hline
\end{tabular}

All four participants agreed that the task was challenging and they had faced difficulties responding to it. Despite the difficulties, the participants managed to accomplish the task given to them. The responses varied from unistructural to multistructural levels of the SOLO taxonomy. This task was categorised as being at the relational level. Only two participants were able to achieve the relational level. This could be seen in the organisation of their end product, and the writing of a summary which was merely listed without combining the ideas. The participants also stated that they were not interested in the topic of the reading texts for this task but the skills that were required for the task were useful.

However, the participants also described the way that, at times, the knowledge and skills taught in the EAP classroom were not transferable due to the limited opportunities presented in the educational environment in their other subjects outside of the EAP classroom. The engineering programme that they were enrolled in did not require much reading and so they were unable to use the reading skills effectively in the other subjects. Another reason was the choice of Bahasa Malaysia that was used at times by some of the lecturers in the other subjects. The participants also provided some insight into some less direct ways that their background as well as the community's view of language use might influence their learning of English.

The participants claimed to have faced challenges in learning and practising English because of their lack of English proficiency as well as their background in using the native language while growing up. The participants also claimed that they made an effort to learn English in the EAP classroom as well as out of the classroom and this effort could be seen through observation in the way they tried to find solutions to solve the difficulties they were experiencing while learning in the classroom. The participants described having attempted to use the 
knowledge from the EAP classroom in other courses that they were taking. They also had taken the initiative to practise the language on their own.

Lastly, although there were many aspects that influenced participants' learning and their practice of English, they all reported that learning the English language was important to achieve their goals.

\subsection{Unit 3}

Brief description of the setting and demographic details of participants

The data for Unit 3 were collected from the same public university as the data for Units 1 and 2. The class in Unit 3 also focused on reading skills and the lessons were conducted twice a week. The participants were enrolled in the engineering programme, majoring in the civil division. There were four participants in this unit, three Malay female participants and one Indian male participant. All the participants have been given pseudonyms. The female participants were Najla, Ezadura, Azrina, and the male participant was Satish. The participants were 19 or 20 years old.

This section of the chapter is divided into responses to learning in the EAP classroom, responses to specific class task, and the overall summary of Unit 3.

\subsubsection{Responses for Learning in the EAP Classroom}

Similar to Units 1 and 2 there were five themes generated in Unit 3. These five themes are having multiple purposes for learning, engaging with the content, acknowledging the environment beyond the EAP classroom, feeling anxious about learning English, and making an effort in learning English. Table 23 shows a summary of themes and sub-themes for unit 3.

Table 22. A summary of themes and sub-themes for unit 3

\begin{tabular}{|c|c|c|c|c|}
\hline \multicolumn{5}{|c|}{ Themes/ sub-themes } \\
\hline $\begin{array}{l}\text { Having multiple } \\
\text { purposes for } \\
\text { learning English }\end{array}$ & $\begin{array}{l}\text { Engaging with } \\
\text { the content }\end{array}$ & $\begin{array}{l}\text { Acknowledging } \\
\text { the environment } \\
\text { beyond the EAP } \\
\text { classroom }\end{array}$ & $\begin{array}{l}\text { Feeling } \\
\text { anxious about } \\
\text { learning } \\
\text { English }\end{array}$ & $\begin{array}{l}\text { Making an effort } \\
\text { in learning } \\
\text { English }\end{array}$ \\
\hline $\begin{array}{l}\text { - Learning } \\
\text { through English } \\
\text { at the university } \\
\text { - Learning for } \\
\text { future careers } \\
\text { - Learning } \\
\text { English for } \\
\text { global } \\
\text { communication } \\
\text { - Having to do } \\
\text { EAP }\end{array}$ & & $\begin{array}{ll}\text { - } & \text { Transferring } \\
\text { into other } \\
\text { subjects } \\
\text { - Being } \\
\text { influenced by } \\
\text { the home } \\
\text { environment } \\
\text { - Having } \\
\text { perceptions } \\
\text { of the social } \\
\text { environment }\end{array}$ & $\begin{array}{l}\text { Worrying } \\
\text { about the } \\
\text { level of } \\
\text { English } \\
\text { proficiency } \\
\text { - Worrying } \\
\text { about } \\
\text { reputation }\end{array}$ & $\begin{array}{ll}\text { - } & \text { Finding ways } \\
\text { to overcome } \\
\text { learning } \\
\text { problems } \\
\text { - Being willing } \\
\text { to learn } \\
\text { Being willing } \\
\text { to participate } \\
\text { in the } \\
\text { classroom }\end{array}$ \\
\hline
\end{tabular}




\begin{tabular}{|l|l|l|l|}
\hline & & & $\begin{array}{l}\text { Being willing } \\
\text { to practise } \\
\text { language }\end{array}$ \\
\hline
\end{tabular}

a) Having multiple purposes for learning English

Similar to Units 1 and 2, participants in Unit 3 admitted that they had multiple reasons for learning English in the EAP classroom. The participants said that they were learning English because it is used as a medium of learning, they were learning new skills, for future careers, for trading purposes, for communication purposes, and for socialising. They were taking the EAP course as an educational obligation and the relationship between taking the EAP course and their other reasons for learning English was never explicit.

\section{i) Learning through English at the university}

The participants reported they learn English because it is used as a medium of learning. Azrina described the importance of the material in class:

Like textbooks. Textbooks. The books nowadays are in English. So even mathematic books are in English. So, I have to read in English.

[Semi-structured Interview]

Ezadura also saw this work as:

Very important. Because most of the books are in English. So, it's important, it's like a second language. So, we have to know. I noticed our education is more towards English.

[Semi-structured Interview]

Learning English was perceived as becoming essential for learning in other courses.

\section{ii) Learning for future careers}

The participants reported that another reason to learn English was to be able to get a job in the future. Azrina mentioned the importance of English, even during the recruitment processes:

Because engineers need to communicate in English ... we need to speak in English in job interviews. Since I'm taking civil engineering, I need to speak English more because the companies uh, interview more in English.

[Semi-structured Interview]

Ezadura plans to set up a boutique in the future and she said that she would need to be able to speak in English to customers because Malaysia is a multilingual country:

Because Chinese and Indians speak more in English. So, if we were to discuss business, they will use English because some might find it difficult to communicate in 
Malay [Bahasa Malaysia]. So, they speak in English more. So that's the only way to help us communicate.

[Semi-structured Interview]

Satish also claimed that he needed to be proficient in English to communicate with companies in the area of information technology:

I am from a computer background, normally I deal with the computer things, so normally, when you want to approach companies to get sponsors or computer parts for demo PC, normally you have to converse in English. And the paperwork too, is in English.

[Semi-structured Interview]

Azrina added that she realised that she would need English in order to expand her online business. She found that she also needed to communicate in English with the customers in their preferred language:

Now l'm doing an online business in Instagram. Maybe I would expand the business so that it will become successful ... sometimes I promote in Malay [Bahasa Malaysia]. But there are some Chinese customers. They order in English, although they understand Malay [Bahasa Malaysia]. So, I speak to them in English too.

[Semi-structured Interview]

These participants predicted that they would use English to assist them in their careers regardless of the type of job they do.

\section{iii) Learning English for global communication}

The participants claimed that learning English would help them in interacting with people in Malaysia as well as people outside of Malaysia. Azrina mentioned that English helped her to communicate with her friends from different ethnic backgrounds:

I also have Chinese friends and they sometimes speak in English. They find it difficult to speak in Malay [Bahasa Malaysia] so I have to speak in English to them.

[Semi-structured Interview]

Najla noted that English helped her communicate with an international student who gives her help in her studies:

I'm friends with an international student. I have to communicate in English with her because she can't understand Malay ... Because I usually consult her for my studies, things that I don't understand. She is smart and is able to explain things that I don't understand to me. Yeah, it's important. When we can't speak English and the other person doesn't understand Malay [Bahasa Malaysia], we can't communicate, like someone from overseas who can't understand Malay [Bahasa Malaysia].

[Semi-structured Interview] 
Satish also mentioned that he is able to communicate with non-Malaysians:

You get to communicate with a lot of people. Not really constrain to uh, the locals.

[Semi-structured Interview]

The participants also added that they used English to socialise with people. Azrina claimed that she had the opportunity to make friends with people across the globe:

Before this we have Facebook, Instagram. So, I have many friends from overseas. I get to communicate with Europeans and try to speak with them.

[Semi-structured Interview]

Ezadura uses English as a conversation starter to make friends:

It helps us sometimes to start conversations with others.

[Semi-structured Interview]

So, it was quite a strong theme in this unit that learning English had opened opportunities for the participants to socialise with people.

The variety of reasons the participants had for learning English linked to learning English within the classroom as well as beyond the classroom.

\section{iv) Having to do EAP}

Participants mentioned that they learn English in the EAP course because it is a required course that they had to enrol in as part of the Bachelor degree programme. Satish reported:

It's a compulsory subject for us ... Actually, no goals and no aims. But just wanted to find out what it is about. What are they going to teach?

[Semi-structured Interview]

Azrina mentioned that she learned English as it will help her in the final examination:

Maybe it will help in the final exam because (name of the lecturer) told us about the final exam. She explained that final exam is about reading and answering questions.

[Stimulated-recall Interview]

Although participants claimed that they enrolled in the EAP course because it was a requisite, the participants in this group also mentioned that they had learned transferable new reading skills. Ezadura noted:

You mean if it's new. Hah. When we were in schools we didn't do it in this manner. Extract the information. We were just asked to highlight points that we think are important. 
Satish stated that he also learnt the new reading strategy of annotation. He described the usefulness of the skill and as a result indicated his positive feeling about the usefulness of the course, suggesting that if a student had not taken the EAP course, he or she would not be able to understand what annotation is:

Let's say for the normal person they wouldn't know what annotation is.

[Stimulated-recall Interview]

Although participants had initially enrolled in the EAP class because it was compulsory, in this group, two participants were able to describe the usefulness of the new skills they had learnt.

\section{b) Engaging with the content}

The participants said that they have particular preferences and expectations when learning English in the EAP classroom.

The participants said that their interest in reading in class depended on the topic. For Satish the title was important (as it was for some participants in the previous unit):

I normally see the title first then ... Then let's say if it's interesting I will continue to read the third and so on.

[Semi-structured Interview]

For Ezadura what was relevant to her interest in the topic in class was her existing preferences for reading; it:

Depends on the type of book that I like to read.

[Semi-structured Interview]

Some insight into the participants' preferences for different topics could be gained from what they read in their leisure time. Najla stated that she likes to read paranormal novels:

Depends on the topic, if the topic is interesting I will read to the end. For example, "Twilight". I'm very interested in the series. This inspired me to read all the series. Which enables me to read till the end.

[Semi-structured Interview]

Ezadura was systematic in her choice of leisure reading:

If I found books that I'm interested in then I will read the synopsis. If I'm interested then only I will buy. If in English, I'm more interested in motivation.

[Semi-structured Interview]

In contrast to their clear enjoyment of leisure reading, the participants said that they feel forced to learn in the EAP classroom. Azrina vividly conveyed her reluctance to become engaged in a task with content that didn't interest her: 
Because sometimes when I read I will feel sleepy and bored. But then the lecturer instructs us to do annotation and I have to be able to focus in order to find the points. uh, it's like that, so half-half. But reading, I find it boring, so I don't really want to read. But when the lecturer asks us to do the annotation then I'm like OK, read again.

[Semi-structured Interview]

For Najla the content could not overcome initial disengagement:

Because sometimes I'm not in the mood to learn English. It distracts me, like I can't read. So, when I'm not in the mood to read, I'm unable to understand what the author is trying to say. So kind of difficult.

[Semi-structured Interview]

Both Azrina's and Najla's comments indicate their frustration with the reading activities in the EAP classroom. A strong feeling emerged that they may find lessons taught in class boring at times and then they lose interest in learning the particular lesson.

To sum up, a strong contrast emerged between the evident pleasure some of these participants had in reading content they had chosen for themselves and the content that was being taught in the EAP classroom which they found boring. This then affected participation in the classroom.

\section{c) Acknowledging the environment beyond the EAP classroom}

The participants in this unit indicated that the out-of-EAP classroom context affected their learning of English. For the purposes of this study the out of EAP environment included the other subjects they were taking, in this case engineering subjects, their home environment and their perception of the community in Malaysia.

\section{i) Transferring into other subjects}

The participants had mixed opinions about using the reading skills taught in the EAP classroom in other subjects. Some of the participants felt that they had limited opportunities to practise the reading skills learnt in the EAP classroom in the other subjects in which they were enrolled. However, as already seen, some mentioned that they were able to use the skills in other subjects.

Azrina could not immediately see any transfer of EAP reading skills:

I'm not sure because other subjects are more towards calculations ... I've enrolled in English, Mathematics and Engineering Mechanics. All of them focus on calculations.

[Semi-structured Interview]

Ezadura was also uncertain whether the reading skills taught in the EAP classroom might have been helpful to her. She could see one possibility when it might have been: 
Maybe. For example, in mathematics. The explanation is in sentence form. Usually, there are usually a lot of sentences. I try to extract main points and write it on the side. Then I do my own equation. That's how I do it.

[Semi-structured Interview]

It seemed as if she was trying to determine whether she had used the skill taught to her.

Najla was, however, more certain:

Yes, yes, like this semester l'm taking Dynamic skills. This subject is similar to this class [refers to English class], it's all about articles. It's difficult to understand and remember all the sentences. Annotation makes it easier for me to revise.

[Stimulated-recall Interview]

Najla's claim that the annotation skill had helped her to recall the information that she read in the Dynamic Skills course is a model of how a confident transfer of the skills from the EAP classroom to other subjects could work. In this sense this response provides a strong contrast to other uncertainties about, or strong denial of the possibility of transfer in the study.

The participants also mentioned that they had limited opportunities for communicating in English in their other studies.

Ezadura explained they did not always have to use English in the engineering subjects and that lecturers allowed participants to choose the language that they would like to use to conduct their presentation:

Some lecturers give us leeway.

[Semi-structured Interview]

Satish found that in his subject context, Bahasa predominated over English:

Here I don't think I do it very often. Other than that, even if I find a person who speaks in English, normally they ... uh, they are normally very far. From different faculty, so it's very rare. And here I speak more Malay [Bahasa Malaysia].

[Semi-structured Interview]

The participants seemed to have different views regarding the use of reading skills in other subjects. They also mentioned that in terms of communicating in English, they did not get the chance to practise the language from the EAP classroom as other tertiary educators do not make English a mandatory language in their classes. In this unit the participants chose Bahasa Malaysia, a language that they were comfortable and familiar with. 


\section{ii) Influence of the home environment}

The language used at home influences participants' learning and use of English and in this unit the participants had different backgrounds. Ezadura and Azrina reported a lot of use of Bahasa Malaysia both at home as previously, and in their academic subjects.

Ezadura said:

I don't really speak in English. I speak at home and here in Malay [Bahasa Malaysia]. It's like if you usually speak in Malay [Bahasa Malaysia], to speak in English is like ... not comfortable, something like that.

[Semi-structured Interview]

Azrina mentioned that Bahasa Malaysia predominated in:

Reading, because my, my home doesn't have English books. Many Malay [Bahasa Malaysia] novels.

[Semi-structured Interview]

Some participants had limited opportunities to practise English at home. However, not all the participants faced this issue. Satish indicated that he speaks English at home.

In this unit it then became clear how strongly the home languages of the participants might be influencing their learning and practising of English. The participants' comments show the degree to which the opportunity to practise English at home or the lack of it may be affecting their comfort level in using the English language in the EAP class.

\section{iii) Having perceptions of the social environment}

Preferences for using language were not just about opportunities to use the language but also about beliefs about the language. Satish said the community's view of English influenced his practice of English. Satish stated:

Because in the Malay [Bahasa Malaysia] community they tend to keep to speaking Bahasa all the time. And let's say in the Indian community they prefer you to be speaking in Tamil itself because if they were to hear you speak in English they will be like oh, this fellow is a white man. White men don't even know how to speak Tamil. Dei you mother tongue, [he used a term mostly used by the Indian community in Malaysia] you should be proud of it and all that. Same goes for the Chinese also.

[Semi-structured Interview]

Satish described the way the community tends to be loyal to their home language. His view was that the community prefers their members to speak in their native language rather than English.

In this section the context for learning English in Malaysia comes through particularly strongly. The participants had a clear understanding of the role the English language plays in Malaysia 
in relation to Bahasa Malaysia and other community languages and how these competing language claims affect where and how they use English.

\section{d) Feeling anxious about learning English}

There had been mixed opinions about the anxiety that the participants face when practising English. Some of the participants mentioned that their anxiety is caused by their lack of proficiency which then leads to admiration and insecurity around other people who are more fluent than them and they are concerned about their reputation. One participant mentioned that he was concerned about simply not providing the right answer because he did not understand the content which might cause others to look down on him.

\section{i) Worrying about the level of English proficiency}

Some of the participants expressed their difficulties in reading due to their lack of proficiency. Azrina explained that:

Most of the students in my class are good at English. So, when they read, they understand quickly. When I read, um, I'm slow at grasping.

[Semi-structured Interview]

This at times makes her feel left out as the teaching of the lessons tends to proceed at a fast pace. Azrina continued:

I'm slow, people are able to understand it faster than me. So, a lot of things happen because of this. All of them know what noun phrase is, I understand it late. So, when I take a lot of time, (name of the lecturer) moves on to something else, I too move on to the next thing rather late.

[Semi-structured Interview]

Ezadura described times when she got stuck because of her lack of proficiency:

There are some. I feel frustrated when I try to find it in Google and I still can't find it. I get stuck; when I get stuck, then I don't know what else to do.

[Semi-structured Interview]

As a result, she felt exasperated when she did not know how to proceed further with the activities done in class.

Another issue for some of the participants was answering in English in the class. Azrina described how lack of proficiency led to nervousness:

If I answer, uh, the question of the lecturer, actually, uh, when lecturer ask I don't know how to answer it, then like uh, I don't know how to say it in English when I'm nervous.

[Semi-structured Interview] 
The participants also reported that their problems with the language cause them to feel particularly nervous when they have to do presentations. Ezadura said:

I have a problem with the language. It's like a mix. Because I'm not sure how to elaborate. I know the point but not sure how to elaborate to make people understand it. Plus, I'm also nervous.

[Semi-structured Interview]

Azrina also agreed that she gets anxious during presentations:

I had a presentation and I spoke in English, I really felt very nervous and at times, uh, I couldn't remember what to say. But since I was nervous, I couldn't speak in English. It's like I forgot what I wanted to say in English.

[Semi-structured Interview]

Previous negative experiences of learning English were a cause of anxiety that some participants identified. Najla stated:

When I was in form five, I was really interested, I used to take classes [refers to extra lessons]. But I used to get low marks in class, like for essays. So, I was fed up.

[Semi-structured Interview]

Ezadura described the consequence of such negative feelings as a desire to avoid learning English altogether:

Because I feel that English is rather difficult to learn. When I was young, I've never learnt in English, usually I will skip the English lessons, go for a walk. Quite normal right? Because I didn't like it.

[Semi-structured Interview]

Azrina assumed she would not do well:

I just like, uh, before this when I was in the secondary school, I didn't like English. I've always scored a 'C'.

[Semi-structured Interview]

Najla, Ezadura and Azrina had scored rather low marks in the subject of English previously. They felt their past experience of low grades had affected their confidence in learning English, resulting in their being anxious about learning and practising the language.

Because of this lack of confidence, these participants felt discouraged from practising English. Najla reported:

It's a confidence issue. Whether others understand what I'm trying to say. If in English, people think what this girl is trying to say. Because there is always "uh", or "er". So, like the audience or people who I'm trying to communicate with would think the same. It's difficult to understand. 
[Semi-structured Interview]

Ezadura was aware that she was not confident in speaking English because she did not see herself as proficient.

Azrina described trying to overcome these negative feelings and that she forces herself to like English because she needs to improve:

I don't like it actually, but I need to like it.

[Semi-structured Interview]

In her case the necessity to use English because of the role it plays in her life was more powerful than her insecurity. Najla, on the other hand, decided to give up and instead use Bahasa Malaysia rather than English:

Not really, I rarely speak in English when I'm out. My speaking is not good. I have to think first. It's time consuming. Like it takes time for me to get across the message so I prefer to use Malay [Bahasa Malaysia].

[Semi-structured Interview]

\section{ii) Worrying about reputation}

Satish mentioned that his reputation and peers' opinions influenced his participation in the classroom.

Satish seemed to be concerned about people's opinions of him in class. He preferred to work alone rather than allow others to see that he was having difficulties:

But sometimes, when I'm given this kind of task, I prefer to do it alone. I don't understand it and then if I were to cloud another fellow's judgement, I don't know ... Let's say, no point you don't understand and you start making a lot of noise, people will be thinking this dumb guy.

[Stimulated-recall Interview]

This led to low participation during group discussions where he prefers to keep his thoughts to himself, rather than discussing them. Satish's anxiety originated not because of his lack of proficiency but because of his lack of understanding of the content.

Najla also said that she does not like to provide answers for fear of being looked down on:

Because I'm afraid the answer might be wrong. Or I'm afraid, I'm not fluent so I'm embarrassed with others, like probably they might not be able to understand what I'm trying to say. 
What comes through this unit strongly then is the participants' reluctance to participate in discussions in class because they did not want to be looked down on by their peers. These challenges caused some of them to fear using the language freely.

\section{e) Making an effort in learning English}

Despite these obstacles, the participants also reported that they do make efforts to learn English. Their effort could be seen through the ways they approached learning in the EAP classroom as well as practising the language away from the EAP classroom.

\section{i) Finding ways to overcome learning problems}

In this unit the participants also recalled examples of how they overcame the challenges they faced while doing reading tasks in the classroom. Najla described specific strategies:

Like combine sentences that are before and after. If I still don't understand it then I will look at the apps.

[Semi-structured Interview]

Azrina stated:

I find in Google for uh, the meaning.

[Stimulated-recall Interview]

Some participants described seeking guidance from others when they faced difficulties in learning in the EAP classroom. Ezadura said:

I will ask my roommate, what she is trying to say.

[Stimulated-recall Interview]

Najla said she relied on the lecturer to explain the lessons when she faced difficulties:

The lecturer said that it was mentioned "these theories", what it meant.

[Stimulated-recall Interview]

So these participants knew how to use the internet, peers and lecturers to help them to overcome the difficulties that they faced in learning.

ii) Being willing to learn

Some participants said that they were keen to learn English. Ezadura said:

I'm interested. Since it is difficult to understand, the feeling to know more is there. Like what do I have to learn if I want to be good. I would still like to learn.

[Semi-structured Interview] 
Azrina described realising the importance of English in her life so that she not only develops the urge to learn but she is also keen to further improve herself.

I think I have to improve more in the future.

[Semi-structured Interview]

Moreover, participants expressed the understanding that learning is progressive. Ezadura noted:

I try to do it on my own ... Then when the lecturer says this is wrong, then I will correct the mistakes.

[Semi-structured Interview]

Azrina added:

So, when I practise that a lot, I'll understand better.

[Semi-structured Interview]

Both Ezadura and Azrina remarked that they have made mistakes and learned from them.

These participants, it seems, could see the benefits in learning English and this had helped them to set goals.

iii) Being willing to participate in the classroom

In this unit the participants also discussed participation in group discussions in class. Some participants said that they made an effort either through attempting to do the tasks individually or collaboratively with their peers. Ezadura preferred to work alone:

Usually I do it in my room.

[Stimulated-recall Interview]

She would participate in groups:

If in the class, I have to. If it's out of class, I participate because I want to.

[Semi-structured Interview]

Azrina, on the other hand, liked to discuss work with friends while doing the tasks in class:

Because friends have many ideas, like my friend has many ideas to talk. Then if I don't have the idea so I just look at my friend and she has ideas, so she tells me like this like this.

[Stimulated-recall Interview]

So, some participants said that they do participate in class but not all the participants enjoyed participating in class. 
iv) Being willing to practise language

Azrina discussed the way she makes the effort to practise English away from the EAP classroom:

For example, like me, I don't know how to speak in English, so I search for words and use it repeatedly, l'll be able to learn even though I didn't learn the words in school. But since I know what to say, I still learn.

[Semi-structured Interview]

That Azrina described the way that she takes the initiative to learn English away from the classroom and she attempts to practise what she learnt shows that for this participant at least, learning English went beyond the classroom.

Participants in Unit 3 discussed their reasons for learning English, their preferences in learning in the EAP classroom, the influence of the out-of-EAP environment, their fear as well as the ways to learn and practise English. These participants differed from the participants in the other units as they seemed to be concerned about their lack of proficiency and their reputation. This was not evident in the other units. The next sub-section will explore the participants' individual responses to a specific reading task done in the EAP classroom.

\subsubsection{Responses to a Specific Task}

\section{Analysis of a written task in the EAP classroom}

Similar to the class activities conducted in Units 1 and 2, the class activities in Unit 3 were conducted in groups. This task was initially given as individual work but the participants had not completed the task so the lecturer had asked the participants to continue the work in the class while discussing it with their peers.

\section{a) Azrina's response to the annotation task}

Azrina said that annotation involved extracting important information:

Annotation is something that makes us understand better. Because at times there are explanations, but it's not important. When we read, we don't understand what is being said. So that's when we do annotation, extract ideas.

[Stimulated recall interview]

Azrina also annotated the ideas in the textbook. Figure 14 shows Azrina's annotation of the passage. Paragraphs 1 and 2 were done with the lecturer's guidance. Paragraph 3 was done by discussing it with her peers. Table 24 indicates the summary of the evaluation of the annotation.

Figure 14. Azrina's annotation of 'Intelligence: heredity versus environment' 


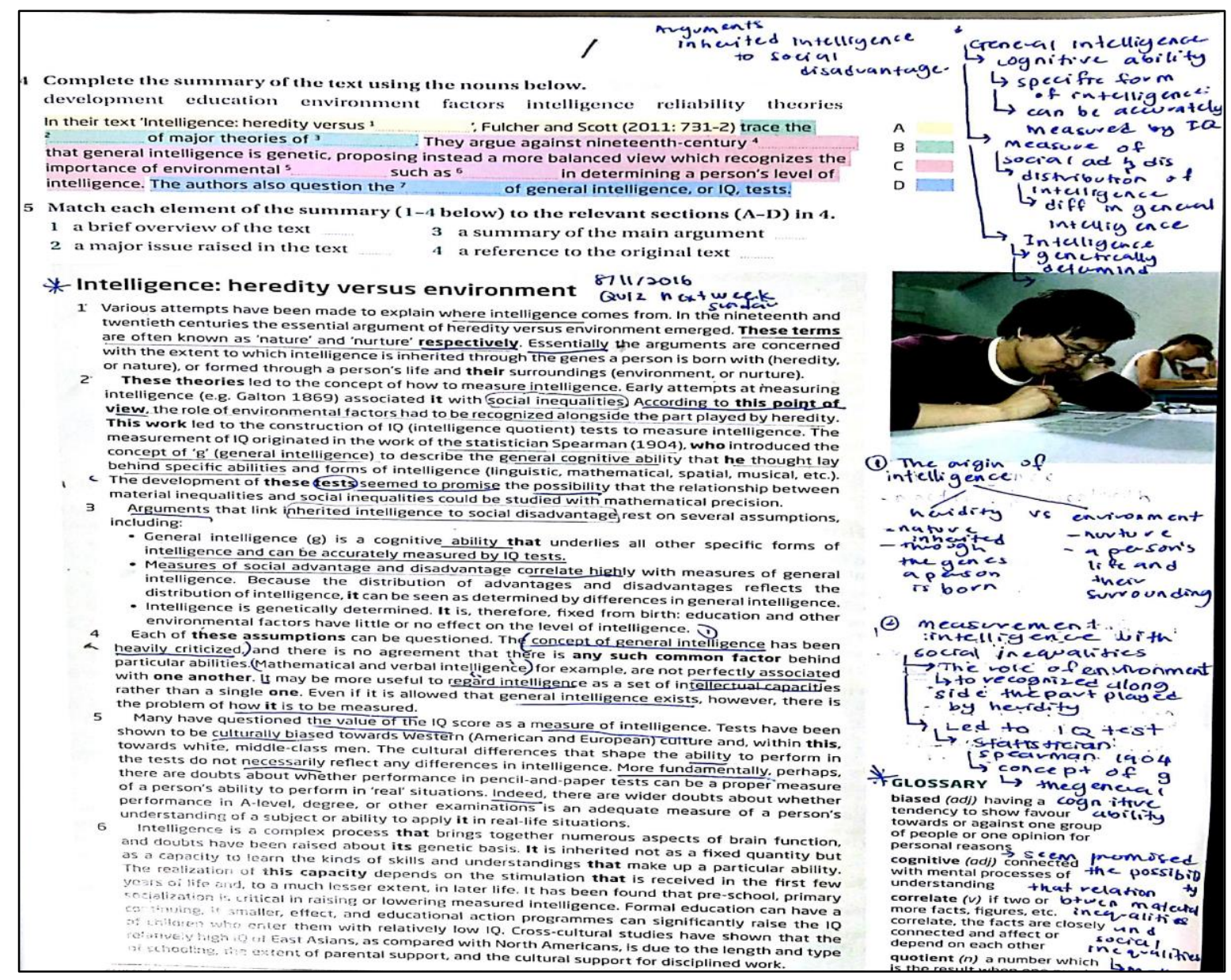

Table 23. Comments on Azrina's annotation

Able to extract pertinent ideas from text

- Ideas are linked within a paragraph

- $\quad$ No connection made between the paragraphs

Azrina was able to identify important ideas from the passage. In paragraph 1, Azrina divided the ideas into two, namely heredity and environment:

l've differentiated heredity and environment. Then I looked for nature and nurture.

[Stimulated recall interview]

She then added elaboration under these ideas. Another example is in paragraph 2. Azrina was able to identify pertinent ideas from each paragraph including:

\section{Measurement intelligence with social inequalities.}

[Annotation Transcript, Paragraph 2]

She was able to summarise the paragraph and pick pertinent ideas from the paragraph:

Based on the signalling words and noun phrase that (name of the lecturer) had taught us. 
Azrina was also able to link the ideas within a paragraph. For example, paragraph 3:

Actually, the second point is related to measure, actually. At the above, it was mentioned "measure by IQ test." Then the second, it explained about measure, what is measure? Then erm, the advantage ... uh, then the "difference in general intelligence", it was mentioned up here, he talked about it again.

[Stimulated recall interview]

There was no connection made between the paragraphs. The annotation was in chunks. She also did not complete the annotation task, only finishing paragraph 1 to paragraph 3 of the passage. She said that there was not enough time to do the task in the class:

On that day, we didn't have enough time to complete, so I just went back.

[Stimulated recall interview]

Of the four participants, she was the only one who completed three paragraphs. The rest of the participants annotated all the paragraphs except for Najla who did not annotate the last paragraph. Based on the annotation made on the paragraphs, this written work could be placed on the unistructural level of the SOLO taxonomy. This is because the work showed pertinent ideas from the paragraphs. There were connections made within the paragraphs but there were no connections shown between the paragraphs.

\section{b) Ezadura's response to the annotation task}

Ezadura annotated the ideas in the textbook (Appendix S-3, pages 277-280). Ezadura stated that her understanding of annotation is extracting and summarising the information in a paragraph:

The main points in a sentence. Like the main idea, what the author is trying to say. That's what I understand. We have to extract that then try to summarize it.

[Stimulated recall interview]

Ezadura stated that the lecturer instructed them to read and annotate the passage:

Firstly she asked us to go through paragraph by paragraph. Then try to annotate and identify uh, if the paragraph is connected to first paragraph. Then identify the connection paragraph by paragraph.

[Stimulated recall interview]

This indicates that Ezadura was clear about the aim of the task. Thus, she understood that the goal of the task was to annotate each paragraph in the passage. Table 25 shows the summary of the evaluation of the annotation task completed by Ezadura. 
Table 24. Comments on Ezadura's annotation

- The ideas are extracted from the paragraph

- The ideas are connected within the paragraphs

- $\quad$ Links between paragraphs

Ezadura extracted the information that she deemed important from the passage:

Spearman (1904) introduce[s] the concept of general intelligence to describe[e] general ability.

[Annotation Transcript, paragraph 2]

Ezadura's written work shows that she was able to connect the ideas within the paragraphs in the passage. For example, she annotated paragraph 5 by drawing arrows between the ideas. Figure 15 shows the annotation for paragraph 5 . 
Figure 15. Ezadura's annotation of 'Intelligence: heredity versus environment'

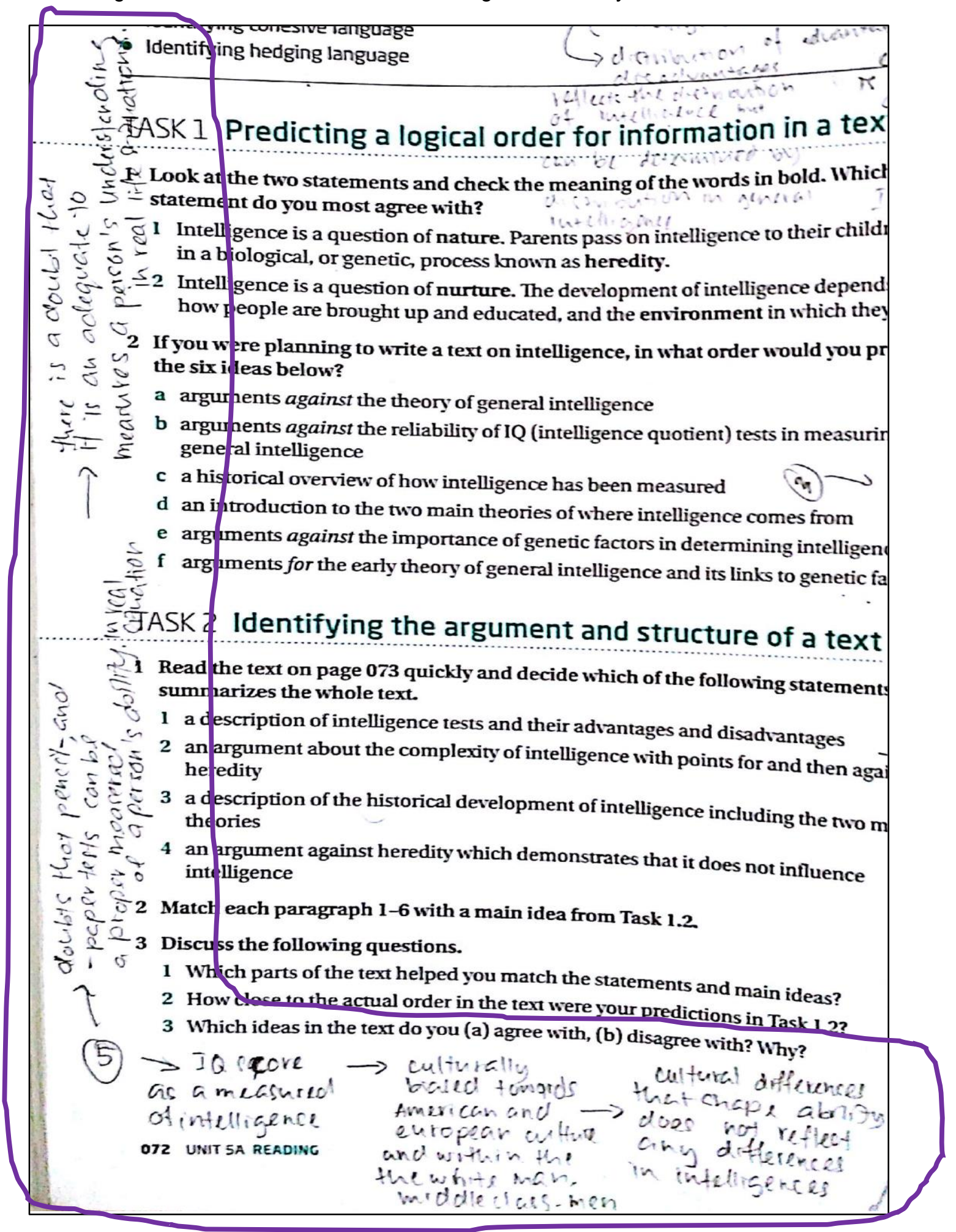

She also linked the paragraphs to show the connections. For example, she drew an arrow between paragraph 3 and paragraph 4 to show that there is a link between the paragraphs. Figure 16 and Figure 17 show how Ezadura linked paragraphs 3 and 4. Figure 16 shows the ideas from paragraph 3 whereas Figure 17 shows the ideas from paragraph 4. 
Figure 16. Ezadura's annotation of 'Intelligence: heredity versus environment'

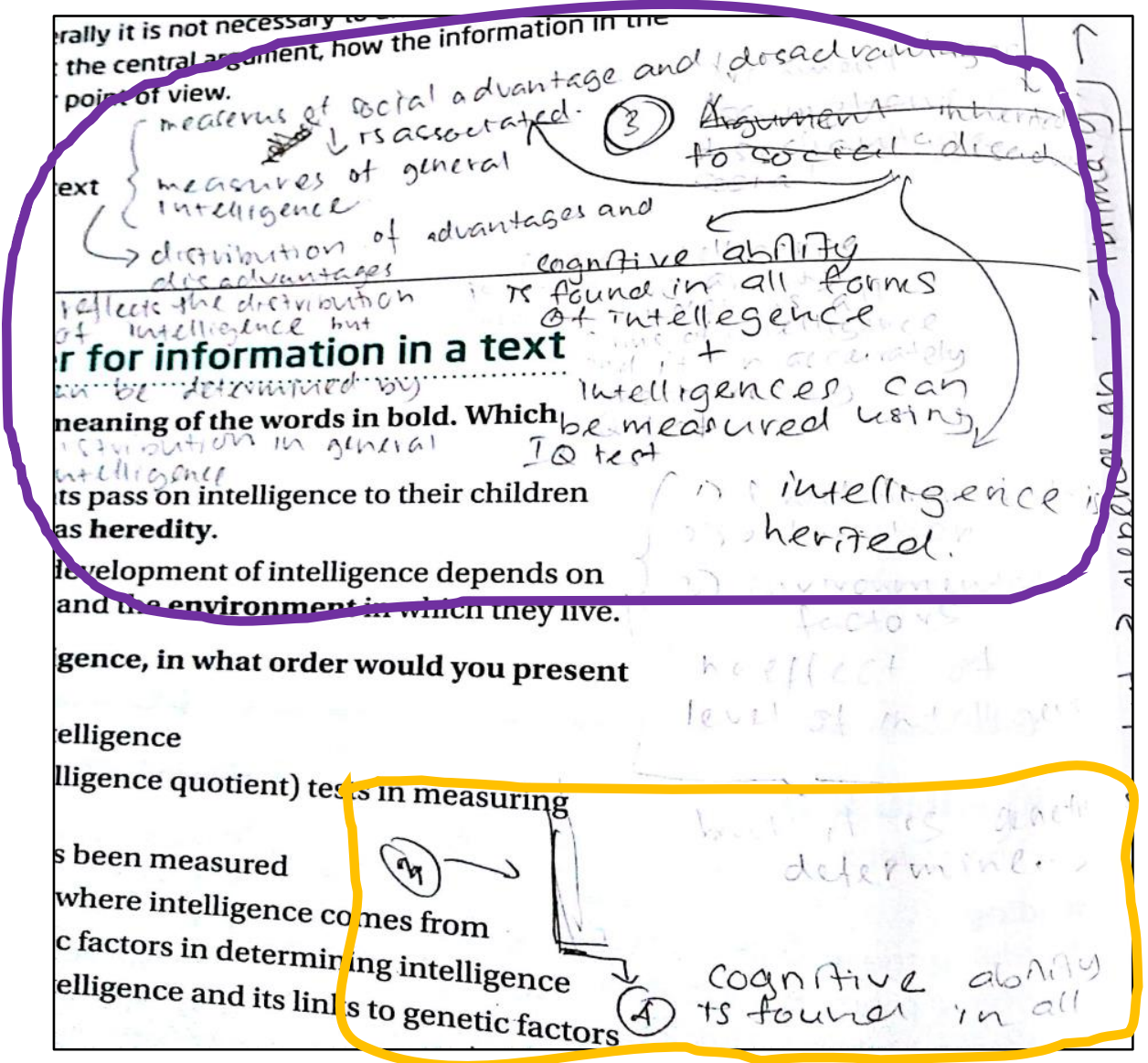


Figure 17. Ezadura's annotation of 'Intelligence: heredity versus environment'

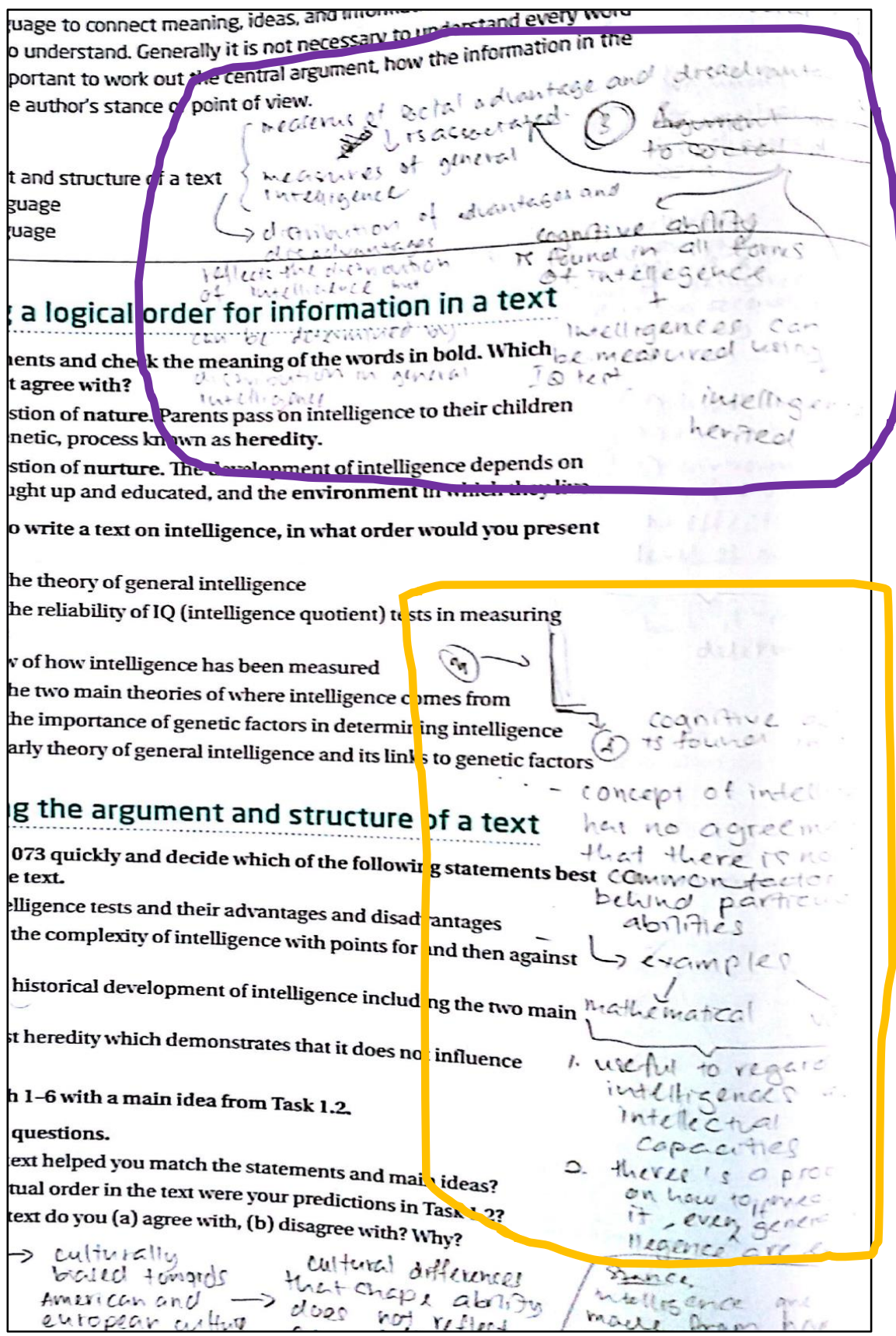

However, Ezadura stated that paragraph 1 was done with the lecturer's guidance. She also stated that she needed assistance from her peers to annotate as well:

I discussed paragraph 2 with (name of the student).

[Stimulated recall interview]

However, she was willing to try to attempt the work on her own as well. She stated that she did paragraphs 3 to 6 on her own. 
This written work could be placed on the multistructural level of the SOLO taxonomy because the written work showed that Ezadura was able to extract information from the passage. She was also able to link the ideas within the paragraphs as well as link between the paragraphs.

\section{c) Najla's response to the annotation task}

Najla stated that her understanding of annotation was identifying pertinent information from a paragraph:

The lecturer taught us annotation is like annotate the most important things that are in the paragraph.

[Stimulated recall interview]

Figure 18 shows Najla's annotation of 'Intelligence: heredity versus environment'. Najla had annotated on a different paper rather than in the book. She said that the first two paragraphs were done with the lecturer's guidance. The lecturer showed her step-by-step how to annotate the two paragraphs. Najla annotated five of the original six paragraphs.

Figure 18. Najla's annotation of 'Intelligence: heredity versus environment'

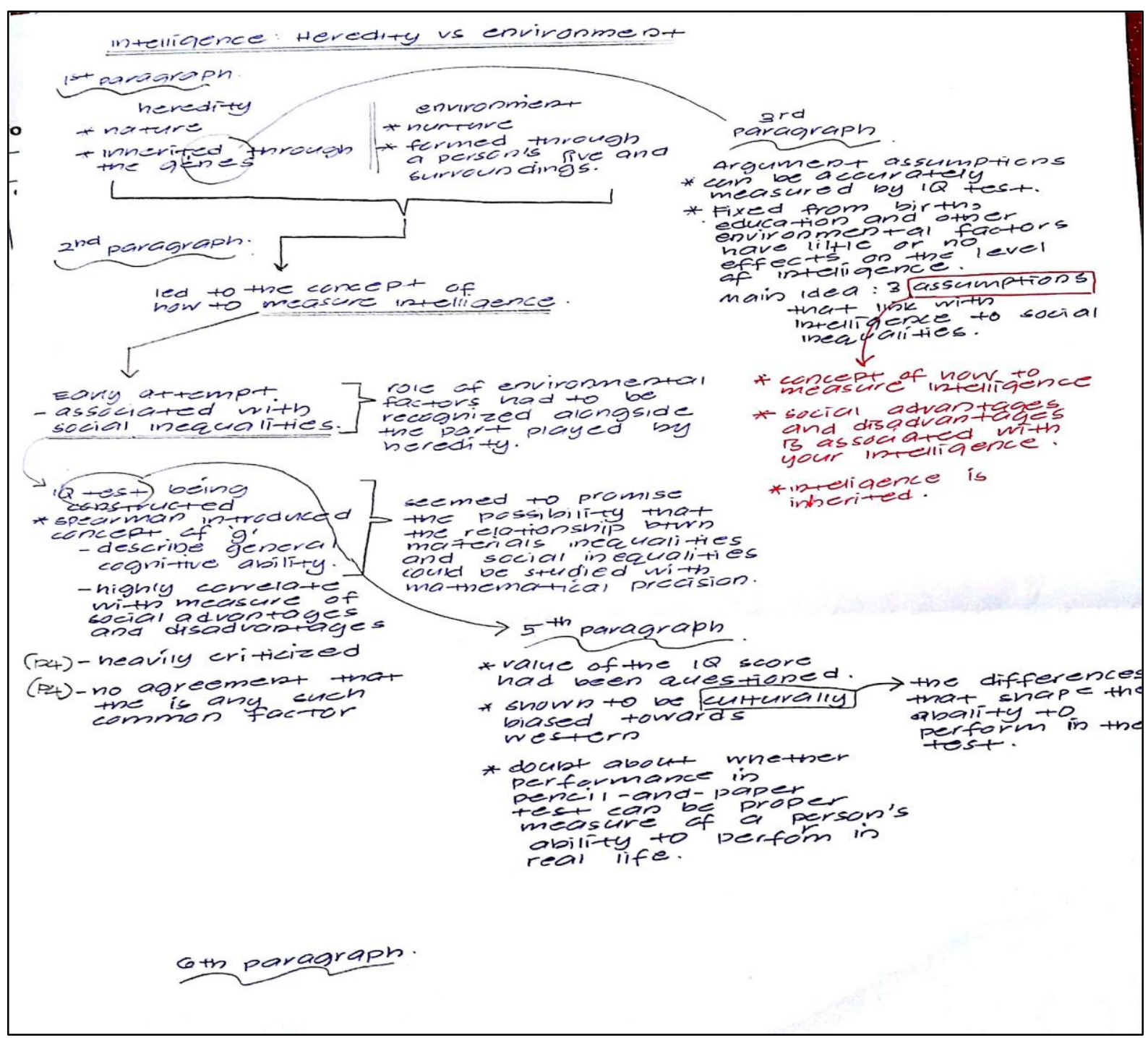


Table 26 shows the summary of the evaluation of the annotation. Najla linked paragraph 3 with paragraph 1. She linked the arguments that relay intelligence is in fact inherited from paragraph 1 to the assumptions made in paragraph 3 . However, she misinterpreted the link between the specific information in paragraphs 1 and 3 . The assumptions made in paragraph 3 should be linked to paragraph 2. This is because paragraph 2 discusses both 'inherited intelligence' and 'social inequalities'. Hence, paragraph 3 is linked to paragraph 2 which is linked to paragraph 1.

Table 25. Comments on Najla's annotation

- The links between paragraphs are made

- Participant is able to summarise the ideas

- Main idea is stated in each paragraph

- Paragraph six is not annotated

Najla also indicated a link between paragraphs 2 and 5. She drew an arrow between paragraph 2 which discusses how IQ tests measure intelligence to paragraph 5 which discusses whether $I Q$ tests are valuable.

However, the annotation for paragraph 4 is unclear. Najla annotated:

No agreement that the (there) is any such common factor.

[Annotation Transcript, paragraph 4]

This information is unclear. She could have explained what 'common factor' means.

Najla is able to annotate by extracting and summarising the information from a paragraph, for example:

Can be accurately measured by IQ test.

[Annotation Transcript, paragraph 3]

This example shows that one of the assumptions that had been made is intelligence which could be measured using IQ tests. This is part of the idea presented in paragraph 3. Another example is that:

[the] Value of the IQ score had been questioned.

[Annotation Transcript, paragraph 5] This shows that she is able to identify the main idea of a paragraph. However, she did not complete the annotation task. She did not annotate paragraph 6 of the passage. Najla said that she could not proceed further because she found the paragraph difficult to understand: 
Because paragraph five looked difficult. Like what you said, it was a bit challenging. So I stopped.

[Stimulated recall interview]

Based on criteria for the annotation task, this piece of writing could be placed on the multistructural level of the SOLO taxonomy. The participant was able to summarise and identify the main idea of each paragraph. She was also able to make the links between the paragraphs in the passage.

\section{d) Satish's response to the annotation task}

Satish stated his understanding of annotation is writing information on the side of the text so that it could be referred to at a later time:

...simple sketch by the side to like whenever you want to refer back, to the paragraph you can just refer to the annotation and then and you can like remember back the whole ... paragraph.

[Stimulated recall interview]

This shows that he understands how to annotate a passage. Figure 19 shows an example of Satish's annotation of the passage. Satish was able to annotate the passage as well as link the ideas. Table 27 shows the summary of the evaluation of the annotation work. 
Figure 19. Satish's annotation of 'Intelligence: heredity versus environment'

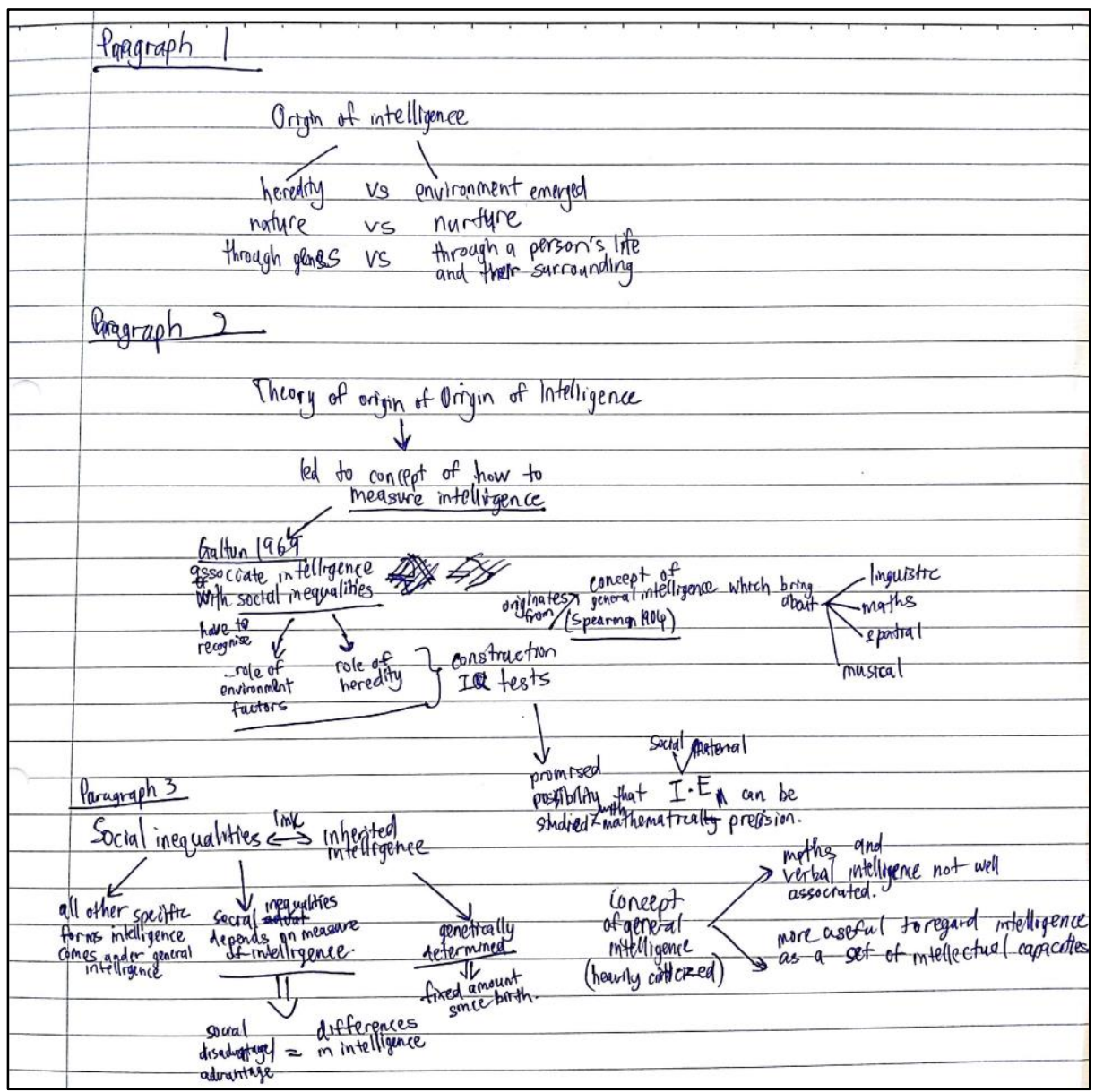

Table 26. Comments on Satish's annotation

- Able to extract information from each paragraph

- Able to link paragraphs with lecturer's guidance

- $\quad$ Able to link ideas within each paragraph

Satish is able to extract pertinent information from a paragraph. For example:

Concept of general intelligence.

[Annotation Transcript, Paragraph 4]

Satish extracted this information from the paragraph as this is an idea that is further elaborated in the paragraph. He is also able to link the paragraphs in the passage with the guidance given by the lecturer:

Yeah, she tried to show that this one has a link and this one has a link. From here, this one has a link.

[Stimulated recall interview]

He was also able to link the ideas using the signalling words that show information is linked between the paragraphs. However, the connection was not shown in the annotation transcript: 
... assumption because here. Ah, this word here. "Rest on several assumption" then I, I thought that ok, this 1,2 and 3 is the assumption. And then from this word "these assumption" is referring to this 1,2 and 3 .

[Stimulated recall interview]

Satish was able to connect the ideas within a particular paragraph. For example:

Galton (1969) associate[s] intelligence with social inequalities.

The above excerpt was linked with:

"Role of environment factors" and "role of heredity.

[Annotation Transcript, Paragraph 2]

The excerpts above indicate that Satish was able to annotate the linked ideas.

Satish completed the annotation task by annotating all six paragraphs (Appendix S-3, pages 282-285). Based on the criteria for the annotation task, this written work could be placed at the multistructural level of the SOLO taxonomy. Although Satish was able to extract the information from the paragraphs, he did not summarise them but chose to extract the exact information from the source. However, he was able to make connections between the paragraphs. This was revealed through the stimulated recall interview.

\section{Interaction with the task}

\section{a) Azrina's views on interacting with the task}

Some interaction with the passage was evident through the interview with Azrina. She was able to relate the text to personal experience:

Then I thought to myself, yeah, it's true because my mother is kind of average but my elder sister is smart. So it's like that.

[Stimulated recall interview]

She also mentioned that she was interested in finding the gist of the passage:

When I read I felt like I would like to know more about it, about intelligence.

[Stimulated recall interview]

Although Azrina claimed that the level of difficulty of the text was medium, she had difficulty in understanding it. This was one of the reasons why there was not much engagement with the passage. She found the words used in the passage difficult to understand:

I didn't understand what it means, uh, sometimes I don't understand the word.

[Stimulated recall interview] 
Another reason for being unable to interact with the passage is difficulty in identifying the text structure:

...Like if this is cause and effect or problem solutions or just a structure. I was confused so I couldn't find the solution.

[Stimulated recall interview]

This also leads to being unable to identify the writers' stance:

I think, wait, I'm still not sure of the stance.

[Stimulated recall interview]

However, Azrina found ways to understand the text. She tried to make sense of the passage that she read by simplifying the information to get a better understanding of the reading:

I realized that if the family is smart, the child will be smart too. It was also stated here [indicating the article] that a child can still be smart even if the parents are average.

[Stimulated recall interview]

She also used some reading strategies to understand the passage. One of the strategies that she used is looking at the bold words. She realised that the bold words relay important information and tried to understand them:

Bolded means it is important. An important idea. So, I'll have to understand why it is bolded.

[Stimulated recall interview]

She had also tried to understand the meaning of the words by googling them:

I google to find the meaning in English and the meaning is displayed in English. It is explained in English.

[Stimulated recall interview]

Azrina stated that the reading task was purposeful. She realised that doing the annotation task was beneficial:

Important, because when the articles are long, it's not like we are able to understand all these long ones. So, when we do it in a simple form, short like this, we don't have to read the long ones. Just read the short ones.

[Stimulated recall interview]

Azrina had also mentioned that annotation will be tested in the exam:

Maybe it will help in the final exam because (name of the lecturer) told us about the final exam. She explained that final exam is about reading and answering questions.... Uh, maybe I have to read on how to do annotation.

[Stimulated recall interview] 
Azrina had some interaction with the passage but she also affirmed the difficulties she faced with understanding the passage. Azrina also admitted that the reading task was important to her because she perceived this task would assist her in the examination. Hence, she accomplished this task with a purpose that was to prepare her for her exam.

\section{b) Ezadura's views on interacting with the task}

Ezadura realised that it is crucial to understand the passage in order to do the annotation task. She claimed that she was thinking of how the paragraphs were linked:

When I started to read paragraphs three and four, I was like where do I connect this?

[Stimulated recall interview]

This shows that she was trying to find ways to make sense of what she was reading.

She also mentioned that at the beginning she responded wrongly to the task:

I didn't understand, when the lecturer had seen my response and she said it's a mind map and not an annotation. Then she asked me to refer to a friend.

[Stimulated recall interview]

Upon discussing with her peers, she understood how to do the task.

Ezadura also faced issues in fully understanding the passage. Her understanding of grammar influenced the ability to fully engage with the task:

My grammar is not good. So, when we read this, we have to determine the subject and verb. It was a bit difficult to find it. Like when the lecturer instructs me to find the subject, I couldn't find it.

[Stimulated recall interview]

Ezadura also stated that she sometimes misinterprets things when she reads:

Sometimes, what I understand and the actual meaning differ. It takes time for me to understand if it's in English.

[Stimulated recall interview]

She also added that she found it difficult to understand the information presented in the passage. This then influenced her interest in further reading the passage:

At first I enjoyed it, but then as I went through, when I came to the part that I didn't understand, I was less interested.

[Stimulated recall interview]

She was also not interested in the topic of the passage. It was: 
Difficult to understand because I didn't know about it.

[Stimulated recall interview]

Ezadura did not have prior knowledge of the topic. This influenced her understanding of the information in the passage and made her unable to relate to the information that she read. However, she found the annotating skill important:

That's the only way we could understand the articles. So it's important.

[Stimulated recall interview]

Ezadura also stated that annotating helped her to recall the information that she had read.

She also found ways to overcome the difficulties that she faced in doing the task. She had tried to find meanings of words that she found difficult to understand:

I searched the meaning in my phone, what is the meaning of 'correlate'. Just type "correlate" and the meaning appears.

[Stimulated recall interview]

She said that she used Google as well as a dictionary to find the meanings of words that she did not understand.

She questioned what the writers were trying to say but these questions were generated to understand the texts rather having the desire to engage with the passage:

Because I was beginning to understand and then there was some like I was thinking what is he trying to say. I was quite lost, so it became less.

[Stimulated recall interview]

She also defined accurately the meaning of a writer's stance; however, she was unable to identify it in the passage:

I couldn't get what was his main point.

[Stimulated recall interview]

Ezadura noted that she planned to use the skill in the future when there is a need to annotate. She found the EAP course beneficial as she learnt new reading skills like annotating which she had never learnt at secondary school:

When we were in school we didn't do it in this manner. Extract the information. We were just asked to highlight points that we think are important.

[Stimulated recall interview]

This shows that part of the reason she found the annotation task useful was because she could employ the skill in the future. 
Overall, Ezadura was able to complete the annotation task although she faced some obstacles while responding to the task. She was concerned about completing the passage successfully. Nevertheless, she found the annotating skill useful and predicted she may use it in the future.

\section{c) Najla's views on interacting with the task}

Najla's interaction with the task could be seen through her engagement with the reading passage. She interacted with the passage by questioning the information that she read in the passage. She wondered:

Like why did he or she do this? Why is the sentence in this manner? So, the "why" makes me want to keep reading the subsequent paragraphs.

[Stimulated recall interview]

She constantly questioned why the information is presented in a certain way. She also mentioned that by having questions, she was motivated to read further to find the answers:

That way I will be able to answer the question.

[Stimulated recall interview]

Najla claimed that the language used in the passage was difficult to understand. She then tried to read the sentence after the one she had difficulty understanding. This shows that she attempted to predict what the sentence actually meant:

The article had both high level and low level. So, when I didn't understand the high level [indicate language] I would refer to the next sentences to understand.

[Stimulated recall interview]

Although Najla was able to identify the passage as using an argumentative text structure, she was unable to describe the writer's stance:

He didn't state which was correct heredity or environment. His opinion was like in the middle, was like on the fence.

[Stimulated recall interview]

Najla made the effort to respond to the task as she realised that a similar type of task would be tested in the examinations:

Important, because she said we will be given a passage with some structured questions for our exam. There will be options for the titles, then we will have to answer the structure based on the article.

[Stimulated recall interview]

Najla attempted to think deeply while reading the passage. She was also able to read and make meaning of the text. However, she was unable to understand what the writer was trying 
to relay. Najla responded to the task because she found it purposeful. This is perhaps because she felt that the task would help in the future regardless of whether during the final exam or in other academic areas.

\section{d) Satish's views on interacting with the task}

Satish said that he found the annotation task challenging because of the reading passage. He claimed that the reading passage was relatively difficult to understand but he found ways to understand it. This was crucial as, in order to respond to the annotation task, he had to first understand the passage. He used reading strategies such as reading the bolded words to make sense of the passage:

Because they were bold or something like that, like, eye catching so, I OK, I should just read this first, maybe that might be the ideas ... ideas.

[Stimulated recall interview] However, Satish realised that reading the bolded words did not make much sense and opted for a different strategy. He then tried to underline the information:

I underline because I feel that that point might be important to my annotation next time.

[Stimulated recall interview] He claimed that underlining helped him to recall the information when he read it again at a later time.

Satish also faced some difficulties in understanding the passage:

Yeah, at first glance when you read it, you don't understand what the uh, the passage is trying to say.

[Stimulated recall interview]

This prompted him to repeatedly read the passage to understand it. One of the things that made understanding the passage difficult was the sentence structure:

When they try to like put a lot of information, very compact a lot of information and try to do it in one sentence.

[Stimulated recall interview]

Although Satish was able to define the meaning of writer's stance, he too was unable to identify it in the passage:

Weighing both sides whether it's a ... what we call whether it's intelligence or the other. [Stimulated recall interview]

He stated that the writers were merely presenting both sides of the argument in the passage. $\mathrm{He}$ also mentioned that he prefers to have some prior knowledge of a passage before reading 
it. This passage was relatively new to him and he did not have the background knowledge of the passage:

Or I have back, I have some knowledge about it. Some, what you call, some knowledge about it. Beforehand. Before reading it.

[Stimulated recall interview]

Being unable to understand the text could be a reason why he could not fully engage with the passage. Moreover, he also claimed that he was uninterested in the topic of the passage.

Satish claimed that the part that discussed the IQ tests was somewhat readable:

I feel that this, if I'm not mistaken, it was somewhere about, the IQ test ... how that, uh, how they actually came up with the idea of IQ tests and how to measure it.

[Stimulated recall interview]

Satish did not find the reading topic interesting and he was unable to relate the topic to his personal experience:

No, I didn't connect it.

[Stimulated recall interview]

However, he found the annotating task beneficial:

If let's say for those texts [that] are very long, then yes. I think it's better to do it. Because you can't read the thing again and again. It's very long.

[Stimulated recall interview]

Satish found the reading skill useful but he did not find the topic interesting. It could then be concluded that he participated in the task because of the lecturer's instruction to complete it.

All four participants claimed that they were not interested in the reading topic. However, they tried to find ways to attempt to do the task. They employed some reading strategies to understand the passage. Due to the lack of prior knowledge of the topic, the participants struggled to understand the gist of it. Azrina mentioned that she was able to relate the topic to personal experience. The rest of the participants were unable to relate the topic to their lives. This shows that she was motivated to understand the knowledge in the text. The participants claimed that the annotation skill that was part of the task was beneficial to them.

The participants in Unit 3 understood the requirement needed to complete the task. Three of the participants' written work was categorised as multistructural whereas one participant's work was categorised as unistructural. 


\subsubsection{Summary of Unit 3}

Similar to Unit 1 and Unit 2, the participants in Unit 3 too stated that they had multiple reasons for learning English in the EAP classroom. They also claimed that they had particular expectations of learning in the EAP classroom. The participants wanted interesting contentbased learning in the classroom. Further, the participants also stated that they were aware of how out of the EAP environment influenced their learning of English. They also admitted to having anxiety when practising the language but they also made an effort to learn as well as practise English.

As in Units 1 and 2, the data from a specific task in the EAP class were used to describe the participants' expectations in learning and their responses to the teaching and learning done in the classroom. Table 28 indicates the participants' responses to the annotation task.

Table 27. Summary of the participants' responses to the written work in unit 3

\begin{tabular}{|c|c|c|c|c|}
\hline Written work & Azrina & Ezadura & Najla & Satish \\
\hline $\begin{array}{l}\text { Level of SOLO } \\
\text { Taxonomy for } \\
\text { annotation task }\end{array}$ & Unistructural & Multistructural & Multistructural & Multistructural \\
\hline $\begin{array}{l}\text { Views on } \\
\text { interacting with } \\
\text { the task }\end{array}$ & $\begin{array}{ll}\text { - } & \text { Reading } \\
\text { passage was } \\
\text { difficult to } \\
\text { comprehend } \\
\text { - Annotated } \\
\text { three } \\
\text { paragraphs } \\
\text { - Found ways } \\
\text { to overcome } \\
\text { the difficulties }\end{array}$ & $\begin{array}{ll}\text { - } & \text { Reading } \\
\text { passage was } \\
\text { difficult to } \\
\text { comprehend } \\
\text { - } & \text { Annotated all } \\
\text { the } & \text { paragraphs } \\
\text { - } & \text { Found ways } \\
\text { to overcome } \\
\text { the difficulties }\end{array}$ & $\begin{array}{ll}\text { - } & \text { Reading } \\
\text { passage was } \\
\text { difficult to } \\
\text { comprehend } \\
\text { - Annotated } \\
\text { paragraphs } \\
\text { one to five } \\
\text { - Found ways } \\
\text { to overcome } \\
\text { the difficulties }\end{array}$ & $\begin{array}{l}\text { - Reading } \\
\text { passage was } \\
\text { difficult to } \\
\text { comprehend } \\
\text { - Annotated all } \\
\text { the } \\
\text { paragraphs } \\
\text { - Found ways } \\
\text { to overcome } \\
\text { the difficulties }\end{array}$ \\
\hline
\end{tabular}

All four participants agreed that the reading passage was difficult to understand. They all went through a certain amount of struggle while reading the passage. Three of the participants mentioned that their low level of language proficiency caused them to face difficulties in understanding the text. The male participant on the other hand claimed that he did not face issues with the language but the way the sentences were structured made him feel confused about the information. The participants had various levels of completion of the task. Only one participant managed to complete annotating the reading passage. The participants' responses were categorised as being at the unistructural and multistructural levels of the SOLO taxonomy.

The participants all interacted with the reading passage. Their interaction could be seen in terms of their ability to question the purpose of the passage, the links made from one paragraph to others and how useful the skills that they had learnt were. Some of the participants claimed 
they could transfer the reading skills that they had learnt to other subjects but some were not able to transfer them.

\subsection{Summary of the Chapter}

The purpose of this chapter was to report the research findings of this study. The analysis of the semi-structured interviews, stimulated recall interviews, and participants' written responses led to the emergence of five themes: purposes for learning English, learning preference in the EAP Classroom, influence of the out-of-EAP environment, anxiety in practising English, and making an effort in learning English. The findings were presented in three parts: Unit 1, Unit 2 and Unit 3. A detailed description of the findings was presented in each unit. This process enables a cross unit analysis and I address the research questions in the next chapter. 


\section{CHAPTER 6 \\ CROSS-UNIT ANALYSIS}

The findings from the three units show that the participants have some similar perceptions of learning in the EAP classrooms and some different perceptions. The participants' perceptions can be divided into their wider perceptions of learning English in the EAP classrooms and their perceptions in response to the specific task done in the class. This chapter presents a crossunit analysis that shows the similarities and differences of the participants' responses to learning in the EAP classrooms. It concludes by looking at this analysis in relation to the research questions for this study.

\subsection{Cross-unit Analysis of Units 1, 2 and 3}

The cross-unit analysis will be discussed in two sections. The first section will analyse all of the participants' responses to learning in the EAP classrooms. The second section will analyse the participants' responses to specific classroom tasks.

\subsubsection{Cross-unit Analysis of Responses to Learning in the EAP Classroom}

The themes and sub-themes for this study emerged through the analysis of the semi-structured interviews and stimulated recall interviews. The five themes were: having multiple purposes for learning English, engaging with the content, acknowledging the environment beyond the EAP classroom, feeling anxious about learning English, and making an effort in learning English. This section discusses the cross-unit analysis across Units 1, 2 and 3 with specific attention to the sub-themes that emerged during the analysis. This cross-unit analysis will provide similarities and differences between the aspects that influence learning English among the participants in the three units of analysis. Table 29 indicates the themes and sub-themes across the three units of analysis. 
Table 28. Themes and Sub-themes across units 1, 2 and 3

\begin{tabular}{|c|c|c|c|c|}
\hline \multicolumn{5}{|c|}{ Themes/ sub-themes } \\
\hline $\begin{array}{l}\text { Having Multiple } \\
\text { purposes for } \\
\text { learning English }\end{array}$ & $\begin{array}{l}\text { Engaging } \\
\text { with the } \\
\text { content }\end{array}$ & $\begin{array}{l}\text { Acknowledging the } \\
\text { environment } \\
\text { beyond the EAP } \\
\text { classroom }\end{array}$ & $\begin{array}{l}\text { Feeling anxious } \\
\text { about learning } \\
\text { English }\end{array}$ & $\begin{array}{l}\text { Making an effort } \\
\text { in learning } \\
\text { English }\end{array}$ \\
\hline 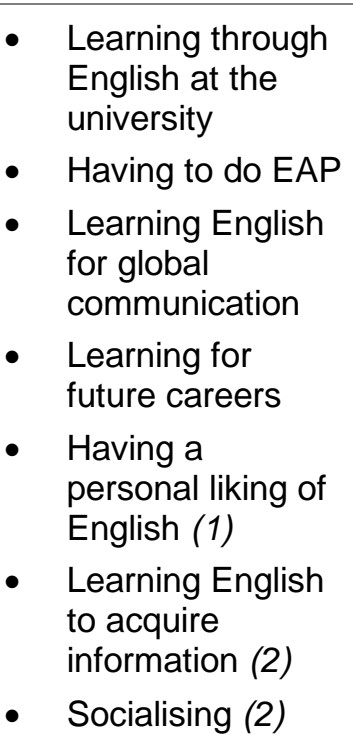 & & 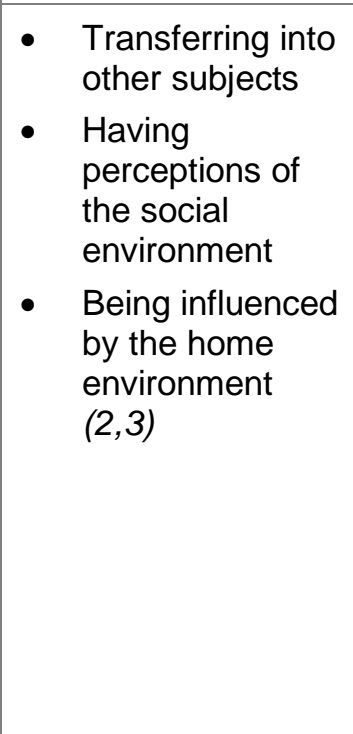 & $\begin{array}{l}\text { - Worrying } \\
\text { about the } \\
\text { level of } \\
\text { English } \\
\text { proficiency } \\
\text { - } \begin{array}{l}\text { Feeling tired } \\
\text { during }\end{array} \\
\text { lessons (1) } \\
\text { - Worrying } \\
\text { about } \\
\text { reputation (3) }\end{array}$ & $\begin{array}{l}\text { - Being willing } \\
\text { to participate } \\
\text { in the } \\
\text { classroom } \\
\text { - Finding ways } \\
\text { to overcome } \\
\text { learning } \\
\text { problems } \\
\text { - Being willing } \\
\text { to learn (3) } \\
\text { Being willing } \\
\text { to practise } \\
\text { language (2, } \\
\text { 3) }\end{array}$ \\
\hline
\end{tabular}

Note: Sub-themes that exist only in one or two units of analysis are indicated numerically

\section{Having multiple purposes for learning English}

Similarities: All the participants from Units 1,2 and 3 described multiple reasons for learning English. Across all the units, there did not seem to be a direct connection between the students' acceptance that they need English in their other subjects and the reasons they gave for learning in the EAP classrooms. All the participants concurred English is important for their present and future lives but some reasons are more important than others. All the participants said that they need English for global communication and for their future careers. They also said that they need English for subjects that are taught in English. The participants talked about the course material in their other subjects and, at times, although perhaps less than might be expected, the teaching used English. Hence, the participants felt the need to be able to comprehend the English language to follow what was being taught in their subjects and thus make the required academic progress to complete their qualifications. Despite the importance of all these factors, the first and main reason all the participants gave for enrolling in the EAP course was because it was compulsory. The first set of factors - English for global communication, for future careers, learning through English at the university, personal liking of English, learning to acquire information and socialising - emerged in relation to questions about why learning English is important. The second set of factors about having to do EAP emerged in relation to the reasons for enrolling in the EAP course. What is notable is that the participants did not in the first instance mention the first group of factors as reasons for enrolling in the EAP course. 
It was also notable that the students in the three units described purposes other than academic ones for learning English. They learn English in order to be able to communicate with people and they interpreted the term communication as being able to speak in English. All the participants communicated variants of the claim that speaking in English assists them to "interact globally" and "interact locally". Some said that they need to speak in English to the international students who they meet at the university. Hussein, a participant from Unit 2, described communicating in English when he is out of Malaysia. Participants in both Unit 1 and Unit 3 referred to a lingua franca use of English, in that they speak in English to their local Chinese friends. This shows that the students felt that being able to converse in English was an important part of being proficient in the language.

Differences: While participants in the three units agreed that they all had reasons to learn English, the reasons varied according to individuals. The different views for the purpose of learning English included having a personal interest in English, being able to get information, and to socialise. One of the participants in Unit 1 said that he learns English because he likes the language. Interestingly, in this case the participant considered English to be one of his home languages. Another participant in Unit 2 gave her reason for learning English as being able to socialise in English. Some of the participants in Unit 2 also articulated that they learnt English to be able to acquire information. These participants claimed that being able to understand the information that they read is important to determine the level of accuracy of the information.

In summary, all the students understood the importance of English for their academic subjects but did not strongly connect this to taking the EAP course. They took this course because it was compulsory to complete their degrees. They all had much wider purposes for learning English including for future jobs, checking information, communicating at a global level, and socialising.

\section{Engaging with the content}

Similarities: There was a strong, although not entirely consistent, theme across all three units of students' lack of interest in, and engagement with the content taught in the EAP classrooms. The participants' engagement, or lack of engagement, could be seen in terms of the reading material used in the class and the reading skills taught to them. The participants said they would prefer to learn interesting topics in class. Participants in Units 1,2 and 3 described the reading material used in the lessons in the EAP classrooms as predominantly uninteresting. One of the participants in Unit 1, however, said that although he was interested in one aspect of one of the reading passages discussed in class, this did not happen often. Another student in Unit 3 said she could relate the information read in the passage to her life. However, these responses were only attained after some probing. Some of the participants in Unit 2 added a 
notable point that they prefer to practise the content that they learn. These participants said that they would like to learn content that they can use in "their lives". In terms of the reading skills taught in the class, participants across the three units indicated that they had learnt new reading skills that were not taught during their schooling years, but they did not like the reading passages that were used to teach these skills.

In summary, participants prefer lessons that focus on interesting topics and this may not be happening in practice.

\section{Acknowledging the environment beyond the EAP classroom}

Similarities: All the participants in Units 1,2 and 3 were enrolled in the engineering programme and had taken courses that were related to their major. Most of the participants said that they did not have many opportunities to use the English skills from the EAP classrooms in their other subjects. There was a range of inconsistent views on the use of the reading skills taught in the EAP classrooms in other subjects among the participants in Units 1,2 and 3. Some of the participants said that they were able to use their reading skills in other subjects. It is possibly important to note that those participants who did describe how they used their reading skills in other subjects only did so after being prompted to think about whether there was any application of these skills to their other subjects. A number of questions were used to help the participants recall the use of reading skills in other subjects. Some, after probing, predicted that their reading skills might help in the future. Some of the participants in Unit 2 predicted that the reading skills taught in the EAP classrooms could help them in other subjects that they enrolled in or even when they started their careers. For example, Samad, a participant in Unit 2 , said that annotation would help him to identify important information when he has to read information pertaining to engineering when he becomes an engineer in the future. Some participants, however, were clear in their view that they could not use the skills because they had enrolled in mostly calculation subjects that did not require reading skills. Moreover, participants from Units 1 and 2 both said that the lecturers give leeway for students to choose English or Malay as the language for presentations. These situations did not leave the students feeling encouraged in the practice of using English in their subjects.

A strong but also subtle influence on more general English use from community beliefs about language also emerged from the cross-case analysis. The participants from Units 1, 2 and 3 agreed that their perceptions of language use in the community influenced their learning and practising of English. Their perceptions could be seen, for example, in the claim that the community preferred to "practise its native language". Satish, a participant from Unit 3, said that he would be criticised for not speaking in Tamil, his native language. This influence was in some tension with the participants' perceptions that although the community's inclination is 
to preserve their native language, the importance of English is visible, and it is hard to establish the relative strength of these conflicting influences on language learning.

Differences: There were some clear differences in the cross-case comparison in participants' opportunities to practise English in their home environment. Some participants in Units 2 and 3 specifically mentioned that their home environment was not strongly supportive of their learning and practising of English. In Unit 2, Azraq mentioned that he realised that to be proficient in a language, one had to constantly practise it. He even used an analogy of "driving a car" to explain his opinion. He stated that he speaks in Malay at home and this has made him less comfortable in practising English out of the home environment. Azrina, a participant in Unit 3, claimed that she had limited material at home that could be used to practise her English.

This cross-unit analysis suggests that the environment in the participants' academic subjects relating to engineering, the community's attitudes towards English and in some participants' home environments were not always supportive of developing either English or academic English.

\section{Feeling anxious about learning English}

Similarities: Across the three units, most of the participants mentioned that they face anxiety about using English in the EAP classrooms which results from their feelings of lack of proficiency in English. Mostly, participants stated that they feel "nervous", "inferior" and had a "lack of confidence". Ezadura, a participant from Unit 3, mentioned that she felt anxious to present information orally in English because she did not know how to explain her ideas. Anxiety in practising and learning English could also be because of participants' previous "negative learning experiences". Some of the participants said that they used to receive low grades in English as a school subject. This could possibly be a reason why they are not comfortable with using English. An interesting sub-theme emerged: despite their nervousness in practising English, some of the participants described feeling more comfortable communicating with "people who have a similar proficiency level." Some of the participants described feeling impressed by people speaking fluently in English, but this made them feel intimidated about attempting to use English themselves. The feeling that emerged was that students were not against learning English but did feel worried about potentially embarrassing themselves.

Differences: A majority of the participants in the three units described feeling that they were not fluent in English. An interesting sub-theme emerged in Unit 1 of students saying that they felt very tired attending EAP lessons. These participants described having a very busy timetable of classes at the university. They said that they have back-to-back lessons on the 
day they have the English lesson and so are unable to sustain their energy by the time they attend the English lesson. This could be a reason why they were unable to concentrate in the class which in turn led to being anxious about learning in the EAP classrooms. This circumstance may have been unique to the timetable of the students in this unit but something of the more general malaise of lack of enjoyment and engagement in the EAP classes also came through this.

The sub-theme of being afraid of losing face with peers came through most strongly from the participants in Unit 3. They were concerned about their reputation in the classroom and as a result preferred not to take part in discussions in the classroom to avoid losing face with their peers. Satish claimed that he preferred working individually during the lessons. As the activities in class were almost always done in groups, this created a friction between his learning preference in class and the teaching and learning style used in the class.

In summary, across all the units, participants described anxiety about their lack of proficiency in English. In Unit 3 the participants described the way their anxiety about potential loss of reputation resulted in lack of participation in class. In Unit 1 students' disengagement was expressed as tiredness.

\section{Making an effort in learning English}

Similarities: Most of the participants go into class with anxiety about their proficiency and for some a fear of losing face. The data collected through semi-structured and stimulated recall interviews also indicate that participants from the three units saw themselves as making an active effort to learn English, both in the classroom and also out of the classroom. One similarity was that all the participants said they learned by participating in the EAP classroom. They participated by "contributing ideas" and "discussing with friends". Although the participants claimed that they were willing to participate, it did emerge that not all necessarily liked doing so. Ezadura claimed that she participated in class, but she preferred to work individually, and it was not clear whether her participation in groups was mandated by the teacher.

All the participants said that they tried to find ways to solve the challenges in learning English. One of the challenges to emerge most strongly was finding it hard to understand the meaning of words that they read. Participants described differing active strategies to overcome this challenge. Some participants mentioned that they employ a "trial and error" method in learning in the classroom. They took the initiative to learn and did not mind making mistakes along the way. In other words, a sense of active participation in learning in the class did emerge.

Differences: It was notable that the participants in Unit 3 shared most clearly their willingness to learn English. They claimed that they would like to brush up their language skills and would 
like to do better in the future. Ezadura described seeing learning English as a challenge that she would like to overcome. This attitude hints at a richer potential for the participants to make autonomous efforts to learn the language. However, the participants' desires to continue to learn were not necessarily related to the English language of the EAP classroom.

A sub-theme that emerged among the participants in Units 2 and 3 was their willingness to practise English out of the classroom. The participants mentioned that they realised that practice was important and hence "attempt to use the words repeatedly" and also "speak in English to build confidence". This sub-theme differs from the previous paragraph about their willingness to learn English. In this part the participants' comments showed that they did not only want to learn the language for communication but made the effort to practise it outside of the academic context.

This cross-analysis suggests that the students actively engage in finding ways to learn English as well as academic English. They made the effort to learn within the EAP classroom and out of the EAP classroom. This suggests that although the students enrolled in the EAP course because it was compulsory and some of them faced anxiety in learning, they made the effort to learn in the EAP classroom.

This sub-section discussed the similarities and differences of themes and sub-themes that were generated across all three units. The next subsection will discuss the participants' responses to specific reading tasks in the EAP classrooms.

\subsubsection{Cross-unit Analysis of Specific Tasks in the EAP Classroom}

This section analyses the responses to the specific reading tasks used in units of analysis 1 , 2 and 3 . Although the reading tasks differed between the units of analysis, the textbooks used were similar. Three reading texts were used in the tasks. Reading tasks in Units 1 and 2 used the texts "The Print Revolution" and "Cyberculture". The reading task in Unit 3 used "Intelligence: heredity versus environment". The reading tasks have been described in detail in the Methodology chapter. Although the participants responded to different reading tasks across the three units, there are some general similarities that can be found in terms of their interaction with the tasks, the difficulties they faced, and how they managed to find solutions to the difficulties. Table 30 indicates a summary of the participants' responses to the specific reading tasks in the EAP classroom. 
Table 29. Participants' response to the specific reading tasks in the EAP classrooms

\begin{tabular}{|c|c|c|c|}
\hline & Unit 1 & Unit 2 & Unit 3 \\
\hline $\begin{array}{l}\text { Level of SOLO } \\
\text { Taxonomy for } \\
\text { written responses }\end{array}$ & $\begin{array}{l}\text { - Multistructural and } \\
\text { relational }\end{array}$ & 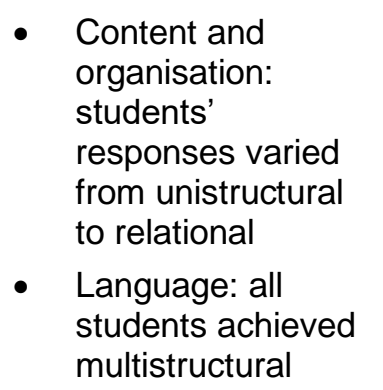 & $\begin{array}{l}\text { - Unistructural and } \\
\text { multistructural }\end{array}$ \\
\hline $\begin{array}{l}\text { Process involved in } \\
\text { doing tasks }\end{array}$ & $\begin{array}{l}\text { - Use of structured } \\
\text { reading process } \\
\text { - Connections made } \\
\text { from existing } \\
\text { knowledge and } \\
\text { experience to the } \\
\text { task }\end{array}$ & $\begin{array}{l}\text { - } \begin{array}{l}\text { Structured reading } \\
\text { process }\end{array} \\
\text { - Connections made } \\
\text { from existing } \\
\text { knowledge and } \\
\text { experience to the } \\
\text { task } \\
\text { - Used timeline to } \\
\text { visualise } \\
\text { information }\end{array}$ & $\begin{array}{ll}\text { - } & \text { Structured reading } \\
\text { process } \\
\text { - } & \text { Question the } \\
\text { information } \\
\text { - } \quad \text { Trial and error } \\
\text { method employed } \\
\text { - Use signalling } \\
\text { words to make } \\
\text { connection }\end{array}$ \\
\hline $\begin{array}{l}\text { Engagement with } \\
\text { the tasks }\end{array}$ & $\begin{array}{l}\text { - Mixed opinion about } \\
\text { the interest in the } \\
\text { reading topic } \\
\text { Doing mind map } \\
\text { helps identify } \\
\text { pertinent } \\
\text { information }\end{array}$ & $\begin{array}{l}\text { Mixed opinion } \\
\text { about the interest } \\
\text { in the reading topic } \\
\text { Doing mind map } \\
\text { helps to extract } \\
\text { information }\end{array}$ & $\begin{array}{l}\text { - Mixed opinion } \\
\text { about the interest } \\
\text { in the reading topic } \\
\text { - Doing annotation } \\
\text { helps in recalling } \\
\text { information }\end{array}$ \\
\hline $\begin{array}{l}\text { Difficulties faced in } \\
\text { doing the tasks }\end{array}$ & $\begin{array}{l}\text { - Challenging task } \\
\text { - Unfamiliar } \\
\text { vocabulary used in } \\
\text { the texts } \\
\text { - The length of the } \\
\text { texts } \\
\text { - Difficult following } \\
\text { the arguments } \\
\text { presented }\end{array}$ & $\begin{array}{l}\text { - Challenging task } \\
\text { - Unfamiliar } \\
\text { vocabulary used in } \\
\text { the texts }\end{array}$ & $\begin{array}{l}\text { - Challenging task } \\
\text { - Unfamiliar } \\
\text { vocabulary used in } \\
\text { the texts } \\
\text { - No background } \\
\text { knowledge }\end{array}$ \\
\hline $\begin{array}{l}\text { Ways used to } \\
\text { resolve difficulties }\end{array}$ & $\begin{array}{l}\text { - Using reading } \\
\text { strategies } \\
\circ \quad \text { Finding } \\
\text { meaning of } \\
\text { words } \\
\text { Translating to } \\
\text { Bahasa } \\
\text { Malaysia } \\
\text { - Seek support from } \\
\text { peer and instructor }\end{array}$ & $\begin{array}{l}\text { - Using reading } \\
\text { strategies } \\
\circ \quad \text { Finding } \\
\text { meaning of } \\
\text { words } \\
\text { Translate to } \\
\text { Bahasa } \\
\text { Malaysia } \\
\text { - Seek support from } \\
\text { peer and instructor }\end{array}$ & $\begin{array}{l}\text { - Using reading } \\
\text { strategies } \\
\circ \quad \text { Finding } \\
\text { meaning of } \\
\text { words } \\
\text { Translate to } \\
\text { Bahasa } \\
\text { Malaysia } \\
\text { - Seek support from } \\
\text { peer and instructor }\end{array}$ \\
\hline
\end{tabular}

Written responses at the SOLO taxonomy level

Similarities: The data from the participants' work in Units 1, 2 and 3 indicated that the requirements of the tasks were achieved in each case. The levels of requirements of the tasks 
in relation to the SOLO taxonomy were different. The participants' written work across the three units had included some work at the multistructural and some at the relational levels of the SOLO taxonomy. The requirements for tasks in Units 1 and 2 were at the relational level. The requirement for the task in Unit 3 was at the multistructural level.

Differences: There were differences in achievement in each of the units. Most of the participants in Units 1 and 3 were able to achieve the requirement set for the task. Most of the participants in Unit 1 were able to achieve at the relational level and most of the participants in Unit 3 were able to achieve at the multistructural level. However, this was not the case with the participants in Unit 2 where only some were able to achieve at the relational level.

The task in Unit 1 required the participants to identify similar information from two reading passages using a mind map technique. Three of the participants' written work in Unit 1 showed the relational level of the SOLO taxonomy except for Syamira's work which was at the multistructural level. In Unit 2, however, due to the requirement of the summary writing task, the participants' written work was not categorised at a specific level. The written work was evaluated in relation to two aspects: content and organisation, and language. Unit 2 required the participants to write a summary based on similarities found in two reading passages. In terms of content and organisation, only two participants' written work was at the relational level. Of the remaining two participants, one participant's work was at the unistructural level and one was at the multistructural level. In terms of language use, all the participants' work was either at the unistructural or multistructural level of the SOLO taxonomy. Unit 3 required the participants to annotate a reading passage. Three of the participants' annotations indicated that they were able to attain the multistructural level of the SOLO taxonomy except for one participant's work which was at the unistructural level.

Participants in Unit 2 seemed to be struggling more than the participants in the other units. This is probably because the process of responding to the task was longer than the process for the other units.

\section{Processes involved in doing the tasks}

Similarities: The participants across the units used a structured reading process while responding to the reading tasks. Although the participants in all three units used a structured reading process, their strategies varied slightly. For example, some of the participants skimmed and scanned the passages. The participants looked at the titles of the reading texts and the bolded words to get the gist of the passages. Some of the participants read each paragraph and tried to make sense of the information. Some of the participants in Units 1 and 2 attempted to relate the reading passages to their prior knowledge. Affiq from Unit 1 was directly able to relate his previous understanding of the internet to the passage. He stated that 
although it seems that information can be accessed freely on the internet, it is actually controlled by certain sources. Participants in Unit 2 attempted to use their prior knowledge and experience to understand the reading passages as well as in doing the task. Azraq from Unit 2 claimed that he had related his experience of noticing the difference in people's behaviour when they are face-to-face compared to when they are using the internet.

Difference: It was apparent that the participants in Unit 3 worked in a less systematic way. They used a questioning method and a trial and error method in doing the task. Both Najla and Ezadura said that they attempted to question what the article was about to improve their understanding of the passage. Ezadura also found that she had made a mistake in doing the task and then tried to do it the right way. She said that she completed the task but was told by the lecturer that she made some mistakes. She then amended her mistakes by discussing the work with some of her friends.

\section{Engagement with task}

Similarities: Participants in all three units had mixed feelings about the reading topics given to them. The topic given to the participants in Units 1 and 2 was about the mass media. The topic given to participants in Unit 3 was about nature versus nurture. Most of the participants claimed that the topic was not interesting. For example, some of the participants in Unit 3 stated that they were able to relate the topic to their surroundings. However, there were some participants who said that they did not find the topic useful or interesting. Satish, a participant in Unit 3, for example, found that he was unable to relate the information to his own life. Hussein, a participant in Unit 2, found the topic uninteresting and was not interested in finding out more about it.

The reading tasks given to the participants required them to use the skills that they had learnt in the class. Across the three units, the participants said that the reading skills that they used in the tasks were beneficial to them. Affiq from Unit 1 found that doing a mind map helped him to find pertinent information but he did need to elaborate on the information. Azraq from Unit 2 had a similar opinion as Affiq as he said that he also finds mind maps helpful. Azraq stated that he will be able to read articles in the future and know how to extract important information. Participants in Unit 3 also agreed that annotation is a helpful tool to condense information and it also enables them to recall information.

\section{Difficulties faced in the reading task}

Similarities: Consistently across all three units, the participants felt that the reading tasks were challenging. For example, Affiq found determining the similarities in the two articles and combining them to form a mind map was challenging. Similarly, participants in Unit 2 also found their reading task difficult. The participants in Unit 2 mostly claimed that they found the 
"Cyberculture" text difficult to understand which made extracting information from this text challenging. All the participants in the three units claimed that they were unable to understand some of the vocabulary in the reading passages and this made understanding the passages hard.

Differences: Interestingly, participants in Unit 3, particularly Ezadura, identified the cause of the reading task being challenging was mostly her lack of background knowledge of the topic. Participants in Unit 3 had mentioned difficulties understanding the information in the paragraphs and uncertainty about the author's stance.

\section{Ways used to solve difficulties}

Similarities: All the participants in this study identified using reading strategies and seeking support from peers and instructors as ways to overcome their challenges. Across the units, the participants either used a dictionary or used the internet to find the meaning of the words. Another method that the participants mostly used to overcome the difficulties of understanding was to translate the words into Bahasa Malaysia. This was done by the Malay students in this study. Another alternative that the participants used was to ask for assistance from their instructors and peers. The participants stated that they asked their instructors for help when they did not know how to go about doing the reading tasks.

In the next section, the research questions that guided the study will be revisited.

\subsection{Revisiting the Research Questions in Relation to the Cross-unit Analysis}

This study's main question is below. To assist in addressing the main question, four subquestions were generated.

Main question:

How do 12 Malaysian tertiary students' perceptions of factors in learning in the EAP classroom align with their responses to tasks and their perceived outcomes of learning in the EAP classroom?

Sub questions:

1) What factors influence students' learning in the EAP classroom?

2) How do students respond to specific tasks in the EAP classroom?

3) How do students perceive the outcomes of learning in the EAP classroom? 


\subsubsection{What Factors Influence Students' Learning in the EAP Classroom?}

Themes: having multiple purposes for learning English, feeling anxious learning English, engaging with the content and acknowledging the environment beyond the EAP classroom

This question was designed to explore the factors that influence learners' learning in the EAP classrooms. I use the word "factors" to remain consistent with the work of Biggs (1999) but acknowledge that this term is related to influences rather than its quantitative meaning in research. The findings showed that the learners had multiple purposes for learning that could be related to proximal and distal goals. English is used as a medium of learning in the participants' academic subjects in the field of engineering and thus students needed English to do well in their courses. Based on the students' perceptions there seemed to be only a weak transfer between this goal and the actual learning in the EAP classrooms. The factor that most strongly influenced learning in the EAP classrooms, based on the students' perceptions, seemed to be the academic obligation to pass the EAP course as a mandatory requirement in the degree. Anxiety about their proficiency was a factor that influenced students' approaches within the EAP classrooms. The students also had wider purposes for learning English, as a mode of communication, in preparation for future careers, because of a personal liking for English, to acquire and check the accuracy of information, and to socialise in English.

The findings also showed that students' preferences in learning the content influenced their learning. The students mentioned that they found the teaching and learning that occurred out of the EAP classrooms, such as in their other classes, and their beliefs about learning the language influenced their motives for learning. The students' beliefs about learning English included the influence of the language spoken while growing up as well as how their own community viewed learning English. Considering the findings in relation to this question showed that there are multiple factors that influence learning in the EAP classrooms.

\subsubsection{How do Students Respond to Specific Tasks in the EAP Classroom?}

\section{Students' written work: students' levels of understanding and interaction with the task}

This question explores the ways the students responded to specific reading tasks given in the EAP class, their engagement with the tasks and the difficulties they faced in responding to the tasks. The students' level of understanding could be seen through their level of responses to the tasks. The analysis revealed that students had different levels of understanding depending on the requirements of the tasks given in the EAP classrooms. The learners' responses to the tasks varied from the unistructural level to the relational level of the SOLO taxonomy. Students' written responses varied in terms of their ability to select accurate information, paraphrase the 
information and organise the ideas. Based on the analysis of the data, it was evident that the students found the tasks challenging.

\subsubsection{How do Students Perceive the Outcomes of Learning in the EAP Classroom?}

\section{Theme: Making an effort in learning English}

This question was designed to explore how the students perceive the outcomes of learning in the EAP classrooms. Biggs (2003) identified the outcomes of learning as being about how much of the content was learnt, how well the content was learnt, and the involvement in learning in the classroom. This question explored learners' perceived outcomes of learning from the extent of involvement in learning in the EAP classrooms.

The students reported making an effort to respond to the tasks and activities. The data showed their efforts in a variety of ways such as finding ways to overcome challenges in learning, using reading strategies, and willingness to participate in the activities given in class.

\subsection{Summary of the Chapter}

This chapter discussed the cross-unit analysis of the three units of study and the research questions generated in this study. The cross-unit analysis shows the factors that influence learning among the EAP learners: purposes for learning English, the type of content taught, the environment beyond the EAP classroom, and their anxiety about learning English. Despite all of these various factors that influence learning, the learners made the effort to participate and learn in the EAP classroom. The learners also faced challenges in learning. The effort, challenges and their understanding level could be seen in their responses to the different tasks undertaken in the EAP classroom. 
This page is intentionally left blank 


\section{CHAPTER 7}

\section{P MODEL AND THE MISMATCH OF ALIGNMENT IN THE EAP CLASSROOM}

This chapter will consider the findings of the cross-unit analysis in relation to Biggs' learning system (Biggs, 2003). The chapter is organised according to the 3P model (Biggs, 1999): presage stage, process stage, and product stage. I will consider the influence of the factors in learning (presage stage) on the participants' processes of learning (process stage) and the participants' perceived outcomes of learning (product stage) and how these influences led to an internal process of compromise in the EAP classrooms in the Malaysian context.

\subsection{Three Key Emerging Ideas}

Using constructive alignment $(\mathrm{CA})$, three ideas emerge from the findings:

1. The learners' personal factors and the contextual factors influenced each other, and these factors affected the learning process as well as the learners' perceived outcomes of learning within the 3P model.

2. From the EAP learners' perspectives, the content taught in the classroom may not match their expectations of learning within the course. This mismatch influenced their motives for learning, fostering a surface approach to learning.

3. When the learners' expectations were unmet in the EAP classroom, the learners adapted themselves to the academic expectations of the course which led to an internal process of compromise taking place. This ultimately led to surface approaches to learning.

I will now support these interrelated ideas with reference to the 3P model and the findings. 
Figure 20. The relationship between students' learning factors, learning process and perceived outcomes of learning in the EAP classroom in this study

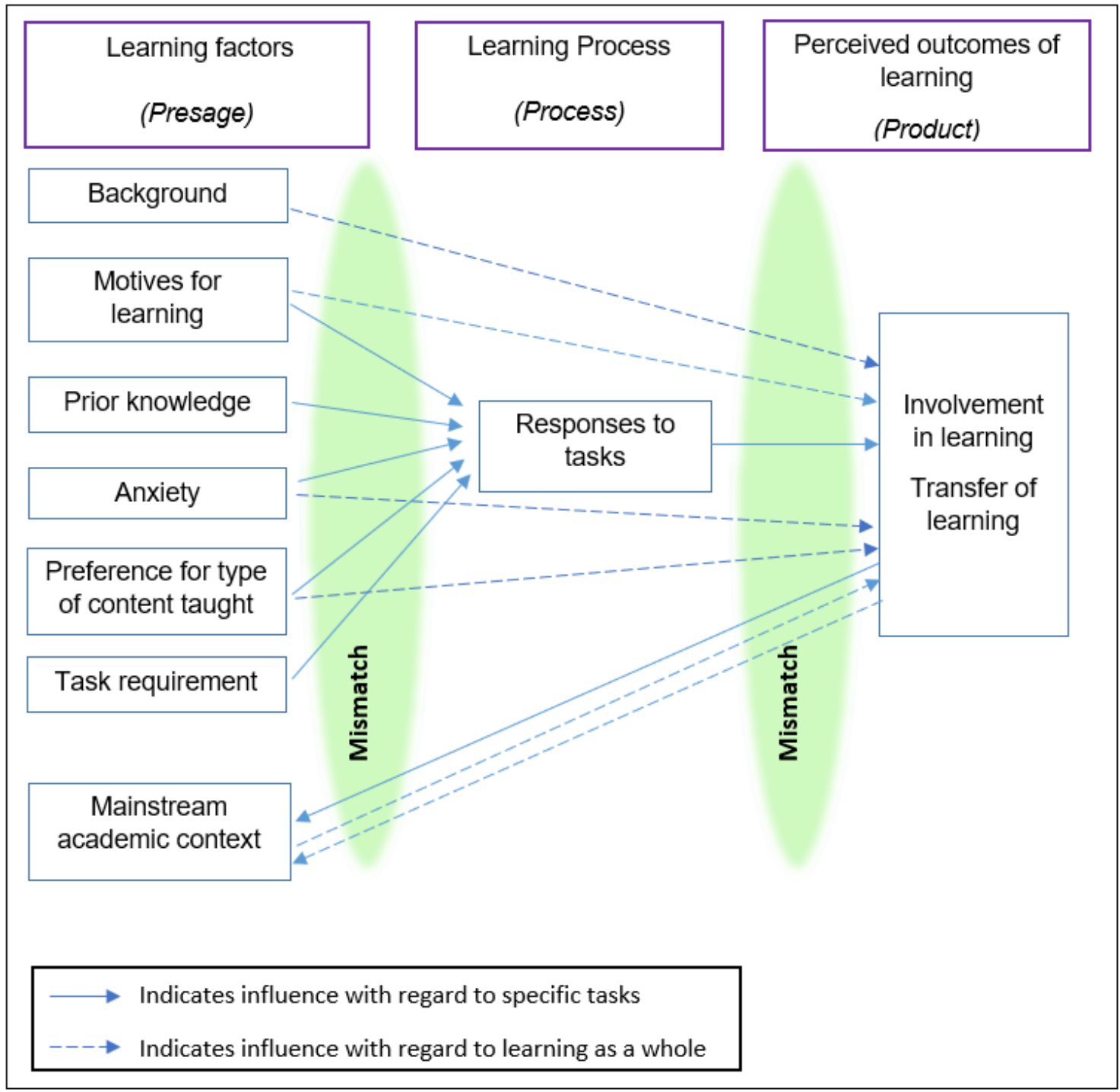

In this section, I use the 3P model to interpret the findings that have emerged. The 3P model includes students' learning factors, their learning processes and the outcomes that they see resulting from learning in an EAP classroom. Figure 20 illustrates this relationship.

The students viewed the learning in the EAP classroom from the dual purpose of learning reading skills and also as a process for gaining skills in English for communication purposes. Figure 20 illustrates the misalignment that exists in the three stages of the model from the participants' perspectives. Biggs' 3P model starts with the presage factor (on the left of the diagram) which consists of both personal and contextual factors. The personal factors and contextual factors are both included under the term "the learning factors" because this stage summarises what "exist(s) prior to engagement that affects learning" (Biggs et al., 2001). Under the contextual factors, Biggs (2003) includes the teaching context, the ethos of the "institutional procedures" which could encompass the compulsory nature of the EAP courses in the research site (p. 19). The learning process includes the responses to the three tasks that were given to 
the students in the three EAP classrooms. Students' perceived learning outcomes equate to their perspectives of the two outcomes - the outcomes of the tasks done in the class as well as outcomes from learning academic English as a whole.

I have combined both personal factors (background, motives for learning, prior knowledge, anxiety and preference for type of content taught) and contextual factors (task requirement and mainstream academic context) under factors in learning - the presage stage - in the model. The basis of this analysis is the cross-unit data rather than differentiating between the personal factors and contextual factors for each of the EAP participants.

The three stages in the 3P model - students' learning factors (the presage stage), the process of learning (the process stage) and the perceived outcomes of learning (the product stage) are interrelated with each other. The straight lines in Figure 20 indicate the relationship between students' learning factors, learning processes, and the perceived learning outcomes for the specific tasks given in the EAP classrooms. The dotted lines on the other hand refer to the relationships between students' learning factors (presage) and their perceived outcomes more broadly (product) for the learning of academic English in the EAP classroom. In order for learners to effectively construct knowledge in the EAP classroom, there should be an alignment between the three elements: learning factors, the responses to the tasks, and the outcome of learning desired by the students.

\subsection{The Use of Constructive Alignment and the 3P Model}

The EAP course is designed to assist students at the tertiary level to not only develop literacy, but also to be able to employ knowledge and skills in an academic environment (Hyland \& Hamp-Lyons, 2002). Ensuring that students have learnt adequate discipline specific literacy to prepare them to meet the demands of the tertiary level is important. Because the participants in this study are English language learners in Malaysia, and because of learning the academic skills needed at the university, the participants are learning in English.

The sections of this chapter will be organised in two parts. Figure 21 below indicates the organisation for this chapter. In the first part, the discussion focuses on EAP students' learning with regard to specific tasks. This is indicated by the straight solid lines in the figure above. The second part of the discussion considers the students' learning of academic English as a whole in the EAP classroom (indicated by the dotted lines).

The discussion is divided into two parts to consider the presage, process and product stages in relation to a specific task and then to the broader picture of learning as a whole which includes a range of reading skills and the purposes for learning in the academic English classroom. 
Figure 21. Organisation of this discussion

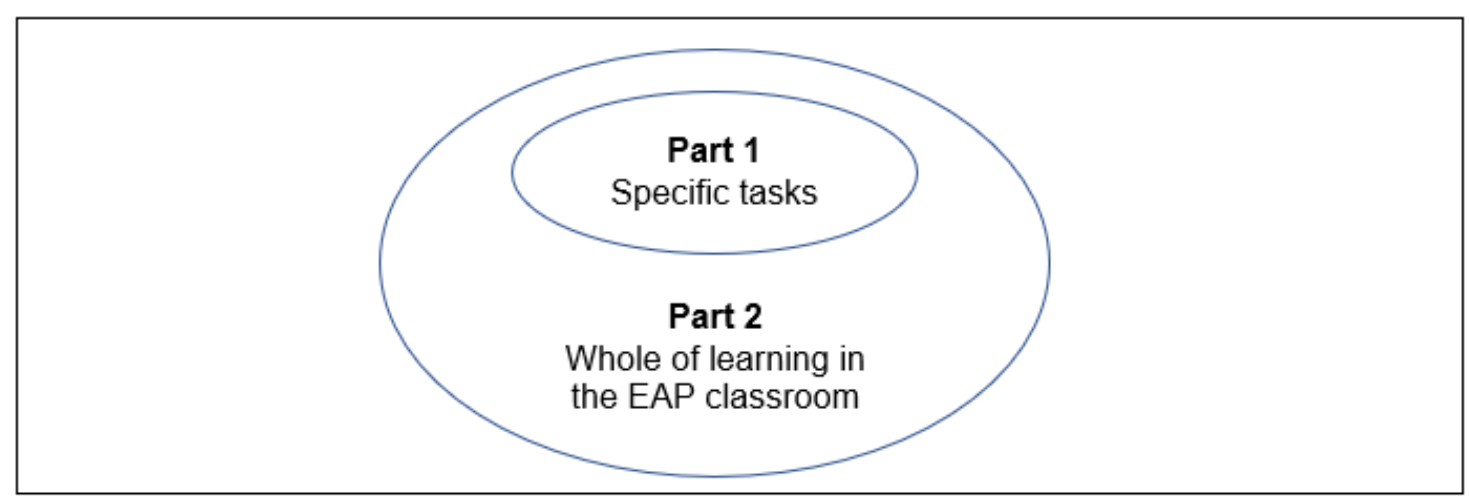

\subsubsection{Part 1: Constructive Alignment and Specific Tasks: Learning Factors and the Learning Process involved in Responding to the Specific Tasks}

In this section, the complex nature of learning is explained in detail drawing on the findings of this study. The first two stages of the 3P model - presage and process - are discussed. The relationship between students' factors in learning (presage) such as background, motives for learning, prior knowledge, anxiety, and preference for type of content used in the tasks and the process in learning (process), which is related to learners' level of responses to the specific tasks, is further elaborated. I will be discussing the personal factors illustrated in red below in Figure 22 and their interaction with the learning though the tasks. This is represented in Figure 22 by the solid lines. 
Figure 22. The relationship between students' learning factors and learning process in the EAP classroom in this study

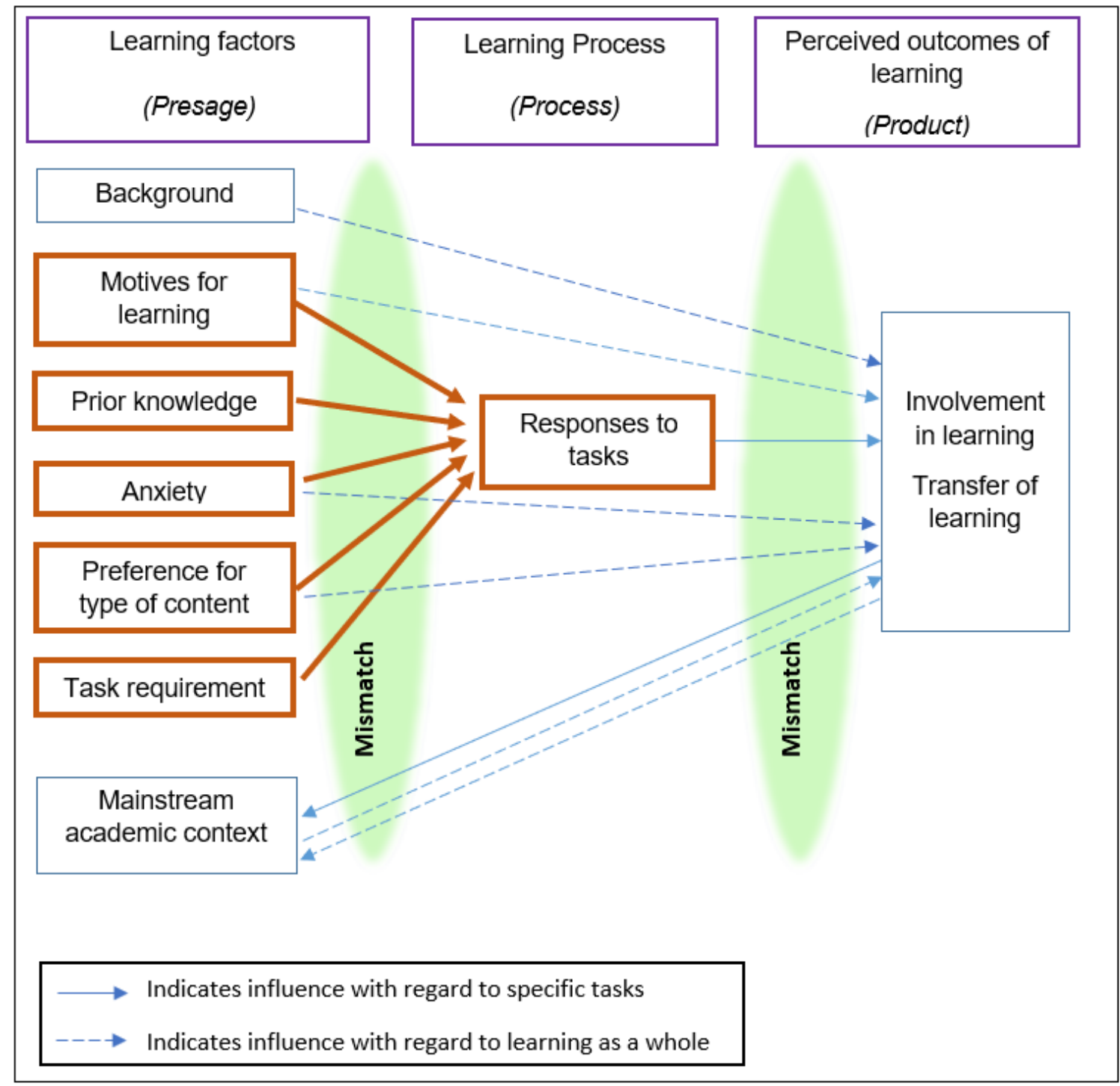

Learning in the EAP classroom is complex because the three stages, namely learners' learning factors, the learning process, and their perceived outcomes in learning, are not linear but form a system (Biggs, 1993, 2003). The personal factors and contextual factors that emerged from the analysis of the findings are the learners' backgrounds, motives for learning, prior knowledge, anxiety, preferences for the type of content taught, task requirements, and mainstream academic context.

The following are some key conclusions that can be drawn from the findings. A degree of possible mismatch between students' factors in learning and their responses to the tasks given in the classes could lead to their opting for surface learning in the EAP classroom (refer to Figure 22). CA encourages quality learning by focusing on assisting the learners to construct their own knowledge (Wang et al., 2013). When CA is evident, the learners can show both what they have learnt and how they have learnt (Biggs \& Tang, 2011). Appropriate learning activities are needed for learners to construct their knowledge. In this study, there were some 
limitations on students being allowed to construct the knowledge in ways that they might prefer. The tasks that were given to the students were conducted as group activities that allowed them the freedom to discuss and find ways to respond to the activities. Some important factors such as students' preferences for the type of reading, their proximal goals in learning, and their prior knowledge were not strongly aligned to the task. Learning anxiety played a role in the learning.

In the analysis of the data, motives for learning emerged as being important in this study. The influence of motives for learning and the influence of the other factors on motives for learning will be discussed in the following section.

\section{Motives for learning in the tasks}

Out of the seven learning factors that exist in this study, five learning factors, namely motives for learning, prior knowledge, anxiety, preference for the type of content taught, and task requirements, were the factors that influenced learners' responses to the tasks. Among all these factors, motives for learning seem to underlie learners' responses to the tasks. In this section, I will discuss how motives for learning influenced the learning process as well as its links to other factors. Further, the apparent mismatch of alignment that exists between these learning factors and the learning process will be further explored.

Learners' approaches to learning are shaped by their motives for learning and the strategies that they use to accomplish their motives are influenced by the context (Biggs, 1993b, 2001; Biggs et al., 2001). As this study was conducted in an EAP context, the focus of the study was what motivated learners to be engaged in learning in the EAP classroom and how they approached the reading tasks given in the classroom.

The data provide evidence of an apparent mismatch of alignment between learning factors and learning processes in the learners' responses to specific tasks (refer to Figure 22). The lack of alignment was particularly evident in a mismatch of learners' motives for learning and the tasks given in the EAP classroom. Biggs and Tang (2011) state that learners' motives for learning are influenced by how valuable learning is to them. In other words, what they learn should carry enough weight and be meaningful enough for them to feel motivated to learn. Within the area of EAP, studies show that learners' motives for learning are based on their goals for learning (Evans \& Morrison, 2011; Liu et al., 2011). The findings indicated the EAP learners' purposes for the tasks were primarily surface because of the compulsory nature of the course. These motives affected the strategies they used when approaching learning in the tasks. The motives appeared to drive the choice of strategies used.

The data indicated that learners had extrinsic motives, rather than intrinsic motives, for participating in the tasks given in the EAP classes. Learners with extrinsic motives are likely to be focused on the end-product of the task rather than going through a careful process of finding 
out how to derive the answers (Biggs \& Tang, 2011). Learners' extrinsic motives can be associated with a surface approach which is fostered by the need to comply with the lecturers' instruction (Biggs \& Tang, 2011). This was evident when the learners reported that they were not particularly interested in the reading of passages given even though some participants anticipated that they might be able to use the reading skills. Moreover, the learners found the reading of passages difficult to understand which could have led to surface motives in doing the task. Their goal in responding to the tasks was to merely complete them rather than to gain an understanding of the passages they had read.

\section{The influence of other factors on motives for learning}

Not all the learning factors played equal roles in this system for the participants. Motives for learning I have suggested had a big influence on responding to tasks. The other learning factors in this study had either a direct or indirect influence on motives for learning. Motives for learning among the participants in this study are affected by other student factors and contextual factors. The other factors that influenced the EAP students' responses to the tasks were relevant prior knowledge of the content of the reading, language learning anxiety, task requirements, and students' preferences for the type of content taught. The way these factors at the presage stage (learning factors) interact and influence each other is a useful illustration of Bigg's theory of the learning system in action (Biggs, 1993b).

Tasks: The tasks had a major influence on learners' motives (refer to Figure 22). As Biggs stated, learners' approaches to learning are context dependent (Biggs, 1993b; Biggs et al., 2001). The requirements of the tasks or learning activities within a context influence how students approach the tasks or learning activities. In the Theoretical Framework chapter I explained that there are two ways to observe approaches to learning: learners' immediate approaches to learning with regard to specific tasks and learners' preferences for approaches to learning more generally (Biggs, 2001; Biggs et al., 2001). In this section, the focus will be on EAP learners' immediate approaches to learning. Learners' immediate approaches to learning can be seen from the outcomes of the three tasks given to them. The students employed approaches to learning according to the level of requirement expected in the task (Biggs et al., 2001).

The tasks that were given to the students in the three EAP classrooms were different. The tasks were: producing graphic organizers (task 1), summary writing (task 2), and annotating information (task 3 ). These tasks were designed to allow learners to explore and understand the reading passages as well as practise the reading skills. They addressed the development of generic skills which are designed to help learners to have a better understanding in the mainstream academic context. The objective of these tasks fits with the aim of the EAP course in which generic skills are taught to the learners so that they can use the skills in the academic 
context. The outcomes of learners' responses to the tasks showed that some of them were able to achieve the requirements set for the tasks but some were not.

Tasks such as producing graphic organizers (Davies, 2011), summary writing (Delaney, 2008; Hedgcock \& Ferris, 2009) and annotation (Liu, 2006; Zywica \& Gomez, 2008) can promote surface approaches to learning or deeper approaches to learning depending on how they are set up for the learners. Graphic organizers, for example, can promote deep approaches to learning, in particular when students are required to produce a complex organizer such as a concept map (Davies, 2011). Similarly, summary writing is considered complex (Delaney, 2008; Hedgcock \& Ferris, 2009) as it is a cognitively demanding task that requires strategies like paraphrasing and the ability to seek pertinent information in a text. Likewise, annotation tasks could either be considered as surface level tasks or deep level tasks depending on the outcomes required (Liu, 2006). Annotation could be either used to identify pertinent information (Zywica \& Gomez, 2008) which is a surface approach or paraphrase and reflect (Feito \& Donahue, 2008) which promote deep approaches.

Table 30. The requirements for the reading tasks and the learners' level of achievement according to the SOLO taxonomy

\begin{tabular}{|l|l|l|l|}
\hline Tasks & Task type & $\begin{array}{l}\text { Level of task (SOLO } \\
\text { Taxonomy) }\end{array}$ & $\begin{array}{l}\text { The level of Participants' } \\
\text { achievement }\end{array}$ \\
\hline 1 & Mind map & Relational & Multistructural and relational \\
\hline 2 & Summary writing & Relational & $\begin{array}{l}\text { Content and organisation: } \\
\text { students' responses varied } \\
\text { from unistructural to relational } \\
\text { Language: all students } \\
\text { achieved multistructural }\end{array}$ \\
\hline 3 & Annotation & Multistructural & $\begin{array}{l}\text { Unistructural and } \\
\text { multistructural }\end{array}$ \\
\hline
\end{tabular}

Table 31 shows the requirements for the reading tasks and the learners' levels of achievement according to the SOLO taxonomy for the current study. Summary writing and mind mapping required deeper approaches while the annotation task required surface approaches. As demonstrated in the findings chapter, the tasks' requirements were at the multistructural and relational levels of the SOLO taxonomy. Most of the learners who did task 1 (Unit 1) were able to engage with the learning at the deepest level of achievement, given the task requirements. Task 1 required students to identify similar information from two reading passages. They were asked to create a compare-and-contrast map to show the similarities found in both the passages. Past studies into the use of graphic organizers in reading concur with the current findings of this study that this technique enables students to develop their ability to identify pertinent information which eventually leads to making sense of the passages (Hay et al., 2008; Setiasih, 2015). In this task, most of the students were able to identify information from the two passages and were able to group it under one theme. In other words, they were able to bring 
the separate information together which is a relational level response on the SOLO taxonomy (Hattie \& Purdue, 1998). In this study there was some support from the instructor to achieve this level.

Students were unable to achieve the relational level in task 2 (Unit 2). The learners undertaking task 2 found the task challenging and struggled to respond to the task. Task 2 was not categorised on a particular level of the SOLO taxonomy because this was a reading to write task. The students' written work was evaluated based not only on the content but also the organisation and the language use as the students were required to write a summary after reading the passages. The responses to the tasks showed that not all the students were able to fully understand the content, although they were all at a similar level with their language use in the summary writing. The students' lack of proficiency as well as their lack of understanding of the content of the passages led to differing abilities to respond to the tasks. The students in Unit 1 did not seem to struggle as much because they were able to extract and use chunks of information from the passage to complete the mind map task. The students in Unit 1 may have had more guidance than the students in Unit 2.

The lack of alignment between the requirements set for the tasks and students' less satisfactory responses could be further seen in task 2 . Task 2 required the students to employ sequential steps such as identifying information, comparing it and finally putting the information together in the form of a summary. Summary writing generally requires students to make choices about information that needs to be included and/or excluded. Writing a summary also includes paraphrasing the original source (Grabe \& Zhang, 2013). Most of the students had copied chunks of information from the passages. The studies conducted by Keck (2006) and Delaney (2008) showed similar findings to the current study in that lack of language proficiency hindered students from paraphrasing information. It is possible that the students were unable to find suitable vocabulary to use to paraphrase. Other possible reasons could be the students' lack of composing skills, including the ability to draw information from different sources and being unsure of how to paraphrase the information in the text (Hirvela \& Du, 2013). A relational level task requires an explanation of how the aspects found in the initial stage can be grouped together (Hattie \& Purdue, 1998). The findings thus indicated that the students had not yet mastered the ability of bringing the information together in the summary writing task.

Task 3 (Unit 3) required students to annotate each paragraph of the reading passage titled 'Intelligence: heredity versus environment'. Compared to past studies conducted with students doing annotation, the students in the current study were making a summary of each paragraph and observing the connection with other paragraphs. Studies conducted by Feito and Donahue (2008) and Liu (2006) revealed that the participants in their studies attempted to understand and fully analyse all the information provided in the text. Evidence of this process of analysis 
was absent in the current study. Interestingly, it was evident through the stimulated recall interview that some of the students had been interested in, and had more widely considered the information presented in the reading passage. This level of understanding, however, was not needed in the task. Hence, students had merely responded mechanically to the requirement by summarising the paragraphs.

It is also possible that the students in this study may have had an unclear understanding of the task instructions given in the class leading to choosing a surface motive in task completion rather than a deeper motive for learning. This then produced a surface approach. This could be seen in task 2 , where students were expected to paraphrase while writing the summary. Unclear expectations of the requirement for the task could have made students opt for the surface approach of merely summarising by directly borrowing words from the reading passages as displayed in task 2. Further, it is possible that students assumed this class task was not important and was not going to be assessed and hence they were not engaged in the tasks given. This could be a reason why they had a surface motive when approaching the tasks. Finally, the students' concern about responding to tasks that are more valuable is related to their motives for doing the tasks (Biggs \& Tang, 2011). Learners will have deep motives when they are able to see the importance of, as well as enjoy doing the tasks (Biggs \& Tang, 2011).

Students' responses to the tasks were categorised using the SOLO taxonomy to identify their levels of understanding of the tasks. The objective of the EAP tasks was not to test students' understanding at a "declarative knowledge level" (Biggs, 2003, p. 41). The tasks given in the three EAP classrooms required students to display their understanding of the reading skills taught to them. All the three tasks had written instructions that indicated that students needed to select information from the reading passages by using techniques such as compare and contrast, annotation, and summary writing as taught in the class. The requirements of these tasks fit into the declarative knowledge category (Biggs \& Tang, 2011). Biggs and Tang stated that declarative knowledge is also commonly known as "content knowledge" which requires students to declare what they have learnt by either paraphrasing or employing their own examples (p. 82). Biggs and Tang argue that it is possible for instructors to encourage students to think at higher levels through employing declarative knowledge in the curriculum. In this study, one of the three tasks assessed a low level of thinking. This could have led to students assuming that this task was not relevant to them (Biggs \& Tang, 2011). This perception could have limited the depth of approach used by the learners.

Language learning anxiety: One of the factors that exists in this study is language learning anxiety (refer to Figure 22). Anxiety in learning in general causes learners to employ surface approaches to learning (Balasooriya et al., 2009; Papinczak, 2009). Studies of language 
learning anxiety indicate a similar effect which is that learners tend to shy away from engaging themselves in the learning activities in the classroom due to lack of language proficiency (Cao, 2011; Liao \& Wang, 2015). Learners' lack of proficiency is one of the reasons why they worry about being judged by others (Chin et al., 2016; Darmi \& Albion, 2012; Liao \& Wang, 2015). The studies show that lack of proficiency causes language learners to be concerned about how others see them when they respond to a question or a discussion in the classroom. According to Horwitz (2000), this is a common occurrence among non-native speakers of English. In this study, fear of giving the wrong answer in front of peers emerged as a way anxiety is caused by a perception of lack of proficiency. This stopped students from participating in the discussion that could have led to the understanding of the reading passages.

Hence, although there might appear to be a lack of a relationship between learners' language anxiety and learners' motives for learning, the influence of the language learning anxiety does affect students' motives. The learners' concern about being judged by others makes them feel reluctant to discuss their answers, particularly in a whole class setting. This strategy may limit their opportunities for interaction and language learning.

Prior knowledge and preference for type of content taught: Lastly, prior knowledge and preferences for the type of content taught in the EAP classroom are two of the factors that not only have an influence on each other but have an impact on motives for learning as well (refer to Figure 22). As mentioned in the theoretical framework chapter (refer to page 26), Biggs and Tang (2011) stated that having enough prior knowledge and interest in the learning activities given in the classroom provides a better understanding of the content taught. Hence, relevant prior knowledge helps learners to participate effectively in class activities and it will assist them in building on new knowledge. Although there have been conflicting findings in studies conducted on whether prior knowledge influences the interest in topics or vice versa in the area of EAP as well as language learning (Eidswick, 2010; Ercetin, 2010; Martinez, 2013), the analysis of the current study shows that both lack of prior knowledge and lack of topic interest influenced students' engagement in the reading tasks in the EAP classroom.

The majority of the students in this study reported that they were not interested in reading topics such as 'Intelligence heredity versus environment', 'Print Revolution' and 'Cyberculture'. Most of the participants did not have extensive background knowledge of the topics in the reading tasks. Learners' lack of prior knowledge and lack of interest in topics had an impact on their interest in doing the tasks. When learners are disinterested in doing the tasks, they tend to opt for surface approaches to learning (Holmes, 2018; Kember et al., 2010). The learners chose a surface approach to learning with the aim of finishing the task because they were told to do so by the instructors (Biggs \& Tang, 2011). These surface approaches were 
seen, for example, in Unit 3. Two of the participants left the task incomplete as they found the reading passage difficult to understand and had not really attempted to do the task. Lack of prior knowledge and lack of interest influenced learners' motives for doing the tasks. When learners have an interest in the topics taught as well as prior knowledge of the topic, they will then be intrinsically motivated to respond appropriately to the learning activities (Biggs \& Tang, 2011). Hence, a relationship between the learners' motives for learning and prior knowledge and interest was very clearly demonstrated in this study.

In this study, learners' lack of relevant background knowledge and interest in topics led to a mismatch between learners' personal factors and the tasks given in the EAP classroom.

Motives for learning played a bigger role than other factors in this study. Factors such as task requirements, anxiety in learning, prior knowledge and preference for types of content, however, do not exist in isolation. These factors are interrelated and have an impact on each other.

\section{Constructive alignment and specific tasks: Students' responses to tasks and their perceived outcomes of learning}

The depth of learning that occurred in the study could be viewed in terms of how and what students have learnt from the tasks given in the class. Students' perceived outcomes of learning for this study can be viewed from two aspects, namely the qualitative and the affective outcomes of learning (Biggs, 2003). The qualitative outcomes of learning in terms of the tasks that were analysed from the learners' perspectives in relation to whether the learners were able to transfer the knowledge that they acquired from doing the tasks to contexts out of the EAP classroom. This is an important aspect of the objectives of teaching in the EAP course (Hyland, 2016; Hyland \& Hamp-Lyons, 2002). The second aspect of learners' perceived outcomes of learning is the affective outcomes of learning. Learners' affective outcomes of learning in this study were determined by their involvement in learning (Biggs, 1993, 2003) when responding to the tasks. Learners' involvement and transfer of learning will be discussed in this section as well as in the next section of this chapter. The EAP learners' involvement and transfer of learning with regard to their responses to the tasks can be seen in the thick lines in Figure 23 below. 
Figure 23. The relationship between learning process and perceived outcomes of learning in the EAP classroom in this study

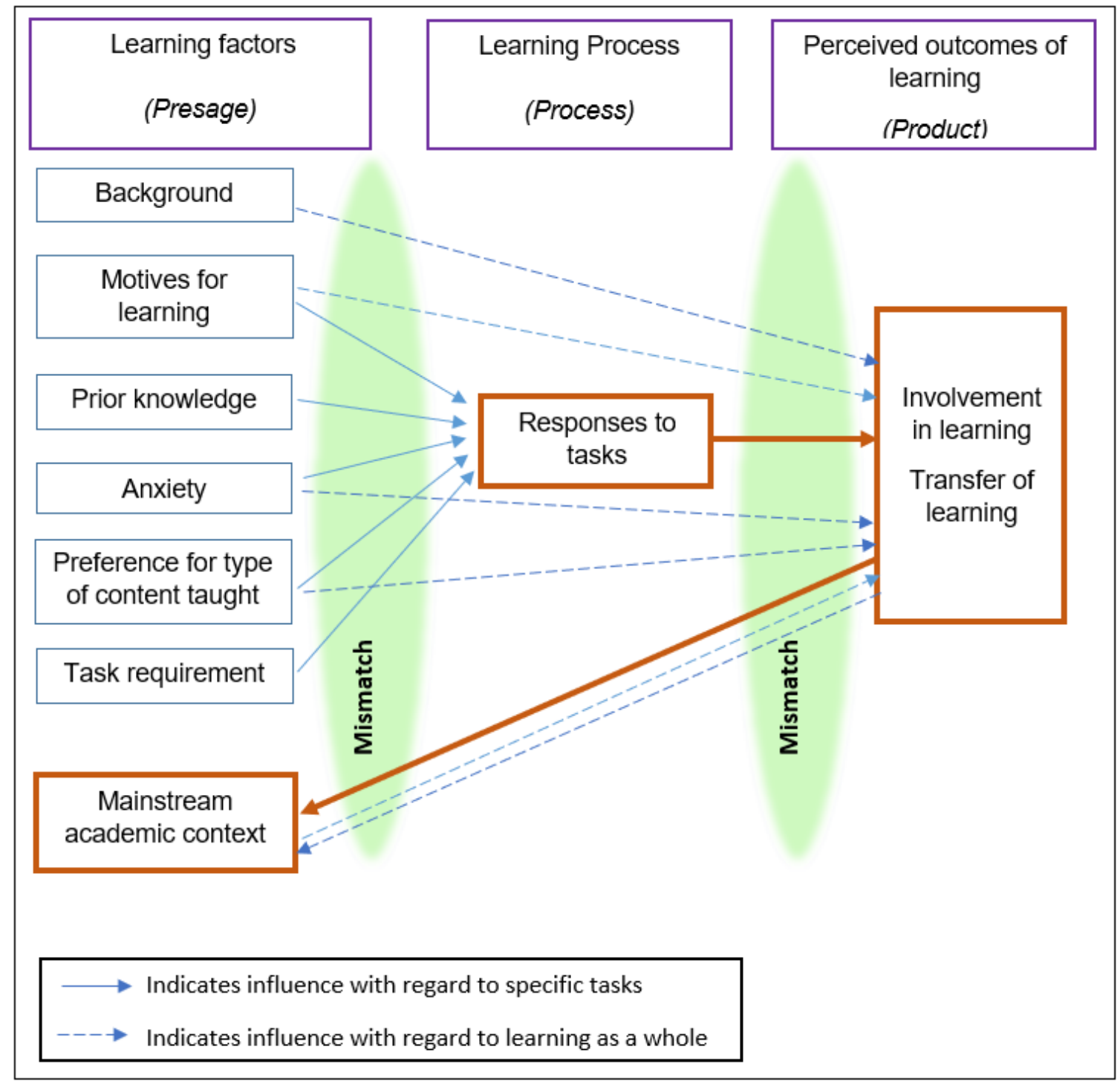

\section{Involvement in learning in relation to tasks}

Students' views of how important the tasks are to them affect their involvement in the tasks (Biggs \& Tang, 2011). Most of the students were not involved in learning the content of the readings in the tasks. This leads to dissatisfaction in learning. In addition, most of the students did not think directly or immediately about ways to transfer the reading skills learnt in the EAP classroom to other subjects in the mainstream academic context. This also contributes to low involvement in the tasks. These factors lead to the students using a more surface level approach. A surface motive for learning contributes to low involvement in the EAP classroom.

\section{Transfer of learning in relation to tasks}

As mentioned above, most of the students found it difficult to see the transfer of learning taking place from the EAP classroom in the current study to the mainstream academic context. These students perceived the reading skills used in the tasks given in the EAP classes as not 
particularly helpful with the mainstream academic work. They were not particularly focussed on how to take the reading skills from the EAP classroom and use them in other subjects (Green, 2015; James, 2010). This did not promote the kind of active learning that is possible when people see the usefulness of learning (Wang et al., 2013). Interestingly, the students were aware of the benefits of learning the reading skills in the three tasks such as annotation, the compare and contrast mapping technique, and summary writing in theory, but most of the students were not particularly focussed on how to transfer these skills to other situations. This could be because they are enrolled in the engineering programme where much of the learning is demonstrated with calculations rather than the text-based reading skills taught in the EAP classes (Green, 2015; James, 2010). This perception of lack of relevance of content taught in the EAP classrooms to the mainstream courses has been found in other studies (Green, 2015; James, 2010). Students perceive the tasks given in the EAP classroom as irrelevant. If the students are unaware of the intended objective of the tasks, this is more likely to happen (Wang et al., 2013). The lack of knowledge of the wider objectives for academic learning influenced the transfer of learning from the EAP context to the mainstream setting.

In summary, students had limited involvement in participating in the tasks. They did not always see opportunities or saw limited opportunities to transfer the knowledge that they had acquired from the tasks to mainstream academic study. There was a level of misalignment between students' involvement with the tasks and transferring the skills learnt in the EAP classrooms.

\subsubsection{Part 2: Constructive Alignment and Learning of Academic English in the EAP Classrooms: Learning Factors and Perceived Learning Outcomes}

The second part of this chapter will discuss the alignment between EAP students' learning factors and their perceived learning outcomes of learning academic English as a whole. Similar to the discussion in Part 1 (refer to page 204), motives for learning play a major role in Part 2 of this chapter. In this section I will further elaborate how motives for learning influence learners' wider aspects of the perceived outcomes of learning. I will also explain how the other learning factors influence motives for learning. The dynamics between these factors are shown by the dotted lines in Figure 24. 
Figure 24. The relationship between learning factors and perceived outcomes of learning in the EAP classroom in this study

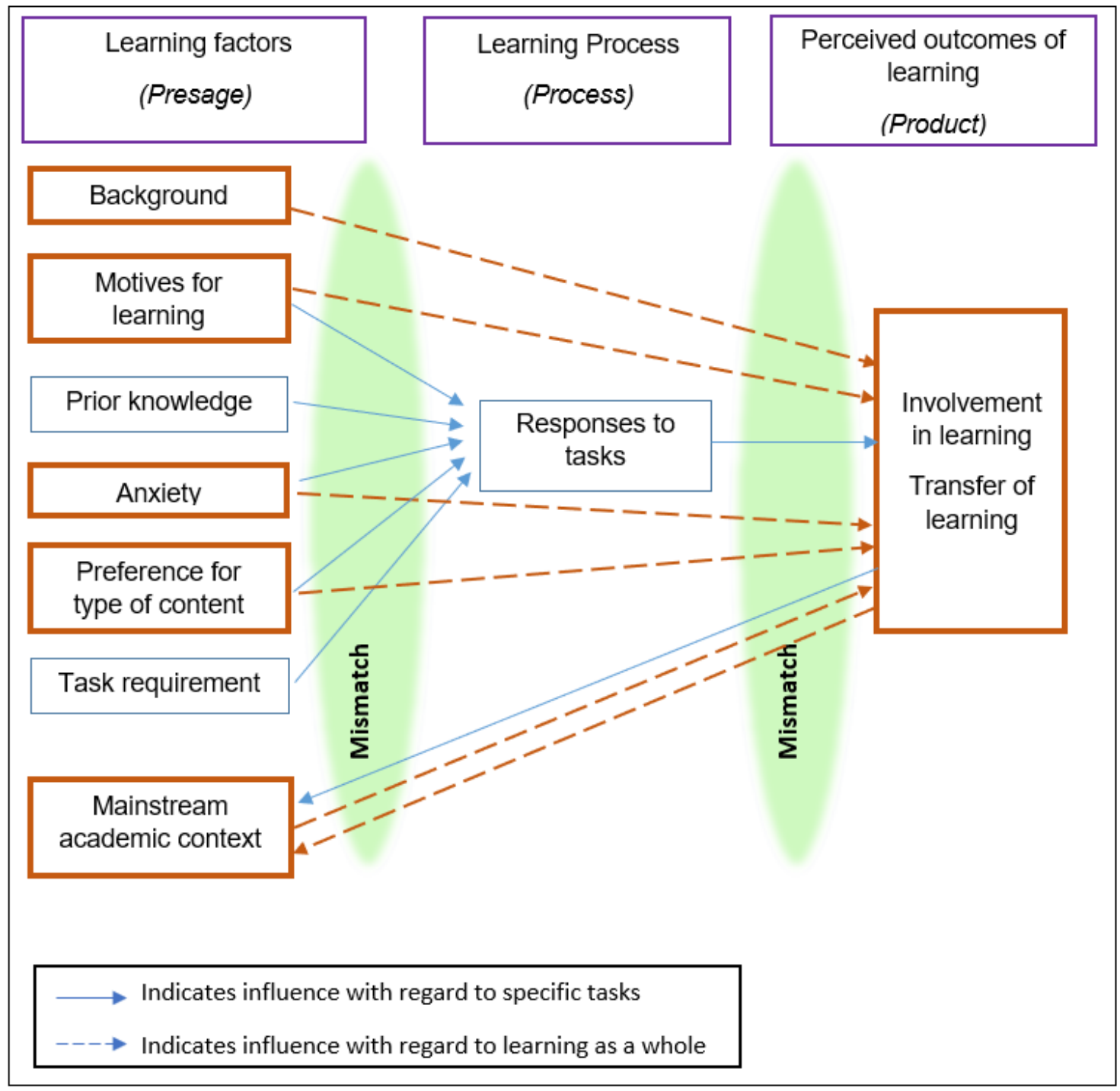

\section{Motives for learning with regard to learning academic English in the EAP classrooms}

Motives for learning are the central factor that influenced learning in these EAP classrooms. Motives for learning are likely to be more important than the other presage factors for these participants. I have discussed motives for learning in relation to the tasks in the EAP classrooms in part 1 of this section (refer to page 204). In this section, I will discuss how motives for learning influence perceived learning more broadly in the EAP classrooms in my study, rather than in specific reading tasks.

Motives for learning in this section relate to a broader perspective both within and beyond the EAP classroom. According to Biggs and Tang (2011), learners have motives for learning in a particular course and these motives depend on various aspects such as their interest, learning experience, and future occupations. Studies on motives for learning support Biggs' notion that learners indeed have various motives for learning which differ for individuals (Kember, 2016; 
Kember et al., 2008). Within the area of language learning and the EAP context, empirical research discusses and describes the goals of tertiary students in learning academic English (Evans \& Morrison, 2011; Liu et al., 2011; Ohata \& Fukao, 2014).

The findings from this study can be divided into EAP learners' distal and proximal goals in learning. The proximal goal in learning reported by the EAP learners shows that they are focused on attaining grades in the EAP course which is a compulsory course at the university. Learners had more long-term goals or distal goals such as being able to communicate in English in society and preparing themselves for their future careers. The findings from this study are different to those of Liu et al. (2011) on EAP and English for General Purposes. The findings from Liu et al. (2011) showed EAP learners who were more academic and career motivated. The EAP learners in the Liu et al. (2011) study claimed they were enrolled in an EAP course because it would be beneficial for their future jobs if they did well in language tests as well as academically. Although learners in the current study had distal goals for learning English, it could be seen that, during their EAP course they were more focused on the proximal or the immediate goals of passing the EAP course. There were surface motives for their learning in the EAP classroom as a result. It is possible that the learners had this goal because they were unaware of how the content, they were learning would be helpful to them in the academic context. Further, the learners in this study also reported that they wanted to be able to communicate in English through speaking, which can be a more general purpose for learning a language, rather than the type of language learned for specific academic purposes.

The learners had both distal and proximal goals in learning; however, they were more focused on their proximal goal which is to complete the EAP course.

\section{The influence of other factors on motives for learning}

The analysis of the data showed all the learning factors interacted in a complex and dynamic way. Factors such as background, language learning anxiety, the influence of the mainstream context, and preferences for the type of content taught contributed to the depth or lack of depth of the learning and influenced motives for learning.

Background: In this study, the learners' background influenced their motives for learning in the EAP classroom. Recapping the theoretical framework, Biggs (1987) stated that the learners' home background influences learning, as learners are influenced by their own beliefs. Within the area of language learning and EAP in Malaysia, studies show that learners' cultural and linguistic identities influence their beliefs about learning languages (Lee, 2003; Musa et al., 2012; Rajadurai, 2010).

The analysis of the data in the current study affirms the findings from the previous studies that learners' background influences language learning. In the current study, students' language 
background could be divided into two categories: students who grew up in situations where some English was spoken at home and students who grew up predominantly in a Bahasa Malaysia speaking environment. These aspects contribute to their identity and beliefs about learning English. Students' identities as Malaysians play an important role in the learning of English in the classroom. Malaysian language learners have been known to constantly shape and reshape their identities due to their background and the context that they live in (Lee, 2003; Rajadurai, 2010). Learners' identities as Malay Malaysian or Indian Malaysian may lead to a dilemma of split loyalty (Lee, 2003). Students who grow up in English-speaking environments, however, find that speaking in English is the norm. The dilemma of split loyalty may be caused by the complex social structure in Malaysia where learners come from diverse sociocultural backgrounds which influence their learning and their involvement in the EAP classroom. Further, as language is closely related to one's identity, the participants in this study who were predominantly Malay learners could have felt loyalty to Bahasa Malaysia which is seen as a symbol representing the Malay identity and unity within Malaysia as a community (Lee, 2003). Another possible reason for the dilemma of split loyalty is the socio-political aspect; Bahasa Malaysia is considered the national language whereas English is a second language in Malaysia. As the national language, Bahasa Malaysia is used as the medium of instruction in schools and is widely used in the civil sector (Lee, 2003). It takes precedence over English. Although English is used in the private sector, it is not used as a medium of instruction in public schools (Lee, 2003). English is seen as an academic subject, making learners feel conflicted about the use of English. Learners' identities indirectly influence their motives to learn English.

Learners' motives then could be seen through the participants' realisation that there is a need to learn and practise English but at the same time they feel that they need to be faithful to their native language. However, not all the learners in the current research faced this issue. This makes the Malaysian community's perception of learning English complex. The environment that the learners grew up in could be another aspect that influences their beliefs about learning English. Some learners also claimed that they grew up in a Malay-centric environment where they did not see the need to communicate in English. Thus, some learners feel that they only need English for specific contexts such as in university classes.

Although learners' backgrounds do not have a direct influence on the learning of academic English, they do influence the learning of English in general which is part of the EAP courses. The identities of the students may influence how learners see their learning in the EAP classroom in the context of multicultural Malaysia.

Language learning anxiety: ESL learners learning a second language tend to have anxiety in learning. In this study, it was evident that language learning anxiety influenced motives for learning. As well as experiencing language learning anxiety in relation to specific reading tasks 
(refer to page 210), the EAP learners were facing anxiety in learning academic English as a whole. This anxiety influences their participation across a range of learning activities. The relationships between learners' anxiety and their responses to the tasks, and learners' anxiety in learning in the EAP classroom more generally could also be due to a lack of language proficiency (Evans \& Green, 2007, Evans \& Morrison, 2011, Liao \& Wang, 2015) and worry about reputation (Liao \& Wang, 2015). These aspects influence learners' motives for learning among the EAP learners.

The EAP learners' concern about their reputation influenced the extent of their participation in the classroom. The concern about their reputation could be based on their lack of proficiency and a fear of giving wrong answers. The teaching and learning in the three EAP classrooms in this study were conducted by having classroom discussions or group discussions. Some learners tended to keep silent during these discussions. The learners' preferences to follow the instructors' answers in the learning activities rather than attempting to share their own thoughts in discussions could, in turn, be associated with surface motives for learning.

Hence, similar to the discussion in Part 1, there seems to be an influence between EAP learners' language learning anxiety and their motives for learning.

Influence of Mainstream Academic Context: The mainstream academic context influences motives for learning in the EAP classroom. An interpretation of the data suggests that the mainstream academic context played a significant role in influencing learners' motives for learning. As in part 1 (refer to page 213), students' perceptions of the potential transfer, or lack of transfer of learning to the mainstream academic context could be seen as having a relationship to the responses to tasks. There is a relationship between learning in the EAP classroom generally and the mainstream academic context. However, the difference between this section and the one in part 1 is that in this section there is a two-way relationship between the content learnt in the EAP classroom and the mainstream academic context. The two-way relationship between the EAP learners' perceived outcomes of learning and the learning factors could be seen through the dotted lines (refer to Figure 24).

Biggs termed learning as a system where all the aspects, regardless of whether within the classroom or out of the classroom, influence each other as well as the outcome of learning (Biggs, 2003). The content taught in the EAP classroom is ideally transferable to other courses within the academic context. Studies conducted in EAP show that transfer of learning from the EAP courses to the mainstream academic context is discipline specific (Green, 2015; James, 2010). In the current study, I found that most of the EAP learners were unable to see the transfer of the reading skills that they had learnt in the EAP classroom to their engineering subjects. Most of the learners said that they were unable to employ the reading skills learnt in the EAP classroom in their other subjects because they were mostly subjects dominated by 
calculations. Hyland (2016) argues that learners may find it difficult to transfer the learning from the EAP classroom to the academic field because different academic fields require different specific skills. A generic academic course may not be applicable for all learners (Hyland, 2016). As a result, there could be less involvement in the EAP classroom as learners are unable to see the reason for learning the content and skills in the EAP classrooms, which in turn affects their motives for learning.

James (2010) found there was a lack of support from mainstream educators in facilitating the transfer from EAP to the other subjects. The learners in the current study reported that they did not have enough support from their mainstream academic instructors to assist them in employing reading skills as well as in using academic English. The mismatch between the content taught in the EAP classroom and the support received in the mainstream context leads to students being less involved in the EAP classroom.

As mentioned in the literature review chapter, Biggs $(2004,1993)$ viewed tertiary education as a "system" comprising micro-systems. In other words, Biggs claimed that the teaching and learning that is done at the tertiary level is bounded by "student, teacher, teaching context, departmental, collegial structures, community or political pressures" (Biggs, 1993, p. 78). A balance between these sub-systems should be achieved to obtain good teaching and learning outcomes. This balance, especially in the wider university structures, was somewhat missing in the current study in relation to a potential goal of improving academic English skills because the mainstream instructors tended to code-switch between English and Bahasa Malaysia while teaching. They also gave leeway to students to choose Bahasa Malaysia or English during their presentations as well as during the teaching and learning activities. The lack of provision of opportunities to use English in the mainstream means that students are not likely to see the need to transfer the knowledge and skills from the EAP course and to see applications of this knowledge and these skills in their careers in the future.

Hence, the misalignment between the students' perceptions of the content taught in the EAP classroom and their opportunities to use English lead to perceptions of the inability to transfer the knowledge into the mainstream context. The learners' perceptions of this misalignment influence their motives for learning in the classroom. When learners do not see the content learnt as valuable, they will be less interested in engaging with learning activities (Biggs \& Tang, 2011). This could be seen in the current study where learners could not make the connection from the EAP classroom to the engineering programme. This leads to their having a surface motive which focuses on completing the EAP course or aiming to pass the course.

Preference for type of content taught: As discussed in part 1 of the discussion chapter, learners' prior knowledge and their preference for the type of content taught in the three EAP classrooms were connected (refer to page 211). In this section, however, the learners provided 
more holistic responses about the type of content they preferred to learn which affected their learning in general in the EAP classroom.

Similar aspects were found between learners' interest and their responses to tasks and learners' interest in learning in the EAP classroom. The learners found the topics introduced in the EAP classrooms were predominantly uninteresting and they seemed detached from their future needs. When learners have less interest in learning, they become less motivated to respond to the learning activities done in the classroom. The EAP learners in this study had a surface motive for learning which is influenced by their extrinsic interest and so they put less value on the learning activities (Biggs \& Tang, 2011). The learners' extrinsic, rather than intrinsic interest originated from the mismatch between their own interests and the various topics and skills used in the reading tasks.

To sum up, based on the discussion thus far in part 1 and part 2 of this chapter, the findings support Biggs' concept that learning is a form of system where each of the aspects that exist in the $3 \mathrm{P}$ model influence each other. In this study, for example, when learners are unable to see the benefits of learning the content in the EAP classroom, they may not be motivated to be enthusiastic about what they learn. It is evident in this study that learners' personal factors and the contextual factors not only influence each other but also how they approach learning in the classroom and ultimately how they perceive learning in the EAP classroom. It is also important to note that the roles of each of the learning factors may not be equally weighted. Motives for learning played a more central role compared to the other learning factors in determining the approaches to learning.

Further, the wider social context within the system appears to influence how language learning takes place and this could also be seen through the findings of this study. This includes the wider university environment and the national environment where English has a role together with other languages. This notion draws on a social constructivism approach that language learning is constructed socially and culturally. In other words, learners' thoughts reflect their interaction with a specific social context. Hence, although the data show that most of the learning is constructed by learners drawing on their individual backgrounds, language learning takes place in a social and cultural context. In this case, the complexity of language use in Malaysia and the influences of English within a global society are all at play when considering language learning from a social constructivism perspective.

\subsection{Mismatch of Alignment Leads to an Internal Process of Compromise: Students' Perspective}

The CA framework refers to a balanced teaching design where appropriate teaching and learning activities and assessments align with the learning outcomes set by the instructors (Biggs, 2014). Although Biggs originally constructed this framework to assist instructors in 
designing appropriate teaching (Biggs, 1996), it is equally important to take into consideration how the teaching is viewed from the learners' perspectives.

An existence of the perception of misalignment could be seen in the teaching and learning conducted in the EAP classrooms in this study. The existence of misalignment could be seen by the mismatch of personal and contextual learning factors with learners' responses to the tasks and their perceived outcomes of learning in terms of the tasks and learning EAP as a whole. The influence of the existence of the learning factors (for example, preference for content taught, language learning anxiety, and mainstream academic context) in the specific tasks as well as in learning EAP across the course show that the mismatch of alignment is evident in the system. Both can lead to a surface motive for learning. In other words, learners' motives for learning influenced the type of strategies they chose in learning. The mismatch of learning factors which predominantly focused on learners' surface motives for learning affected their perceived outcomes of learning in the EAP classroom. It was evident from the analysis that learners' inability to see a connection between the content taught in the EAP classroom and their academic subject content and so the potential for transfer that could take place to the mainstream academic context, further added to the mismatch problem. The unclear objectives for learning led to a tendency to opt for surface motives and surface strategies for learning.

Interestingly, it was also evident that despite the mismatch of alignment between learning factors, the responses to the tasks as well as learning EAP in the whole course, learners in this study adapted their learning to suit the classroom situation. The learners chose to keep going on with the tasks as this was what was expected from them in the classroom. They were also aware that they had to complete this course which was a requirement set by the university. In other words, these EAP learners adapted their learning by practising an internal process of compromise to suit the situation that they found themselves in, in the EAP classroom. They were making the best of the existing situation. As Asian learners, they may be constructing their own learning strategies to suit the context they are in (Biggs, 1990, 1998). It could be said that the internal process of compromise is a form of coping strategy that the learners in this context use to learn in the EAP classroom. This internal process of compromise happens during the learning process.

To sum up, in spite of the existence of misalignment in learning from the learners' perspectives, these EAP learners chose to adapt themselves to the teaching and learning in the EAP classroom. This internal process of compromise enabled them to attempt to learn the content and skills taught in the class. Hence, construction of knowledge takes place although a mismatch exists in the EAP classroom. However, the construction of knowledge does not promote deep approaches but leads to more surface approaches to learning. 


\subsection{Summary of the Chapter}

This chapter discussed the complex nature of learning that takes place in the EAP classroom based on the existence of different learning factors (personal and contextual factors), the process that these learners go through to learn the content and skills as well as their perceived outcomes in learning. Further, from the discussion it was apparent that the learning factors, the learning process and the learners' perceived outcomes of learning influenced and interacted with each other. The EAP learners' perceptions confirmed that the content taught in the classroom did not match their expectations of learning. This mismatch of expectations led to their adapting themselves to the learning environment by practising internal processes of compromise which ultimately lead to surface approaches to learning. Each individual student was influenced by a combination of factors in learning which then affect the learning process stage and how the student perceives his or her learning outcomes.

To sum up, there was an apparent misalignment between the learners' perceptions of the factors in learning with the process of learning and their perceived outcomes of learning in the EAP classroom. Learning factors influence how the students approach a task as well as how they approach learning in the EAP classroom across the course more generally. The learning factors and the process of learning also influenced how the learners perceive their outcomes in an EAP classroom. 


\section{CHAPTER 8 \\ CONCLUSION}

This chapter reviews the research study. In this section I will discuss the contributions and implications of the research study. Finally, the limitations and suggestions for future research are included.

\subsection{Summary of the Study}

This study addressed the question:

How do 12 Malaysian tertiary students' perceptions of factors in learning in the EAP classroom align with their responses to tasks and their perceived outcomes of learning in the EAP classroom?

The nature of EAP is an on-going debate (Chapter 3). EAP courses are supposedly designed to cater to the language learners' needs in terms of the language demands of study in mainstream classes, and the thinking skills required in the academic context, as well as being able to participate in the social context (Hyland \& Hamp-Lyons, 2002). Generic academic language skills, rather than discipline specific skills, are taught in EAP classes.

This study used the case study methodology to examine the learning of 12 Malaysian students in three different EAP classes. The data were gathered using semi-structured interviews about learners' perceptions of learning in the EAP classroom, stimulated recall interviews on the tasks done in the classroom, written samples of tasks, and classroom observations. These data collection methods were triangulated to provide a view of learners' perceptions of the teaching and learning of academic English and the process of responding to three reading tasks.

The findings were analysed using CA complemented by the 3P model: presage, process and product stages. CA and the 3P model are common theoretical and practical frameworks that have been used to examine students' approaches to learning but there is little published research about their use in EAP classrooms.

The findings from this study show that learning in the three EAP classrooms is complex. This is firstly because there are many learning factors that influence the learning of EAP in the classroom in the presage stage. These factors influence each other as well as the process of learning and how the learners perceive the outcomes of learning in the EAP classroom. Factors relating to language learning such as language learning anxiety were evident. The other factor that influenced the approach to learning was motives for learning. The students did not necessarily see the skills and knowledge from the EAP classroom as useful either in being able to transfer them to the other subjects they were studying in mainstream classrooms or to 
their future aspirations. The influence of these factors showed the complexity of Biggs' concept of a system in action.

Secondly, from the EAP learners' perspectives, there was a mismatch of alignment between the learners' learning factors and the skills and reading strategies in the classroom, causing the learners to internally compromise their learning to meet the academic requirement of passing the course. Learning took place but at a more surface level which should have been surpassed through the opportunities offered in the tasks. This has implications for course design and EAP teaching and challenges the goal of EAP as a course to develop thinking skills.

\subsection{Contributions of the Study}

The contributions of this study can be viewed from two aspects: in terms of theory and methodology.

This study contributes theoretically by demonstrating how the 3P model could be of value in the EAP classroom as it has been in other subjects. The inclusion of the learners' background as a learning factor, particularly in those aspects that relate to learning English in a multilingual environment, is a useful re-addition to the model. Although Biggs (1978) had included home background as a factor in the $3 \mathrm{P}$ model, it is not always considered in studies using his framework. Learners' background and the learning of an additional language cannot be separated. This study indicates that learners' background factors, such as their identity and language learning beliefs, play a role in learning in the EAP classroom. The findings in this study show that learners' identity and language learning beliefs affect how they approach learning in the EAP classroom.

This study also contributes by showing the value of the use of CA as a framework for evaluating teaching and learning in relation to student perceptions. This research used CA for particular groups of learners by gathering qualitative data to explore the existence of alignment from the learners' point of view. This approach reached across a range of aspects of CA by including the influence of various learning factors, the learners' responses to typical EAP reading tasks, and the students' satisfaction with the perceived outcomes of learning the skills and content in the EAP classroom. The use of the CA framework in the current study differs from the more common focus on the alignment between teaching methods and assessments that result in the intended learning outcomes (Biggs, 2014).

The CA framework and the 3P model are located within a social constructivism paradigm. This social constructivism lens enabled me to observe how EAP learners not only construct their own knowledge, but how learning is a product of the classroom context and out-of-classroom context. This study highlights the concept that second language EAP learners come to the 
classroom with various experiences, beliefs and attitudes towards learning which influence what they learn and how they learn. It draws on the concept of learning as a system where learners' backgrounds are an important part of the system.

This study is qualitative in nature. There have not been many qualitative studies conducted using $\mathrm{CA}$ and the $3 \mathrm{P}$ model. Many studies have used a quantitative approach with questionnaires (such as Kuhn \& Rundle-Thiele, 2009; Larkin \& Richardson, 2013). Hence, this study contributes rich knowledge about what the learners actually do and how they report approaching tasks which require different levels of thinking. Students' perspectives on learning allow researchers as well as educators to hear how students report the influences on learning in the EAP classroom and the satisfaction and involvement that takes place in learning.

Stimulated recall interviews, rather than a quantitative measure, provided more understanding of CA from the learners' individual and collective perspectives. This data collection tool assisted in collecting nuanced data from the learners and highlighted the learning process that took place in the EAP classroom. The learners were able to discuss the steps that they went through in responding to the tasks, the challenges that they met and how they resolved these challenges. Incidentally, recalling what they had done during the learning activities indirectly allowed them to reflect on their learning which, in a way, may have promoted their own deep learning.

Lastly, in terms of contribution to the EAP course in a second language context, this study depicts the complexity of learning in the second language environment. Learning EAP in a second language context includes various factors such as learners' background and attitudes towards the second language, language proficiency, and motives for learning, as well as the tasks, which affect how learners approach their learning. This study provides a system approach to learning which could assist EAP practitioners to become more aware of the learners' experience in the classroom and what influences these learners. An awareness of how the parts of the system interact could allow EAP practitioners to design EAP courses that are likely to engage learners in tasks that interest them, have clear transfer to the mainstream course and address the future career aspirations of the learners. The learners' perspectives which reveal any mismatch of alignment have the potential to provide EAP practitioners with an understanding of the learners' motives for learning.

At an institutional level, the offering of generic EAP courses, including using generic textbooks, deserves further examination, particularly if the learners are expected to transfer knowledge and skills to a subject like the study of engineering. The challenge is to find the alignment of each of the three stages during the process of learning and teaching. 


\subsection{Implications of the Study}

The implications of the study are divided into EAP course design and EAP practitioners and learners.

\subsubsection{EAP Course Design}

There is an existing debate on what should be taught in the EAP course and how it accommodates the learners' needs (Flowerdew, 2013). As we have seen in the literature review, Hyland, argues that EAP courses should become ESAP courses. They should be more focussed on the specific features of different disciplines. (Hyland, 2016; Hyland \& HampLyons, 2002). Charles and Pecorari (2016), in their textbook for EAP, argued similarly that the teaching of EAP is best done through subject specific academic content such as engineering, although this may be cost prohibitive. Baik and Greig (2009) reported that there is not sufficient evidence that students can transfer generic academic skills to discipline specific contexts and this had resulted in a choice to replace EAP courses with ESL courses at the University of Melbourne. Hyland (2016) noted that a focus on abstract concepts may be more helpful to social science than to science students. Hyland, in particular, notes that when students cannot see the transfer of such generic skills as skimming and scanning for information they lose motivation.

Hyland and Hamp-Lyons (2002), Charles and Pecorari (2016), Evans and Green (2007), Ananyeva (2014) and Liyanage and Walker (2014) all express in different ways concern that EAP students need to learn the higher thinking skills required for academic study and that the generic EAP course may not sufficiently equip them for this higher level thinking. There is also some concern that EAP courses neglect the backgrounds of their students (Canagarajah, 2014; Hamp-Lyons, 2015; Hyland \& Hamp-Lyons, 2002) and rely too heavily on textbooks rather than content drawn from students' backgrounds or web-based content that could interest students (Hyland \& Hamp-Lyons, 2002; Siew et al., 2012).

This study provides support for these concerns from the student perspective. In this way it provides an insider's view of the insight that generic EAP courses may not be effective in helping learners to transfer the content learned in the classroom to the mainstream academic context. This study indicates that EAP courses must be designed to suit specific skills according to their subject areas instead of attempting to be cost effective (Hyland, 2016). The study implies that EAP course writers must be aware that "one size may not fit all". Further, as Biggs and Tang (2011) mentioned, learners in tertiary education should be able to operate at the functioning knowledge level which requires them to not only be communicatively competent but to develop their ability to use higher order thinking skills. Taking this into consideration, this study shows that the learning activities in the EAP course can be designed to assist learners to develop and practise higher order skills by encouraging them to employ 
deep approaches to learning. The learners' responses to the reading tasks given in the classroom indicate that employing deep approaches to learning is a possibility, depending on the opportunities offered in the tasks.

\subsubsection{EAP Practitioners and Learners}

The use of the 3P model in this study is useful as a systematic way of looking at learning for both EAP learners and practitioners. When learners are able to reflect on their own learning factors, the process that they adopt during learning and their own perceptions of learning outcomes, it gives them an understanding of their learning needs and expectations in the EAP classroom. The 3P model could also assist EAP practitioners to be aware of how learners' personal and contextual factors have an impact on the learning process and the outcomes of learning if they develop ways to elicit students' responses to the learning process. The practitioners may be able to then reflect on their teaching and change their teaching methods to meet the objectives of the EAP course.

Another implication of this study relates to the learners' needs in the EAP classroom. This study argues that there should be an alignment between the factors that influence learning and learners' perceived outcomes of learning. This alignment can influence learners' deep motives for learning in the EAP classroom. As shown in this study, the EAP learners have their own motives for learning which could be aligned with the EAP curriculum if careful measures are taken by EAP practitioners. EAP practitioners must take into consideration the learners' needs when designing the course. They will have to observe what kind of content the learners need and want to learn in order to function in the academic context. EAP courses in most cases are offered to students from all kinds of programmes, which is not always effective as learners from different disciplines require different linguistic resources and assistance to make sense of these resources (Hyland, 2016).

The findings from this study show that having a mismatch of alignment between the learners' needs and the content taught led to a process of internal compromise among the students. The implication from this is that EAP practitioners need to be aware of the existence of an internal process of compromise taking place among the learners. This is because the EAP course aims to help learners to employ the different skills taught in the classroom in a wider academic environment which requires higher order skills. As mentioned earlier, tertiary institutions aim for learners to be able to demonstrate functioning knowledge, hence, students making the internal process of compromise to simply meet the minimal requirement of learning in the EAP classroom may not prove helpful.

Finally, this study implies that the use of a generic textbook influences students' interest in learning as the topics may not interest the learners. Learning materials must engage students' 
interest to produce quality learning that not only helps learners to internalise but also transfer their learning to the wider academic context. EAP instructors should take into consideration using personalised learning material that promotes learning.

\subsection{Limitations of Study}

There are a few limitations in this study, namely: the sample size, the criteria for participant recruitment, and the tasks given in the EAP classrooms. The findings were drawn from 12 participants in this study doing annotation, mind map and summary writing tasks and they cannot be generalised. The majority of learners in the study were of Malay ethnicity except for two who reported Indian Malaysian ethnicity. The participants were enrolled in a first-year engineering programme at a public university. Further, only learners who were interested in the study were recruited. It is a possibility that the learners who volunteered were interested to find out how they learn in the EAP classroom. A much wider sample size of learners from similar programmes within the EAP context could offer more generalisable findings on learners' processes of approaching learning and their perceptions of the outcomes of learning in the EAP classroom. However, the use of interviews, observations and analysis of learning tasks enabled rich data to be triangulated.

Moreover, these learners were in their first year and their view of the EAP course at this stage of their studies may mean they were unable to see how the EAP course is beneficial. This is because it is possible that the learners were still struggling to fit themselves into the tertiary context which is different to the school environment and the single task in each unit provided only a snapshot to investigate learners' process of learning in each of the three EAP classrooms.

Lastly, learning EAP in a second language environment is contextual. Firstly, there is no structured EAP curriculum to align all tertiary institutions in Malaysia; thus, each institution has different content taught to their learners. Next, second language learners come into the EAP classroom with various experiences, beliefs, attitudes and backgrounds regarding language learning. This affects how they view learning in the EAP classroom. Furthermore, every individual learner is different and their experiences and beliefs about language learning may not be the same despite coming from similar backgrounds. It is equally important to remember at this juncture that the tasks given in the classrooms are a part of learning in the EAP classroom. Based on the tasks used in the current study, it cannot be generalised that all learning in the EAP classroom is surface, as learning could be seen as progressive; hence the tasks given in the classes could vary from giving students opportunities to use deep approaches to opportunities to use surface approaches to learning. 


\subsection{Directions for Future Research}

Researchers could investigate EAP learners from different disciplines and the many ethnic groups within the Malaysian context regarding their perceptions of learning and their process of learning. Having views from learners enrolled in various disciplines and drawing data from participants of different ethnicities could reveal differences in the motives for learning of EAP learners. This could assist in designing EAP courses for future use.

Future studies could be conducted using various tasks and various levels of difficulty. This could provide an insight into how learners respond to tasks that require surface approaches and tasks that require deep approaches as well as investigating the influence of task experience on EAP learners. There are possibilities for further quantitative studies using experimental design with different tasks for different groups.

Finally, studies could be carried out on post-EAP learners in their second or third year at tertiary institutions who have more learning experience in tertiary education. These learners may have different views of how the EAP course helped them in the tertiary academic environment.

\subsection{Summary of the Chapter}

This thesis argues not only the importance but also the complexity of examining the alignment of all parts of the 3P model to ensure quality learning takes place. It suggests the value of using, at least sometimes, the qualitative tool of student perceptions of purposes for learning and student reflection on the detail of interaction with tasks. This study suggests that qualitative engagement with student perceptions both with the detail of specific tasks and with the other factors that contribute to learning may allow a deeper examination of the complex relationship of the aspects with each other. 


\section{References}

Abdullah, S. K. (2013). Balancing the Act: Incorporating the constructive alignment in promoting and enhancing higher order thinking skills among the $\mathrm{CHC}$ learners. GSE Journal of Education, 1, 88-109.

Allen, S. (2003). An analytic comparison of three models of reading strategy instruction. IRAL, 41, 319-338. doi.org/10.1515/iral.2003.015

Ananyeva, M. (2014). A learning curriculum: Toward student-driven pedagogy in the context of adult English for academic purposes, English for specific purposes, and workplace English programs. TESOL Journal, 5(1), 8-31. doi.org/10.1002/tesj.73

Ashwin, P., \& Trigwell, K. (2012). Evoked prior experiences in first-year university student learning. Higher Education Research and Development, 31(4), 449-463. doi.org/10.1080/07294360.2011.634384

Baik, C., \& Greig, J. (2009). Improving the academic outcomes of undergraduate ESL students: The case for discipline-based academic skills programs. Higher Education Research \& Development, 28(4), 401-416. doi.org/10.1080/07294360903067005

Balasooriya, C., Hughes, C., \& Toohey, S. (2009). Impact of a new integrated medicine program on students' approaches to learning. Higher Education Research \& Development, 28(3), 289-302. doi.org/10.1080/07294360902839891

Baxter, P., \& Jack, S. (2008). Qualitative case study methodology: Study design and implementation for novice researchers. The Qualitative Report, 13(4), 544-559.

Biggs, J. (1990). Asian students' approaches to learning implications for teaching overseas students. Paper presented at the 8th Australasian Tertiary Learning Skills and Language Conference, Queensland University of Technology, Australia.

Biggs, J. (1993a). From theory to practice: A cognitive systems approach. Higher Education Research and Development, 12(1), 73-85. doi.org/10.1080/0729436930120107

Biggs, J. (1993b). What do inventories of students' learning process really measure? A theoretical review and clarification. British Journal of Educational Psychology, 63, 319. doi.org/10.1111/j.2044-8279.1993.tb01038.x

Biggs, J. (1995). Assessing for learning: Some dimensions underlying new approaches to educational assessment. Alberta Journal of Educational Research, 12(1), 1-17.

Biggs, J. (1996). Enhancing teaching through constructive alignment. Higher Education, 32, 347-364. doi.org/10.1007/BF00138871

Biggs, J. (1999). Teaching for quality learning at university: What the student does ( $1^{\text {st }}$ ed.). United Kingdom: Open University Press.

Biggs, J. (2001). Enhancing learning: A matter of style or approaches? In L. Zhang \&

R. J. Sternberg (Eds.), Perspectives on thinking, learning, and cognitive styles. New Jersey: Lawrence Erlbaum.

Biggs, J. (2003). Teaching for quality learning at university: What the student does (2 $2^{\text {nd }}$ ed.). United Kingdom: Open University Press.

Biggs, J. (2014). Constructive alignment in university teaching. HERDSA Review of Higher Education, 1, 5-22. 
Biggs, J. B. (1972). Study behaviour and matriculation performance in two school populations. The Australian Journal of Education, 16(2), 187-204. doi.org/10.1177/000494417201600209

Biggs, J. B. (1978). Individual and group differences in study processes. British Journal of Educational Psychology, 48, 266-279. doi.org/10.1111/j.2044-8279.1978.tb03013.x

Biggs, J. B. (1987). Student approaches to learning and studying. Australia: Australian Council for Educational Research.

Biggs, J. B., \& Collis, K. F. (1982). Evaluation of the quality of learning: The SOLO taxonomy (structure of the observed learning outcome). New York: Academic Press.

Biggs, J., \& Tang, C. (2007). Teaching for quality learning at university: What the student does ( $3^{\text {rd }}$ ed.). New York: Open University Press.

Biggs, J., \& Tang, C. (2011). Teaching for quality learning at university: What the student does $\left(4^{\text {th }}\right.$ ed.). Maidenhead, Berkshire: Society for Research into Higher Education.

Biggs, J., Kember, D., \& Leung, D. Y. P. (2001). The revised two-factor study process questionnaire: R-SPQ-2F. British Journal of Educational Psychology, 71, 133-149. doi.org/10.1348/000709901158433

Braun, V., \& Clarke, V. (2013). Successful qualitative research: A practical guide for beginners. London: SAGE.

Bryman, A. (2008). Social research methods ( $3^{\text {rd }}$ ed.). USA: Oxford University Press.

Campbell, C. (1990). Writing with others' words: Using background reading text in academic compositions. In B. Kroll (Ed.), Second language writing (pp. 211-230). Cambridge: Cambridge University Press.

Campbell, J., Smith, D., \& \& Brooker, R. (1998). From conception to performance: How undergraduate students conceptualise and construct essay. Higher Education, 36, 449-469.

Campion, G. C. (2016). 'The learning never ends': Exploring teachers' views on the transition from General English to EAP. Journal of English for Academic Purposes, 23, 59-70. doi.org/10.1016/j.jeap.2016.06.003

Canagarajah, S. (2014). Challenges and possibilities. In I. Liyanage \& T. Walker (Eds.), English for academic purposes (EAP) in Asia: Negotiating appropriate practices in a global context (pp. 93-102). Rotterdam: Sense.

Cao, Y. (2011). Investigating situational willingness to communicate within second language classrooms from an ecological perspective. System, 39, 468-479. doi.org/10.1016/j.system.2011.10.016

Carlson, J. A. (2010). Avoiding traps in member checking. The Qualitative Report, 15(5), $1102-1113$.

Chan, C. C. C., Tsui, M. S., Chan, M. Y. C., \& Hong, J. H. (2002). Applying the Structure of the Observed Learning Outcomes (SOLO) taxonomy on students' learning outcomes: An empirical study. Assessment \& Evaluation in Higher Education, 27(6), 511-527. doi.org/10.1080/0260293022000020282 
Chan, Y. K. (2014). Learning approaches and academic achievement in full-time and parttime sub-degree Hong Kong Chinese students. International Journal of Continuing Education and Lifelong Learning, 6(2), 75-86.

Charles, M., \& Pecorari, D. (2016). Introducing English for academic purposes. Oxon: Routledge. Retrieved from https://www.taylorfrancis.com/books/9781315682129

Charmaz, K. (2014). Constructing grounded theory (2 $2^{\text {nd }}$ ed.). London: SAGE.

Chazal, E., \& McCarter, S. (2012). Oxford EAP: A course in English for academic purposes. Oxford: Oxford University Press.

Chick, H. (1998). Cognition in the formal modes: Research mathematics and the SOLO taxonomy. Mathematics Education Research Journal, 10(2), 4-26. doi.org/10.1007/BF03217340

Chin, V., Ting, H. L., \& Yeo, J. Y. (2016). Investigating English language anxiety among UiTM Sarawak undergraduates. Journal of Creative Practices in Language Learning and Teaching, 4(1), 50-62.

Clinton, V. (2014). The relationship between students' preferred approaches to learning and behaviors during learning: An examination of the process stage of the 3P model. Instructional Science, 42, 817-837. doi.org/10.1007/s11251-013-9308-z

Corbetta, P. (2003). Social research: Theory, methods and techniques. London: Sage. Retrieved from http://methods.sagepub.com.helicon.vuw.ac.nz/book/social-researchtheory-methods-and-techniques

Creswell, J. W. (2007). Qualitative inquiry \& research design: Choosing among five approaches. USA: Sage.

Creswell, J. W. (2009). Research design: Qualitative, quantitative, and mixed methods approaches ( $3^{\text {rd }}$ ed.). California: SAGE.

Creswell, J. W. (2014). Educational research: Planning, conducting and evaluating quantitative and qualitative research $\left(4^{\text {th }}\right.$ ed.). USA: Pearson Education.

Darmi, R., \& Albion., P. (2013). English language in Malaysian education system: Its existence and implication. Paper presented at the Malaysian Postgraduate Conference New South Wales, Australia.

Darmi, R., \& Albion, P. (2014). Assessing the language anxiety of Malaysian undergraduate English language learners. Paper presented at the Proceeding of the Global Conference on Language Practice \& Information Technology Sabah, Malaysia.

Darvin, R., \& Norton, B. (2015). Identity and a model of investment in applied linguistics. Annual Review of Applied Linguistics, 35, 36-56. doi.org/10.1017/S0267190514000191

Davies, M. (2011). Concept mapping, mind mapping and argument mapping: What are the differences and do they matter? Higher Education, 62, 279-301. doi.org/10.1007/s10734-010-9387-6

Davis, J. (2007). Dialogue, monologue and soliloquy in the large lecture class. International Journal of Teaching and Learning in Higher Education, 19(2), 178-182.

Delaney, Y. A. (2008). Investigating the reading-to-write construct. Journal of English for Academic Purposes, 7, 140-150. doi.org/10.1016/j.jeap.2008.04.001 
Department of Statistics. (2018). Current population estimates, Malaysia, 2017-2018 [Press release]

Devine, J. (1993). The role of metacognition in second language reading and writing. In J. G. Carson \& I. Leki, (Eds.), Reading in the composition classroom, second language perspectives (pp. 105-127). Boston: Heinle \& Heinle.

Duff, A., Boyle, E., Dunleavy, K., \& Ferguson, J. (2004). The relationship between personality, approach to learning and academic performance. Personalities and Individual Differences, 6(2004), 1907-1920. doi.org/10.1016/j.paid.2003.08.020

Dull, R. B., Schleifer, L. L., \& McMillan, J. J. (2015). Achievement goal theory: The relationship of accounting students' goal orientations with self-efficacy, anxiety, and achievement. Accounting Education, 24(2), 152-174.

doi.org/10.1080/09639284.2015.1036892

Eidswick, J. (2010). Interest and prior knowledge in second language reading comprehension. JALT, 32(2), 149-168.

Entwistle, N., \& McCune, V. (2004). The conceptual bases of study strategy inventories. Educational Psychology Review, 16(4), 325-345. doi.org/10.1007/s10648-004-0003-0

Entwistle. N., McCune, V., \& Walker, P. (2001). Conceptions, styles, and approaches within higher education: Analytic abstractions and everyday experience. In L. Zhang \& R. J. Sternberg (Eds.), Perspectives on thinking, learning, and cognitive styles. New Jersey: Lawrence Erlbaum.

Ercetin, G. (2010). Effects of topic interest and prior knowledge on text recall and annotation use in reading: A hypermedia text in the L2. European Association for Computer Assisted Language Learning, 22(2), 228-246. doi.org/10.1017/S0958344010000091

Evans, S., \& Green, C. (2007). Why EAP is necessary: A survey of Hong Kong tertiary students. Journal of English for Academic Purposes, 6, 3-17.

doi.org/10.1016/j.jeap.2006.11.005

Evans, S., \& Morrison, B. (2010). The first term at university: Implications for EAP. ELT Journal, 65(4), 387-397. doi.org/10.1093/elt/ccq072

Evans, S., \& Morrison, B. (2011). Meeting the challenges of English-medium higher education: The first-year experience in Hong Kong. English for Specific Purposes, 30(3), 198-208. doi.org/10.1016/j.esp.2011.01.001

Feito, J. A., \& Donahue, P. (2008). Minding the gap: Annotation as preparation for discussion. Arts \& Humanities in Higher Education, 7(3), 295-307. doi.org/10.1177/1474022208094413

Flick, U. (2007). Qualitative research kit: Managing quality in qualitative research. Retrieved from http://methods.sagepub.com/book/managing-quality-in-qualitative-research

Flowerdew, L. (2013). English for academic purposes. Chichester: Blackwell. Retrieved from https://onlinelibrary.wiley.com/doi/full/10.1002/9781405198431.wbeal0376

Flowerdew, J., \& Peacock, M. (2001). Issues in EAP: A preliminary Perspective. In J. Flowerdew \& M. Peacock (Eds.), Research perspectives on English for Academic Purposes (pp. 8-24). Cambridge: Cambridge University Press.

Foo, B., \& Richards, C. (2004). English in Malaysia. Regional Language Centre Journal, 35(2), 229-240. doi.org/10.1177/003368820403500209 
Gao, Y., \& Bartlett, B. (2014). Opportunities and challenges for negotiating appropriate EAP practices in China. In I. Liyanage \& T. Walker (Eds.), English for academic purposes $(E A P)$ in Asia: Negotiating appropriate practices in a global context (pp. 13-33). Rotterdam: Sense. Retrieved from https://ebookcentral.proquest.com/lib/vuw/detail.action?doclD=3034982

Gardner, R. C., Masgoret, A. M., \& Tremblay, P. F. (1999). Home background characteristics and second language learning. Journal of Language and Social Psychology, 18(4), 419-437. doi.org/10.1177/0261927X99018004004

Gass, S. M., \& Mackay, A. (2000). Stimulated recall: Methodology in second language research. New Jersey: Lawrence Erlbaum.

Grabe, W., \& Stoller, F. L. (2011). Teaching and researching reading. In C. N. Candlin, \& D. R. Hall (Series Ed.), Applied linguistics in action series ( $2^{\text {nd }}$ ed.). United Kingdom: Pearson Education.

Grabe, W., \& Stoller, F. L. (2018). Introduction to reading. In J. M. Newton, D. R. Ferris, C. C. M. Goh, W. Grabe. F. L. Stoller, \& L. Vandergrift (Ed.), Teaching English to second language learners in academic contexts: Reading, writing, listening and speaking. New York: Routledge.

Grabe, W., \& Zhang, C. (2013). Reading and writing together: A critical component of English for academic purposes teaching and learning. TESOL Journal, 4(1), 9-24. doi.org/10.1002/tesj.65

Grapragasem, S., Krishnan, A., \& Mansor, A. N. (2014). Current trends in Malaysian higher education and the effect on education policy and practice: An overview. International Journal of Higher Education, 13(1), 85-93. doi.org/10.5430/ijhe.v3n1p85

Green, J. H. (2015). Teaching for transfer in EAP: Hugging and bridging revisited. English for Specific Purposes, 37, 1-12. doi.org/10.1016/j.esp.2014.06.003

Griffin, P., Coates, H., Mclnnis, C., \& James, R. (2003). The development of an extended course experience questionnaire. Quality in Higher Education, 9(3), 259-266. doi.org/10.1080/135383203200015111

Groth, R. E., \& Bergner, J. A. (2006). Preservice elementary teachers' conceptual and procedural knowledge of mean, median, and mode. Mathematical Thinking and Learning, 8(1), 37-63. doi.org/10.1207/s15327833mt10801_3

Hamp-Lyons, L. (2001). English for academic purposes. In R. Carter, \& D. Nunan (Eds.), The Cambridge guide to teaching English to speakers of other languages. Cambridge: Cambridge University Press.

Hamp-Lyons, L. (2015). The future of JEAP and EAP. Journal of English for Academic Purposes, 20, A1-A4. doi.org/10.1016/j.jeap.2015.10.004

Hartas, D. (2011). Families' social backgrounds matter: Socioeconomic factors, home learning and young children's language, literacy and social outcomes. British Educational Research Journal, 37(6), 893-914. doi.org/10.1080/01411926.2010.506945

Hartfield, P. J. (2010). Reinforcing constructivist teaching in advanced level biochemistry through the introduction of case-based learning activities. Journal of Learning Design, 3(3), 20-31. doi.org/10.5204/jld.v3i3.59 
Harvey, M., \& Baumann, C. (2012). Using student reflections to explore curriculum alignment. Asian Social Science, 8(14), 9-18. doi.org/10.5539/ass.v8n14p9

Hashim, A. (2014). English and the linguistic ecology of Malaysia. World Englishes, 33(4), 458-471. doi.org/10.1111/weng. 12107

Hashim, C. N., Ariffin, A., \& Hashim, N. M. (2013). Ideal vs. reality: Evidences from senior teachers' experiences on the Malaysian school-based assessment system (SBA). Proceedings of the Malaysian Education Deans' Council.

Hashim, H., \& Isa, I. S. M. (2012). Students' anxiety level towards speaking in English: Malaysia polytechnic experience. Paper presented at the IEEE Symposium on Business, Engineering and Industrial Applications. Bandung, Indonesia.

Hattie, J., \& Purdie, N. (1998). The SOLO model: Addressing fundamental measurement issues. Melbourne: The Australian Council for Educational Research.

Hay, D. B. (2007). Using concept maps to measure deep, surface and non-learning outcomes. Studies in Higher Education, 32(1), 39-57. doi.org/10.1080/03075070601099432

Hay, D. B., Wells, H., \& Kinchin, I. M. (2008). Quantitative and qualitative measures of student learning at university level. Higher Education, 56, 221-239. doi.org/10.1007/s10734-007-9099-8

Hedgcock, J. S., \& Ferris, D. R. (2009). Teaching readers of English students, texts, and contexts. New York: Routledge.

Hennink, M., Hutter, I., \& Bailey, A. (2011). Qualitative research methods. London: SAGE.

Hidi, S. (2000). An interest researcher's perspective: The effects of extrinsic and intrinsic factors on motivation. In C. Sansone \& J. Harackiewicz (Eds.), Intrinsic and extrinsic motivation: The search for optimal motivation and performance (pp. 309-339). USA: Academic Press.

Hiew, W. (2012). English language teaching and learning issues in Malaysia: Learners' perceptions via facebook dialogue journal. Journal of Arts, Science \& Commerce, 3(1), 11-19.

Hill, R. (2012). Whackademia: An insider's account of the troubled university. Sydney, New South Wales Publishing:

Hirvela, A., \& Du, Q. (2013). "Why am I paraphrasing?”: Undergraduate ESL writers' engagement with source-based academic writing and reading. Journal of English for Academic Purposes, 12, 87-98. doi.org/10.1016/j.jeap.2012.11.005

Holmes, A. (2018). The role of interest and enjoyment in determining students' approach to learning. Educational Process: International Journal, 7(2), 140--150. doi.org/10.22521/edupij.2018.72.4

Hook, P., \& Mills, J. (2012). SOLO taxonomy: A guide for schools book 2: Planning for differentiation. New Zealand: Essential Resources.

Horwitz, E. K. (2000). It ain't over 'til it's over: On foreign language anxiety, first language deficits, and the confounding of variables. The Modern Language Journal, 84(2), 256-259.doi.org/10.1111/0026-7902.00067 
Horwitz, E. K., Horwitz, M. B., \& Cope, J. (1986). Foreign language classroom anxiety. The Modern Language Journal, 70(2), 125-132. doi.org/10.1111/j.1540-

4781.1986.tb05256.x

Hwang, K. K., \& Han, K. H. (2012). Oxford handbook of Chinese psychology. Retrieved from https://www.oxfordhandbooks.com/view/10.1093/oxfordhb/9780199541850.001.0001/ oxfordhb-9780199541850-e-29

Hyland, K. (2016). General and specific EAP. In K. Hyland \& P. Shaw (Eds.), The Routledge handbook of English for academic purposes (pp. 17-29). New York: Routledge.

Hyland, K. H-L., \& Hamp-Lyons, L. (2002). EAP: Issues and directions. Journal of English for Academic Purposes, 1, 1-12. doi.org/10.1016/S1475-1585(02)00002-4

INTSIG Information Co. Ltd. (2016). CamScanner (version 2016) [Mobile application software]. Retrieved from Google Play Store.

James, M. A. (2010). Transfer climate and EAP education: Students' perceptions of challenges to learning transfer. English for Specific Purposes, 29, 133-147.

James, M. A. (2012). An investigation of motivation to transfer second language learning. The Modern Language Journal, 96(1), 51-69. doi.org/10.1111/j.15404781.2012.01281.x

Jervis, L. M., \& Jervis, L. (2005). What is the constructivism in constructive alignment? Bioscience Education, 6, 1-14. doi.org/10.3108/beej.2005.06000006

Johnson, B., \& Christensen, L. (2014). Educational research: Quantitative, qualitative and mixed approaches ( $5^{\text {th }}$ ed.). USA: Sage.

Jones, C., \& Asensio, M. (2001). Experiences of assessment: using phenomenography for evaluation. Journal of Computer Assisted Learning, 17, 314-321.

doi.org/10.1046/j.0266-4909.2001.00186.x

Keck, C. (2006). The use of paraphrase in summary writing: A comparison of L1 and L2 writers. Journal of Second Language Writing, 15, 261-278.

doi.org/10.1016/j.jslw.2006.09.006

Kember, D. (2016). Understanding the nature of motivation and motivating students through teaching and learning in higher education. Singapore: Springer.

Kember, D., Ho, A., \& Hong, C. (2010). Characterising a teaching and learning environment capable of motivating student learning. Learning Environments Research, 13(1), 4357. doi.org/10.1007/s10984-009-9065-8

Kember, D., Hong, C., \& Ho, A. (2008). Characterizing the motivational orientation of students in higher education: A naturalistic study in three Hong Kong universities. British Journal of Educational Psychology, 78(2), 313-329. doi.org/10.1348/000709907X220581

Kember, D., Leung, D. Y. P., \& Kwan, K. P. (2002). Does the use of student feedback questionnaires improve the overall quality of teaching? Assessment \& Evaluation in Higher Education, 27(5), 411-425. doi.org/10.1080/0260293022000009294

Kuhn, K. L., \& Rundle-Thiele, S.R. (2009). Curriculum alignment: Exploring student perception of learning achievement measures. International Journal of Teaching and Learning in Higher Education, 21(3), 351-361. 
Kyndt, E., Berghmans, I., Dochy, F., \& Bulckens, L. (2014). 'Time is not enough.' Workload in higher education: a student perspective. Higher Education Research \& Development, 33(4), 684-698. doi.org/10.1080/07294360.2013.863839

Lake, D. (1999). Helping students to go SOLO: Teaching critical numeracy in the biological sciences. Journal of Biological Education, 33(4), 191-198. doi.org/10.1080/00219266.1999.9655664

Larkin, H., \& Richardson, B. (2013). Creating high challenge/high support academic environments through constructive alignment: Student outcomes. Teaching in Higher Education, 18(2), 192-204. doi.org/10.1080/13562517.2012.696541

Larsen-Freeman, D. (2013). Transfer of learning transformed. Language Learning Journal, 63, 107-129. doi.org/10.1111/j.1467-9922.2012.00740.x

Lee, S. K. (2003). Multiple identities in a multicultural world: A Malaysian perspective. Journal of Language, Identity \& Education, 2(3), 137-158.

doi.org/10.1207/S15327701JLIE0203_1

Liao, H., \& Wang, Y. (2015). Creating a positive learning environment for students with English classroom anxiety. Psychological Reports, 116(2), 631-646.

doi.org/10.2466/11.PR0.116k21w8

Lincoln, Y. S., \& Guba, E. G. (1985). Naturalistic inquiry. Beverly Hills: SAGE.

Liu, J. Y., Chang, Y. J., Yang, F. Y., \& Sun, Y. C. (2011). Is what I need what I want? Reconceptualising college students' needs in English courses for general and specific/academic purposes. Journal of English for Academic Purposes, 10, 271-280. doi.org/10.1016/j.jeap.2011.09.002

Liu, K. (2006). Annotation as an index to critical writing. Urban Education, 41(2), 192-207. doi.org/10.1177/0042085905282261

Liyanage, I., \& Walker, T. (2014). Accommodating Asian EAP practices within postgraduate teacher education. In I. Liyanage \& T. Walker (Eds.), English for academic purposes $(E A P)$ in Asia: Negotiating appropriate practices in a global context (pp. 1-12). Rotterdam: Sense. Retrieved from https://ebookcentral.proquest.com/lib/vuw/detail.action?doclD=3034982

Lucas, U., \& Mladenovic, R. (2009). The identification of variation in students' understandings of disciplinary concepts: The application of the SOLO taxonomy within introductory accounting. Higher Education, 58, 257-283. doi.org/10.1007/s10734-009-9218-9

Lyle, J. (2003). Stimulated recall: A report on its use in naturalistic research. British Educational Research Journal, 29(6), 861-878. doi.org/10.1080/0141192032000137349

Maarof, N., \& Munusamy, I. M. (2015). Learner's learning experiences \& difficulties towards (ESL) among UKM undergraduates. Advances in Language and Literary Studies, 6(3), 83-87.

Manan, A. A., Ali, N. L., \& Shamsudin, S. (2013). Does the Malaysian English language syllabus cater to the academic vocabulary needs of secondary school students entering universities? Journal Teknologi, 65(2), 7-14. 
Mackey, A., \& Gass, S. M. (2016). Second language research: Methodology and design (2nd ed.). New York: Routledge. Retrieved from https://ebookcentral-proquestcom.helicon.vuw.ac.nz/lib/vuw/detail.action?doc/D=3570143

Martinez, A. (2013). The use of various assessment tasks in the analysis of the effect of prior knowledge and interest on $L 2$ reading comprehension. RESLA, 26, 289-306.

Marton, F., \& Saljo, R. (1976a). On qualitative differences in learning: i-outcome and process. British Journal of Educational Psychology, 46, 4-11. doi.org/10.1111/j.20448279.1976.tb02980.x

Marton, F., \& Saljo, R. (1976b). Learning processes and strategies-ii on qualitative differences in learning-ii outcome as a function of the learner's conception of the task. British Journal of Educational Psychology, 46, 115-127. doi.org/10.1111/j.20448279.1976.tb02304.x

Matters, G. (2009). A problematic leap in the use of test data: From performance to inference. In C. Wyatt-Smith \& J. J. Cumming (Eds.), Educational assessment in the 21st century: Connecting theory to practice (pp. 209-225). London: Springer.

Maulan, S., \& Ibrahim, R. (2012). The teaching and learning of English for academic purposes in blended environment. Procedia - Social and Behavioral Sciences, 67, 561-570. doi.org/10.1016/j.sbspro.2012.11.361

Mavor, S., \& Trayner, B. (2001). Aligning genre and practice with learning in higher education: An interdisciplinary perspective for course design and teaching. English for Specific Purposes, 20, 345-366. doi.org/10.1016/S0889-4906(01)00025-4

McCune, V., \& Entwistle, N. (2000). The deep approach to learning: Analytic abstraction and idiosyncratic development. Paper presented at the Innovations in Higher Education Conference, Finland.

McMahon, T., \& Thakore, H. (2006). Achieving constructive alignment: Putting outcomes first. Quality of Higher Education, 3, 10-19.

McPhan, G. (2008). A developmental framework for assessing concept maps. Proceeding of the Third International Conference on Concept Mapping, Finland.

Merriam, S. B. (2009). Qualitative research. Retrieved from http://ebookcentral.proquest.com/lib/vuw/detail.action?doclD=1662771

Merriam, S. B., \& Tisdell, E. J. (2016). Qualitative research: A guide to design and implementation ( ${ }^{\text {th }}$ ed.). San Francisco: Jossey-Bass.

Miles, M. B., Huberman, A. M., \& Saldaña, J. (2014). Qualitative data analysis: A methods sourcebook ( $3^{\text {rd }}$ ed.). Califorinia: SAGE.

Ministry of Education. (2013). Malaysia Education Blueprint 2013-2025. Retrieved from https://www.moe.gov.my/index.php/en/dasarmenu/pelan-pembangunan-pendidikan2013-2025.

Ministry of Education. (2014). Dasar Memartabatkan Bahasa Malaysia Memperkukuh Bahasa Inggeris (MBMMBI): Buku Penerangan: Malaysia: Ministry of Education. Retrieved from https://www.moe.gov.my/index.php/menumedia/mediacetak/penerbitan/dasar/1198-dasar-memartabatkan-bahasa-malaysia-memperkukuhbahasa-inggeris-mbmmbi/file 
Moulding, N. T. (2010). Intelligent design: Student perceptions of teaching and learning in large social work classes. Higher Education Research \& Development, 29(2), 151165. doi.org/10.1080/07294360903470977

Mulhall, A. (2003). In the field: Notes on observation in qualitative research. Journal of Advanced Nursing, 41(3), 306-313. doi.org/10.1046/j.1365-2648.2003.02514.x

Musa, N. C., Koo, Y. L., \& Azman, H. (2012). Exploring English language learning and teaching In Malaysia. GEMA Online Journal of Language Studies, 12(1), 35-51.

Mustaffa, R. (2006). The effects of culture on students' learning styles. $3 L$ Journal of Language Teaching, Linguistics and Literature, 12, 83-94.

Nadzri, M. M. N. (2018). The 14th General Election, the fall of Barisan Nasional, and political development in Malaysia, 1957-2018. Journal of Current Southeast Asian Affairs, 37(3), 139-171. doi.org/10.1177/186810341803700307

Nambiar, R. M. K. (2007). Enhancing academic literacy among tertiary learners: A Malaysian experience. 3L: Journal of Language Teaching, Linguistics and Literature, 13, 1-21.

Noor, M. N. (2006). Reading academic text: Awareness and experiences among university ESL learners. GEMA Online Journal of Language Studies, 6(2), 65-78.

Noor, M. N. (2010). ESL learners' reading approaches of an academic expository text. $3 L$ : The Southeast Asian Journal of English Language Studies, 16(2), 19-46.

Nor, F. N. M., Azman, H., \&, \& Hamat, A. (2013). Investigating students' use of online annotation tool in an online reading environment. 3L: The Southeast Asian Journal of English Language Studies, 9(3), 87-101.

Norton Peirce, B. (1995). Social identity investment, and language learning. TESOL Quarterly, 29(1), 9-31.

Norton, B. (2010). Identity, literacy, and English-language teaching. TESL Canada Journal, 28(1), 1-13. doi.org/10.18806/tesl.v28i1.1057

Norton, B. (2013). Identity and language learning: Extending the conversation (2 ${ }^{\text {nd }}$ ed.). Bristol: Multilingual Matter.

Ohata, K., \& Fukao, A. (2014). L2 learners' conceptions of academic reading and themselves as academic readers. System, 42, 81-92. doi.org/10.1016/j.system.2013.11.003

Othman, Z., \& Rashid, T. (2011). Is it EAP OR ESP? The wind of change. English for Specific Purposes World, 11(33), 1-12.

Papinczak, T. (2009). Are deep strategic learners better suited to PBL? A preliminary study. Advances in Health Sciences Education, 14(3), 337-353. doi.org/10.1007/s10459008-9115-5

Phillips, E. M. (1992). The effects of language anxiety on students' oral test performance and attitudes. The Modern Language Journal, 76(1), 14-26. doi.org/10.1111/j.15404781.1992.tb02573.x

Pittaway, D. S. (2004). Investment and second language acquisition. Critical Inquiry in Language Studies: An International Journal, 1(4), 203-218. 
Porter-O'Donnell, C. (2004). Beyond the yellow highlighter: Teaching annotation skills to improve reading comprehension. English Journal, 93(5), 82-89.

doi.org/10.2307/4128941

Rajadurai, J. (2010). "Malays are expected to speak Malay": Community ideologies, language use and the negotiation of identities. Journal of Language, Identity, and Education, 9, 91-106. doi.org/10.1080/15348451003704776

Ramburuth, P., \& Mladenovic, R. (2004). Exploring the relationship between students' orientations to learning, the structure of students' learning outcomes and subsequent academic performance. Accounting Education, 13(4), 507-527. doi.org/10.1080/0963928042000306774

Rashid, R. A., Rahman, S. B. A., \& Yunus, K. (2017). Reforms in the policy of English language teaching in Malaysia. Policy Futures in Education, 15(1), 100-112. doi.org/10.1177/1478210316679069

Reaburn, P., Muldoon, N., \& \& Bookallil, C. (2009). Blended spaces, work based learning and constructive alignment: Impacts on student engagement. Paper presented at the Ascilite, Auckland.

Renninger, K. A. (2000). Individual interest and its implications for understanding intrinsic motivation. In C. Sansone \& J. Harackiewicz (Eds.), Intrinsic and extrinsic motivation: The search for optimal motivation and performance (pp. 373-404). USA: Academic Press.

Rubin, H. J., \& Rubin, I. S. (2005). Qualitative interviewing: The art of hearing data (2 ${ }^{\text {nd }}$ ed.). California: SAGE.

Saldaña, J. (2013). The coding manual for qualitative researchers ( $2^{\text {nd }}$ ed.). London: SAGE.

Salleh, D. N. S. D. A., Lit, A., \& Lias, K. (2013). Implementation of constructive alignment approach in Department of Electronic Engineering, Faculty of Engineering, Universiti Malaysia Sarawak. Paper presented at the International Conference on Teaching, Assessment and Learning for Engineering (TALE), Bali, Indonesia.

Schunk, D. H. (2008). Learning theories: An educational perspective (5 ${ }^{\text {th }}$ ed.). New Jersey: Pearson Prentice Hall.

Schunk, D. H. (2012). Learning theories: An educational perspective (6 $6^{\text {th }}$ ed.) Boston: Pearson.

Selvaraj, B. (2010). English language teaching (ELT) curriculum reforms in Malaysia. Voice of Academia, 5(1), 51-60.

Setiasih, L. (2015). Chunking, elaborating, and mapping strategies in teaching reading comprehension using content area materials. World Journal of English Language, 5(1), 32-47.

Siew, M. T., Fook, F. W., Noor, N. M., Mustaffa, R., Mahmud, N., \& Ismail, K. (2012). Using a blended approach to teach English for academic purposes: Malaysian students' perceptions of redesigned course materials. International Journal of Pedagogies and Learning, 7(2), 142-153. doi.org/10.5172/ijpl.2012.7.2.142

Spack, R. (1993). Student meets text, text meets student: Finding a way into academic discourse. In J. G. Carson \& I. Leki (Eds.), Reading in the composition classroom, second language perspectives (pp.183-196). Boston: Heinle \& Heinle. 
Spielmann, G., \& Radnofsky, M. L. (2001). Learning language under tension: New directions from a qualitative study. The Modern Language Journal, 85(2), 259-278.

doi.org/10.1111/0026-7902.00108

Stake, R. E. (2006). Multiple case study analysis. New York: The Guilford Press.

Storey, J. M. (2013). Should undergraduate students be introduced to a greater range of written genres in EAP courses? A pilot study from a Malaysian University. Procedia Social and Behavioral Sciences, 90, 21-219. doi.org/10.1016/j.sbspro.2013.07.084

Thang, S. M. (2005). Comparing approaches to studying of Malaysian Distance learners and on-campus learners: Implications to distance education. Turkish Online Journal of Distance Education, 6(2), 70-86.

Tiwari, A., Chan, S., Wong, E., Wong, D., Chui, C., Wong, A., \& Patil, N. (2006). The effect of problem-based learning on students' approaches to learning in the context of clinical nursing education. Nurse Education Today, 26(5), 430-438.

doi.org/10.1016/j.nedt.2005.12.001

Too, W. K. (2017). English language teaching and policies at the tertiary level in Malaysia. Abingdon: Routledge. Retrieved from https://www.researchgate.net/publication/318461149 English Language Teaching a nd Policies at the Tertiary Level in Malaysia/download

Trigwell, K., Ashwin, P., \& Millan, E. S. (2013). Evoked prior learning experience and approach to learning as predictors of academic achievement. British Journal of Educational Psychology, 83, 363-378. doi.org/10.1111/j.2044-8279.2012.02066.x

Tweedie, M. G., \& Kim, M. (2015). EAP curriculum alignment and social acculturation: Student perceptions. TESL Canada Journal, 33(1), 41-57. doi.org/10.18806/tesl.v33i1.1226

Vygotsky, L. S. (1962). Piaget's Theory of Child Language and Thought. In E. Hanfmann \& G. Vakar (Eds.), Thought and language (pp.9-24). Cambridge, MA: MIT Press. doi.org/:10.1037/11193-002

Walker, B. J. (2012). Diagnostic teaching of reading: Techniques for instruction and assessment ( $7^{\text {th }}$ ed.). Boston: Pearson Education.

Walsh, A. (2007). An exploration of Biggs' constructive alignment in the context of workbased learning. Assessment \& Evaluation in Higher Education, 32(1), 79-87. doi.org/10.1080/02602930600848309

Wang, X., Su, Y., Cheung, S., Wong, E., \& Kwong, T. (2013). An exploration of Biggs' constructive alignment in course design and its impact on students' learning approaches. Assessment \& Evaluation in Higher Education, 38(4), 477-491. doi.org/10.1080/02602938.2012.658018

Whalley, J. L., Lister, R., Thompson, E., Clear, T., Robbins, P., Kumar, P. K., \& Prasad, C. (2006). An Australasian study of reading and comprehension skills in novice programmers, using the Bloom and SOLO taxonomies. Proceedings of the 8th Australasian Conference on Computing Education, 52, 243-252.

Wigfield, A., \& Cambria, J. (2010). Students' achievement values, goal orientations, and interest: Definitions, development, and relations to achievement outcomes. Developmental Review, 30(1), 1-35. doi.org/10.1016/j.dr.2009.12.001 
Wolfe, J. (2002). Marginal pedagogy: How annotated texts affect a writing-from-sources task. Written Communication, 19, 2. doi.org/10.1177/074108830201900203

Wong, C. SP. (2007). View on the adoption and implementation of the SOLO taxonomy. In S. Frankland (Ed.), Enhancing teaching and learning through assessment (pp. 4-15). Netherlands: Springer. https://doi.org/10.1007/978-1-4020-6226-1

Yamat, H., Fisher, R., \& Rich, S. (2014). Revisiting English language learning among Malaysian children. Asian Social Science, 10(3), 174-180. doi.org/10.5539/ass.v10n3p174

Yin, R. (2014). Case study research: Design and methods ( $5^{\text {th }}$ ed.). Los Angeles: SAGE.

Zin, Z. M., Wong, B. E., \& Rafik-Galea, S. (2014). Critical reading ability and its relation to L2 proficiency of Malaysian ESL learners. 3L: The Southeast Asian Journal of English Language Studies, 20(2), 43-54. doi.org/10.17576/3L-2014-2002-04

Zulkifli, V. (2007). Language classroom anxiety: A comparative study of ESL learners. Asian Journal of University Education, 3(2), 75-99.

Zywica, J., \& Gomez, K. (2008). Annotating to support learning in the content areas:

Teaching and learning science. Journal of Adolescent \& Adult Literacy, 52(2), 155165. doi.org/10.1598/JAAL.52.2.6 
Appendices 
MEMORANDUM

Plone 044635480

Cmail susancorbeltovusach

\begin{tabular}{l|l}
\hline TO & Bharathi Vijayan \\
\hline COPY TO & \\
\hline FROM & AProf Susan Corbett, Convener, Human Ethics Committee \\
\hline
\end{tabular}

\begin{tabular}{l|l}
\hline DATE & 13 April 2016 \\
\hline PAGES & 1 \\
\hline
\end{tabular}

\begin{tabular}{l|l} 
SUBJECT & $\begin{array}{l}\text { Ethics Approval: } 22611 \\
\text { Investment and Reading Practices in English for Academic } \\
\text { Purposes Classrooms in Malaysia }\end{array}$ \\
\hline
\end{tabular}

Thank you for your application for ethical approval, which has now been considered by the Standing Committee of the Human Ethics Committee.

Your application has been approved from the above date and this approval continues until 30 June 2018. If your data collection is not completed by this date you should apply to the Human Ethics Committee for an extension to this approval.

Best wishes with the research.

Kind regards

Susan Corbett

Convener, Victoria University Human Ethics Committee 


\section{Appendix B: Approval to Conduct Research in Malaysia from the Prime Minister's}

Department

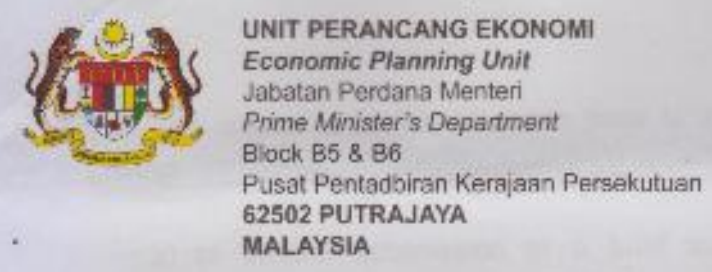

UNIT PERANCANG EKONOMI

Economic Planning Unil

Pusat Pentadbiran Kerajaan Persekutuan

TRAJAYA

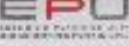

MALAYSIA

\begin{tabular}{|c|c|c|}
\hline & $\begin{array}{l}\text { Ruj. Tuan: } \\
\text { Your Ref:- }\end{array}$ & UPE $40 / 200 / 19 / 3311$ \\
\hline Ms. Bharathi Naidu aip Vijayan & $\begin{array}{l}\text { Ruj, Kami: } \\
\text { Our Ref: }\end{array}$ & 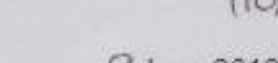 \\
\hline
\end{tabular}

Email : rathi.lifestyle@hotmail.com

\section{APPLICATION TO CONDUCT RESEARCH IN MALAYSIA}

With reference to your application. I am pleased to inform that your application to conduct research in Malaysia has been approved by the Research Promotion and Co-ordination Committee, Economic Planning Unit, Prime Minister's Department. The details of the approval are as follows:

Researcher's name

BHARATHI NAIDU A/P VIJAYAN

Passport No./I.C No

$850320-01-5254$

Nationality

MALAYSIAN

Title of Research

"INVESTMENT AND READING PRACTICES IN ENGLISH FOR ACADEMIC PURPOSES CLASSROOMS IN MALAYSIA"

Period of Research Approved

1 year $(8.6 .2016-8.6 .2017)$

2. Please take note that the study should avoid sensitive issues pertaining to local values and norms as well as political elements. At all time. please adhere to the conditions stated by the code of conduct for researchers as attached.

"Merancang Ke Arah Kecemerlangan" 


\section{Appendix C: Approval from Cambridge University Press}

Permission request 383 - Title: 9780194001762 - OXFORD EAP B2 SB (PK/C) Approved

support@requestbox.ne

Sat 29/12/2018 1:30 AM

To: rathi.lifestyle@hotmail.com <rathi.lifestyle@hotmail.com>

Hi Bharathi Vijayan,

We are pleased to inform you that your request for permission to use material from one of our products has been approved.

Title: 9780194001762 - OXFORD EAP B2 SB (PK/C)

Not Listed:

View Request

Regards,

ELT Permissions Team 


\section{Appendix D: Information Sheet for the Management of the University}

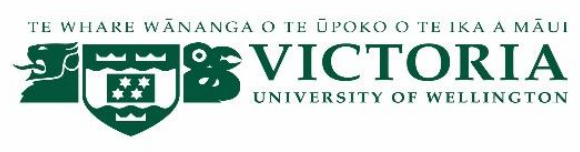

\section{FACULTY OF EDUCATION}

Information sheet for management

\section{Research Project: Investment and Reading Practices in English for Academic Purposes Classrooms in Malaysia}

Dear sir/madam,

Thank you for your interest in this project. Please read this information before deciding whether or not to take part.

\section{The researcher}

I am Bharathi Naidu Vijayan and I am a Doctoral student in Education at Victoria University of Wellington, New Zealand. This research project is a work towards my thesis.

\section{The purpose of my PhD research}

This study seeks to identify undergraduate students' learning approaches to reading tasks and their investment in the EAP classrooms in Malaysia. This project focuses primarily on language learners' approaches to learning and their investment. Data gained from observations of classroom reading tasks will provide information on approaches to learning in a particular task.

I would like your consent to approach the lecturers who teach English courses and their students to participate in my research study. I would also like your consent to observe the English classes of those lecturers who volunteer to be part of my study. Specific details are given in the section below on the research design.

\section{Research questions}

How do Malaysian tertiary students' approaches to learning and their investment in reading in English align with their reading practices in the EAP classroom?

\section{Specific questions:}

1) What approaches to learning do tertiary students in four EAP classes in Malaysia report using?

2) What levels of thinking are evident in students' responses to reading tasks (using SOLO taxonomy)?

3) What investment do students in EAP classes report having in their reading practices?

4) What are the constraints and enablers that students report when engaging with reading tasks?

\section{The research design}

The purpose of this study is to identify Malaysian tertiary Students' Approaches to Learning (SAL) and how the notion of investment in reading is aligned with students' reading practices in English for 
Academic Purposes (EAP) classrooms. The research will be carried out at (name of institution: ) and involves lecturers and students. Students' approaches to learning depends on the tasks they are required to complete. Hence, the reading tasks from the EAP classroom is selected to assist in determining students' approaches to learning. This research will use questionnaires, classroom observations, interview sessions to identify students' approaches to learning and their investment in the reading classroom. A mixed methods research design inclusive of two phases will be employed. In the first phase of this study, questionnaires will be distributed to students. In the second phase, selected students will be invited to participate in the project based on the feedback from the questionnaire.

\section{Research participants}

As part of my research, I will be inviting two classes of EAP students from your university to participate in the first phase of filling out a questionnaire. Participation in this research is entirely voluntary. In the second phase, I will seek the lecturers consent to observe the class. Four students from each class will be invited to participate in interviews about their reading activities.

\section{Research process and data collection procedures with lecturers and students:}

- Initial meeting with lecturers and students for briefing on the research project and invite them to participate

- Distribute questionnaires to students

- Conduct observation during reading lessons (using indicative checklist and audio recorder)

- Request students' work samples from participants

- Interview the participants using a stimulated recall method and semi-structured interviews on their responses to reading tasks in class

\section{Confidentiality and access to information}

The information participants provide is strictly confidential. The name of the institute and the research participants will not be identifiable. Pseudonyms will be used to ensure the participants' confidentiality. All material collected will be kept confidential. No other person besides me, my supervisors (Dr. Carolyn Tait and Dr. Gillian Hubbard), and/or a transcriber who will be required to complete a confidentiality form will have access to the data. Data will be destroyed five years after the end of the project.

Information collected will be kept confidential as electronic files on my password protected computer and summaries of the research findings can be requested. Feedback will be obtained by sending participants transcripts of their own individual interview for review and verification.

This research focuses on the types of approaches to learning students use and their investment in the reading class. Hence, the research does not focus on the quality of teaching.

\section{Participation}

Participants may withdraw from the research project for any reason by $15^{\text {th }}$ December 2016 when data collection would have been completed and any data contributed via questionnaire, interviews and observations would then be destroyed. 


\section{Publication of results}

The data collected in this research will be used for publication purposes including academic or professional journals, conference papers and appropriate articles and for the inclusion in the $\mathrm{PhD}$ theses which will be deposited in the Victoria University of Wellington library.

Your consent to participate in this study is highly appreciated. Please complete, sign and return the attached consent form by (date: participate in this study.

\section{Human Ethics Committee information}

If you have any questions or would like to receive further information about the research, please contact me at Bharathi.Vijayan@vuw.ac.nz. You can also contact my supervisors, Dr Carolyn Tait at Carolyn.Tait@vuw.ac.nz, Tel: 64(4)463 9590 and/or Dr Gillian Hubbard Gillian.Hubbard@vuw.ac.nz, Tel: 64(4)4639690.

If you have any ethical questions about this research please contact Associate Professor Susan Corbett, Convener of the Human Ethics Committee, Victoria University of Wellington (susan.corbett@vuw.ac.nz, Tel: 64(04) 4635480).

This project has been reviewed and approved by the Victoria University Human Ethics Committee (ref no. 22611).

Thank you,

Bharathi Vijayan

Email: Bharathi.Vijayan@vuw.ac.nz 


\section{Appendix E: Consent for the Management of the University}

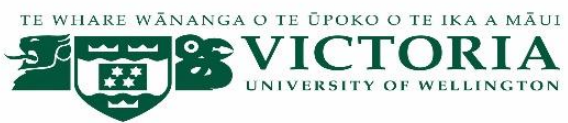

\section{FACULTY OF EDUCATION}

\section{Consent form for management}

\section{Research Project: Investment and Reading Practices in English for AcademicPurposes Classrooms in Malaysia}

This consent form will be held for 5 years.

Researcher: Bharathi Naidu Vijayan, School of Education, Victoria University of Wellington.

- I have been given, and have understood, an explanation relating to the nature and purpose of this research. I have had the opportunity to ask questions about it.

- I give permission for the researcher to collect data for this research through survey, classroom observations and interviews.

- I understand that the data collected will be kept secure. Only the researcher, research supervisors and transcriber (who will sign a confidentiality agreement) will have access to the data.

- I understand that the names of lecturers and students will not be attributed to specific data in any publications or presentations arising from this research, instead pseudonyms will be used.

- I understand that the data collected will only be used in the thesis, professional and academic journals or in educational or research conference presentations.

- I understand that participation in this research is entirely voluntary and that the participating students and teachers may withdraw from this study without giving a reason up until $15^{\text {th }}$ December 2016. Any data provided by them would then be destroyed.

- I understand that participants will have a chance to check the accuracy of any interviews.

- I understand that transcripts and tapes and raw data will be destroyed five years after the conclusion of the project.

Name:

Date:

Signature: 


\section{Appendix F: Information Sheet for Lecturers}

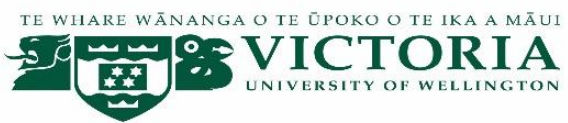

FACULTY OF EDUCATION

Information sheet for lecturers

\section{Research Project: Investment and Reading Practices in English for Academic Purposes Classrooms in Malaysia}

Dear lecturers,

Thank you for your interest in this project. Please read this information before deciding whether or not to take part.

\section{Who am I?}

I am Bharathi Naidu Vijayan and I am a Doctoral student in Education at Victoria University of Wellington, New Zealand. This research project is at the data collection stage of my thesis. I would like to invite you to participate in my research study by participating in the observations.

\section{What is the aim of the project?}

This study seeks to identify undergraduate students' learning approaches to reading tasks and their investment in the EAP classrooms in Malaysia. This project focuses primarily on language learners' approaches to learning and their investment. Data gained from observations of classroom reading tasks will provide information on approaches to learning in a particular task.

\section{How can you help?}

\section{1) Observation sessions}

I will attend the reading lessons that you nominate during the semester. I will observe four reading lessons. During each observation, I will audio record the teaching and learning about reading in the classroom. This could include students' discussions with their peers and student-teacher interaction.

\section{2) Documents}

With your permission, I would also like to look at course outline, lesson plans and (also with their permission) students' work sample of reading activities. This data will assist me in identifying students' approaches to learning and their investment in the reading classroom.

\section{If you accept this invitation, you will be able:}

- to withdraw from the study for any reason by $15^{\text {th }}$ December 2016 when data collection would have been completed

- to get clarification regarding the study at any time during your participation;

Participation in the research is on a voluntary basis. No pressure will be put on you to participate in this research. All information collected will be strictly confidential. Your identity will be protected using 
a pseudonym. Access to the data is restricted to my supervisors and me. All data will be stored in password protected files and will be kept for 5 years, after which they will be destroyed.

\section{What will the project produce?}

The information from my research will be used in my $\mathrm{PhD}$ dissertation. You will not be identified in my report. I may also use the results of my research for conference presentations, and academic reports. I will take care not to identify you in any presentation or report.

\section{Human Ethics Committee information}

If you have any questions or would like to receive further information about the research, please contact me at Bharathi.Vijayan@vuw.ac.nz. You can also contact my supervisors, Dr. Carolyn Tait at Carolyn.Tait@vuw.ac.nz,Tel: 64(4)463 9590 and/or Dr. Gillian Hubbard

Gillian.Hubbard@vuw.ac.nz, Tel: 64(4)463 9690.

If you have any ethical questions about this research please contact Associate Professor Susan Corbett, Convener of the Human Ethics Committee, Victoria University of Wellington (susan.corbett@vuw.ac.nz,Tel: 64(04) 4635480).

This project has been reviewed and approved by the Victoria University Human Ethics Committee (ref no. 22611).

Thank you,

Bharathi Vijayan

Email: Bharathi.Vijayan@vuw.ac.nz 


\section{Appendix G: Consent for the Lecturers}

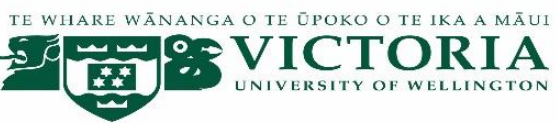

FACULTY OF EDUCATION

\section{Consent form for lecturers}

\section{Research Project: Investment and Reading Practices in English for Academic Purposes Classrooms in Malaysia}

This consent form will be held for 5 years.

Researcher: Bharathi Naidu Vijayan, School of Education, Victoria University of Wellington.

- I have read the Information Sheet and the project has been explained to me. My questions have been answered to my satisfaction. I understand that I can ask further questions at any time.

- I I agree to take part in the classroom observations.

- I lagree to allow my students to participate in the research.

- I agree to share copies of course outline and any relevant lesson planning with the researcher for the purpose of the research study.

- I agree to share sample of students' work with the researcher for the purpose of the research study.

I understand that:

- My participation is entirely voluntary

- $\quad$ the observation will be audio recorded and transcribed

- I may withdraw from the study for any reason by $15^{\text {th }}$ December 2016 and any information that I have provided will be returned to me or destroyed.

- The information from the classroom observations will be destroyed 5 years after the research is finished.

- All documents, transcripts and audio recordings of the classroom observations will be kept confidential to the researcher, the supervisors and/or transcriber. I understand that the results will be used for a PhD report and a summary of the results may be used in academic reports and/or presented at conferences.

- My name will not be used in reports, nor will any information that would identify me.

I would like a summary of the findings of the research

Yes

No $\square$

Name:

Date:

Signature:

Mobile number: 


\section{Appendix H: Information Sheet for Survey Participation}

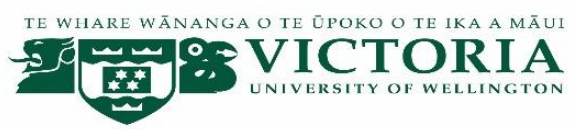

FACULTY OF EDUCATION

Information sheet for survey participation

\section{Research Project: Investment and Reading Practices in English for Academic Purposes Classrooms in Malaysia}

Dear students,

Thank you for your interest in this project. Please read this information before deciding whether or not to take part.

\section{Who am I?}

I am Bharathi Naidu Vijayan and I am a Doctoral student in Education at Victoria University of Wellington, New Zealand. I would like to invite you to participate in my research study by responding to a questionnaire.

\section{What is the aim of the project?}

This study seeks to identify undergraduate students' learning approaches to reading tasks and their investment in the EAP classrooms in Malaysia.

Students in two universities in Malaysia are being invited to participate in this project. The questionnaire should take approximately 15-20 minutes to complete. This questionnaire will provide a general idea of how students approach learning. This information could help future educators to be aware of the types of approaches students use in their learning.

\section{How can you help?}

Participation in the research is on a voluntary basis. If you consent to participate in the research project, please complete the questionnaire. Your response to this questionnaire is anonymous. No information from this survey will identify you. If you wish to receive a summary of the findings from the questionnaire, please email your contact details to me at Bharathi.Vijayan@vuw.ac.nz.

If you decide you are interested in being selected to participate in the second phase of the research, you will be asked to complete some contact details on the questionnaire. You will be given a separate information and consent form for the second phase. I will be selecting four participants with different profiles of approaches to learning from your class. If you volunteered to participate and were not selected for the second phase, I will let you know by email.

\section{What will happen to the information you give?}

There are no "right" or "wrong" answers to the questionnaire. This research will have no impact on your grade. Your name and university will not be identified in any publications resulting from the research. 
Access to the data is restricted to my supervisors and me. All data will be stored in password protected files and will be kept for 5 years, after which they will be destroyed.

\section{What will the project produce?}

The information from my research will be used in my $\mathrm{PhD}$ dissertation. You will not be identified in my report. I may also use the results of my research for conference presentations, and academic reports. I will take care not to identify you in any presentation or report.

\section{If you accept this invitation, what are your rights as a research participant?}

If you agree to participate in this research project, you have the following rights:

- to withdraw by not completing the questionnaire;

- to refuse to answer a particular question;

- to ask any additional questions regarding the study at any time;

- to provide the information with an assurance of data confidentiality;

- to be provided with a summary of findings if you wish. The findings will be sent to you by email.

\section{Human Ethics Committee information}

If you have any questions or would like to receive further information about the research, please contact me at Bharathi.Vijayan@vuw.ac.nz. You can also contact my supervisors, Dr. Carolyn Tait at Carolyn.Tait@vuw.ac.nz, Tel: 64(4)463 9590 and/or Dr. Gillian Hubbard Gillian.Hubbard@vuw.ac.nz, Tel: 64(4)4639690.

If you have any ethical questions about this research please contact Associate Professor Susan Corbett, Convener of the Human Ethics Committee, Victoria University of Wellington (susan.corbett@vuw.ac.nz, Tel: 64(04) 4635480).

This project has been reviewed and approved by the Victoria University Human Ethics Committee (ref no. 22611).

Thank you,

Bharathi Vijayan

Email: Bharathi.Vijayan@vuw.ac.nz 


\section{Appendix I: Information Sheet for Principal Participants}

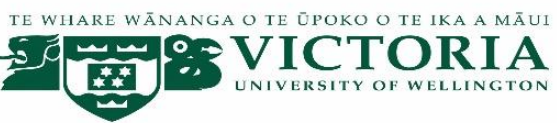

\section{FACULTY OF EDUCATION}

Information sheet for principal participants

\section{Research Project: Investment and Reading Practices in English for Academic Purposes Classrooms in Malaysia}

Dear students,

Thank you for your interest in this project. Please read this information before deciding whether or not to take part.

\section{Who am I?}

I am Bharathi Naidu Vijayan and I am a Doctoral student in Education at Victoria University of Wellington, New Zealand. This research project is at the data collection stage of my thesis. I would like to invite you to participate in my research study by participating in the observations and interview sessions.

\section{What is the aim of the project?}

This study seeks to identify undergraduate students' learning approaches to reading tasks and their investment in the EAP classrooms in Malaysia.

\section{How can you help?}

\section{1) Observation sessions}

Classroom observations will be conducted four times during the reading lessons. During each observation, I will audio record the discussions that take place in the classroom pertaining to the reading lessons. This covers your discussions with your lecturer and peers in relation to the reading lessons in the classrooms. This will provide information about the ways students talk about reading tasks.

\section{Some of your writing about reading}

Sometimes in class you are asked to write about texts that you read in class. It would be helpful if I could see some of these samples. I will photocopy these samples and return them to you. This will provide information on how students approach reading in EAP classes.

\section{2) Interview Sessions}

If you consent to participate in the research project, you will be invited to an initial interview after one of the observations about reading tasks in class and a later interview to talk about reading more generally. The interviews will take approximately 40 minutes to one hour.

If you accept this invitation, you will be able:

- to decline to answer any particular questions; 
- to withdraw from the study for any reason by $15^{\text {th }}$ December 2016 when data collection would have been completed;

- to get clarifications regarding the study at any time during your participation;

- to provide information on the understanding that your name will not be revealed;

- to have the interview transcriptions sent to you by email and have a chance to verify it and change any part of it;

- to be given access to a summary of the study findings when it is concluded if you wish. This will be sent to you by email.

Participation in the research is on a voluntary basis. All information collected will be strictly confidential. Your identity will be protected using a pseudonym. This study will have no impact on your grade. There is no penalty for participating or not participating in this research. Access to the data is restricted to my supervisors and me. All data will be stored in password protected files and will be kept for 5 years, after which they will be destroyed.

\section{What will the project produce?}

The information from my research will be used in my $\mathrm{PhD}$ dissertation. You will not be identified in my report. I may also use the results of my research for conference presentations, and academic reports. I will take care not to identify you in any presentation or report.

\section{Human Ethics Committee information}

If you have any questions or would like to receive further information about the research, please contact me at Bharathi.Vijayan@vuw.ac.nz. You can also contact my supervisors, Dr. Carolyn Tait at Carolyn.Tait@vuw.ac.nz, Tel: 64(4)463 9590 and/or Dr. Gillian Hubbard Gillian.Hubbard@vuw.ac.nz, Tel: 64(4)4639690.

If you have any ethical questions about this research please contact Associate Professor Susan Corbett, Convener of the Human Ethics Committee, Victoria University of Wellington (susan.corbett@vuw.ac.nz, Tel: 64(4) 4635480).

This project has been reviewed and approved by the Victoria University Human Ethics Committee (ref no. 22611).

Thank you,

Bharathi Vijayan

Email: Bharathi.Vijayan@vuw.ac.nz 


\section{Appendix J: Consent Form for Principal Participants}

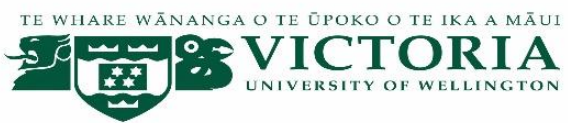

FACULTY OF EDUCATION

\section{Consent form for principal participants}

\section{Research Project: Investment and Reading Practices in English for Academic Purposes Classrooms in Malaysia}

This consent form will be held for 5 years.

Researcher: Bharathi Naidu Vijayan, School of Education, Victoria University of Wellington.

- I have read the Information Sheet and the project has been explained to me. My questions have been answered to my satisfaction. I understand that I can ask further questions at any time.

- I agree to take part in audio recorded interviews.

- I agree to take part in the classroom observations.

- I agree to share some of the samples of my writing with the researcher.

I understand that:

- My participation is entirely voluntary.

- the interviews and observations will be audio recorded and transcribed.

- I may withdraw from the study for any reason by $15^{\text {th }}$ December 2016 and any information that I have provided will be returned to me or destroyed.

- The information I have provided will be destroyed 5 years after the research is finished.

- $\quad$ Any information I provide will be kept confidential to the researcher, the supervisors and/or transcriber. I understand that the results will be used for a PhD report and a summary of the results may be used in academic reports and/or presented at conferences.

- My name will not be used in reports, nor will any information that would identify me.

- I will have a chance to check the accuracy of the interview sessions and take out information.

I would like a copy of the transcript of my interview and have Yes $\square$ No added my email address below:

Name:

Date:

Signature:

Mobile Number:

Email: 


\title{
Appendix K: Information Sheet for Observation Participants
}

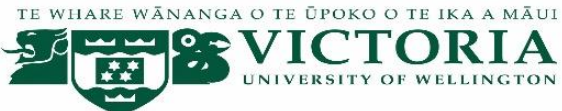 \\ FACULTY OF EDUCATION \\ Information sheet for observation participants
}

\section{Research Project: Investment and Reading Practices in English for Academic Purposes Classrooms in Malaysia}

Dear students,

Thank you for your interest in this project. Please read this information before deciding whether or not to take part.

\section{Who am I?}

I am Bharathi Naidu Vijayan and I am a Doctoral student in Education at Victoria University of Wellington, New Zealand. This research project is at the data collection stage of my thesis. I would like to invite you to participate in my research study by participating in the classroom observation sessions.

\section{What is the aim of the project?}

This study seeks to identify undergraduate students' learning approaches to reading tasks and their investment in the EAP classrooms in Malaysia.

\section{How can you help? \\ Observation sessions}

I will be closely observing and audio recording the interactions of some students in the classroom for my research. While your interactions are not the primary focus of my research, you may fall within the scope of my data collection. Your discussions with selected participants may be recorded. However, you will not be identified in any part of my research. Classroom observations will take place four times in the reading lessons. These data will provide information about the ways students talk about reading tasks.

\section{If you accept this invitation, you will be able:}

- to withdraw from the study for any reason by $15^{\text {th }}$ December 2016 when data collection would have been completed;

- to get clarification regarding the study at any time during your participation;

- to provide information on the understanding that your name will not be revealed;

Participation in the research is on a voluntary basis. All information collected will be strictly confidential. Your identity will be protected using a pseudonym. This study will have no impact on your grade. There is no penalty for participating or not participating in this research. Access to the data is restricted to my supervisors and me. All data will be stored in password protected files and will be kept for 5 years, after which they will be destroyed. 


\section{What will the project produce?}

The information from my research will be used in my $\mathrm{PhD}$ dissertation. You will not be identified in my report. I may also use the results of my research for conference presentations, and academic reports. I will take care not to identify you in any presentation or report.

\section{Human Ethics Committee information}

If you have any questions or would like to receive further information about the research, please contact me at Bharathi.Vijayan@vuw.ac.nz. You can also contact my supervisors, Dr. Carolyn Tait at Carolyn.Tait@vuw.ac.nz, Tel: 64(4)463 9590 and/or Dr. Gillian Hubbard Gillian.Hubbard@vuw.ac.nz, Tel: 64(4)4639690.

If you have any ethical questions about this research please contact Associate Professor Susan Corbett, Convener of the Human Ethics Committee, Victoria University of Wellington (susan.corbett@vuw.ac.nz, Tel: 64(4) 4635480).

This project has been reviewed and approved by the Victoria University Human Ethics Committee (ref no. 22611).

Thank you,

Bharathi Vijayan

Email: Bharathi.Vijayan@vuw.ac.nz 


\title{
Appendix L: Consent Form for Students (Observation Participation)
}

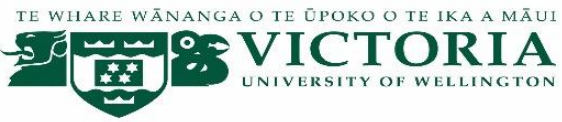 \\ FACULTY OF EDUCATION \\ Consent form for students (observation participation)
}

\section{Research Project: Investment and Reading Practices in English for Academic Purposes Classrooms in Malaysia}

This consent form will be held for 5 years.

Researcher: Bharathi Naidu Vijayan, School of Education, Victoria University of Wellington.

I understand that:

- The observations will be audio recorded and transcribed.

- I may be part of the discussions however I will not be identified in the research.

- Classroom discussions and interactions with the lecturer along with peers will be recorded.

- $\quad$ Any information from the observations will be kept confidential to the researcher, the supervisors and/or transcriber. I understand that the results will be used for a PhD report and a summary of the results may be used in academic reports and/or presented at conferences.

The project has been explained to me and my questions have been answered to my satisfaction. I understand that I can ask further questions at any time.

Name:

Date:

Signature: 


\section{Appendix M: Interview Guide for Research Participants}

\section{Interview Guide for Research Participants}

\section{A) Stimulated Recall Interview for Participants}

1) Is it possible for you to explain what the lecturer wanted you to do for this task?

a. How did you and your friends manage to get the answers?

2) What did you find interesting about these articles: print revolution and cyberculture?

3) How do you find the texts- difficult, medium or easy to understand? Why?

4) Which article did you read first? Is there a particular reason to begin reading the article?

a. When you were asked to read again, which did you read first?

b. How many times you read? Why?

5) How did you approach the reading?

a. Did you look at the picture first?

b. Did you create any questions in your mind?

c. Keywords?

6) How did you manage to get information from article to mind map to summary?

7) How did you decide to present the mind map as such? (this is how the mind map should look like)

8) Was it easy to form the concept map? If difficult/ easy, why? How did you manage to overcome it if it was difficult?

9) What made you do mind maps before writing the summary?

10) How did you shift from mind map to summary?

11) How did you determine the important ideas that needs to be displayed in the map/ summary?

12) Would you call this a challenging task? How easy/ difficult and which part?

13) What reading techniques/strategies were taught in class? like annotations, making summary

a. Are you able to relate these reading techniques/strategies in other class? Can you give some examples?

14) Are you able to relate the topic (cyberculture/ printing revolution) that you learnt in classto your outside class? Can you give some examples?

\section{B) Semi structured Interviews}

1. What type of reading do you do? (inside class and outside class) (Do you read social media, printed books, online materials, etc.?)

2. How important is reading in English to you? Does learning English benefits you in any way?

3. Can you describe some of the ways you engage/ don't engage in the EAP class?

4. What are your future plans? What would you like to do when you complete your studies? 


\section{Appendix N: Questionnaire}

By completing this survey, I acknowledge that I have read the information sheet and had a chance to ask questions. Any information I provide will be kept confidential to the researcher and the supervisors. I understand that the results will be used for a $\mathrm{PhD}$ report and a summary of the results may be used in academic reports and/or presented at conferences. My name will not be used in reports, nor will any information that would identify me. I recognise that the data I give will be anonymous and that I will have a chance at the end to give my contact details if I wish to participate in phase two of the project.

Dear student,

This survey aims to understand your attitudes towards reading practice. There are three parts in the response form. Please read carefully each statement and answer all the parts.

Part A comprises of your personal details.

Part B is a survey on your approaches to learning which requires your choice of response.

Part C comprises short answer questions which require your thoughts about reading experiences.

\section{Part A: Demographic Details}

1. Please indicate your gender:

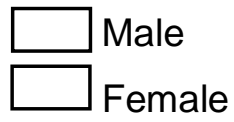

2. Please indicate which age group you fit into:
ए 19-20
21-22
$\square$ 23-24
$\square$ 25-26
27 and above

3. Please indicate your field of study:
$\square$ Commerce
$\square$ Science
$\square$ Language
$\square$ Law
$\square$ Education
$\square$ Others, please specify:

4. Please indicate your level of proficiency in reading skills in English based on your personal assessment: 
High proficient

Proficient

Fairly proficient

Somewhat proficient

Low proficient

\section{Part B: Studying Approaches}

This questionnaire has a number of questions about your attitudes towards your studies and your usual way of studying in English for Academic Purposes (EAP) class. There is no right way of studying. You may have your own style depending on the course you are taking. It is accordingly important that you answer each question as honestly as you can.

Tick $(\sqrt{ })$ the one most appropriate response to each question. Remember there is no right or wrong answer.

\begin{tabular}{|c|c|c|c|c|c|}
\hline & $\begin{array}{l}\text { This item } \\
\text { is never } \\
\text { or only } \\
\text { rarely } \\
\text { true of } \\
\text { me }\end{array}$ & $\begin{array}{l}\text { This item } \\
\text { is } \\
\text { sometim } \\
\text { es true of } \\
\text { me }\end{array}$ & $\begin{array}{l}\text { This item } \\
\text { is true of } \\
\text { me about } \\
\text { half the } \\
\text { time }\end{array}$ & $\begin{array}{l}\text { This item } \\
\text { is } \\
\text { frequentl } \\
y \text { true of } \\
\text { me }\end{array}$ & $\begin{array}{l}\text { This item } \\
\text { is always } \\
\text { or almost } \\
\text { always } \\
\text { true of } \\
\text { me }\end{array}$ \\
\hline $\begin{array}{l}\text { 1. I find that at times studying } \\
\text { gives me a feeling of deep } \\
\text { personal satisfaction. }\end{array}$ & & & & & \\
\hline $\begin{array}{l}\text { 2. I find that I have to do a lot of } \\
\text { work on my own before I can } \\
\text { arrive at a conclusion. }\end{array}$ & & & & & \\
\hline $\begin{array}{l}\text { 3. My aim is to pass the course } \\
\text { while doing as little work as } \\
\text { possible. }\end{array}$ & & & & & \\
\hline $\begin{array}{l}\text { 4. I only study seriously what's } \\
\text { given in class or in the course } \\
\text { outlines. }\end{array}$ & & & & & \\
\hline $\begin{array}{l}\text { 5. I feel that almost any topic can } \\
\text { be highly interesting once I get } \\
\text { into it. }\end{array}$ & & & & & \\
\hline $\begin{array}{l}\text { 6. I find most new topics } \\
\text { interesting and often spend } \\
\text { extra time trying to obtain more } \\
\text { information about them. }\end{array}$ & & & & & \\
\hline $\begin{array}{l}\text { 7. I do not find my course very } \\
\text { interesting so I keep my work to } \\
\text { the minimum. }\end{array}$ & & & & & \\
\hline
\end{tabular}


8. I learn some things by rote (going over repeatedly) until I know them by heart even if I do not understand them.

9. I find that studying academic topics can at times be as exciting as a good novel or movie.

10. I test myself on important topics until I understand them completely.

11.I find I can manage most assessments by memorising key sections rather than trying to understand them.

12. I generally study to what is specifically set as I think it is unnecessary to do anything extra.

13. I work hard at my studies because I find the material interesting.

14. I spend a lot of my free time finding out more about interesting topics which have been discussed in different classes.

15. I find it is not helpful to study topics in depth. It confuses and wastes time, when all you need is a basic understanding of the topics.

16. I believe that lecturers shouldn't expect students to spend significant amounts of time studying material everyone knows won't be examined.

17. I come to most classes with questions in mind that I want answers for.

18. I make a point of looking at most of the suggested readings that go with the lectures. 
19. I see no point in learning material which is not likely to be in the examination.

20. I find the best way to pass examinations is to try to remember answers that are likely to be tested.

\section{Part C: Reading Experience}

1. Think about what you do when you are asked to read a text in class? (about 50 words)

- Describe the process you go through.

- When you read in class, what things are easy and what are hard for you?

2. Think about the reading you do out of class. (about 50 words)

- In what language do your read?

- How much reading do you do?

- What sorts of things do you read and in what medium (e.g. books, on screen, etc.).

Please provide your personal details if you would like to participate in the second phase of the research.

\begin{tabular}{|l|l|l|l|}
\hline Name & $\begin{array}{l}\text { Mobile } \\
\text { number }\end{array}$ & \\
\hline $\begin{array}{l}\text { Email } \\
\text { address }\end{array}$ & & \\
\hline
\end{tabular}




\section{Appendix O: Observation Checklist}

Instruction: Use (I) to indicate the amount of times the lecturer has used the categories and write the total in the column provided.

\section{Observation Checklist}

Lecturer

University structural

\begin{tabular}{|c|c|c|c|}
\hline & Memorize & Identify & Recognize \\
\hline $\begin{array}{l}\text { Not } \\
\text { applicable }\end{array}$ & $\begin{array}{l}\text { The task } \\
\text { requires } \\
\text { students to } \\
\text { recall from } \\
\text { memory }\end{array}$ & $\begin{array}{l}\text { The task } \\
\text { requires } \\
\text { students to } \\
\text { identify }\end{array}$ & $\begin{array}{l}\text { The task } \\
\text { requires } \\
\text { students to } \\
\text { recognize }\end{array}$ \\
\hline & & information & information \\
\hline
\end{tabular}

\begin{tabular}{|c|c|c|}
\hline assify & $\begin{array}{l}\text { lescribe/ } \\
\text { st }\end{array}$ & $\begin{array}{l}\text { Compare/contras } \\
t\end{array}$ \\
\hline equires & & The tas \\
\hline ude & $\begin{array}{l}\text { requires } \\
\text { students to }\end{array}$ & students \\
\hline & deccribel & compare/contrast \\
\hline & $\begin{array}{l}\text { list } \\
\text { information }\end{array}$ & information \\
\hline
\end{tabular}

Class

Start

Multistructural

Relational

Explain causes

The task

requires

students to

explain

causes that

occur
Date

Finish

Extended abstract

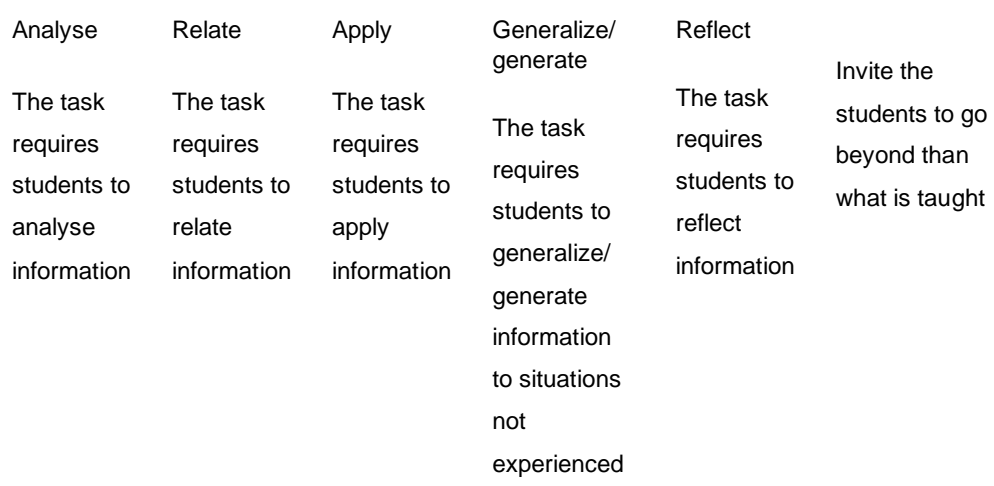




\section{Appendix P: Sample of the Process of Combining Codes to Categories}

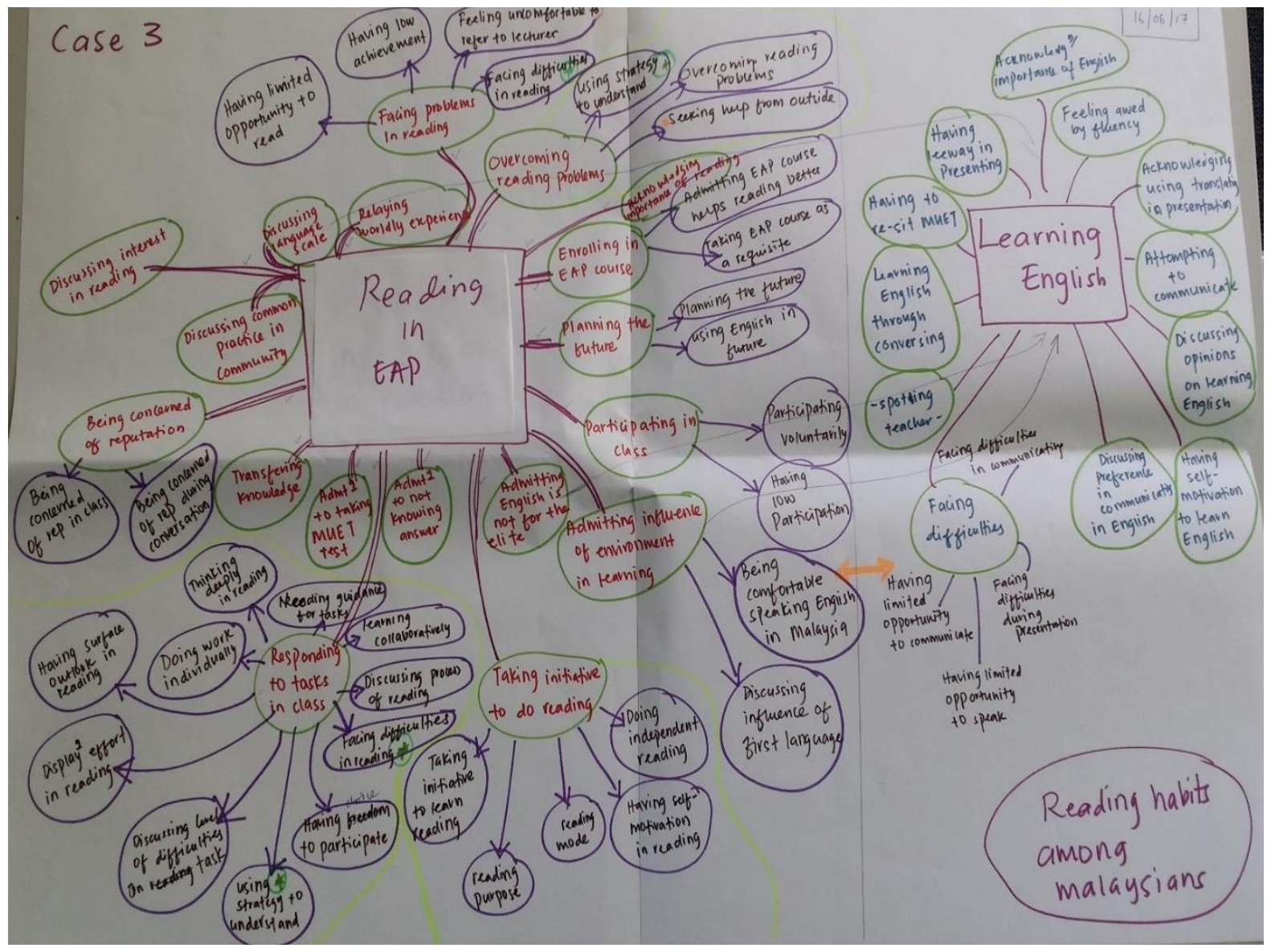




\section{Appendix Q: The Print Revolution Passage}

\section{A Reading Textbooks (2)}

Academic textbooks present information and, to some extent, arguments and opinions. Paragraphs in textbooks typically have one main idea (usually expressed in a topic sentence), plus some supporting evidence, often involving reasons and examples. To gain an overview of the text, it is important to work out what are the main ideas and the supporting evidence. You also need to understand the author's stance (or point of view), and how using specific language can change the author's meaning.

This module covers:

- Identifying main ideas and supporting evidence in a text

- Building word families

- Using adverbs to express stance

\section{TASK 1 Gaining an overview of a text}

1 You are going to read a short text entitled The print revolution. Decide which of the items below you would expect to be included. Add any others, and give reasons. where and when printing developed how printing developed the future of printing the most popular printed books printing technology the main languages in print

2 Read Text 1 and check your predictions in 1 .

\section{The print revolution}

1 The earliest known book was printed in China in the year 868 and metal type was in use in Korea at the beginning of the fifteenth century, but it was in Germany around the year 1450 that a printing press using moveable metal type was invented.

2 Capitalism turned printing from an invention into an industry. Right from the start, book printing and publishing were organized on capitalist lines. The biggest sixteenth-century printer, Plantain of Antwerp, had twenty-four printing presses and employed more than a hundred workers. Only a small fraction of the population was literate, but the production of books grew at an extraordinary speed. By 1500, some 20 million volumes had already been printed (Febvre and Martin 1976).

3 The immediate effect of printing was to increase the circulation of works that were already popular in a handwritten form, while less popular works went out of circulation. Publishers were interested only in books that would sell fairly quickly in sufficient numbers to cover the costs of production and make a profit. Thus, while printing enormously increased access to books by making cheap, high-volume production possible, it also reduced choice.

4 The great cultural impact of printing was that it facilitated the growth of national languages. Most early books were printed in Latin, the language of educated people, but the market for Latin was limited, and in its pursuit of larger markets the book trade soon produced translations into the national languages emerging at this time. Printing indeed played a key role in standardizing and stabilizing these languages by fixing them in print, and producing dictionaries and grammar books. Latin became obsolete as national literatures were established in the sixteenth century.

source: Fulcher, ]. \& Scott, ]. (2011). pp.370-1. Sociology (4th ed.) Oxford: Oxford University Press.

3 What is the main purpose of Text 1 ? To offer:

a a description of the development of printing

b a comparison between the contributions of different countries

c an evaluation of capitalism and printing

d an argument for the importance of printed books.
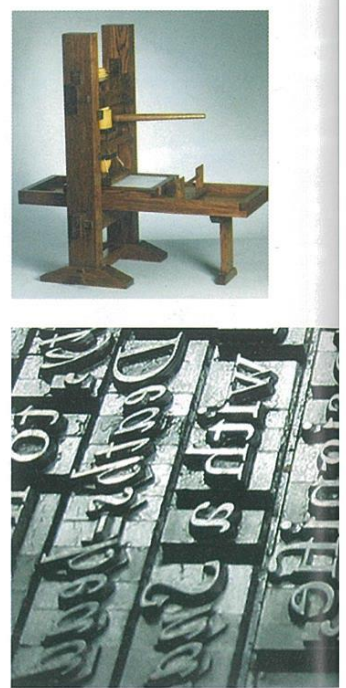

GLOSSARY

circulation ( $n$ ) the movemen of something between people or places

facilitate (v) make somethin possible or easier

literate (adj) able to read and write

obsolete (adj) out of date useless 


\section{Appendix R: Cyberculture: the artificial world of the internet Passage}

Read Text 2 and decide which statements in 1 are true, according to the text. Identify the paragraph which corresponds to each statement.

\section{Cyberculture: the artificial world of the internet}

The internet and the World Wide Web have provided a new medium for culture, generally labelled cyberculture, because it exists in cyberspace, 'the conceptual space where computer networking hardware, network software and users converge' (Gauntlett 2000: 220).

The internet and the Web made possible a culture apparently free of many of the constraints that

operated in other media. The Webwas

$v^{2} v^{2}$ and business corporations. Information could be freely)exchanged without anyone censoring or

siting it. When on the Net, people were anonymous and could assume, and play with, any identity

$\left.s^{\prime}{ }^{\prime}\right)$ they chose. With others they could construct their own virtual communities, their own society, their own world. They were free of their relationships, their communities, their bodies.

3 Indeed, Sherry Turkle (1997) argues that they can become free of themselves. In a world of screens, this virtual world can become more real to people than the 'real world' and can shape their behaviour in the 'real world'. Aspects of identity developed in the virtual world can form the basis for relationships in the 'real world'.

4 With the growth of what Silver (2000) has labelled 'critical cyberculture studies', the celebration With timitations. Many familiar constraints are at work behind the scenes.

5 The inequalities found in society at large are present in the world of the internet too. The rapid rise in numbers of those using the internet led people to view cyberculture as a new popular culture, but there is plentiful evidence of a growing 'digital divide' between 'haves' and 'have-nots'. Cyberspace has also been considered a predominantly male space, with a typically male 'frontier culture' (Silver 2000: 26-7).

6 Arguably, a 'technopower spiral' has brought about control by a technical elite. This spiral is the result of the vast, and ever increasing, amount of information available on the Web, which has led flow of information. It thas become increasingly difficult for ordinary users to operate according to their own values, as they are dependent on the tools created and controlled by the technical elite. These tools are constructed according to the beliefs and values of the elite and in the language it has developed (Jordan 1999: 101).

7 Nor is cyberculture free of commercial and political pressures. Commercial pressures are blatantly present in the pop-up advertising which finances so much 'free' activity. Commercial interests also steer and manipulate users in covert ways, and governments can find ways of censoring Web content.

8 This raises the broad question of quite how different cyberculture is from other cultural media. That it is different to some degree is undeniable. It does provide opportunities for individuals and groups to engage in cultural exploration in a relatively unconstrained way. Cyberculture is by no means immune, however, from the social processes of manipulation, domination, and commercialization that operate in society at large and shape culture in general.

source: Fulcher, J. \& Scott, 1. (2011). pp.367-8. Sociology (4th ed.). Oxford: Oxford University Press.

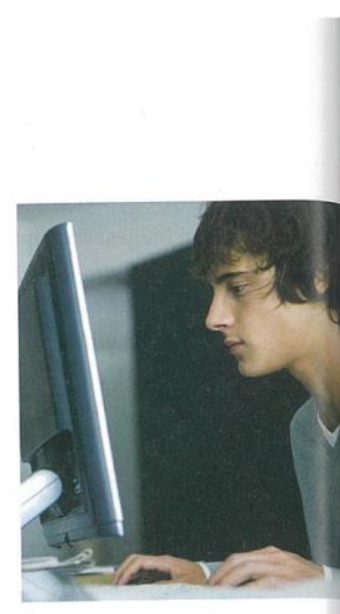

intenet ho liwitationt

GLOSSARY

censor ( $v$ ) to remove parts of a book, film, etc. that are considered to be offensive, immoral, or a political threat constraint $(n)$ a thing that limits or restricts something, or your freedom to do

something

converge (v) to move towards each other and meet at a point elite $(n)$ a group of people in a society, etc. who are powerfu and have a lot of influence predominantly (adv) mostly, mainly

3 Decide which of statements 1-3 represents the authors' stance in Text 2 .

1 Cyberculture is unlike other cultures and gives its users freedom.

2 Cyberculture allows a certain degree of freedom, but with certain limits.

3 Cyberculture is broadly similar to other cultures because it greatly limits users freedom.

\section{TASK 5 Identifying main ideas and supporting evidence}

1 Note down the main ideas and supporting evidence for paragraphs 3-8 of Text 2. Example:

Paragraph Main idea

2 the internet made possible a web-decentralized + outside government control; information freely exchanged; relatively free culture anonymous; allows individual identities; free

2 Discuss the extent to which you agree with the supporting evidence offered for each main idea. Give reasons and examples of your own.

042 UNIT 3A READINC 


\section{Appendix S: Sample of Participants' Written Work for Unit 1, Unit 2 and Unit 3}

$S(1)$

Affiq and Halim (Unit 1): Mind map combining the effects of "Cyberculture" and "The print Revolution

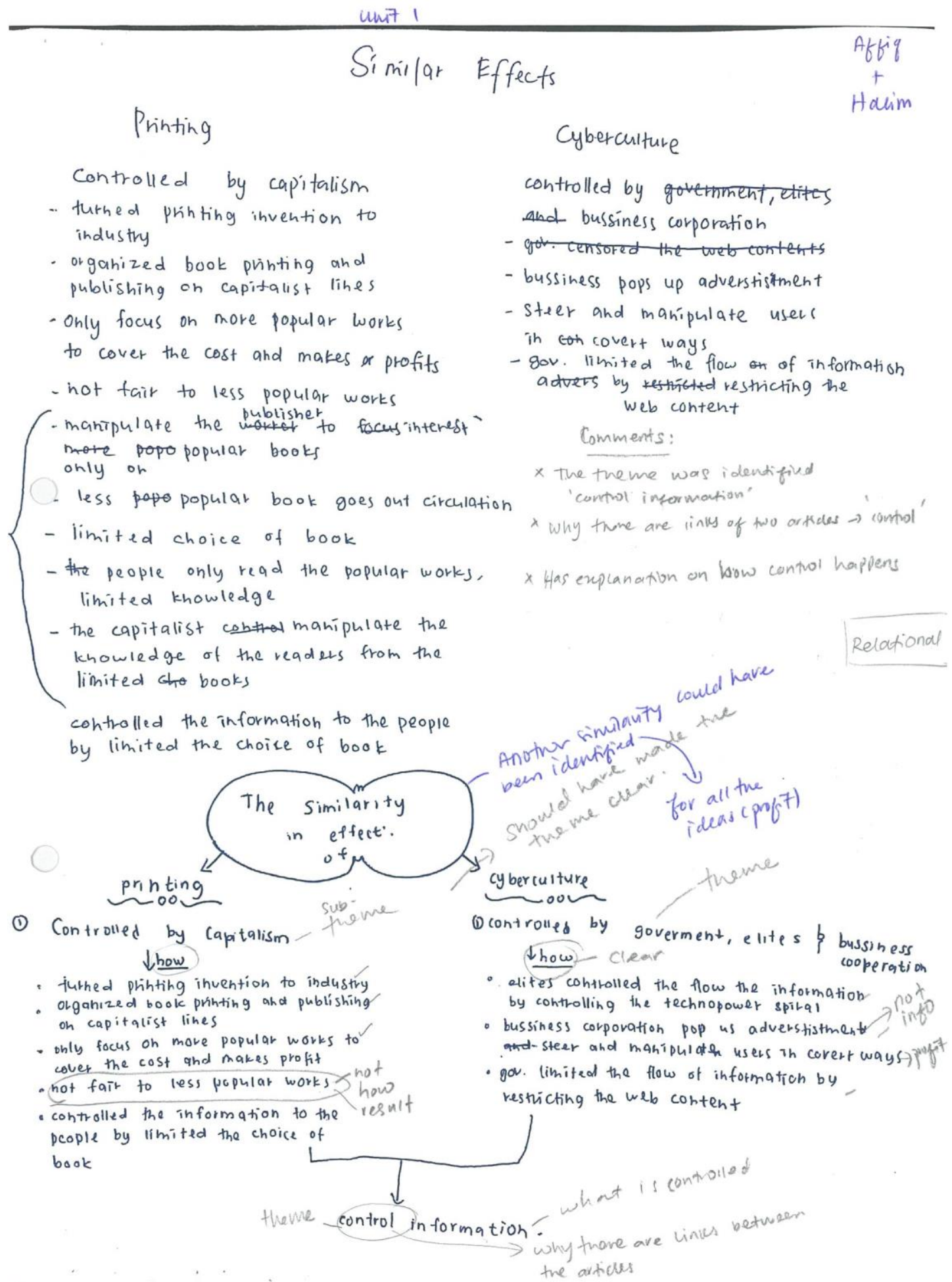


Immanuel (Unit 1): Mind map combining the effects of "Cyberculture" and "The print Revolution

UNA 1

immanuel

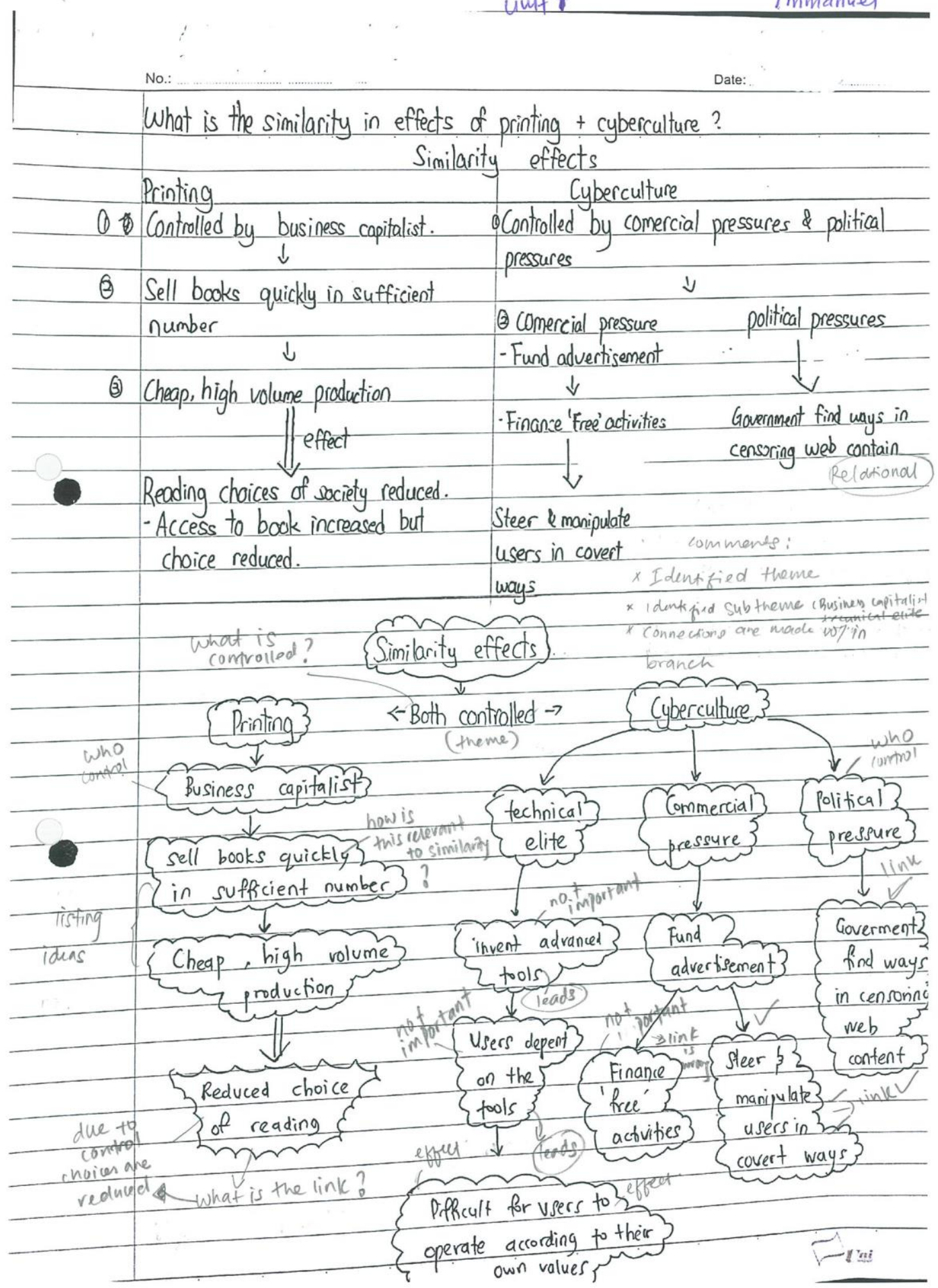




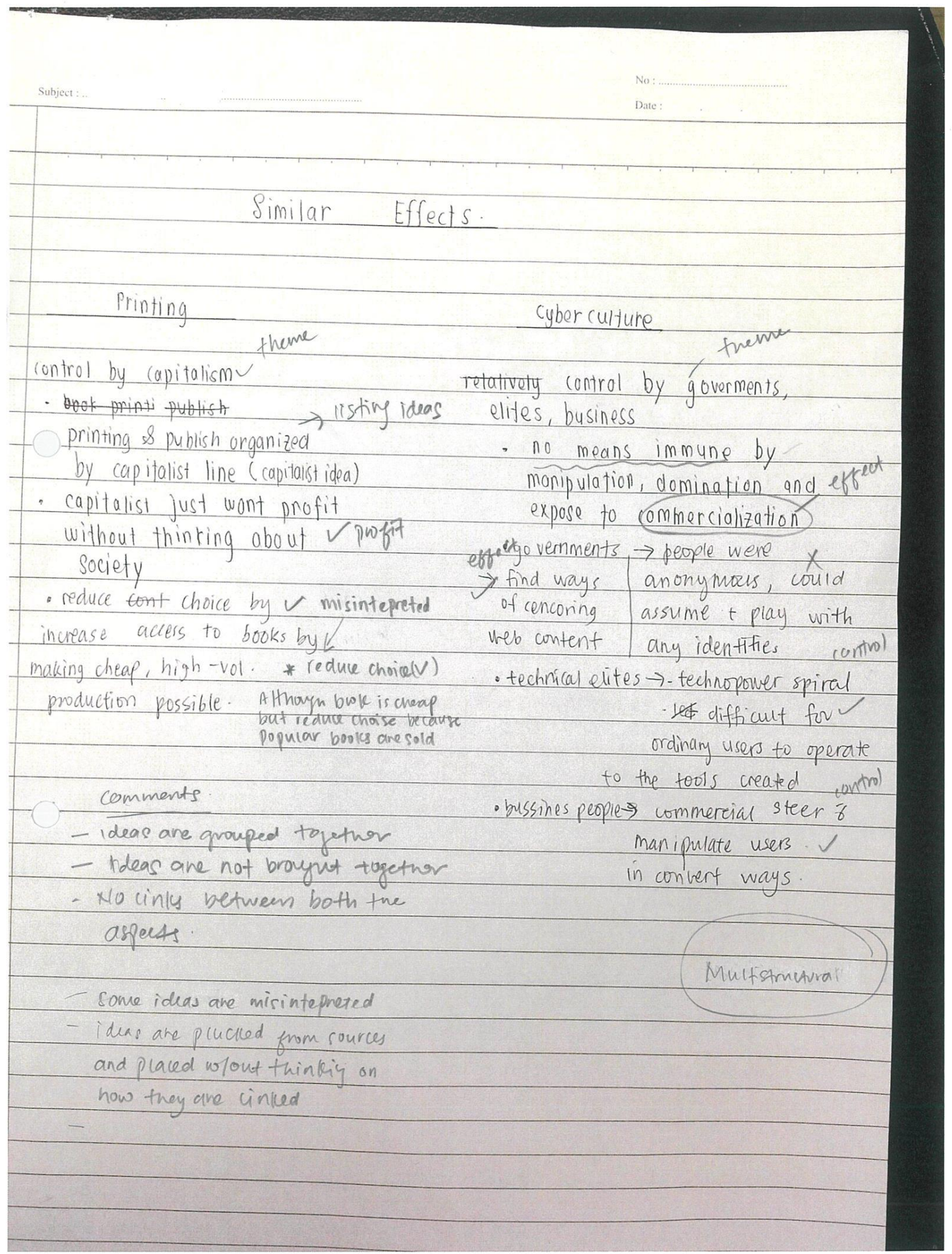




\section{Appendix S (2)}

Azraq and Samad (Unit 2): Summary writing

A2rag \& samad:

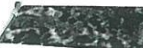

(1) content

Effects of Printing and Cybaculture - Thare are companizon of effects - most of the ideas are elaborated bat some are unclear

no introduction.... idias are accurately extracted

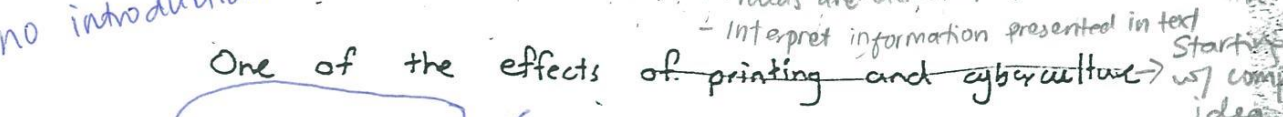

cultural effects. [In cyberaulture, identity is hod

the cultural effects. Uscers are allowed to cre a flow

their own world and identity. This influence the behavioure and relationship. OOthes thon that, the inequalities in gender h wbere there are different genders and status of users In addition. the users are influerced theirguno supportiy technical elites). Honterer, the cultural effect in printing is language, which was stondordiseet by translating warks from Latin to national languages. Besides that, the economical

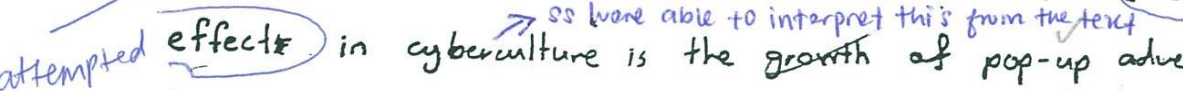
to ase to make profit.. $\rightarrow$ Both are the same idea. Why diffenent paragraphs? increment lopeat The economical effect of printing is the publighed ot suitable popular sooks fand recluction of chole of bouks. phatiy

Lastly, the political effect of rybercunture is the wels content can be easily cerssoved by the government. organization

- No introduction ly

- Anattempt to organise at some places

the writing is apparent Was not in the Air table.

compore/contrast

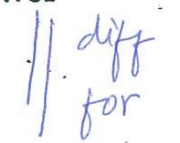

ay bercut

use of transition is seen

belt mau not be suitable / tou many

* The ideas stands out and dont biend. Hot much of flfow Although B) there is a frow, it iwos forced. Not muen of discussion. content

- Ehosizes of rocato

- Afttempt to paraphrase is made $\rightarrow$ Eg: hehaviour 
Hussein (Unit 2): Summary writing

unit 2

Hussain

$\ldots+\cdots$

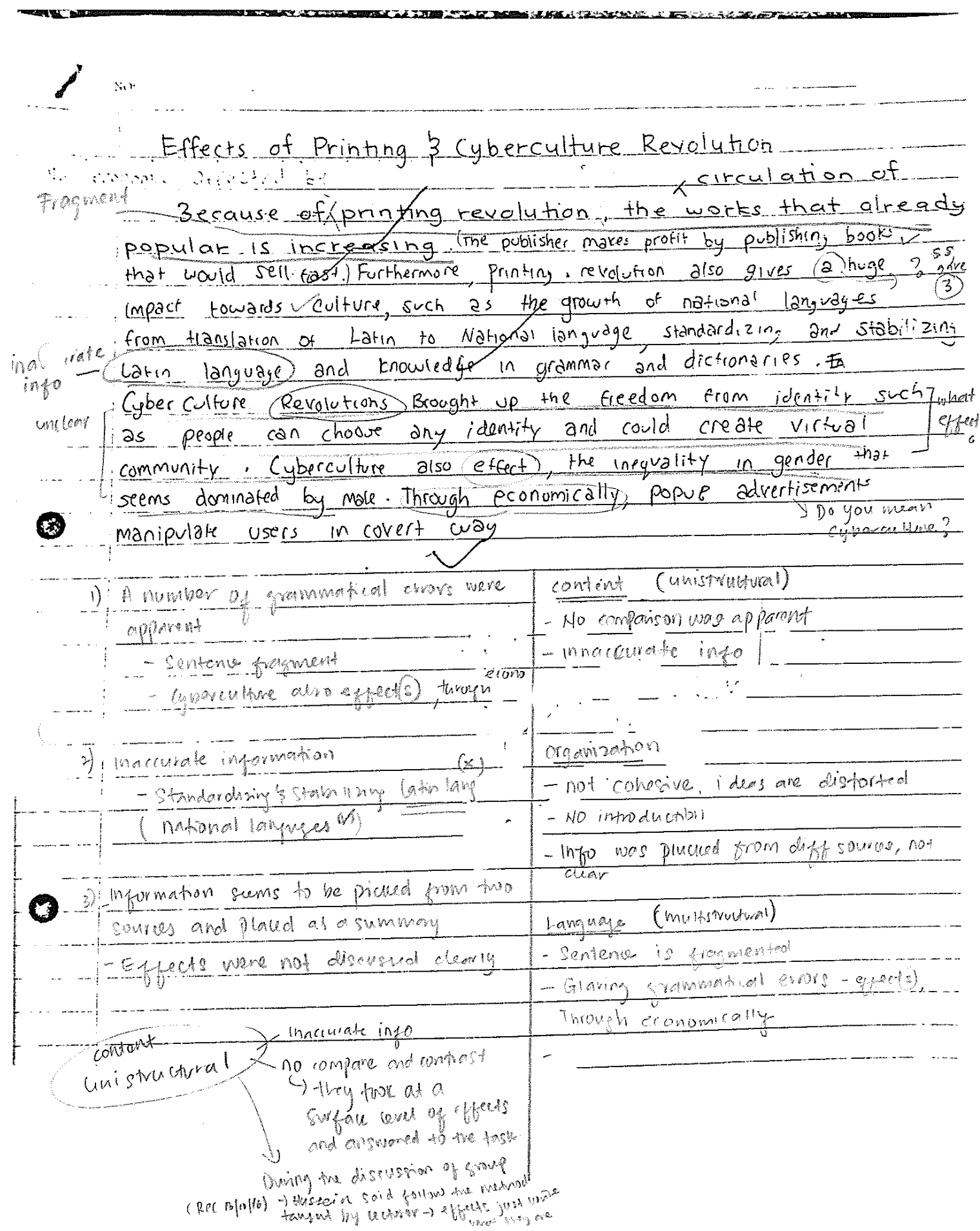


Nazira (Unit 2): Summary writing

Nasirg

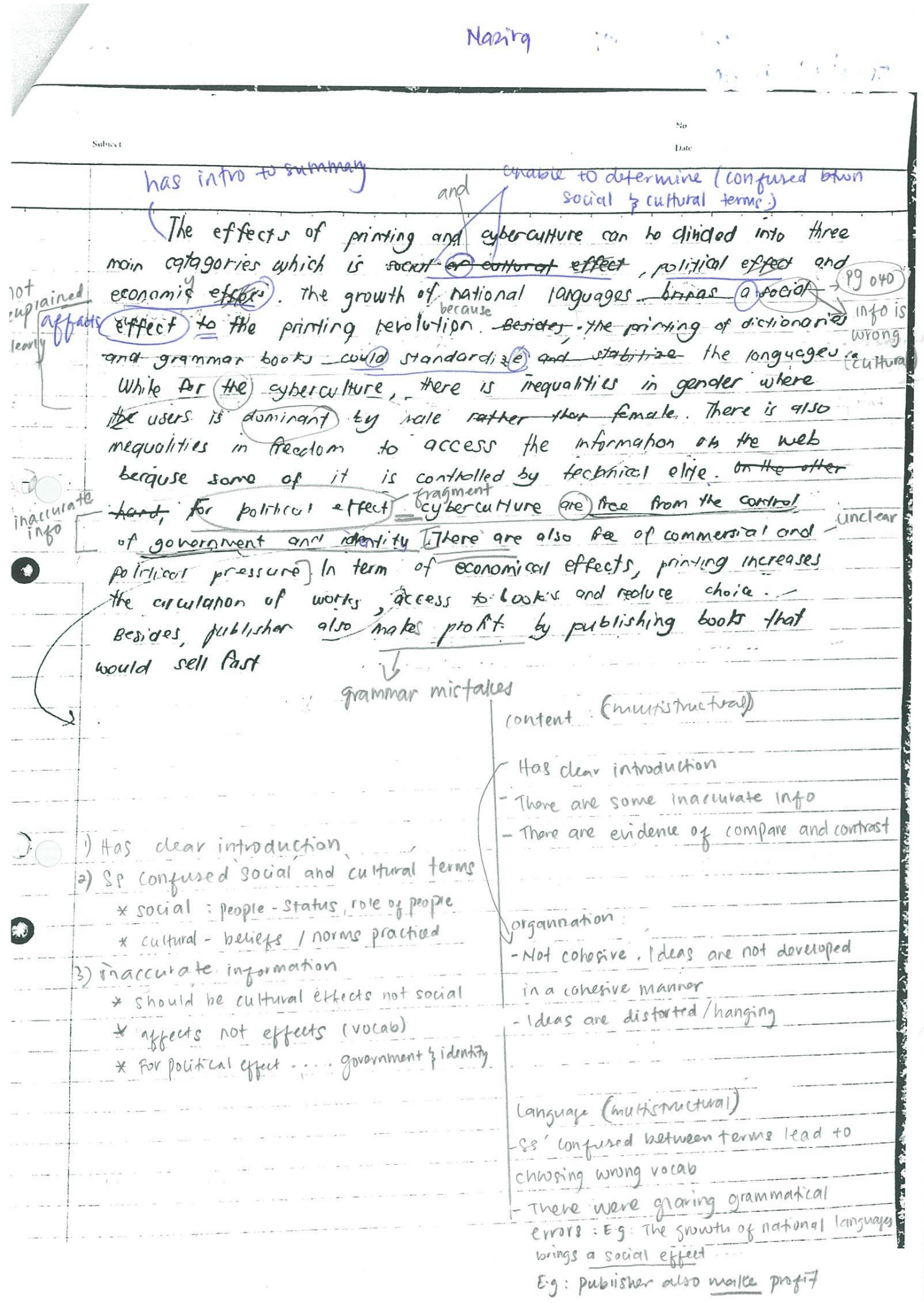




Whistuctural (1) Identify ideas from Anguments Parag(3)
text

4 Complete the summary of the text using the nouns below. (inked of poras development education environment factors intelligence reliability theories In their text 'Intelligence: heredity versus ${ }^{1}$ $2 \quad$ of major theories of ${ }^{3}$

$\therefore$ Fulcher and Scott (2011: 731-2) trace the . They argue against nineteenth-century ${ }^{4}$ posing instead a more balanced view which recognizes the in determining a person's level of intelligence. The authors also question the ? of general intelligence, or IQ, tests

5 Match each element of the summary (1-4 below) to the relevant sections ( $A-D)$ in 4. 1 a brief overview of the text

2 a major issue raised in the text

3 a summary of the main argument

4 a reference to the original text

\section{* Intelligence: heredity versus environment $8711 / 2016$}

1. Various attempts have been made where intelligence comes from. In the nineteenth and are often kno essential argument of heredity versus environment emerged. These terms are often known as 'nature' and 'nurture' respectively. Essentially the arguments are concerned with the extent to which intelligence is inherited through the genes a person is born with (heredity. or nature), or formed through a person's life and their surroundings (environment, or nurture).

2 These theories led to the concept of how to measure intelligence. Early attempts at measuring intelligence (e.s. Calton 1869) associated it with Social inequalities, According to this point of view, the role of environmental factors had to be recognized alongside the part played by heredity. This work led to the construction of $I Q$ (intelligence quotient) tests to measure intelligence. The measurement of $\mid Q$ originated in the work of the statistician Spearman (1904), who introduced the concept of ' $\mathrm{g}$ ' (general intelligence) to describe the general cognitive ability that he thought lay behind specific abilities and forms of intelligence (linguistic, mathematical, spatial, musical, etc.). The development of these fests seemed to promise the possibility that the relationship between material inequalities and social inequalities could be studied with mathematical precision.

3 Arguments that link inherited intelligence to social disadvantage, rest on several assumptions, including:

- General intelligence $(\mathrm{g})$ is a cognitive ability that underlies all other specific forms of intelligence and can be accurately measured by 10 tests.

- Measures of social advantage and disadvantage correlate highly with measures of general intelligence. Because the distribution of advantages and disadvantages reflects the distribution of intelligence, it can be seen as determined by differences in general intelligence. - Intelligence is genetically determined. It is, therefore, fixed from birth: education and other environmental factors have little or no effect on the level of intelligence.

4 Each of these assumptions can be questioned. The concept of general intelligence has been particular abilities. (Mathematical and verbant that there is any such common factor behind with one another. It mathatical and verbal intelligence) for example, are not perfectly associated with one another. It may be more useful to regärd intelligence as a set of intellectualcapacities rather than a single one. Even if it is allowed that general intelligence exists, however, there is
the problem of how it is to be measured.

5 Many have questioned the value of the $\mathrm{QQ}$ score as a measure of intelligence. Tests have been shown to be culturally biased towards Western (American and European) cutture and, within this, the tests do not middle-class men. The cultural differences that shape the ability to perform in there are doubts about whether performance in in intelligence. More fundamentally, perhaps, of a person's ability whether performance in pencil-and-paper tests can be a proper measure of a person's ability to perform in 'real' situations. Indeed, there are wider doubts about whether performance in A-level, degree, or other examinations is an adequate measure of a person's understanding of a subject or ability to apply it in real-life situations.

6 Intelligence is a complex process that brings together numerous aspects of brin function and doubts have been raised about its genetic basis. It is inherited aspects of brain function, as a canacity to learn the kinds of skills and understandings that not as a fixed quantity but The realization of this capacity depends on the stimulating that make a particular ability. yeris oilife ard, to a much lcsser extent in the stimulation that is received in the first few trialization i: critical in raising or lower, in later life. It has been found that pre-school, primary

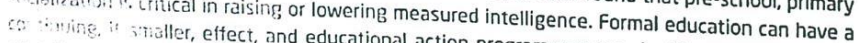
wister, effect, and educational action programmes can significantly raise the 10 and we cross-cultural studies have shown that the

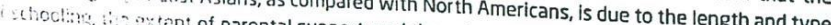
-

14. 1 . (2011). pp.731-2. Sociology (4th ed.). Oxford: Oxford University Press

\author{
(3)
}

Gene-al intelligencer

4 cognitive ability L specifre form of intelligens:

$\rightarrow$ can be aceuratcly measured by IQ A $B \rightarrow$ measure of C Lsocial ad 3 dis D $\rightarrow$ distribution at intciligence $\rightarrow$ diff in genem intcuig ence

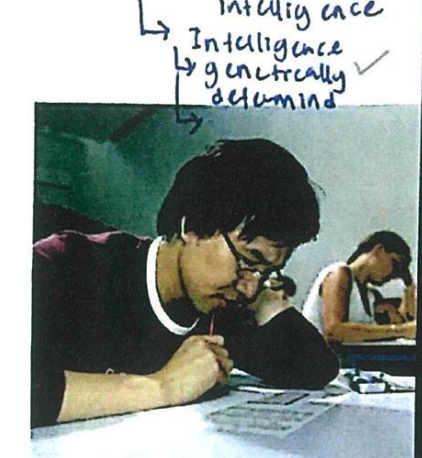

(1). The argin of

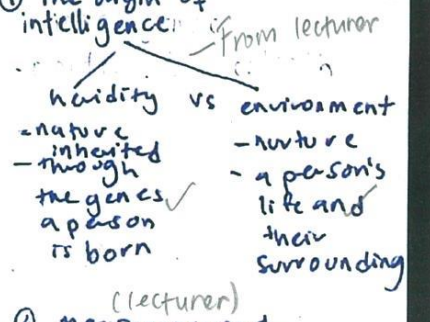
(2) measuremen:

intelligence dith socral inequalities $\rightarrow$ The vole of en vivonment $\rightarrow$ to vecognized cllong side the part plawed by heydity

4 Led to IQtest $\rightarrow$ Statis tician: spearman 1904 * Flossary $\rightarrow$ concept of 9 biased (ndj) havencal biased (adj) having a $\operatorname{cog}_{n}$ itive tendency to show favour cubility towards or against one group
of people or one opinion for personal reasons cognitive (adj) connected pomored with mental processes of the possibid understanding that relation t correlate $(v)$ if two or b+wation more facts, figures, etc. incqualiti correlate, the facts are closely un connected and affect or socia incial quotient $(n)$ a number which 1 is the result when one numb is the result when one number mathe
is divided by another statistician (n) a person who studies or works with statistie

UNIT 5A DEAniair 


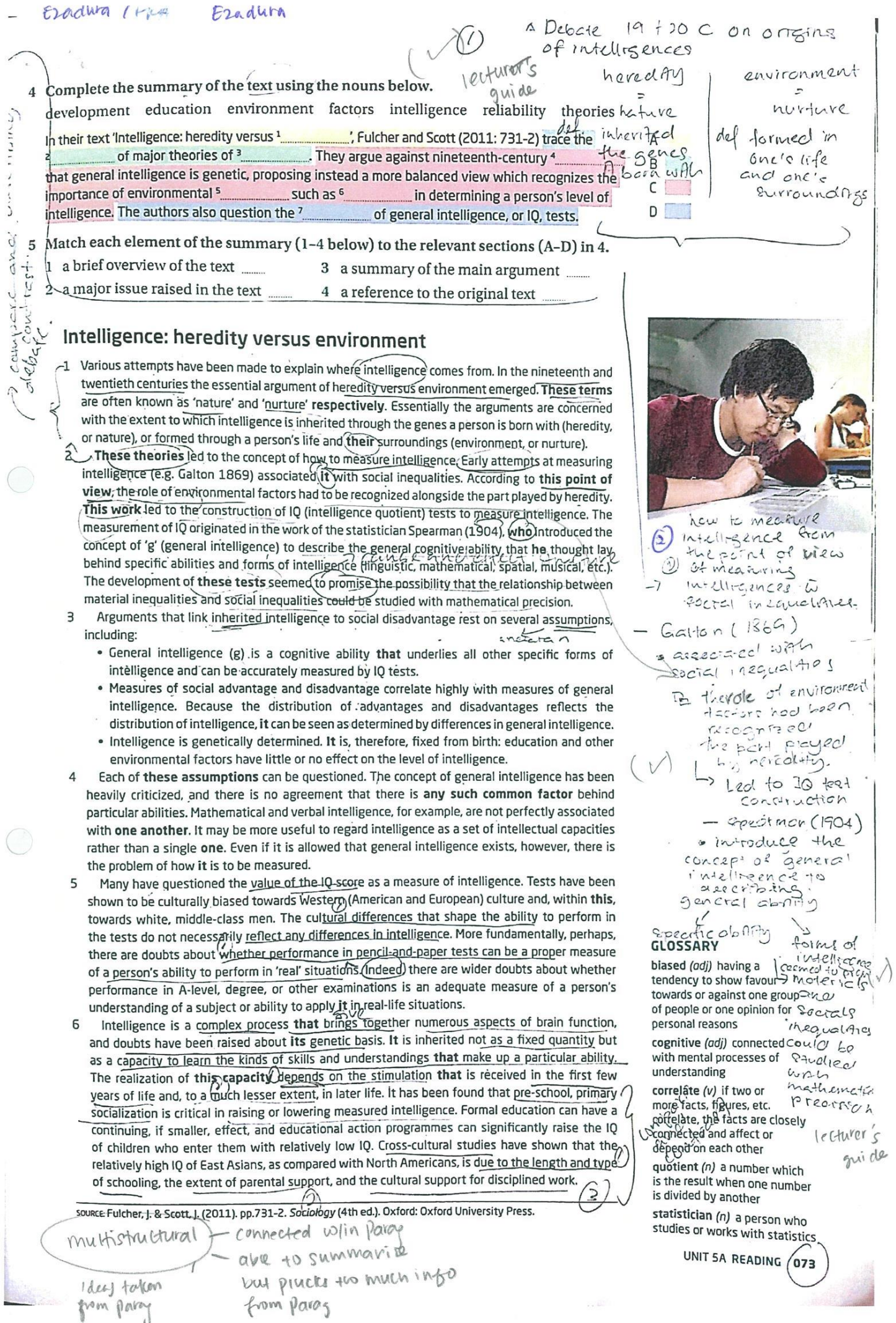




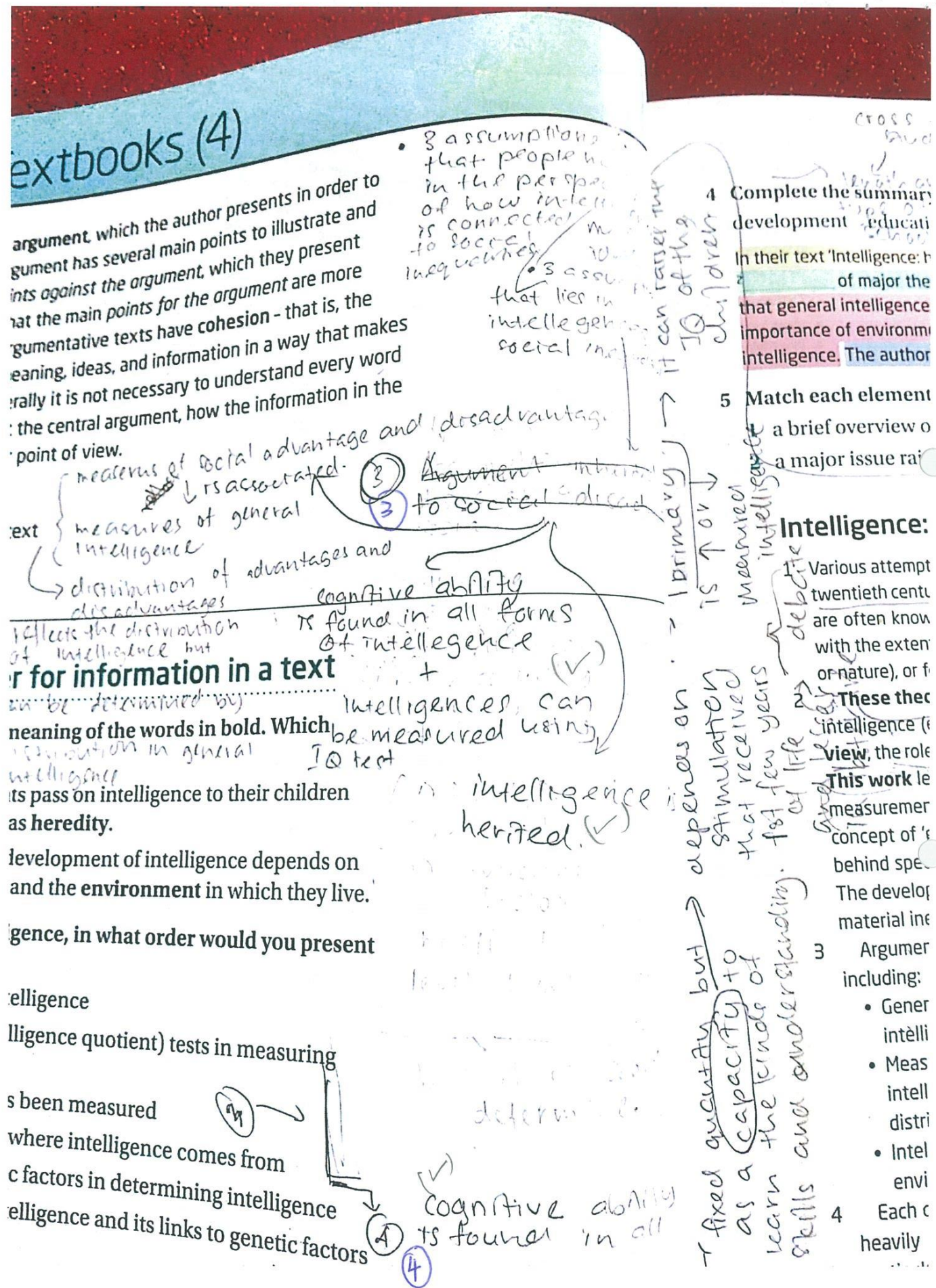




\section{(1) \\ 5 A Reading Textbooks (4)} Argumentative texts are based around an argument which the author presents in to audience. The argument has several main points to tilus trasen present support it. The author may also include points ogainst the orgument which they pre more to provide a contrast and to demonstrate that the main points for the orgumen - that is, the convincing. Like other texts, well-written argumentative texts have cohesion-that is that makes author uses specific langua we to critten argumentatios, and information in a way that maker the text clear and easy to understand. Generally it is not necessary to understand mation in the he central argument, how the inform text is presented, and the author's stance or point of view.

This module covers:

- Identifying the argument

- Identifying cohesive language

$\frac{1}{2}$

Identifying hedging language

ASK 1 Predicting a logical order for information in a text

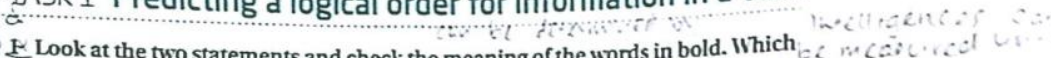

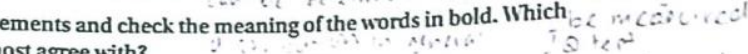

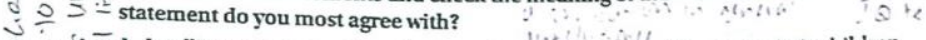

ب 1 Intelligence is a question of nature. Parents pass on intelligence to their children

in a biological, or genetic, process known as heredity.

$\leq 2$ Intelligence is a question of nurture. The development of intelligence depends on how people are brought up and educated, and the environment in which they live.

o ${ }_{2}$ If you were planning to write a text on intelligence, in what order would you present

$\simeq s \approx$ the six ideas below?

$\simeq \simeq 5$ a arguments against the theory of general intelligence

b arguments against the reliability of IQ (intelligence quotient) tests in measuring general intelligence

c a historical overview of how intelligence has been measured

d an introduction to the two main theories of where intelligence comes from

e arguments against the importance of genetic factors in determining intelligence

f arguments for the early theory of general intelligence and its links to genetic factors

JैASK 2 Identifying the argument and structure of a text - concep

summarizes the whole text

1 a description of intelligence tests and their advantages and disadvantages

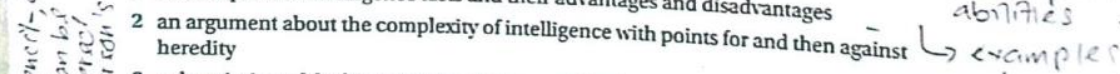

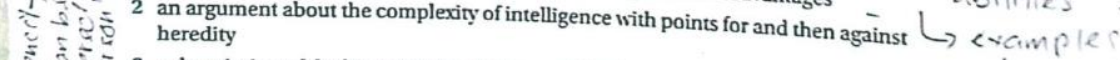

that there it

a description of the historical development of intelligence including the two main n-a the batec

theories

belwinontes abilizies

$0 \leqslant 54$ an argument

$<\rightarrow 0$ intelligence

Tatch each paragraph 1-6 with a main idea from Task 1.2

证 3 Discuss the following questions.

51 Which parts of the text helped

2 How close to the actual order in the tevatch the statements and main ideas?

3 Which ideas in the texr do you (a) agext were your predictions in Task 1.2?

(b) disagree with? Why?

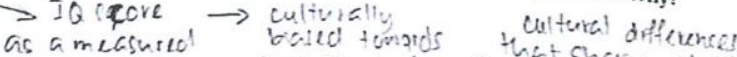

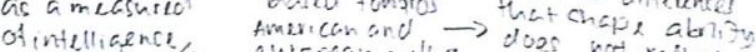

072 UNIT SA READING

eutopear wito does pot reflect

and ostitin

the whits ion

midde lacis-ien
(V)

in

midde las ar.
(V)

1. uieful to reget

intlitizences

intelectral

copecities

D. theree's o probem

on how to measure

it, ever it

neánce are

sance.

intellegence

racere frae

ories 


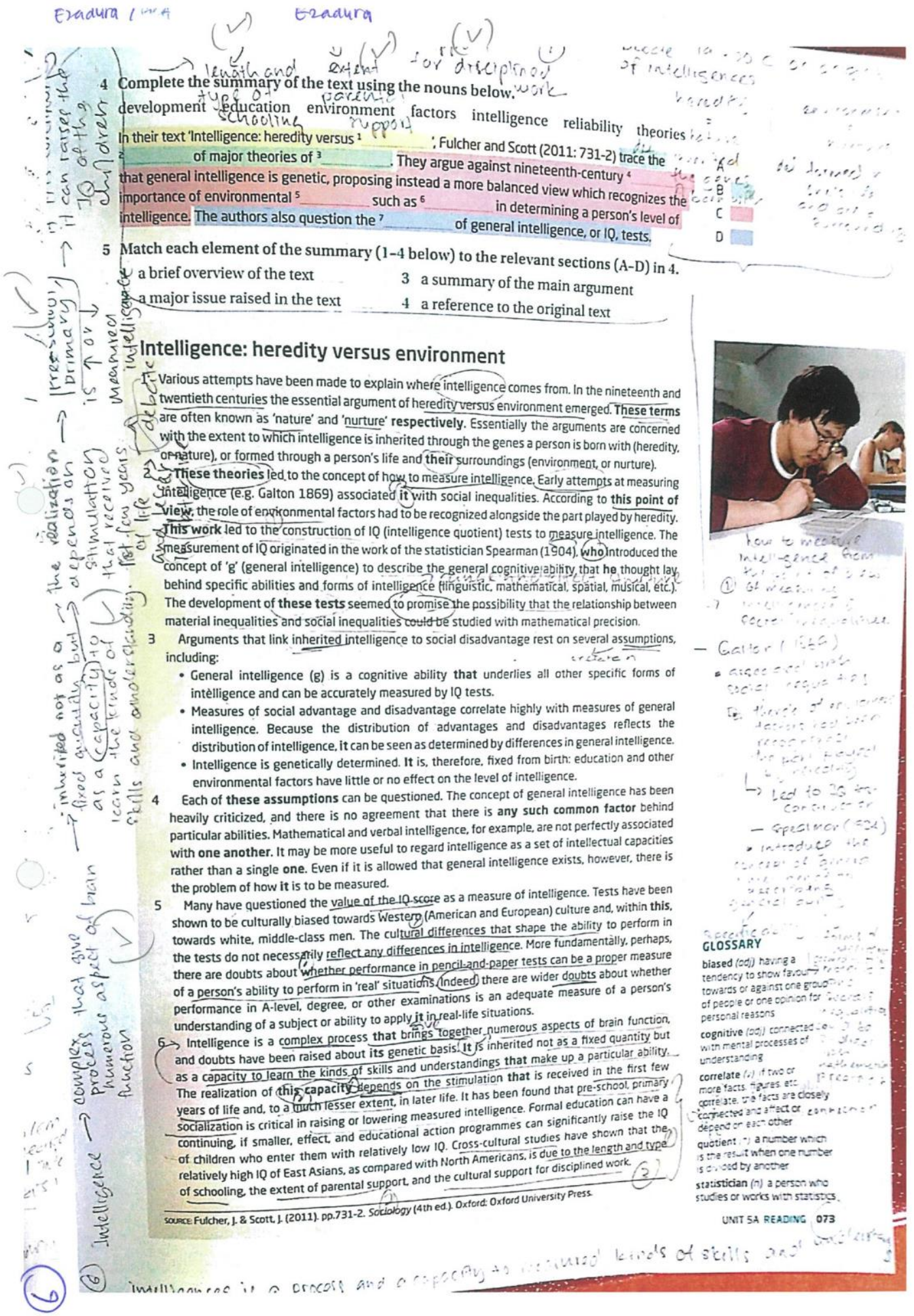


Najla (Unit 3): Annotation on: "Intelligence: heredity versus environment" (Paragraphs 1-5)

Unit 3

\author{
Majla I'PrA
}

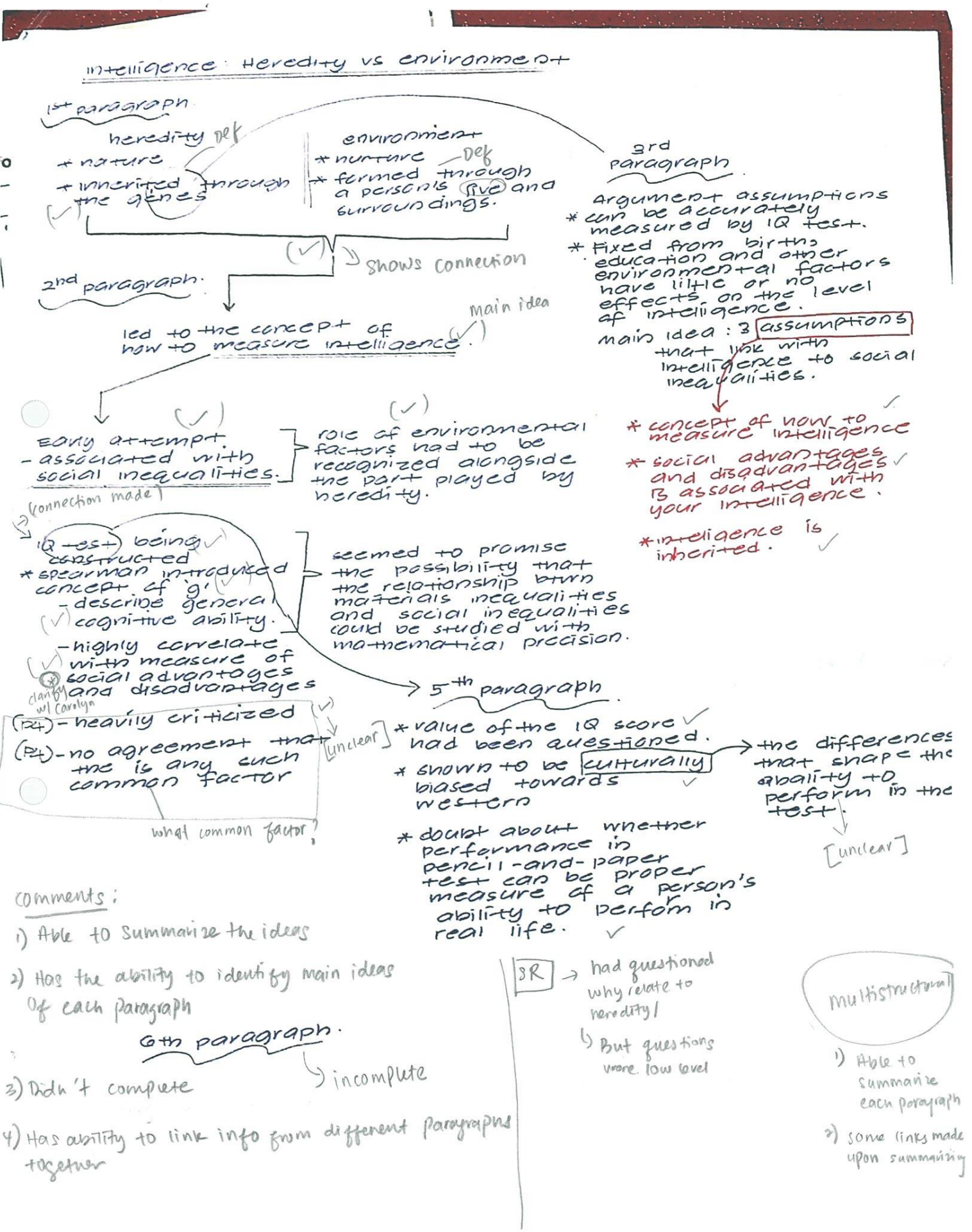


Satish: Annotation on: "Intelligence: heredity versus environment" (Paragraphs 1-3)

SATISt.... Sotion

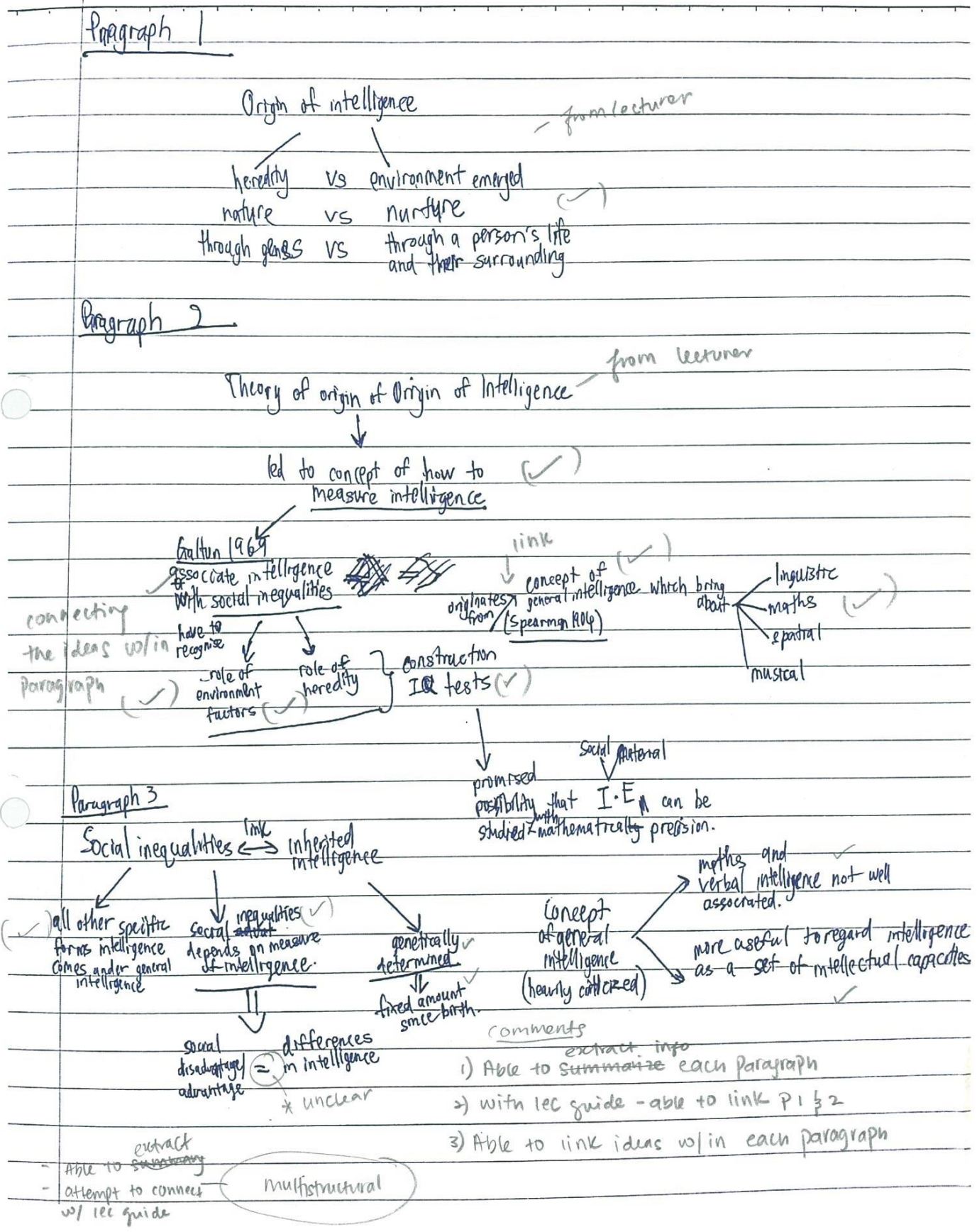


Satish: Annotation on: "Intelligence: heredity versus environment" (Paragraph 4)

Solish

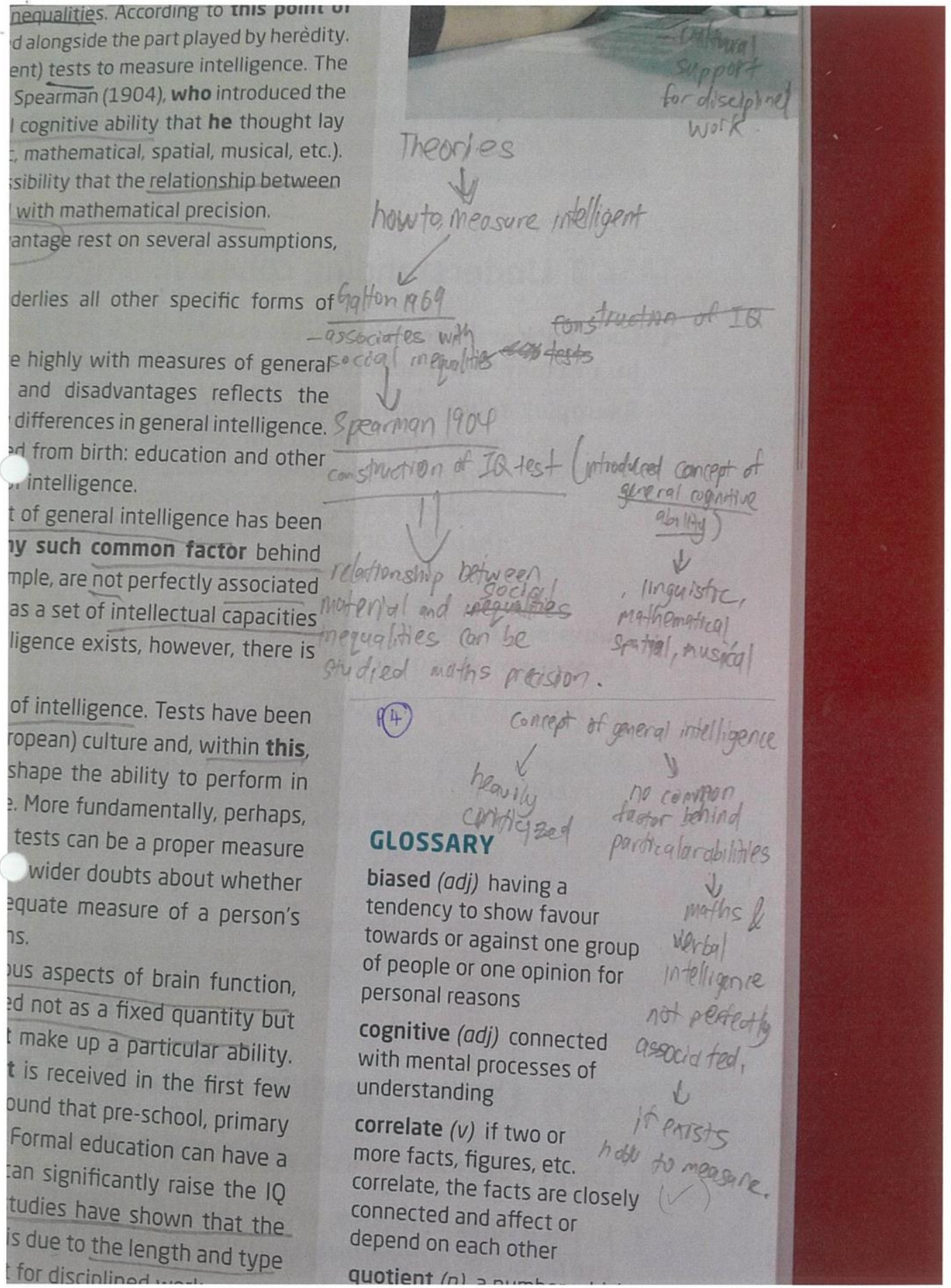

summanize 
Satish: Annotation on "Intelligence: heredity versus environment" (Paragraph 5)

Sation

\section{order for information in a text}

ck the meaning of the words in bold. Which

Parents pass on intelligence to their children known as heredity.

e. The development of intelligence depends on Icated, and the environment in which they live. intelligence, in what order would you present eral intelligence

$\mathrm{Q}$ (intelligence quotient) tests in measuring rCe has been measured

ies of where intelligence comes from genetic factors in determining intelligence ral intelligence and its links to genetic factors

\section{ent and structure of a text}

cide which of the following statements best

eir advantages and disadvantages

elligence with points for and then against

of intelligence including the

nstrates that it does not influence

from Task 1.2

he statements and main ideas?

re your predictions in Task 1.2 ?

th, (b) disagree with? Why?

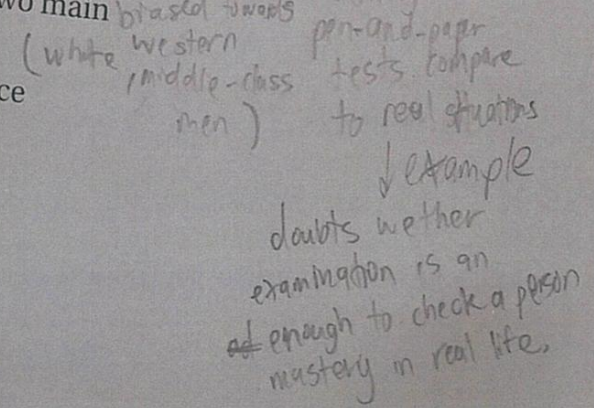


Satish Annotation on: "Intelligence: heredity versus environment" (Paragraph 6)

SATISH / FRA

summany 2

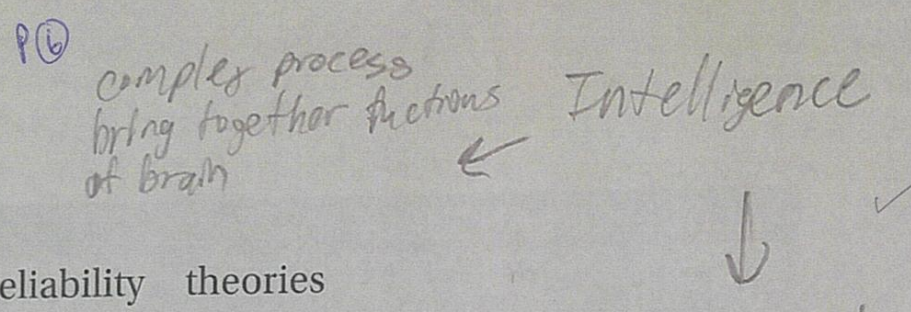

ns below.

intelligence reliability theories

Icher and Scott (2011: 731-2) trace the

le against nineteenth-century ${ }^{4}$

more balanced view which recognizes the

in determining a person's level of

of general intelligence, or IQ, tests.

to the relevant sections (A-D) in 4.

imary of the main argument

rence to the original text

Iment

Oryin of intellisermal edu

A

in notas fixed

B

C

D

$\frac{\text { hacing to learn diff }}{\text { hond of slealls andundestandigy }}$

Preschool amang cross withinal

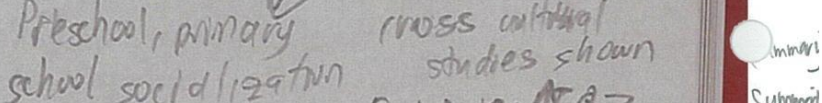
school socidlization East Asian Ita> Summin

elligence comes from. In the nineteenth and versus environment emerged. These terms 1. Essentially the arguments are concerned sh the genes a person is born with (heredity, iurroundings (environment, or nurture). e intelligence. Early attempts at measuring al inequalities. According to this point of ized alongside the part played by heredity. uotient) tests to measure intelligence. The cian Spearman (1904), who introduced the neral cognitive ability that he thought lay uistic, mathematical, spatial, musical, etc.) e possibility that the relationship between udied with mathematical precision.

disadvantage rest on several assumptions,

lat underlies all other specific forms of Gig fon 1969 tests.

sociates with

Theories North american $\downarrow 6603$

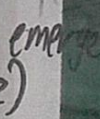

